DOC.20040922.0003

QA: QA

MDL-NBS-HS-000004 REV 03

September 2004

\title{
Seepage Calibration Model and Seepage Testing Data
}

Prepared for:

U.S. Department of Energy

Office of Civilian Radioactive Waste Management

Office of Repository Development

1551 Hillshire Drive

Las Vegas, Nevada 89134-6321

Prepared by:

Bechtel SAIC Company, LLC

1180 Town Center Drive

Las Vegas, Nevada 89144

Under Contract Number

DE-AC28-01RW12101 
This report was prepared as an account of work sponsored by an agency of the United States Government. Neither the United States Government nor any agency thereof, nor any of their employees, nor any of their contractors, subcontractors or their employees, makes any warranty, express or implied, or assumes any legal liability or responsibility for the accuracy, completeness, or any third party's use or the results of such use of any information, apparatus, product, or process disclosed, or represents that its use would not infringe privately owned rights. Reference herein to any specific commercial product, process, or service by trade name, trademark, manufacturer, or otherwise, does not necessarily constitute or imply its endorsement, recommendation, or favoring by the United States Government or any agency thereof or its contractors or subcontractors. The views and opinions of authors expressed herein do not necessarily state or reflect those of the United States Government or any agency thereof. 
Seepage Calibration Model and Seepage Testing Data MDL-NBS-HS-000004 REV 03 September 2004 


\section{OCRWM Model Signature Page/Change history}

Page Iii

1. Total Pages: 246

\section{Type of Mathematical Model}

$\triangle$ Process Moded

Describe Intended Use of Model
Abstraction Model
System Model

The purpose of the Seepage Calibrarion Model (SCM) is (1) to cstablish the concepnal basis for the Secpage Model for Performance As5essment (SMPA), and (2) to derive scepage-rclevant, model-rclated parameters and their disuributions for ase in the SMPA and seepage abstraction in support of the Total System Pefformance Assessment for Liccense Application (TSPA-LA). The SCM is incended to be used only within this Model Report for the estimasion of seepage-rejevant parameters through calibration of the model against seepage-rate data from liquid-release tests performed in several niches and in the Cross-Drift.

\section{Title}

Scepage Callbration Model and Seepage Testing Data

4. Ol (Inctuding Rev. No., if applicablo): MDL-NBS-HS-000004 REV 03
5. Total Appendices
7
No. of Pages in Eech Appendix
A-20, B-6, C-12, D-4, E-26, F-6, G-8

7. Originator
8. Independent Technical
Revlewer

13. Remarks

Additional contributors;

R.C. Trauk: Secpage testing in niches

P.J. Cook: Seepage testing in ECR日 Cross-Drift

T.A. Ghezzehei: Analysis of scepage-rate dam from Niche 1620

C.F. Ahlers: Analysis of seepage-rate data from Niches 3107,3650 , and 4788 
Change History

\begin{tabular}{|c|c|}
\hline \multicolumn{2}{|r|}{ Change History } \\
\hline 14. Revision No. & 15. Description of Change \\
\hline REV00 & Initial Issue \\
\hline REV01 & $\begin{array}{l}\text { The Seepage Calibration Model is recalibrated against new long-term liquid-release test data. } \\
\text { The entire model documentation was revised according to AP-3.10Q, Rev. 2, ICN 3, Step } \\
\text { 5.9d)2); the changes were too extensive to use revision tracking of individual modifications. }\end{array}$ \\
\hline REV02 & $\begin{array}{l}\text { Include analysis of seepage-test data from Niche } 1620 \text { and additional systematic testing } \\
\text { boreholes in the lower lithophysal unit. Included evaporation effects. }\end{array}$ \\
\hline REV02 Errata 001 & Errata in response to CR-1079 \\
\hline REV02 Errata 002 & Errata in response to CR-1100 \\
\hline REV03 & $\begin{array}{l}\text { Increased transparency in response to the regulatory-focused evaluation performed by the } \\
\text { Regulatory Integration Team. Entire model documentation was revised. Side bars are not } \\
\text { used because the changes were too extensive to use Step 5.8f)1) per AP-SIII.10Q, REV 02, } \\
\text { ICN } 06 \text {. }\end{array}$ \\
\hline
\end{tabular}




\section{CONTENTS}

Page

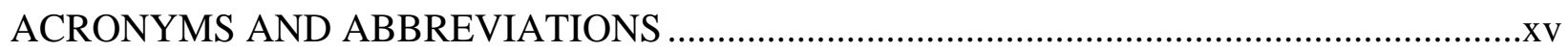

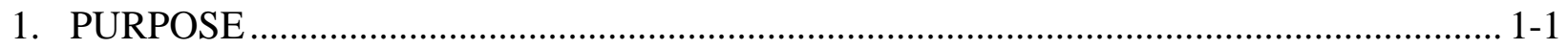

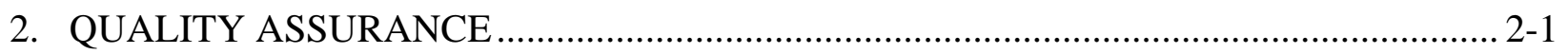

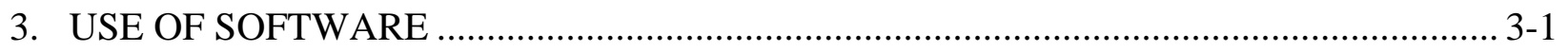

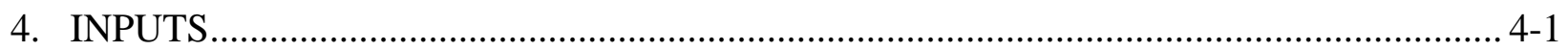

4.1 DIRECT INPUT …………………………….............................................

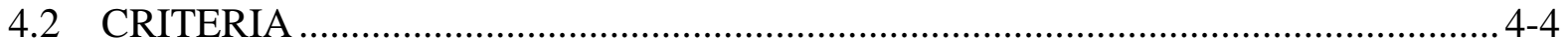

4.3 CODES, STANDARDS, AND REGULATIONS ..................................................... 4-7

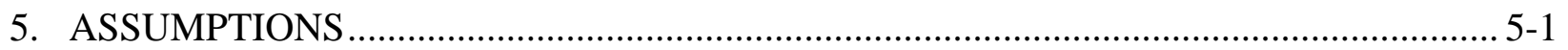

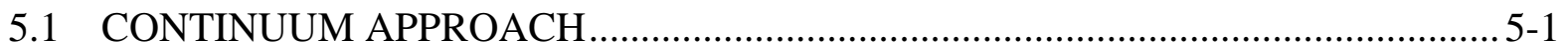

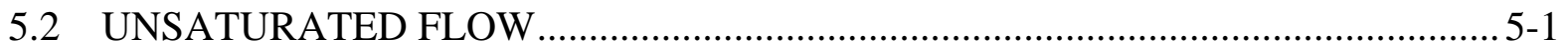

5.3 CHARACTERISTIC CURVES …………………………………………….... 5-2

5.4 EFFECTIVE CAPILLARY-STRENGTH PARAMETER ............................................ 5-2

5.5 EVAPORATION IN CLOSED-OFF NICHES ……............................................ 5-3

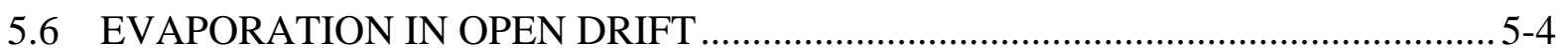

5.7 LITHOPHYSAL CAVITIES............................................................................... 5-4

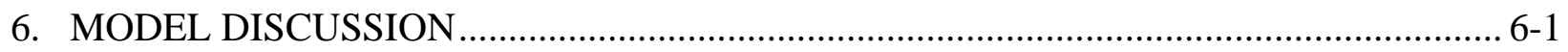

6.1 MODELING OBJECTIVES AND DEFINITIONS …….......................................... 6-1

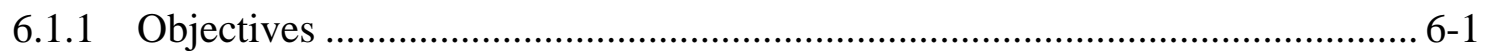

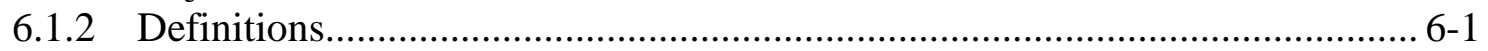

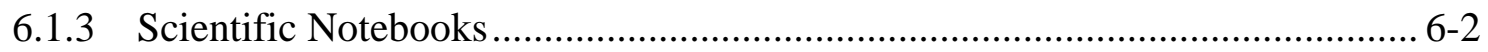

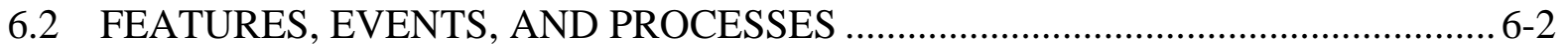

6.3 BASE-CASE CONCEPTUAL MODEL …………............................................ 6-4

6.3.1 Seepage Phenomena and Processes .............................................................. 6-4

6.3.2 Continuum Approach............................................................................ 6-5

6.3.3 Factors and Properties Affecting Seepage During Liquid-Release Tests......... 6-9

6.3.4 General Modeling and Data-Analysis Approach ............................................ 6-16

6.4 ALTERNATIVE CONCEPTUAL MODELS ..................................................... 6-20

6.4.1 Discrete Fracture Network Model .............................................................. 6-20

6.4.2 Seepage Governed by Ponding Probability ............................................... 6-22

6.4.3 Inferring Seepage from Geochemical Data..................................................... 6-23

6.4.4 Inferring Seepage Threshold Directly From Liquid-Release Tests ................. 6-23

6.5 DESCRIPTION OF SEEPAGE EXPERIMENTS ……………………................. 6-24

6.5.1 Test Location and Borehole Configuration................................................... 6-24

6.5.2 Air-Injection Tests ................................................................................. 6-27

6.5.3 Liquid-Release Tests................................................................................ 6-28

6.5.4 Relative Humidity and Evaporation Rate Measurements ................................ 6-32 


\section{CONTENTS (Continued)}

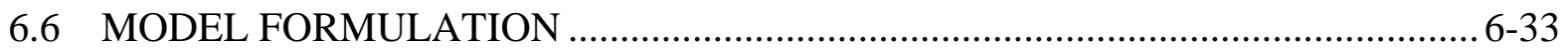

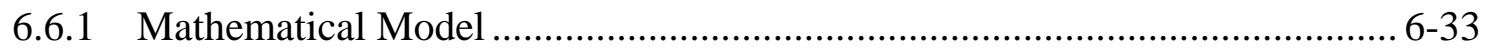

6.6.2 Development of Forward Model............................................................ 6-41

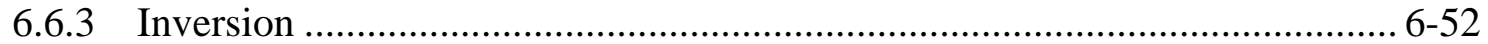

6.6.4 Summary and Compilation of Results ......................................................... 6-73

6.7 IMPACT OF RELATIVE HUMIDITY ON SEEPAGE ........................................ 6-75

6.8 DESCRIPTION OF BARRIER CAPABILITY ..................................................... 6-76

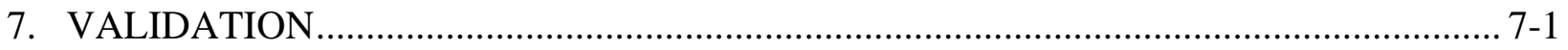

7.1 LEVEL OF RELATIVE MODEL IMPORTANCE ...............................................

7.2 VALIDATION ACTIVITIES AND CONFIDENCE EVALUATION

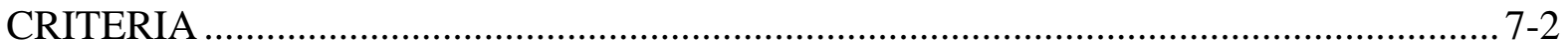

7.2.1 Confidence Building during Model Development to Establish the Scientific Bases and Accuracy for Intended Use.............................................. 7-2

7.2.2 Confidence Building after Model Development to Support the Scientific Basis of the Model .................................................................................... 7-4

7.3 RESULTS OF MODEL VALIDATION ACTIVITIES ................................................ 7-7

7.4 SUMMARY OF MODEL VALIDATION ……………......................................... 7-19

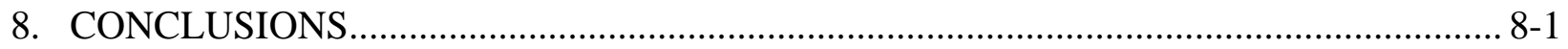

8.1 SUMMARY AND CONCLUSIONS ………….................................................. 8-1

8.2 MODEL OUTPUT, UNCERTAINTIES, AND LIMITATIONS.................................. 8-3

8.3 ADEQUACY OF INPUT DATA AND MODELING APPROACH.......................... 8-5

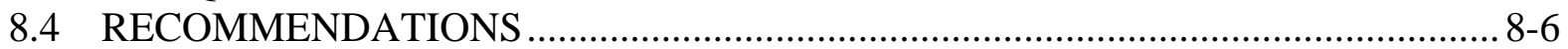

8.5 HOW THE ACCEPTANCE CRITERIA ARE ADDRESSED .................................. 8-7

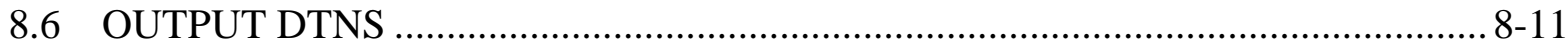

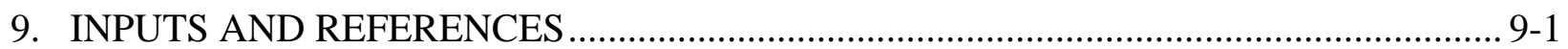

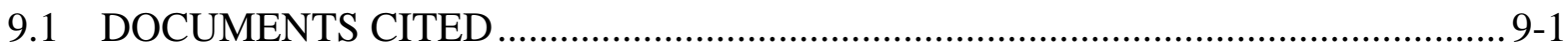

9.2 CODES, STANDARDS, REGULATIONS, AND PROCEDURES ............................9-7

9.3 SOURCE DATA, LISTED BY DATA TRACKING NUMBER …………................9-7

9.4 OUTPUT DATA, LISTED BY DATA TRACKING NUMBER ………..................... 9-9

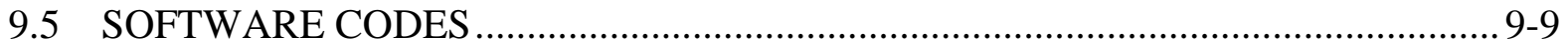

APPENDIX A LIST OF COMPUTER FILES SUBMITTED WITH THIS MODEL

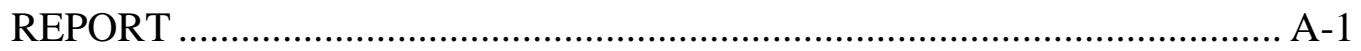

APPENDIX B VARIOGRAM FITTING ……………........................................................

APPENDIX C MESH GENERATION FOR SIMULATION OF SEEPAGE TESTS

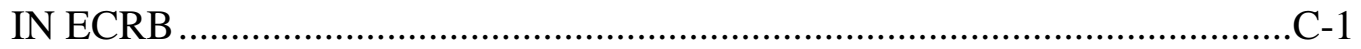

APPENDIX D MESH GENERATION FOR SIMULATION OF SEEPAGE TESTS IN NICHES 2, 3, AND 4 ............................................................................ D-1 


\section{CONTENTS (Continued)}

APPENDIX E MESH GENERATION FOR SEEPAGE TEST SIMULATIONS IN

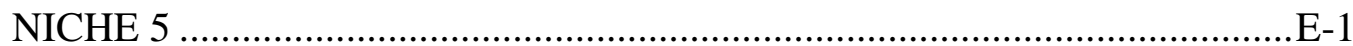

APPENDIX F PREPARATION OF SEEPAGE RATE AND RELATIVE-HUMIDITY DATA FOR THE SIMULATION OF LIQUID-RELEASE TESTS IN THE ECRB CROSS-DRIFT.

APPENDIX G EXECUTION OF MULTIPLE INVERSIONS OF DATA FROM ECRB ..... G-1 


\section{INTENTIONALLY LEFT BLANK}




\section{FIGURES}

6-1. Schematic Showing Two Fractures Intersecting a Drift ................................................ 6-6

6-2. Two-Dimensional Discrete Feature Model.......................................................... 6-21

6-3. Two-Dimensional Discrete Fracture Network Model .............................................. 6-21

6-4. Schematic Geologic Map Showing Approximate Location of Niches and Systematic Testing Boreholes SYBT-ECRB-LA\#1-3 ……….................................... 6-25

6-5. (a) Capillary-Pressure Curves and (b) Relative-Permeability Curves for Different Illustrative van Genuchten Parameters. ......................................................................... 6-35

6-6. Schematic Description of Seepage Condition............................................................. 6-36

6-7. Relative Humidity, Temperature, and Measured and Fitted Evaporation Rates from Experiments Conducted outside Niche 5 .....

6-8. Relative Humidity, Temperature, and Measured and Fitted Evaporation Rates from Experiments Conducted inside Niche 5

6-9. Cumulative Frequency Distribution of the Log-Transformed Permeability Values and Corresponding Cumulative Normal Probability Density Function for Niche 5 ..... 6-43

6-10. Empirical Post-Excavation Air-Permeability Semivariograms and Spherical Semivariogram Model for Niche 5

6-11. Post-Excavation Permeability Data of Niche 5, Borehole \#3 and the Corresponding Generated Permeability Values from One Representative Realization, which Honors the Measured Data.

6-12. Empirical Post-Excavation Air-Permeability Semivariograms and Fitted Spherical Semivariogram Models for Niches 2, 3, and 4

6-13. Cumulative Distribution Functions of Air Permeabilities for Niches 2, 3, and 4.......... 6-46

6-14. Numerical Grid with one Realization of the Permeability Field Used for the Simulation of Liquid-Release Tests Conducted in Zone 2 of Borehole SYBTECRB-LA\#2

6-15. Numerical Grid with one Realization of the Permeability Field Used for the Simulation of Liquid-Release Tests Conducted in Niche 5.

6-16. Computational Meshes and Permeability Field for 3-D Seepage Calibration Model Used for the Analysis of Seepage Data

6-17. Interference between Concurrent Liquid-Release Tests in Borehole \#3 (21-22 ft) and Borehole \#5 (28-29ft) in Niche 5

6-18. (a) Flux and (b) Saturation Distribution at the End of Liquid-Release Testing in Zone 2 of Borehole SYBT-ECRB-LA\#1

6-19. Calibration of Seepage-Rate Data from Liquid-Release Tests in Zone 2 of Borehole SYBT-ECRB-LA\#1

6-20. Calibration of Seepage-Rate Data from Liquid-Release Tests in Zone 2 of Borehole SYBT-ECRB-LA\#1

6-21. Saturation Distribution Simulated With Model Calibrated against Seepage-Rate Data from Liquid-Release Tests Conducted in Zone 2 of Borehole SYBT-ECRBLA\#2

6-22. Calibration of Seepage-Rate Data from Liquid-Release Tests Conducted in Zone 2 of Borehole SYBT-ECRB-LA\#2. 


\section{FIGURES (Continued)}

Page

6-23. Calibration of Seepage-Rate Data from Liquid-Release Tests Conducted in Zone 3 of Borehole SYBT-ECRB-LA\#2

6-24. Calibration of Seepage-Rate Data from Liquid-Release Tests Conducted in Zone 1 of Borehole SYBT-ECRB-LA\#3 ………………….............................................. 6-66

6-25. Calibration of Seepage-Rate Data from Liquid-Release Tests Conducted in Interval 10-11 ft of Borehole \#4 in Niche 5

6-26. Simulated (a) Saturation And (b) Flux Distribution at the End of Liquid-Release Testing (After 13 Days) in Interval 10-11 ft of Borehole \#4 in Niche 5.

6-27. Calibration of Seepage-Rate Data from Liquid-Release Tests Conducted in Interval 28-29 ft of Borehole \#5 in Niche 5

6-28. Simulated (a) Saturation and (b) Flux Distribution at the End of Liquid-Release Testing (After 13 Days) in Interval 28-29 ft of Borehole \#5 in Niche 5.

6-29. Comparison Between Simulated and Measured Seepage Rates from Three Liquid-Release Tests Conducted in Interval UM 4.88-5.18 of Niche 3.

6-30. Simulated Late-Time Saturation Distribution for Liquid-Release Tests in Niche 4, Intervals (a) UL 6.72-7.93 (November 3, 1999), (b) UM 6.10-6.40 (November 16, 1999), and (c) UR 5.18-5.48 (December 7, 1999) ...

6-31. Comparison between Simulated and Measured Seepage Rates from Six Liquid-Release Tests Conducted in Three Different Borehole Intervals of Niche 4..... 6-73

6-32. Histograms and Related Normal Distributions of Van Genuchten CapillaryStrength Parameter $1 / \alpha$ for (a) the Middle Nonlithophysal Zone, and (b) the Lower Lithophysal Zone.....

6-33. Effect of Relative Humidity on Seepage and Evaporation Percentages, Based on the Simulation of a Liquid-Release Test in Interval 10-11 ft of Borehole \#4 in Niche 5 6-76

6-34. Rates of Water Released, Evaporated, Diverted around the Niche, Stored in the Formation above the Niche, and Captured in the Seepage Collection System as a Function of Time.

6-35. Water Collected in the Slot on the Side of Niche 5 Confirming Flow Diversion around the Opening.

7-1. Liquid-Release Rates, Measured Seepage Rates, and Range of Predicted Seepage Rates Containing 90 Percent of the 100 Monte Carlo Simulations of the Experiment Conducted in Zone 1 of Borehole SYBT-ECRB-LA\#2.

7-2. Liquid-Release Rates, Measured Seepage Rates, and Range of Predicted Seepage Rates Containing 90 Percent of the 100 Monte Carlo Simulations of the Experiment Conducted in Zone 2 of Borehole SYBT-ECRB-LA\#2.

7-3. Liquid-Release Rates, Measured Seepage Rates, and Range of Predicted Seepage Rates Containing 90 Percent of the 100 Monte Carlo Simulations of the Experiment Conducted in Zone 3 of Borehole SYBT-ECRB-LA\#2.

7-4. Liquid-Release Rates, Measured Seepage Rates, and Range of Predicted Seepage Rates Containing 90 Percent of the 100 Monte Carlo Simulations of the Experiment Conducted in Zone 2 of Borehole SYBT-ECRB-LA\#3. $7-10$ 


\section{FIGURES (Continued)}

Page

7-5. Liquid-Release Rates, Measured Seepage Rates, and Range of Predicted Seepage Rates Containing 90 Percent of the 100 Monte Carlo Simulations of the Experiment Conducted in Interval 28-29 ft of Borehole \#5 in Niche 5, Starting on May 6, 2002.

7-6. Liquid-Release Rates, Measured Seepage Rates, and Range of Predicted Seepage

Rates Containing 90 Percent of the 100 Monte Carlo Simulations of the Experiment Conducted in Interval 28-29 ft of Borehole \#5 in Niche 5, Starting July 15, 2002.

7-7. Liquid-Release Rates, Measured Seepage Rates, and Range of Predicted Seepage

Rates Containing 90 Percent of the 100 Monte Carlo Simulations of the Experiment Conducted in Interval 10-11 ft of Borehole \#4 Niche 5

7-8. Validation of Seepage Calibration Model and Tptpmn Seepage-Relevant Parameters Using Data From Niche 3 (Events 1, 2, 3, 7, 9, 10, 11, 12 of Table 6-5)....

7-9. Validation of Seepage Calibration Model and Tptpmn Seepage-Relevant

Parameters Using Data from Niche 4 (Events 40, 42, 44, 47, and 49 of Table 6-5) ..... 7-16

7-10. Validation of Seepage Calibration Model and Tptpmn Seepage-Relevant Parameters Using Data from Niche 2

7-11. Comparison between Pre-Test Seepage-Rate Prediction with Preliminary Seepage Calibration Model and Seepage-Rate Data Observed in Niche 5

C-1. Input File mesh3dblock to Generate Primary Mesh............................................................

C-2. Input File perm.par to Generate Random Field of Log-Permeability Modifiers ...............-3

C-3. Input File onestep Used to Perform a Single Time Step....................................................-4

C-4. File sh.onestep Used to Execute a Forward Run with a Single Time Step........................-4

C-5. File sh.LAx_zoneY_mes Used To Execute Mesh Generation Steps 3-11............................

C-6. Excerpt from Sample Mesh File LAx_zoneY.mesZ ..........................................................-9

E-1. Excerpts from Interpolated Ceiling Profile of Niche 5 ....................................................

E-2. Plan View of Niche 5 Ceiling and Slot Surface Roughness.........................................

E-3. Input File N5BH5_28-29ft Used to Generate Primary Mesh........................................E-15

E-4. Input File Parameter File N5BH5_28-29ft_sisim.par for Random Permeability

Field Generating Software SISIM ..............................................................................E-16

E-5. Measured Air-Permeability Data Provided in File measured_log-k_12_N5.dat for Conditioning the Generated Permeability Field ............................................................E-17

E-6. Excerpt from the Generated Permeability Field ………………........................................ E-18

E-7. Excerpts from Interpolated Left Slot Profile of Niche 5...................................................-18

E-8. Excerpts from Interpolated Right Slot Profile of Niche 5 …….....................................-18

E-9. File sh.N5BH5_28-29ft_mesh Used to Execute Mesh Generation Steps 1-11 ..............E-23

E-10. Script File sh.N5BH5_28-29ft_run Used to Generate Multiple Meshes with Different Permeability Field Realizations 


\section{FIGURES (Continued)}

Page

F-1. $\quad$ Excerpt from Calibration Data File LA1_zone2_set2.dat

F-2

F-2. $\quad$ Excerpt from Boundary Condition Data File LA1_zone2_set2.bc.

G-1. File sh.run Used to Execute Multiple Inversions. G-2

G-2. Representative TOUGH2 Input File $L A x \_z o n e Y \_i n i n o e v a p$ (as Input to iTOUGH2 V5.0 (LBNL 2002 [DIRS 160106])) to Execute Initial Steady-State Simulation without Evaporation Effects

G-3. Representative TOUGH2 Input File $L A x \_z o n e Y \_s e t Z$ (as Input to iTOUGH2 V5.0 (LBNL 2002 [DIRS 160106])) Used to Simulate Liquid Release Test and Solving the Forward Problem. G-4

G-4. Excerpt from Representative iTOUGH2 (LBNL 2002 [DIRS 160106]) Input File $L A x \_z o n e Y \_s e t 2 i$ Used to Solve the Inverse Problem G-5

G-5. Reformatted Excerpt from Representative iTOUGH2 (LBNL 2002 [DIRS 160106]) Output File LAx_zoneY_set2i.out Showing Estimated Parameter G-5 


\section{TABLES}

Page

3-1. Qualified Software Used in this Report ........................................................................ 3-1

3-2. Software Products Exempt from Software Qualification ............................................. 3-3

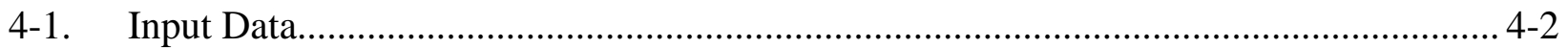

4-2. Hydrogeologic Input Parameters ....................................................................... 4-3

4-3. Mesh Coordinates and Flow Field Used to Calculate Local Percolation Flux ................. 4-3

4-4. Project Requirements and Yucca Mountain Review Plan Acceptance Criteria Applicable to this Model Report..................................................................................... 4-4

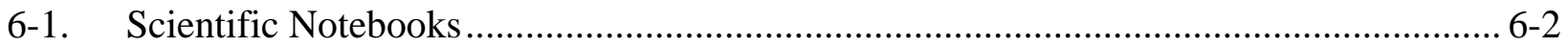

6-2. FEPs Addressed in this Model Report..................................................................... 6-3

6-3. Borehole Designations in Niches........................................................................... 6-26

6-4. Mean and Standard Deviation of Post-Excavation Log-Air-Permeability Values ........ 6-28

6-5. Liquid-Release Test Events, Approximate Release Rate, Occurrence of Seepage, and Their Use for Calibration or Validation Purposes.

6-6. Boundary-Layer Thickness Estimated Using Eq. 6-11 and Relative Humidity, Temperature, and the Evaporation Data from a Free Water Surface............................... 6-40

6-7. Geostatistical Parameters of Spherical Semivariogram Models ...................................... 6-46

6-8. Summary Statistics of Estimated Capillary-Strength Parameter for Lower Lithophysal Zone and Middle Nonlithophysal Zone

6-9. Mass Balance for Typical Seepage Test in Borehole \#4 of Niche 5, on September 27, 2002 at 16:20 (Day 10).

8-1. Mean and Standard Deviation of Capillary-Strength Parameter $1 / \alpha$ for Lower Lithophysal Zone and Middle Nonlithophysal Zone

A-1. File Name and Description for Modeling of Liquid-Release Tests in Niche 5 .............. A-1

A-2. File Name and Description for Modeling of Liquid-Release Tests in ECRB CrossDrift.

B-1. EXCEL Spreadsheet Vario.xls for Fitting Spherical Variogram to Empirical LogPermeability Variogram

C-1. Input Z-Coordinates to Software AddBorehole V1.0 (Borehole Interval Elevations)

E-1. Survey Data Sources for the Ceiling of Niche 5..............................................................

E-2. Datum of Niche 5 in the Nevada Coordinate System .......................................................

E-3. Niche 5 Profile Survey Data and Slot Survey Data and Their Corresponding Values in the $X-Y-Z$ Coordinate System......................................................................

E-4. Niche 5 Ceiling Roughness Data ..................................................................................

E-5. Original and Transformed Coordinates of Borehole Collars and Projected Bottoms 


\section{TABLES (Continued)}

Page

E-6. Locations of Air-Injection Test Intervals and Measured Air-Permeabilities.................E-12

E-7. Locations of Air-Injection Test Intervals and Measured Air-Permeabilities.................E-13

E-8. Primary Dimensions of Niche 5 Meshes ................................................................. E-14 


\section{ACRONYMS AND ABBREVIATIONS}

2-D two-dimensional

3-D three-dimensional

AFM Active Fracture Model

CS construction station

DFNM Discrete Fracture Network Model

DTN Data Tracking Number

ECRB enhanced characterization of repository block

ESF Exploratory Studies Facility

FEP feature, event, and process

FOSM first-order-second-moment

LA License Application

PA Performance Assessment

SCM Seepage Calibration Model

SMPA Seepage Model for Performance Assessment

SN Scientific Notebook

TDMS Technical Data Management System

TH thermal hydrologic

Tptpll lower lithophysal zone of Topopah Spring Tuff

Tptpmn middle nonlithophysal zone of Topopah Spring Tuff

TSPA Total System Performance Assessment

TWP Technical Work Plan

UL upper left

UM upper middle

UR upper right

UZ Unsaturated Zone

UZ Model Unsaturated Zone Flow and Transport Model

YMRP Yucca Mountain Review Plan 


\section{INTENTIONALLY LEFT BLANK}




\section{PURPOSE}

The purpose of this Model Report is to document the Seepage Calibration Model (SCM). The SCM was developed (1) to establish the conceptual basis for the Seepage Model for Performance Assessment (SMPA), and (2) to derive seepage-relevant, model-related parameters and their distributions for use in the SMPA and seepage abstraction in support of the Total System Performance Assessment for License Application (TSPA-LA). This Model Report has been revised in response to a comprehensive, regulatory-focused evaluation performed by the Regulatory Integration Team [Technical Work Plan for: Regulatory Integration Evaluation of Analysis and Model Reports Supporting the TSPA-LA (BSC 2004 [DIRS 169653])].

The SCM is intended to be used only within this Model Report for the estimation of seepagerelevant parameters through calibration of the model against seepage-rate data from liquid-release tests performed in several niches along the Exploratory Studies Facility (ESF) Main Drift and in the Cross-Drift. The SCM does not predict seepage into waste emplacement drifts under thermal or ambient conditions. Seepage predictions for waste emplacement drifts under ambient conditions will be performed with the SMPA [Seepage Model for PA Including Drift Collapse (BSC 2004 [DIRS 167652])], which inherits the conceptual basis and modelrelated parameters from the SCM. Seepage during the thermal period is examined separately in the Thermal Hydrologic (TH) Seepage Model [see Drift-Scale Coupled Processes (DST and TH Seepage) Models (BSC 2004 [DIRS 170338])].

The scope of this work is (1) to evaluate seepage rates measured during liquid-release experiments performed in several niches in the Exploratory Studies Facility (ESF) and in the Cross-Drift, which was excavated for enhanced characterization of the repository block (ECRB); (2) to evaluate air-permeability data measured in boreholes above the niches and the Cross-Drift to obtain the permeability structure for the seepage model; (3) to use inverse modeling to calibrate the SCM and to estimate seepage-relevant, model-related parameters on the drift scale; (4) to estimate the epistemic uncertainty of the derived parameters, based on the goodness-of-fit to the observed data and the sensitivity of calculated seepage with respect to the parameters of interest; (5) to characterize the aleatory uncertainty of the parameters as a result of spatial variability; (6) to evaluate prediction uncertainty based on linear uncertainty-propagation analyses and Monte Carlo simulations; (7) to validate the SCM during model development, and validate the SCM using the post-development activities outlined in the Technical Work Plan (TWP, see below); (8) to provide the technical basis for the resolution of unconfirmed issues previously labeled "to be verified" (TBV); and (9) to provide the technical basis for screening of certain seepage-related features, events, and processes (FEPs). 
The primary caveats and limitations in the scope of this Model Report and the results from the SCM are as follows:

1. The seepage models are intended to provide estimates of the seepage flux averaged over a $5 \mathrm{~m}$ drift segment (the approximate length of a waste package). The seepage models are not expected to quantitatively predict individual seepage events or the precise spatial seepage distribution along the drift.

2. By definition, the derived parameters are related to the specific model structure used, i.e., these parameters are only applicable to a conceptual and numerical model similar to the SCM. (Note that the SCM and the SMPA are compatible in this sense.) The parameters are also process specific and scale dependent, i.e., while they can be considered optimal for seepage calculations on the drift scale, they are not necessarily applicable to other processes on different scales.

3. The effective parameters derived in this Model Report capture many processes and features leading to dripping of formation water into a large underground opening. However, this does not include water dripping as a result of condensate accumulation on the drift surface or other in-drift moisture redistribution processes.

More detailed discussions of the appropriateness of the modeling approach, the sufficiency of the data, and the inherent limitations and caveats can be found throughout this Model Report.

The technical scope, content, and management of this Model Report are described in the planning document Technical Work Plan for: Unsaturated Zone Flow Model Report Integration (BSC 2004 [DIRS 169654], Section 2). This document does not deviate from the TWP; no additional criteria were identified in the TWP.

Direct inputs to this Model Report are listed in Section 4.1. These source data include the air-permeability and liquid-release test data described in the report In Situ Field Testing of Processes (BSC 2004 [DIRS 170004], Sections 6.2 and 6.11), calculated percolation flow fields described in the report UZ Flow Models and Submodels (BSC 2001 [DIRS 158726]) and the related numerical grid described in the report Development of Numerical Grids for UZ Flow and Transport Modeling (BSC 2001 [DIRS 159356]), fracture property data described in the reports Analysis of Hydrologic Properties Data (BSC 2004 [DIRS 170038]) and Calibrated Properties Model (CRWMS M\&O 2000 [DIRS 144426]).

This Model Report mainly supports the reports that document the SMPA (BSC 2004 [DIRS 167652]) and seepage abstraction [Abstraction of Drift Seepage (BSC 2004 [DIRS 169131])]. In addition, the discussions and results are used in the reports Features, Events, and Processes in UZ Flow and Transport (BSC 2004 [DIRS 170012], Section 6.1.24), and Drift-Scale Coupled Processes (DST and TH Seepage) Models (BSC 2004 [DIRS 170338]).

This report also addresses the following issues: The development of a collection system in Niche 5 (also referred to as Niche 1620) for mass balance considerations (see Sections 6.5.3 and 6.8); monitoring and estimation of evaporation effects (see Sections 6.3.3.4, 6.5.4, 6.6.1.3, 6.6.1.4, 6.6.2.3, and 6.6.3.3); inclusion of film flow effects (see Sections 6.1.2, 6.3.3, 6.3.3.2, 6.3.4, and 6.6.3.1); inclusion of effects from small-scale irregularities at the drift surface (see 
Sections 6.3.3, 6.3.3.2, 6.3.3.3, 6.3.3.5, 6.3.4, 6.6.2.2, 6.6.3, 6.6.3.3, 8.2, and Appendices C-E); justification of the continuum approach (see Sections 6.3.2, 6.3.3.2, 6.3.4, and 6.4.1); discussion of differences between continuum models and discrete fracture network models (see Sections 6.3.2 and 6.4.1); and the use of Niche 5 data to improve parameter estimates (see Sections 1, 4.1, 6.5, 6.6.2, 6.6.3, 7.3, 7.4, 8.1, and 8.2). 


\section{INTENTIONALLY LEFT BLANK}




\section{QUALITY ASSURANCE}

Development of this model report and the supporting modeling activities have been determined to be subject to the Yucca Mountain Project's quality assurance program as indicated in Technical Work Plan for: Unsaturated Zone Flow Model Report Integration (BSC 2004 [DIRS 169654], Section 8.1). Approved quality assurance procedures identified in the TWP (BSC 2004 [DIRS 169654], Section 4) have been used to conduct and document the activities described in this model report. The TWP also identifies the methods used to control the electronic management of data (BSC 2004 [DIRS 169654], Section 8.4) during the modeling and documentation activities.

This model report examines the properties of natural barriers identified that are classified in the Q-List (BSC 2004 [DIRS 168361]) as "Safety Category" because they are important to waste isolation, as defined in AP-2.22Q, Classification Analyses and Maintenance of the Q-List. The report contributes to the analysis and modeling data used to support performance assessment (PA). The conclusions of this model report do not affect the proposed repository design or engineered features important to safety, as defined in AP-2.22Q. 


\section{INTENTIONALLY LEFT BLANK}




\section{USE OF SOFTWARE}

The software programs used in this study are listed in Table 3-1. These programs were selected because they are appropriate for the intended application. They were used only within the range of validation; there are no limitations on outputs due to the selected software. The software programs were obtained from Software Configuration Management; their qualification and baseline status is given in the Document Input Reference System (DIRS).

Table 3-1. Qualified Software Used in this Report

\begin{tabular}{|l|l|l|c|}
\hline \multicolumn{1}{|c|}{ Software Name } & Version & \multicolumn{1}{|c|}{ Software Tracking Number } & \multicolumn{1}{c|}{ Reference } \\
\hline iTOUGH2 & 4.0 & $10003-4.0-00$ & LBNL 1999 [DIRS 139918] \\
\hline iTOUGH2 & 5.0 & $10003-5.0-00$ & LBNL 2002 [DIRS 160106] \\
\hline GSLIB Module SISIM & 1.203 & $10001-1.0 M S I S I M V 1.203-00$ & LBNL 1999 [DIRS 134136] \\
\hline GSLIB Module SISIM & 1.204 & $10397-1.0 S I S I M V 1.204-00$ & LBNL 2000 [DIRS 153100] \\
\hline GSLIB Module GAMV2 & 1.201 & $10087-1.0 M G A M V 2 V 1.201-00$ & LBNL 1999 [DIRS 134139] \\
\hline GSLIB Module GAMV3 & 1.201 & $10398-1.0 G A M V 3 V 1.201-00$ & LBNL 2000 [DIRS 153099] \\
\hline EarthVision & 4.0 & $10174-4.0-00$ & Dynamic Graphics 2003 [DIRS 162369] \\
\hline AddCoord & 1.0 & $10355-1.0-00$ & LBNL 2000 [DIRS 152814] \\
\hline MoveMesh & 1.0 & $10358-1.0-00$ & LBNL 2000 [DIRS 152824] \\
\hline AddBound & 1.0 & $10357-1.0-00$ & LBNL 2000 [DIRS 152823] \\
\hline Perm2Mesh & 1.0 & $10359-1.0-00$ & LBNL 2000 [DIRS 152826] \\
\hline CutNiche & 1.2 & $10356-1.2-00$ & LBNL 2000 [DIRS 152815] \\
\hline CutNiche & 1.3 & $10402-1.3-00$ & LBNL 2000 [DIRS 152828] \\
\hline CutDrift & 1.0 & $10375-1.0-00$ & LBNL 2000 [DIRS 152816] \\
\hline AddBorehole & 1.0 & $10373-1.0-00$ & LBNL 2000 [DIRS 152822] \\
\hline ECRB-XYZ & .03 & $30093-V .03$ & CRWMS M\&O 1999 [DIRS 147402] \\
\hline EXT & 1.0 & $10047-1.0-00$ & LBNL 1999 [DIRS 134141] \\
\hline
\end{tabular}

The use of the software programs identified in Table 3-1 is documented in Section 6 and in the supporting scientific notebooks (SNs). A summary description of the programs and their use is given below.

The software program iTOUGH2 V4.0 (LBNL 1999 [DIRS 139918]) provides forward and inverse modeling capabilities for unsaturated and multiphase flow in fractured porous media. The iTOUGH2 V5.0 (LBNL 2002 [DIRS 160106]) program has-among other features-the extended capability of efficiently simulating evaporation effects [Requirements Document (RD) for iTOUGH2 V5.0-00 (BSC 2002 [DIRS 161067], Section 1.2)]. Both programs are used in this Model Report for simulating liquid-release experiments and predicting seepage rates. Moreover, they solve the inverse problem by automatically calibrating the model against measured data, and calculate prediction uncertainties for model validation.

The GSLIB modules GAMV2 V1.201 and GAMV3 V1.201 (LBNL 1999 [DIRS 134139]; LBNL 2000 [DIRS 153099]) analyze spatial correlation of, respectively, two-dimensional (2-D) and three-dimensional (3-D), irregularly spaced datasets. These programs are used for the geostatistical analysis of air-permeability data. 
The GSLIB module SISIM V1.203 (LBNL 1999 [DIRS 134136]) generates 3-D spatially correlated random fields by means of sequential indicator simulations. It is used in this Model Report to generate spatially correlated fields of log-permeability modifiers. Module SISIM V1.204 (LBNL 2000 [DIRS 153100]) is an extended version of SISIM V1.203 (LBNL 1999 [DIRS 134136]), in which coordinates are directly output along with the log-permeability modifiers, making the use of software program AddCoord V1.0 (see below; LBNL 2000 [DIRS 152814]) unnecessary.

The following utility programs support the generation of computational meshes. The software program MoveMesh V1.0 (LBNL 2000 [DIRS 152824]) adds a constant to the coordinates of a mesh file, translating the coordinate system. The software program AddBound V1.0 (LBNL 2000 [DIRS 152823]) adds boundary elements to a mesh file. The software program AddCoord V1.0 (LBNL 2000 [DIRS 152814]) adds coordinates to the output file of SISIM V1.203 (LBNL 1999 [DIRS 134136]) in preparation for its use by the software program Perm2Mesh V1.0 (LBNL 2000 [DIRS 152826]), which maps a field of log-permeability modifiers onto a mesh file. The visualization software EarthVision V4.0 (Dynamic Graphics 2003 [DIRS 162369]) is used to extract coordinates of the rough ceilings of Niches 3 (also referred to as Niche 3107) and Niche 4 (also referred to as Niche 4788) in preparation for the use of the software program CutNiche V1.2 (LBNL 2000 [DIRS 152815]), which cuts a niche with a rough ceiling from a mesh file. The software program CutNiche V1.3 (LBNL 2000 [DIRS 152828]) cuts a smooth niche from a mesh file. The software program CutDrift V1.0 (LBNL 2000 [DIRS 152816]) cuts a cylindrical drift from a mesh file. The software program AddBorehole V1.0 (LBNL 2000 [DIRS 152822]) inserts a borehole into a mesh file. The software program ECRB-XYZ V.03 (CRWMS M\&O 1999 [DIRS 147402]) calculates the coordinates of a given ECRB station number, so the location of ECRB test beds can be related to the coordinates of the computational mesh.

The software program EXT V1.0 (LBNL 1999 [DIRS 134141]) takes the forward output file from iTOUGH2 (V4.0 or V5.0) and converts it into a Tecplot (all versions, see Table 3-2) input file; this software is used for visualization purposes only.

Table 3-2 summarizes the commercial off-the-shelf software used in support of this Model Report. This software is exempt from software qualification. Computations performed using the standard functions of the software products listed in Table 3-2 are described in the model documentation (Section 6) and the cited appendices. For visualization purposes, certain units have been converted using the equation utility of Tecplot. A factor of 1/86,400 was used to convert time from seconds to days; a factor of $1 / 60,000$ was used to convert water flow rates from milliliter per minute $(\mathrm{ml} / \mathrm{min})$ to kilograms per second $(\mathrm{kg} / \mathrm{s})$, which implies a water density of 1 gram per milliliter $(\mathrm{g} / \mathrm{ml})$. Information needed to reproduce the work, including the input, formulae or algorithm, and output, is included in this Model Report and the cited references. 
Table 3-2. Software Products Exempt from Software Qualification

\begin{tabular}{|c|c|c|c|}
\hline Software Name & Version & Platform Information & Used for \\
\hline \multirow{3}{*}{$\begin{array}{l}\text { Microsoft } \\
\text { EXCEL }\end{array}$} & 97 (SR-2) & PC, Windows 98 & \multirow{3}{*}{$\begin{array}{l}\text { Data reduction, computation, } \\
\text { graphical representation of output }\end{array}$} \\
\hline & 2000 (9.0.3821 SR-1) & PC, Windows 98 & \\
\hline & 2000 (9.0.3821 SR-1) & PC, Windows 2000 Professional & \\
\hline \multirow{2}{*}{$\begin{array}{l}\text { Microsoft } \\
\text { WORD }\end{array}$} & 2000 (9.0.3821 SR-1) & PC, Windows 98 & \multirow[t]{2}{*}{ Word processing } \\
\hline & 2000 (9.0.3821 SR-1) & PC, Windows 2000 Professional & \\
\hline vim & 6.0 .12 & PC, Linux & Text editing \\
\hline Adobe Illustrator & V8.0.1 & Mac, MacOS 9.0.4 & \multirow[t]{2}{*}{ Schematic figures } \\
\hline $\begin{array}{l}\text { Microsoft } \\
\text { PowerPoint }\end{array}$ & 2000 (9.0.3821 SR-1) & PC, Windows 98 & \\
\hline \multirow[t]{4}{*}{ Tecplot } & $8.0-1-0$ & Sun, SunOS 5.5.1 & \multirow[t]{4}{*}{ Technical figures } \\
\hline & $8.0-0-6$ & PC, Windows 98 & \\
\hline & 7.5 & PC, Windows 98 & \\
\hline & $9.0-3-0$ & PC, Windows 2000 Professional & \\
\hline Exceed & V6.1/V5.3 & PC, Windows 98 & \multirow{2}{*}{$\begin{array}{l}\text { Communication and file transfer } \\
\text { between PC and Unix workstation }\end{array}$} \\
\hline F-Secure & V5.1 (Build 21) & PC, Windows 2000 Professional & \\
\hline
\end{tabular}




\section{INTENTIONALLY LEFT BLANK}




\subsection{DIRECT INPUT}

\section{INPUTS}

Input data and parameters needed for the development of the Seepage Calibration Model (SCM) are obtained from the Technical Data Management System (TDMS). As stated in Section 1, the SCM is used to estimate seepage-relevant parameters through model calibration. In general, calibration is a process of fixing certain parameters considered known, relatively certain, or insensitive, and adjusting others that are unknown, uncertain, or highly sensitive to minimize the misfit between measured data and model output. Input data were measured in or refer to the middle nonlithophysal and the lower lithophysal zones of the Topopah Spring welded unit (the repository units). Appropriate data for the middle nonlithophysal zone have been measured in Niches 2, 3, and 4, and appropriate data for the lower lithophysal zone have been measured in Niche 5 and in boreholes SYBT-ECRB-LA\#1-\#3 drilled into the ceiling of the ECRB CrossDrift. Specific input data sets and the associated Data Tracking Numbers (DTNs) are listed in Table 4-1; specific input parameters are listed in Table 4-2; Technical Product Output (TPO) used as input to calculate local percolation fluxes is summarized in Table 4-3. These data and parameters are considered appropriate as input for the development of the SCM for the following reasons:

1. Profile alignments and borehole (BH) survey information (Table 4-1). These survey data are accurate and thus considered appropriate as a basis for defining niche geometry and identifying injection elements in the numerical mesh.

2. Air-permeability data (Table 4-1). These data are used as a basis for the geostatistical analysis and generation of spatially correlated permeability fields near the niches and the ECRB Cross-Drift. The data are location-specific and on the appropriate scale, and thus suitable for representing the local rock properties and the structure of subdrift-scale heterogeneities.

3. Liquid-release test data (Table 4-1). These data are used for calibration and validation of the SCM. Liquid-release test data are appropriate for the calibration of the SCM and the estimation of seepage-relevant parameters, because they reflect the salient processes and features affecting seepage. Moreover, they are taken on a representative scale comparable to that of a waste emplacement drift.

4. Calibrated drift-scale fracture properties for the middle nonlithophysal and lower lithophysal zone of the Topopah Spring welded unit. Because they are directly measured or derived from data collected at Yucca Mountain, these fracture parameters are considered appropriate to be used as reference input parameters. Only the parameters that are fixed during an inversion, and for which no location-specific data are available, are needed as input; this subset is summarized in Table 4-2. Because of their small sensitivity on predicted seepage rates (see Section 6.6.3.1), a minor change in any of these input parameters has a negligible impact on the estimated model parameters or the conclusions of this Model Report.

5. Coordinates of the Unsaturated Zone Flow and Transport Model (UZ Model) grid and calculated flow rates for extraction of background percolation flux (Table 4-3). In the 
absence of direct observations of percolation flux, the percolation fluxes calculated by the UZ Flow Model, which is based on site-specific data, are considered appropriate for their intended use in the SCM.

Table 4-1. Input Data

\begin{tabular}{|c|c|}
\hline $\mathrm{DTN}^{\mathrm{a}}$ & Data Description \\
\hline \multicolumn{2}{|r|}{ Niche Geometry } \\
\hline MO0003GSC00096.000 [DIRS 152167] & ESF Niche 2 (Niche 3650) profile alignment \\
\hline MO0002GSC00076.000 [DIRS 152623] & ESF Niche 2 (Niche 3650) borehole as-built information \\
\hline MO0003GSC00103.000 [DIRS 152176] & ESF Niche 3 (Niche 3107) profile alignment \\
\hline MO0002GSC00064.000 [DIRS 152625] & ESF Niche 3 (Niche 3107) borehole as-built information \\
\hline MO0008GSC00273.000 [DIRS 152626] & ESF Niche 4 (Niche 4788) profile alignment \\
\hline MO0107GSC01069.000 [DIRS 156941] & ESF Niche 4 (Niche 4788) borehole as-built information \\
\hline MO0009GSC00332.000 [DIRS 155370] & ECRB Niche 5 (Niche 1620) profile survey data \\
\hline MO0107GSC01061.000 [DIRS 155369] & ECRB Niche 5 (Niche 1620) slot survey data \\
\hline MO0312GSC03176.000 [DIRS 169532] & $\begin{array}{l}\text { ECRB Niche } 5 \text { (Niche 1620) survey data for collars, bottoms, and } \\
\text { intervals }\end{array}$ \\
\hline LB0301N5CEILNG.001 [DIRS 161733] & ECRB Niche 5 (Niche 1620) detailed niche ceiling roughness data \\
\hline \multicolumn{2}{|r|}{ Air-Permeability Data } \\
\hline LB0011AIRKTEST.001 [DIRS 153155] & Air permeability data from ESF Niche 2 (Niche 3650) \\
\hline LB990601233124.001 [DIRS 105888] & $\begin{array}{l}\text { Air permeability data from ESF Niche } 3 \text { (Niche 3107) and Niche } 4 \\
\text { (Niche 4788) }\end{array}$ \\
\hline LB0110AKN5POST.001 [DIRS 156904] & Air permeability data from ECRB Niche 5 (Niche 1620) \\
\hline LB00090012213U.001 [DIRS 153141] & Air permeability data from ECRB borehole SYBT-ECRB-LA\#2 \\
\hline \multicolumn{2}{|r|}{ Liquid-Release Test Data } \\
\hline LB0010NICH3LIQ.001 [DIRS 153144] & Liquid-release test data from ESF Niche 3 (Niche 3107), March 1999 \\
\hline LB0010NICH4LIQ.001 [DIRS 153145] & Liquid-release test data from ESF Niche 4 (Niche 4788), Nov. 1999 \\
\hline LB0207NICH5LIQ.001 [DIRS 160408] & Liquid-release test data from ECRB Niche 5 (Niche 1620), June 2000 \\
\hline LB0209NICH5LIQ.001 [DIRS 160796] & Liquid-release test data from ECRB Niche 5 (Niche 1620), June 2002 \\
\hline LB0211NICH5LIQ.001 [DIRS 160792] & Liquid-release test data from ECRB Niche 5 (Niche 1620), August 2002 \\
\hline LB0110ECRBLIQR.002 [DIRS 156879] & $\begin{array}{l}\text { Liquid-release test data from ECRB borehole SYBT-ECRB-LA\#1, Feb. } \\
2001\end{array}$ \\
\hline LB00090012213U.002 [DIRS 153154] & $\begin{array}{l}\text { Liquid-release test data from ECRB borehole SYBT-ECRB-LA\#2, May } \\
2000\end{array}$ \\
\hline LB0110SYST0015.001 [DIRS 160409] & $\begin{array}{l}\text { Liquid-release test data from ECRB borehole SYBT-ECRB-LA\#2, Oct. } \\
2000\end{array}$ \\
\hline LB0203ECRBLIQR.001 [DIRS 158462] & $\begin{array}{l}\text { Liquid-release test data from ECRB borehole SYBT-ECRB-LA\#3, May } \\
2001\end{array}$ \\
\hline \multicolumn{2}{|c|}{$\begin{array}{l}\text { a Traceability to the specific information extracted from these DTNs is given in the appendices and cited Scientific } \\
\text { Notebooks. } \\
\text { This DTN superseded MO0008GSC00310.000 [DIRS 152627], which was the source for borehole coordinates } \\
\text { available at the time of model development for Niche 4. Borehole coordinates in both DTNs are identical, i.e., } \\
\text { there is no impact on the models, analyses, and conclusions presented in this Model Report. }\end{array}$} \\
\hline \multicolumn{2}{|l|}{ DTN=Data Tracking Number } \\
\hline
\end{tabular}


Table 4-2. Hydrogeologic Input Parameters

\begin{tabular}{|c|c|c|c|}
\hline DTN & Parameter & Value & Units \\
\hline \multicolumn{4}{|c|}{ Middle Nonlithophysal Zone of Topopah Spring Welded Unit (Fracture Parameter for tsw34) } \\
\hline LB997141233129.001ª [DIRS 104055] & van Genuchten parameter, $m$ & 0.608 & [dimensionless] \\
\hline LB997141233129.001 ${ }^{\mathrm{a}}$ [DIRS 104055] & Residual liquid saturation, $S_{l r}$ & 0.01 & [dimensionless] \\
\hline LB997141233129.001 ${ }^{\mathrm{a}}$ [DIRS 104055] & Satiated saturation, $S_{l s}$ & 1.00 & [dimensionless] \\
\hline \multicolumn{4}{|c|}{ Lower Lithophysal Zone of Topopah Spring Welded Unit (Fracture Parameters for tsw35) } \\
\hline LB0205REVUZPRP.001 [DIRS 159525] & Porosity & 0.96 & {$[\%]$} \\
\hline LB997141233129.001 ${ }^{\mathrm{a}}$ [DIRS 104055] & van Genuchten parameter, $m$ & 0.611 & [dimensionless] \\
\hline LB997141233129.001 ${ }^{\mathrm{a}}$ [DIRS 104055] & Residual liquid saturation, $S_{l r}$ & 0.01 & [dimensionless] \\
\hline LB997141233129.001 ${ }^{\mathrm{a}}$ [DIRS 104055] & Satiated saturation, $S_{l s}$ & 1.00 & [dimensionless] \\
\hline \multicolumn{4}{|c|}{$\begin{array}{l}\text { The superceded fracture parameters of DTN: LB997141233129.001 [DIRS 104055] [which is a qualified } \\
\text { product output from a previous revision of the Calibrated Properties Model (CRWMS M\&O } 2000 \text { [DIRS } \\
\text { 144426])] are suitable for their intended use within this Model Report. The superceded and superceding } \\
\text { values are identical with the exception of the van Genuchten parameter } m \text {; the superceding value for both } \\
\text { units is } 0.633 \text {. The difference between the superceded and superceding values are inconsequential for the } \\
\text { estimation of drift seepage, because (1) the sensitivity of seepage to the } m \text { parameter (or the related } n \\
\text { parameter) is very limited (as discussed in Section 6.6.3.1), and (2) consistent values are used in the } \\
\text { calibration and prediction models. Moreover, the superceded values, which originated from a reliable source, } \\
\text { have been used in previous analyses of flow, transport, and seepage for the same units; the superceded value } \\
\text { is considered pertinent to the property of interest. The values were superceded because (1) the numerical grid } \\
\text { was modified and (2) a new inversion methodology was employed. }\end{array}$} \\
\hline
\end{tabular}

DTN=Data Tracking Number

Table 4-3. Mesh Coordinates and Flow Field Used to Calculate Local Percolation Flux

\begin{tabular}{|c|c|}
\hline DTN & TPO Description \\
\hline LB990701233129.001 ${ }^{\mathrm{a}}$ [DIRS 106785] & 3-D UZ model grid, including coordinates \\
\hline LB990801233129.003 a [DIRS 122757] & Calculated percolation flux, flow field \#3 \\
\hline \multicolumn{2}{|c|}{$\begin{array}{l}\text { The calculated percolation fluxes from the superceded DTN: LB990801233129.003 [DIRS 122757] (which are } \\
\text { based on the related numerical grid contained in the superceded DTN: LB990701233129.001 [DIRS 106785]) } \\
\text { are considered suitable for the intended use in this Model Report, because (1) the estimated parameters, } \\
\text { output, and conclusions presented in this Model Report are insensitive to the specified background } \\
\text { percolation flux, (2) the superceded data originated from a reliable source, and (3) the superceded data have } \\
\text { been used in previous analyses of flow, transport, and seepage in the unsaturated zone, i.e., they are } \\
\text { pertinent to the properties of interest. The UZ Flow model providing percolation fluxes was revised (1) to } \\
\text { accommodate a new repository design (requiring a new numerical grid), (2) to incorporate revised property } \\
\text { sets, and (3) to employ a finer vertical discretization of the PTn hydrogeologic unit. The flow fields calculated } \\
\text { with the revised UZ Flow model (see DTN: LB03023DSSCP9I.001 [DIRS 163044]) yield local percolation } \\
\text { fluxes at Niches } 3650,3107,4788, \text { and } 1620 \text { of } 4.0,4.7,2.4, \text { and } 6.2 \text { mm/year, respectively. Given the low } \\
\text { sensitivity of the estimated parameters to the background percolation flux (see discussion in Section 6.6.2.3), } \\
\text { the differences between these and the superceded values are inconsequential. }\end{array}$} \\
\hline
\end{tabular}

3-D=three-dimensional: DTN=Data Tracking Number; UZ=Unsaturated Zone; PTn=Paintbrush nonwelded tuff; TPO=Technical Product Output

Equations are discussed in the context of model development in Section 6 with appropriate citations to their sources. The collection of the input data used for the development and calibration of the SCM is described in detail in the report In Situ Field Testing of Processes (BSC 2004 [DIRS 170004], Sections 6.2 and 6.11) and is summarized in Section 6.5. The analysis of the seepage-rate data is described in Section 6.6.3. Uncertainties in the input data and parameters are addressed throughout Section 6 and are summarized in Section 8.2. 


\subsection{CRITERIA}

The licensing criteria for postclosure performance assessment are stated in 10 CFR 63 [DIRS 156605]. The requirements to be satisfied by TSPA are identified in the Yucca Mountain Project Requirements Document (Canori and Leitner 2003 [DIRS 166275]). The acceptance criteria that will be used by the U.S. Nuclear Regulatory Commission (NRC) to determine whether the technical requirements have been met are identified in Yucca Mountain Review Plan, Final Report (YMRP; NRC 2003 [DIRS 163274]). The pertinent requirements and criteria for this Model Report are summarized in Table 4-4. Section 8.5 provides cross-references to demonstrate how the acceptance criteria are addressed.

Table 4-4. Project Requirements and Yucca Mountain Review Plan Acceptance Criteria Applicable to this Model Report

\begin{tabular}{|c|c|c|c|}
\hline $\begin{array}{c}\text { Requirement } \\
\text { Number }\end{array}$ & Requirement Title & 10 CFR 63 Link & YMRP Acceptance Criteria \\
\hline \multirow[t]{2}{*}{$\begin{array}{l}\text { PRD-002/T-015 } \\
\text { (Canori and } \\
\text { Leitner } 2003 \\
\text { [DIRS 166275]) }\end{array}$} & \multirow[t]{2}{*}{$\begin{array}{l}\text { Requirements for } \\
\text { Performance Assessment }\end{array}$} & \multirow[t]{2}{*}{$\begin{array}{l}10 \text { CFR } 63.114 \\
\quad(a-c) \\
\text { [DIRS 156605] }\end{array}$} & $\begin{array}{l}\text { Criteria } 1 \text { to } 4 \text { for Quantity and Chemistry of } \\
\text { Water Contacting Waste Packages and } \\
\text { Waste Forms (NRC } 2003 \text { [DIRS 163274], } \\
\text { Section 2.2.1.3.3.3). }\end{array}$ \\
\hline & & & $\begin{array}{l}\text { Criteria } 1 \text { to } 4 \text { for Flow Path in the } \\
\text { Unsaturated Zone (NRC } 2003 \text { [DIRS } \\
\text { 163274], Section 2.2.1.3.6.3). }\end{array}$ \\
\hline
\end{tabular}

YMRP=Yucca Mountain Review Plan

Where a subcriterion includes several components, only some of those components may be addressed. How these components are addressed is summarized in Section 8.5.

The acceptance criteria identified in Section 2.2.1.3.3.3 of the YMRP (NRC 2003 [DIRS 163274]) are given below.

\section{Section 2.2.1.3.3.3, Quantity and Chemistry of Water Contacting Waste Packages and Waste Forms}

Acceptance Criterion 1, System Description and Model Integration are Adequate:

Subcriterion (2): The abstraction of the quantity and chemistry of water contacting engineered barriers and waste forms uses assumptions, technical bases, data, and models, that are appropriate and consistent with other related U.S. Department of Energy abstractions. For example, the assumptions used for the quantity and chemistry of water contacting engineered barriers and waste forms are consistent with the abstractions of "Degradation of Engineered Barriers" (Section 2.2.1.3.1); "Mechanical Disruption of Engineered Barriers (Section 2.2.1.3.2); "Radionuclide Release Rates and Solubility Limits" (Section 2.2.1.3.4); "Climate and Infiltration" (Section 2.2.1.3.5); and "Flow Paths in the Unsaturated Zone" (Section 2.2.1.3.6). The descriptions and technical bases provide transparent and traceable support for the abstraction of quantity and chemistry of water contacting engineered barriers and waste forms. 
Subcriterion (8): Adequate technical bases are provided, including activities such as independent modeling, laboratory or field data, or sensitivity studies, for inclusion of any thermal-hydrologic-mechanical-chemical couplings and features, events, and processes

\section{Acceptance Criterion 2, Data are Sufficient for Model Justification:}

Subcriterion (1): Geological, hydrological, and geochemical values used in the license application are adequately justified. Adequate description of how the data were used, interpreted, and appropriately synthesized into the parameters is provided.

Subcriterion (2): Sufficient data were collected on the characteristics of the natural system and engineered materials to establish initial and boundary conditions for conceptual models of thermal-hydrologic-mechanical-chemical coupled processes, that affect seepage and flow and the engineered barrier chemical environment.

Acceptance Criterion 3, Data Uncertainty is Characterized and Propagated Through the Model Abstraction:

Subcriterion (1): Models use parameter values, assumed ranges, probability distributions, and bounding assumptions that are technically defensible, reasonably account for uncertainties and variabilities, and do not result in an under-representation of the risk estimate.

Subcriterion (2): Parameter values, assumed ranges, probability distributions, and bounding assumptions used in the total system performance assessment calculations of quantity and chemistry of water contacting engineered barriers and waste forms are technically defensible and reasonable, based on data from the Yucca Mountain region (e.g., results from large block and drift-scale heater and niche tests), and a combination of techniques that may include laboratory experiments, field measurements, natural analog research, and process-level modeling studies.

Subcriterion (4): Adequate representation of uncertainties in the characteristics of the natural system and engineered materials is provided in parameter development for conceptual models, process-level models, and alternative conceptual models. The U.S. Department of Energy may constrain these uncertainties using sensitivity analyses or conservative limits. For example, the U.S. Department of Energy demonstrates how parameters used to describe flow through the engineered barrier system bound the effects of backfill and excavation-induced changes.

\section{Acceptance Criterion 4, Model Uncertainty is Characterized and Propagated Through the Model Abstraction:}

Subcriterion (1): Alternative modeling approaches of features, events, and processes are considered and are consistent with available data and current scientific 
understanding, and the results and limitations are appropriately considered in the abstraction.

Subcriterion (2): Alternative modeling approaches are considered and the selected modeling approach is consistent with available data and current scientific understanding. A description that includes a discussion of alternative modeling approaches not considered in the final analysis and the limitations and uncertainties of the chosen model is provided.

Subcriterion (3): Consideration of conceptual model uncertainty is consistent with available site characterization data, laboratory experiments, field measurements, natural analog information and process-level modeling studies; and the treatment of conceptual model uncertainty does not result in an under-representation of the risk estimate.

The acceptance criteria identified in Section 2.2.1.3.6.3 of the YMRP (NRC 2003 [DIRS 163274]) are given below.

\section{Section 2.2.1.3.6.3, Flow Paths in the Unsaturated Zone}

\section{Acceptance Criterion 1, System Description and Model Integration are Adequate:}

Subcriterion (1): The total system performance assessment adequately incorporates important design features, physical phenomena, and couplings, and uses consistent and appropriate assumptions throughout the flow paths in the unsaturated zone abstraction process. Couplings include thermal-hydrologic-mechanicalchemical effects, as appropriate.

Subcriterion (2): The aspects of geology, hydrology, geochemistry, physical phenomena, and couplings that may affect flow paths in the unsaturated zone are adequately considered. Conditions and assumptions in the abstraction of flow paths in the unsaturated zone are readily identified and consistent with the body of data presented in the description.

Subcriterion (6): Adequate spatial and temporal variability of model parameters and boundary conditions are employed in process-level models to estimate flow paths in the unsaturated zone, percolation flux, and seepage flux.

Subcriterion (7): Average parameter estimates used in process-level models are representative of the temporal and spatial discretizations considered in the model.

\section{Acceptance Criterion 2, Data are Sufficient for Model Justification:}

Subcriterion (1): Hydrological and thermal-hydrological-mechanical-chemical values used in the license application are adequately justified. Adequate descriptions of how the data were used, interpreted, and appropriately synthesized into the parameters are provided. 
Subcriterion (5): Sensitivity or uncertainty analyses are performed to assess data sufficiency, and verify the possible need for additional data.

Subcriterion (6): Accepted and well-documented procedures are used to construct and calibrate the numerical models.

Subcriterion (7): Reasonably complete process-level conceptual and mathematical models are used in the analyses. In particular: (i) mathematical models are provided that are consistent with conceptual models and site characteristics; and (ii) the robustness of results from different mathematical models is compared.

Acceptance Criterion 3, Data Uncertainty is Characterized and Propagated Through the Model Abstraction:

Subcriterion (1): Models use parameter values, assumed ranges, probability distributions, and bounding assumptions that are technically defensible, reasonably account for uncertainties and variables, and do not result in an under-representation of the risk estimate.

Subcriterion (4): The initial conditions, boundary conditions, and computational domain used in sensitivity analyses and/or similar analyses are consistent with available data. Parameter values are consistent with the initial and boundary conditions and the assumptions of the conceptual models for the Yucca Mountain site.

Subcriterion (6): Uncertainties in the characteristics of the natural system and engineered materials are considered.

Acceptance Criterion 4, Model Uncertainty is Characterized and Propagated Through the Model Abstraction:

Subcriterion (1): Alternative modeling approaches of features, events, and processes, consistent with available data and current scientific understanding, are investigated. The results and limitations are appropriately considered in the abstraction.

\subsection{CODES, STANDARDS, AND REGULATIONS}

No specific, formally established standards have been identified as applying to this modeling activity. 


\section{INTENTIONALLY LEFT BLANK}




\section{ASSUMPTIONS}

This section contains a list of assumptions used for the development of the Seepage Calibration Model (SCM). Each statement of an assumption is immediately followed by the rationale for why the assumption is considered valid or reasonable. Assumptions in immediately preceding upstream documentations have no significant impact on the results of the present model or they are discussed in the following subsections.

\subsection{CONTINUUM APPROACH}

Assumption: The continuum approach is assumed to be a valid concept to calculate percolation flux and drift seepage at Yucca Mountain.

Rationale: The continuum approach can be considered appropriate (1) if it appropriately represents the key features and processes determining seepage into large underground openings, and (2) if it is capable of reproducing and predicting seepage rates into a drift in a fractured formation.

As discussed in detail in Section 6.3.2, diversion of water around an underground opening on account of the capillary barrier effect predominantly occurs within fracture planes that are oriented approximately perpendicular to the drift axis. Flow within a fracture plane (or a collection of fracture planes) can be described by a continuum model with a heterogeneous permeability field.

As demonstrated in Sections 6.6.3 and 7.2.2.1, a continuum model is capable of reproducing and predicting seepage rates into a drift section, i.e., on the scale of interest. The continuum approach is therefore considered appropriate for seepage studies if applied within the framework described in this Model Report. Inverse modeling should be used for the estimation of processspecific, model-related, and scale-dependent parameters, and the same or similar conceptual model should be used for the subsequent seepage predictions, specifically the SMPA.

No further confirmation is required for this assumption, which is used throughout Sections 6 and 7.

\subsection{UNSATURATED FLOW}

Assumption: Water flow under unsaturated conditions is assumed to be governed by Richards' equation [“Capillary Conduction of Liquids Through Porous Mediums” (Richards 1931 [DIRS 104252], pp. 318-333)].

Rationale: This assumption is justified because (1) gravitational force is ubiquitous, and (2) rough-walled or partially filled fractures exert varying degrees of capillary pressure at different saturation levels. The constant of proportionality-relative permeability-is saturationdependent because (1) porous-medium continuum laws also apply to water flow through fractures filled with porous material, and (2) in the absence of fracture fillings, the thickness of the water film and connectivity of liquid islands on the fracture surface are saturation dependent ["Water Film Flow Along Fracture Surfaces of Porous Rock." (Tokunaga and Wan 1997 [DIRS 139195], pp. 1287-1295). 
Richards' equation follows from (1) the continuity equation and (2) the Buckingham-Darcy equation [Dynamics of Fluids in Porous Media (Bear, 1972 [DIRS 156269], pp. 487-502)]. Richards' equation states that isothermal flow of water in a porous medium or rough-walled fracture occurs under the combined effect of gravitational and capillary forces, that flow resistance is a function of saturation, and that, for the purposes of this representation, movement of the nonwetting air phase can be neglected.

This general concept, which is further discussed in Section 6.6.1.1 and used throughout Sections 6 and 7, is reasonable for unsaturated water flow through both porous matrix as well as partially filled or rough-walled fractures and does not require further confirmation.

\subsection{CHARACTERISTIC CURVES}

Assumption: Relative permeability and capillary pressure are assumed to be described as continuous functions of effective liquid saturation, following the expressions given by the van Genuchten-Mualem model ["A Closed-Form Equation for Predicting the Hydraulic Conductivity of Unsaturated Soils.” (van Genuchten 1980 [DIRS 100610], pp. 892-893)].

Rationale: The van Genuchten-Mualem model is the standard model used in the suite of UZ models; it was chosen in this work to ensure consistency. Furthermore, the applicability of relative permeability and capillary pressure functions is consistent with the continuum assumption (see Sections 5.1 and 6.6.1.1) and is appropriate to represent fractures that are roughwalled and/or partially filled with porous material. The calibration process and the consistent conceptualization in the downstream models (specifically the SMPA) make this assumption a valid approach.

No further confirmation is required for this assumption, which is used throughout Sections 6 and 7.

\subsection{EFFECTIVE CAPILLARY-STRENGTH PARAMETER}

Assumption: The effective, seepage-relevant capillary-strength parameter to be estimated for each test location is assumed to be spatially uniform on the drift scale and thus not correlated to the small-scale heterogeneous permeability field.

Rationale: The capillary-strength parameter to be estimated by calibration of the model against seepage-rate data is considered an effective parameter that includes a number of seepage-relevant features and processes, such as (1) the continuum capillarity of a network of rough-walled fractures, (2) capillary rise within finite fracture segments intersected by the underground opening, (3) small-scale drift-wall roughness (including effects of lithophysal cavities; see Section 5.7), and (4) capillary adsorption of water along drift wall leading to film flow.

The capillary strength of the fracture system is correlated to the fracture aperture distribution. Similarly, permeability may be correlated to aperture, suggesting that capillarity and permeability are (negatively) correlated. However, given that these parameters describe continuum properties of a fracture network (rather than those of a single fracture), it should be noted that an increase in permeability might be associated with an increase in fracture density 
(rather than an increase in aperture). An increase in fracture density does not affect capillarity. Consequently, capillarity and permeability are not necessarily correlated.

Items (2) through (4) are features and processes related to capillarity, and are thus well represented by a capillary-strength parameter; however, they are not related to permeability. Finally, since capillary strength is an effective parameter estimated by inverse modeling for a given conceptual model, its value is appropriate for use in a prediction model that has the same model structure, i.e., that uses the same assumption regarding the uniformity of this parameters.

Given that (1) capillarity and permeability are not necessarily correlated, (2) seepage-relevant features and processes not related to permeability are represented by the capillary-strength parameter, and (3) the effective parameter is estimated and used within a suite of conceptually consistent models, it is appropriate to consider the capillary-strength parameter uniform on the drift scale and not correlated to the small-scale heterogeneous permeability field. This assumption, which is used throughout Sections 6 and 7, does not require further confirmation.

\subsection{EVAPORATION IN CLOSED-OFF NICHES}

Assumption: The effect of evaporation on the seepage rates observed in closed-off niches in the middle nonlithophysal zone is assumed to be insignificant, i.e., water removal from the formation, at the drift surface, and from the capture system by evaporation and vapor diffusion is assumed to be small.

Rationale: Under isothermal conditions, potential evaporation at the wall or in the capture system of a closed-off and humidified niche is small compared to the amount of water being released. Seepage experiments in the middle nonlithophysal zone of the Topopah Spring welded unit were conducted in niches that were closed off by a bulkhead, which leads to comparatively high relative humidity and low air circulation. Moreover, a humidifier was used in some of the experiments to ensure high relative humidity. For these conditions, Ho ["Evaporation of Pendant Water Droplets in Fractures.” (1997 [DIRS 141521])] and Or and Ghezzehei ["Dripping into Subterranean Cavities from Unsaturated Fractures under Evaporative Conditions." (2000 [DIRS 144773])] provide a detailed description of evaporation mechanisms on the scale of individual water droplets within fractures or emerging from fractured formations. The evapo-infiltration threshold calculated by Ho (1997 [DIRS 141521], p. 2670) is significantly lower than the applied injection rates, suggesting a very minor influence of evaporation on measured seepage rates in experiments conducted in the niches.

Evaporation effects were included in the modeling of liquid-release tests performed in Niche 5, which exhibited relative humidity conditions slightly lower than those expected to have prevailed in Niches 2, 3, and 4. The impact of evaporation on seepage rates and thus on the estimation of seepage-relevant parameters is minor (as demonstrated in Section 6.7), confirming that neglecting evaporation effects in closed-off niches is appropriate.

No further confirmation is required for this assumption, which is used in Sections 6.6.3 and 7.2.2.1. Note that evaporation effects in the open, ventilated ECRB Cross-Drift are considered significant and are taken into account in the model based on relative humidity and evaporation rate measurements (see Sections 5.6, 6.5.4, and 6.6.1.4). 


\subsection{EVAPORATION IN OPEN DRIFT}

Assumption: Evaporation from the drift surface is assumed to be governed by one-dimensional vapor diffusion across an evaporative boundary layer, the thickness of which can be estimated from measurements of relative humidity and evaporation rate from a free water surface.

Rationale: As water injected during a liquid-release test reaches the opening, it spreads along the surface on account of capillarity within the rough surface. As a result, water potentially seeping into the opening may not only form droplets or lines along fracture traces with a small surface area, but may spread across the drift surface over a relatively large area. This phenomenon is qualitatively confirmed by the geometry of the wet spot observed at the niche ceiling during seepage experiments [(BSC 2004 [DIRS 170004], Section 6.2.1.3.4, Figure 6.2.1-7); ["Seepage into an Underground Opening Constructed in Unsaturated Fractured Rock under Evaporative Conditions.” (Trautz and Wang 2002 [DIRS 160335], Figures 7 and 9)]. The geometry of the wet spot does not have a clear correlation with the visible fractures traces. Even though water first appears along fracture traces (Trautz and Wang (2002 [DIRS 160335], Figure 10 ), the wet spot grows in an areal fashion. The short arrival time and the average speed at which the leading edge of the plume moves across the ceiling makes it obvious that the water is not transmitted through the matrix, but spreads along the ceiling as a surface film, possibly supported by flow through microfractures. Evaporation from such wet areas is similar to evaporation from a free water surface, where the evaporation rate is governed by onedimensional vapor diffusion across a relatively thin boundary layer of linearly decreasing vapor concentration. A detailed description of the corresponding conceptual and mathematical model and the estimation of the evaporation boundary-layer thickness is given in Sections 6.6.1.3 and 6.6.1.4.

No further confirmation is required for this assumption, which is used in Sections 6.6.3 and 7.2.2.1.

\subsection{LITHOPHYSAL CAVITIES}

Assumption: The impact of lithophysal cavities on seepage is assumed to be appropriately captured in the estimation of an effective capillary-strength parameter.

Rationale: The impact of lithophysal cavities on flow and seepage is twofold: (1) lithophysal cavities are essentially obstacles to water flow because they act as capillary barriers, focusing the water that flows around them; (2) lithophysal cavities intersected by the drift lead to a rough drift wall, potentially creating seepage points at local topographic lows. Both effects tend to promote seepage.

The assumption states that the effect of lithophysal cavities on seepage can be captured through the estimation of an effective capillary-strength parameter, making the explicit inclusion of lithophysal cavities into the process model unnecessary. This approach is considered appropriate for the following reasons: (1) omitting lithophysal cavities in the process model used for inverse modeling yields lower estimates of the capillary-strength parameter and is thus conservative; (2) consistency between the calibration model (the SCM) and the prediction model (the SMPA) removes the impact of a potential estimation bias; (3) the approach followed allows for the 
development of a single SMPA conceptual model for both the middle nonlithophysal and lower lithophysal zones, yielding a single look-up table for TSPA to sample from; and (4) explicit modeling of lithophysal cavities is not warranted because of insufficient information regarding their location, shape, and frequency.

No further confirmation is required for this assumption, which is used in Sections 6.6.3 and 7.2.2.1. 


\section{INTENTIONALLY LEFT BLANK}




\section{MODEL DISCUSSION}

\subsection{MODELING OBJECTIVES AND DEFINITIONS}

\subsubsection{Objectives}

The following sections describe the development, calibration, and validation of the Seepage Calibration Model (SCM). The purpose of the SCM is to provide a methodological and conceptual basis for the subsequent development of the Seepage Model for Performance Assessment (SMPA). Furthermore, seepage-relevant parameters are derived as input to the abstraction for drift seepage.

The seepage models are not expected to accurately predict individual seepage events or the precise spatial distribution along the drift. Instead, the seepage models are intended to provide estimates of the seepage flux averaged over a $5 \mathrm{~m}$ drift segment (the approximate length of a waste package) as a function of the percolation flux on the drift scale. The seepage experiments and modeling approach are designed to address seepage on this specific scale.

A list of the data corroborating and supporting the SCM (including the corresponding source DTNs) is provided in Table 6-5 below.

\subsubsection{Definitions}

Seepage is defined as flow of liquid water into an underground opening such as a niche, the ECRB Cross-Drift, or a waste emplacement drift; the water originates from the rock mass and forms drops that subsequently detach from the opening surface. According to this definition, seepage does not include advective or diffusive vapor flow into the opening or condensation of water vapor on surfaces, which may lead to drop formation and drop detachment. Some of the water entering an underground opening may also evaporate or flow along the wall, thus not contributing to seepage in the narrow sense defined here. Note, however, that evaporation, condensation, and film flow along the surface of the opening affect the moisture conditions in the waste emplacement drift and may thus impact repository performance.

Seepage rate is the amount of water seeping into the opening per unit of time.

Seepage flux is defined as the seepage rate per unit area of the projected drift outline.

Seepage percentage is defined as the ratio of seepage flux divided by percolation flux. As outlined in Section 6.1.1, a five-meter long drift section (the approximate length of a waste package) is used as the reference scale for calculating percolation and seepage fluxes. In the context of liquid-release tests, seepage percentage is the ratio of the rate or amount of water that seeped into the niche divided by the rate or amount of water released.

Seepage threshold is defined here as the critical percolation flux below which no seepage occurs, i.e., all percolating water is diverted around the opening, evaporates, or flows along the drift surface as a thin water film. Note that Philip et al. ["Unsaturated Seepage and Subterranean Holes: Conspectus, and Exclusion Problem for Circular Cylindrical Cavities.” (1989 
[DIRS 105743])] did not consider evaporation and film-flow effects when defining the critical seepage conditions.

Seepage fraction is defined as the fraction of waste packages affected by seepage. This is equivalent to the fraction of $5 \mathrm{~m}$ drift sections that exhibit a nonzero seepage percentage.

Capillary barrier is a technical term used to describe the fact that water is diverted around an underground opening, preventing seepage or reducing the seepage flux below the incident percolation flux. This technical definition of a barrier is different from regulatory definition of 10 CFR 63.2 [DIRS 156605]. However, the usage of the term in the context of the capillary barriers discussed in this Model Report is unambiguous.

\subsubsection{Scientific Notebooks}

The scientific notebooks (SN) listed in Table 6-1 provide details potentially needed to reproduce the modeling work discussed in this Model Report.

Table 6-1. Scientific Notebooks

\begin{tabular}{|l|l|l|l|}
\hline \multicolumn{1}{|c|}{$\begin{array}{c}\text { LBNL Scientific } \\
\text { Notebook ID }\end{array}$} & \multicolumn{1}{|c|}{$\begin{array}{c}\text { M\&O Scientific } \\
\text { Notebook ID }\end{array}$} & \multicolumn{1}{c|}{ Relevant Pages } & \multicolumn{1}{c|}{ Citation } \\
\hline YMP-LBNL-SAF-1 & SN-LBNL-SCl-087-V1 & $1-4,100-102,139$ & Finsterle 1999 [DIRS 153448] \\
\hline YMP-LBNL-SAF-2 & SN-LBNL-SCI-171-V1 & $1-2,34-42,47-95$ & Finsterle 2002 [DIRS 161043] \\
\hline YMP-LBNL-SAF-3 & SN-LBNL-SCl-228-V1 & $1-26,31-37$ & Wang 2003 [DIRS 161456] \\
\hline YMP-LBNL-SAF-TG-1 & SN-LBNL-SCI-223-V1 & $9-44$ & Wang 2003 [DIRS 161456] \\
\hline YMP-LBNL-RCT-DSM-1 & SN-LBNL-SCl-157-V1 & $1-37$ & Trautz 2001 [DIRS 161044] \\
\hline YMP-LBNL-RCT-2 & SN-LBNL-SCI-156-V1 & $35-45$ & Trautz 2001 [DIRS 156903] \\
\hline YMP-LBNL-JSW-6C & SN-LBNL-SCl-122-V1 & $108-123$ & Wang 1999 [DIRS 153449] \\
\hline YMP-LBNL-DSM-CFA-1 & SN-LBNL-SCI-180-V1 & $4-6,8-10,13,15-58$ & Ahlers 2002 [DIRS 161045] \\
\hline YMP-LBNL-YSW-JH-2 & SN-LBNL-SCI-143-V1 & 124 & Hinds 2001 [DIRS 155955] \\
\hline YMP-LBNL-RCT-RH-1 & SN-LBNL-SCI-175-V1 & $27-29$ & Hedegaard 2002 [DIRS 161046] \\
\hline
\end{tabular}

LBNL=Lawrence Berkeley National Laboratory

\subsection{FEATURES, EVENTS, AND PROCESSES}

Table 6-2 contains a list of FEPs taken from the LA FEP List (DTN: MO0407SEPFEPLA.000 [DIRS 170760]). The selected FEPs are those taken from the LA FEP List that are associated with the subject matter of this report (BSC 2004 [DIRS 169654], Table 2.1.5-1). The results of this model are part of the basis for the treatment of FEPs as discussed in the Total System Performance Assessment-License Application Methods and Approach (BSC 2003 [DIRS 166296], Section 3.2.2). The cross-reference for each FEP to the relevant sections of this report is also given in Table 6-2. 
Table 6-2. FEPs Addressed in this Model Report

\begin{tabular}{|c|c|c|}
\hline FEP No. & FEP Name & Relevant Sections of this AMR \\
\hline 1.2.02.01.0A & Fractures & $\begin{array}{l}\text { Air-permeability and seepage testing as well as the heterogeneous } \\
\text { fracture continuum model characterize and account for flow through and } \\
\text { seepage from fractures (see Sections } 6.3 .2,6.3 .3 .2 \text {, and } 6.5 \text { ) }\end{array}$ \\
\hline 2.1.08.02.0A & $\begin{array}{l}\text { Enhanced influx at } \\
\text { the repository }\end{array}$ & $\begin{array}{l}\text { The impact of an underground opening on the unsaturated flow field } \\
\text { (including dry-out from evaporation, capillary-barrier effect, and flow } \\
\text { diversion around the drift) is captured in the seepage process model by } \\
\text { solving the equations governing unsaturated flow in fractured porous } \\
\text { media and by specifying appropriate boundary conditions at the drift wall. } \\
\text { It leads to reduced (not enhanced) influx (see Sections } 6.3,6.3 .2,6.3 .3 \text {, } \\
6.6 \text {, and 6.8). }\end{array}$ \\
\hline 2.2.01.01.0A & $\begin{array}{l}\text { Mechanical effects of } \\
\text { excavation/ construc- } \\
\text { tion in the near field }\end{array}$ & $\begin{array}{l}\text { Excavation effects are taken into account through the use of post- } \\
\text { excavation air-permeability data and the estimation of a capillary-strength } \\
\text { parameter determined from seepage data that reflect seepage from an } \\
\text { excavation-disturbed zone around a large opening (see Sections } 6.3 .3 .2 \text {, } \\
6.3 .4,6.5 .2,6.6 .3 .1 \text {, and } 6.6 .3 .3 \text { ). }\end{array}$ \\
\hline 2.2.03.02.0A & $\begin{array}{l}\text { Rock properties of } \\
\text { host rock and other } \\
\text { units }\end{array}$ & $\begin{array}{l}\text { Location-specific rock properties are (1) taken from supporting reports } \\
\text { (see Table 4-2), (2) determined from local air-permeability data (including } \\
\text { measures of heterogeneity and spatial correlation), and (3) determined } \\
\text { through inverse modeling. Variability is accounted for on various scales } \\
\text { (see Sections 4.1, 6.5.2, and 8.2). }\end{array}$ \\
\hline 2.2.07.02.0A & $\begin{array}{l}\text { Unsaturated ground- } \\
\text { water flow in the } \\
\text { geosphere }\end{array}$ & $\begin{array}{l}\text { Unsaturated flow processes are accounted for in the conceptual and } \\
\text { mathematical model (see Sections 6.3.2 and 6.6.1.1). }\end{array}$ \\
\hline 2.2.07.04.0A & $\begin{array}{l}\text { Focusing of unsatu- } \\
\text { rated flow (fingers, } \\
\text { weeps) }\end{array}$ & $\begin{array}{l}\text { Explicitly modeled heterogeneity induces flow focusing. Impact of small- } \\
\text { scale flow focusing effects on seepage is included in effective parameter } \\
\text { (see Sections } 6.3,6.3 .3 .1,6.6 .2 .1 \text {, and } 6.6 .3 .3 \text { ). }\end{array}$ \\
\hline 2.2.07.08.0A & $\begin{array}{l}\text { Fracture flow in the } \\
\text { UZ }\end{array}$ & $\begin{array}{l}\text { Liquid flow through unsaturated fractures is simulated using site-specific } \\
\text { fracture properties; explicit inclusion of heterogeneity leads to flow } \\
\text { channeling (see Sections } 6.3 .2,6.3 .3 .2 \text {, and 6.6.2.1) }\end{array}$ \\
\hline 2.2.07.09.0A & $\begin{array}{l}\text { Matrix imbibition in } \\
\text { the UZ }\end{array}$ & $\begin{array}{l}\text { Matrix imbibition is considered small under near-steady seepage } \\
\text { conditions and is therefore neglected (see Section 6.3.3.2). }\end{array}$ \\
\hline 2.2.07.18.0A & $\begin{array}{l}\text { Film flow into the } \\
\text { repository }\end{array}$ & $\begin{array}{l}\text { If water originating from film flow seeps into the opening during a liquid- } \\
\text { release test, it is reflected in the corresponding seepage data point used } \\
\text { for model calibration, i.e., film flow is automatically accounted for in the } \\
\text { estimated seepage-related parameter and thus in the prediction of } \\
\text { seepage into waste emplacement drifts (see Sections } 6.1 .2,6.3 .2 \text {, } \\
6.3 .3 .2,6.3 .4 \text {, and 6.6.3.1). }\end{array}$ \\
\hline 2.2.07.20.0A & $\begin{array}{l}\text { Flow diversion around } \\
\text { repository drifts }\end{array}$ & $\begin{array}{l}\text { The impact of an underground opening on the unsaturated flow field } \\
\text { (including dry-out from evaporation, capillary-barrier effect, and flow } \\
\text { diversion around the drift) is captured in the seepage process model by } \\
\text { solving the equations governing unsaturated flow in fractured porous } \\
\text { media and by specifying appropriate boundary conditions at the drift wall. } \\
\text { Drift shadow is simulated as a result of seepage exclusion (see Sections } \\
6.3,6.3 .2,6.3 .3,6.6 \text {, and } 6.8 \text { ). }\end{array}$ \\
\hline
\end{tabular}

FEP=features, events, and processes; UZ=Unsaturated Zone 


\subsection{BASE-CASE CONCEPTUAL MODEL}

\subsubsection{Seepage Phenomena and Processes}

To understand the seepage process and to identify the factors affecting seepage, a description is given of the fate of water percolating through the unsaturated zone of Yucca Mountain, eventually encountering the immediate vicinity of a waste emplacement drift. This description is based on and consistent with the related discussion found in the scientific literature (see, for example, Philip et al. (1989 [DIRS 105743]) and "Using the Continuum Approach to Model Unsaturated Flow in Fractured Rock.” (Finsterle 2000 [DIRS 151875]) and references therein).

Water that penetrates the ground surface and reaches a depth that is unaffected by evapotranspiration starts to percolate downwards, driven by gravity and capillary forces. The detailed flow path is determined by the degree of fracturing, fracture geometry, orientation, and connectivity, as well as the hydrogeologic properties of the fractures and the matrix. Depending on these factors, the water phase in the unsaturated fracture network will either disperse or focus along the flow path. Tilted contacts between hydrogeologic units (especially between welded and nonwelded tuffs) may affect the overall flow pattern or lead to a change in the frequency and spacing of flow channels. However, the channeling process (i.e., the redistribution of water leading to local fluxes in portions of the fracture network that are higher and lower than the average flux) is likely to diminish with depth. As flow concentration continues to occur, the distance between the individual channels carrying focused flow increases, so the likelihood of two channels meeting and merging decreases with depth. Flow focusing and dispersion of flow paths also happens within a rough-walled fracture, where asperity contacts and locally larger fracture openings lead to small-scale redistribution of water within the fracture. A general discussion of channeling effects under unsaturated flow conditions can be found in "Solute Channeling in Unsaturated Heterogeneous Porous Media" (Birkholzer and Tsang 1997 [DIRS 119397]). Flow focusing is important for seepage, because seepage depends on the local rather than average percolation flux.

As water approaches the potential waste emplacement drift (one to several meters above the drift ceiling), conditions change in several ways, all affecting the amount of water that will eventually seep into the opening. The water may first encounter a dry-out zone caused by drift ventilation. The dry-out zone may also develop as a result of increased temperatures, in which case it is referred to as a boiling zone. Under these thermal conditions, the dry-out zone may be surrounded by a two-phase zone in which heat-pipe effects determine water, vapor, and heat fluxes, and a condensation zone with increased saturation. (Note that ventilation and elevated temperatures are limited in time and thus do not affect long-term seepage.)

In addition, formation properties around the openings are likely to be altered as a result of stress redistribution during drift excavation, which leads to local opening or partial closing of fractures and potentially the creation of new fractures. Thermal expansion of the rock matrix may also induce changes in apertures. Finally, the local chemical environment, which is altered by evaporation and thermal effects, may lead to dissolution and precipitation of minerals, again affecting porosity, permeability, and capillarity of the fracture system as well as fracture-matrix interaction. Such thermally and geochemically induced alterations were of no significance during the ambient liquid-release tests analyzed by the SCM. In general, however, all the 
conditions discussed above lead to a flow pattern in the vicinity of a waste emplacement drift different from that in the undisturbed formation under ambient conditions.

Provided that liquid water penetrates the boiling or dry-out zone (for details, see Drift-Scale Coupled Processes (DST and TH Seepage) Models (BSC 2004 [DIRS 170338])), it reaches the immediate vicinity of the drift wall, where (at least under ambient conditions) a boundary layer of increased saturation is expected to develop as a result of the capillary barrier effect (Philip et al. 1989 [DIRS 105743]). The water is prevented from seeping into the drift because of capillary suction, which retains the wetting fluid in the pore space. If permeability and capillarity of the fracture network within this boundary layer are sufficiently high, all or a portion of the water is diverted around the drift under partially saturated conditions. Locally, however, the water potential in the formation may be higher than that in the drift, and water appears at the drift surface. At the drift surface, the water either evaporates, follows the inclined, rough wall in a water film, or forms a drop that grows and eventually detaches (Or and Ghezzehei 2000 [DIRS 144773]). Only this last mechanism is considered drift seepage according to the definition of Section 6.1.2.

To summarize, the rate of water dripping into an opening in an unsaturated geologic formation is expected to be less than the downward percolation rate because (1) the cavity acts as a capillary barrier, (2) water may flow along the drift surface without dripping into the opening, and (3) water may evaporate. Even if the seepage threshold was exceeded and seepage occurred, the seepage flux would be lower than the percolation flux.

Section 6.3.2 describes the rationale and justification for using a heterogeneous continuum model for the simulation of drift seepage. Section 6.3.3 discusses specific factors and properties affecting seepage during liquid-release tests and how they are incorporated into the conceptual model.

\subsubsection{Continuum Approach}

The Seepage Calibration Model is conceptualized as a heterogeneous continuum model. The continuum approach can be considered appropriate for seepage studies if it is capable of predicting seepage rates for a drift in a fractured formation.

Water flow through the Topopah Spring welded unit (TSw) and seepage into openings at Yucca Mountain occurs predominantly through the fracture network, suggesting that a discrete fracture network model is more appropriate than a fracture continuum model for the reproduction and prediction of drift seepage. However, it is important to recognize that flow diversion around the opening occurs primarily within the fracture plane (in-plane diversion). The need to engage multiple fractures arises only if the fracture is too short and the flow path within the fracture plane is interrupted. In this case, water is diverted into the next connected fracture. This fracture is again unlikely to be parallel to the drift axis, allowing the in-plane flow-diversion process to continue. The situation is schematically illustrated in Figure 6-1, which shows two fractures intersected by a drift. In Figure 6-1a, the two fractures are aligned with the drift axis (which is an implicit assumption made in two-dimensional fracture network models used to predict drift seepage). As an artifact of this specific and unrealistic fracture orientation, in-plane flow diversion is prevented, and the resulting impact of discreteness on seepage is exaggerated. 
Two-dimensional fracture network models (including those shown by Finsterle (2000 [DIRS 151875], Plate 1) and in "A Note on Unsaturated Flow in Two-Dimensional Fracture Networks" (Liu et al. 2002 [DIRS 160230], Figures 1-6)) represent extreme cases that are not representative of and appropriate for site-specific seepage modeling. (The advantages and disadvantages of the discrete fracture network model are further discussed in Section 6.4.1).

In Figure 6-1b, the fractures are approximately perpendicular to the drift axis. Flow diversion occurs within the fracture plane, a process that is appropriately captured by a heterogeneous fracture continuum model even for a single fracture. In-plane flow occurring in multiple fractures can be readily combined and described by an effective fracture continuum.

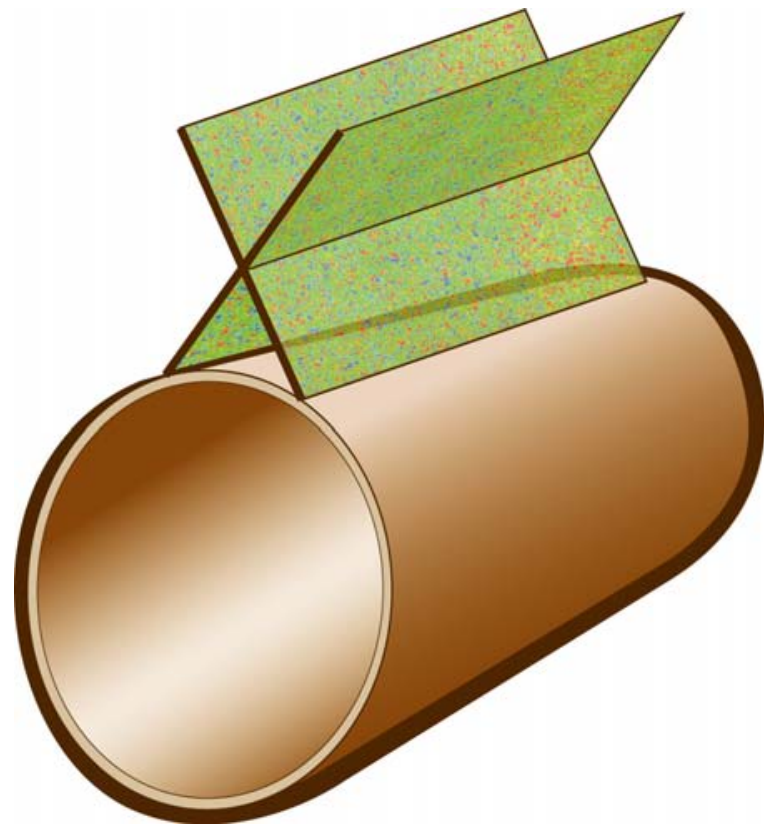

(a)

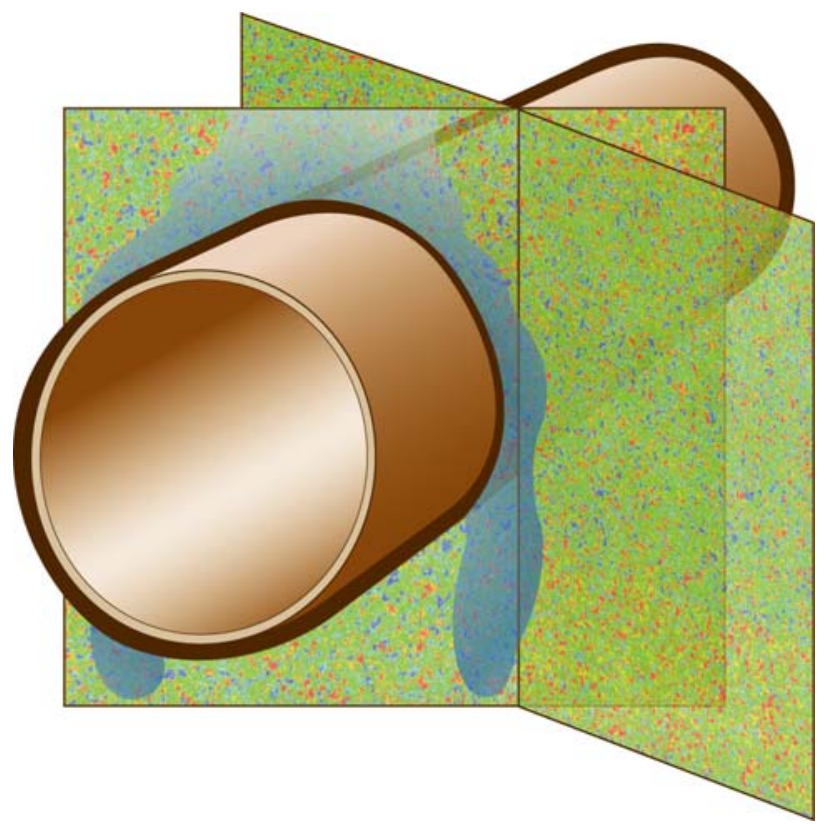

(b)

NOTE: (a) Drift intersected by network of fractures that are parallel to drift axis; note that a 2-D fracture network model (see, for example, Figure 6-3a) assumes that all fractures are parallel to the drift axis, preventing flow diversion within the fracture plane: (b) Drift intersected by randomly oriented fractures; note that a 2$\mathrm{D}$ (and 3-D) fracture continuum model considers flow diversion occurring within multiple, randomly oriented fracture planes.

Figure 6-1. Schematic Showing Two Fractures Intersecting a Drift

In Geology of the ECRB Cross-Drift - Exploratory Studies Facility, Yucca Mountain Project, Yucca Mountain, Nevada, Mongano et al. (1999 [DIRS 149850], pp. 65-72, 76-79) documented in their detailed line survey report that fracture frequencies observed in the Topopah Spring upper lithophysal (Tptpul), middle nonlithophysal (Tptpmn), and lower lithophysal (Tptpll) zones range from $3.2 \mathrm{~m}^{-1}$ to $4.3 \mathrm{~m}^{-1}$, and that fractures are predominantly developed in two or three orientations resulting in well connected networks. Connectivity of fractures is further enhanced by the presence of numerous microcracks as observed at the site. Fracture network connectivity has been determined at a drift scale through air-injection tests, which indicate that fractures networks are well connected within the moderately to densely welded rocks selected to host the repository (see Section 6.5.2). 
Given the significance of in-plane flow diversion around the drift in combination with relatively high fracture density of variable orientation, a three-dimensional, heterogeneous fracture continuum model is an appropriate conceptualization. The continuum concept captures the relevant processes more realistically than, for example, a two-dimensional discrete fracture network model.

In addition, the appropriateness of the continuum approach to simulate flow through fractured rock was studied by Jackson et al. ["Self-Consistency of a Heterogeneous Continuum Porous Medium Representation of a Fractured Medium” (2000 [DIRS 141523])] using synthetic and actual field data. They concluded that heterogeneous continuum representations of fractured media are self-consistent; i.e., appropriately, estimated effective continuum parameters are able to represent the underlying fracture-network characteristics.

Finsterle (2000 [DIRS 151875]) demonstrated that seepage into underground openings excavated from a fractured formation could be simulated using a model based on the continuum concept, provided that the model is calibrated against seepage-relevant data (such as data from liquid-release tests). Synthetically generated data from a model that exhibits discrete flow and seepage behavior were used to calibrate a simplified fracture continuum model. The calibrated continuum model was used to predict average seepage rates into a sufficiently large section of an underground opening for low percolation fluxes, i.e., conditions significantly different from those encountered during calibration. The extrapolation from high-rate liquid-release tests to low-rate percolation fluxes is equivalent to the extrapolation from the calibration runs performed with the SCM to the predictive simulations that will be performed by the SMPA. As discussed by Finsterle (2000 [DIRS 151875]), the extrapolated seepage predictions performed with the continuum model were consistent with the synthetically generated data from the discrete-feature model under low percolation conditions. This demonstrates that (1) the calibrated continuum model and discrete-feature model yield consistent estimates of average seepage rates, and (2) that the continuum approach is appropriate for performing seepage predictions even if extrapolated to percolation fluxes that are significantly lower than those induced by liquid-release tests. The tests were performed at relatively high injection rates to generate seepage data useable for model calibration. Note that the discrete-feature model used in the study makes the extreme assumption that all fractures are oriented parallel to the drift axis, as discussed above and illustrated in Figure 6-1a. Even under these unfavorable conditions, the continuum approach proved to be appropriate.

Note that the fracture density and hydraulic parameters used by Liu et al. (2002 [DIRS 160230]; see also Figure 6-3a below) result in very little flow diversion around the opening. This is a direct result of the unrealistic assumption that all fractures are parallel to the drift axis, which prevents in-plane flow diversion. In such a two-dimensional discrete fracture network model, flow diversion occurs only if the fracture density and/or the capillary-strength parameter are high. This was recognized by Liu et al. (2002 [DIRS 160230], p. 15-8), who concluded that fracture network models need to be three-dimensional for them to be able to realistically evaluate the capillary barrier effects in fractured formations. As discussed above, in-plane flow diversion in a three-dimensional fracture network can be appropriately represented by a heterogeneous continuum model. A calibrated continuum model is appropriate even in the extreme case where all fractures are perfectly parallel to the drift axis, as demonstrated by Finsterle (2000 [DIRS 151875]) and discussed in the previous paragraph. Note that the synthetic fracture 
network and hydraulic parameters used in the discrete model by Finsterle (2000 [DIRS 151875]; see also Figure 6-2a below) induced some flow diversion. This difference in flow diversion capability between the models by Finsterle (2000 [DIRS 151875]) and Liu et al. (2002 [DIRS 160230]) is caused by their respective parameter choices. This difference, however, does not affect the finding that the continuum approach captures the seepage-relevant processes more appropriately than two-dimensional discrete fracture network models. The advantages and disadvantages of the discrete fracture network model are further discussed in Section 6.4.1.

The continuum approach is considered appropriate for seepage studies if applied within the framework described in this Model Report. Inverse modeling should be used for the estimation of process-specific, model-related, and scale-dependent parameters, and the same or similar conceptual model should be used for the subsequent seepage predictions, specifically the SMPA.

Adopting the continuum approach, water flow under unsaturated conditions is governed by Richards' equation (Richards 1931 [DIRS 104252]), which states that (1) isothermal flow of water in a porous medium or rough-walled fracture occurs under the combined effect of gravitational and capillary forces, (2) flow resistance is a function of saturation, and (3) - for the purposes of this representation-movement of the nonwetting air phase can be neglected. This general concept is reasonable, because gravitational force is ubiquitous, and rough-walled or partially filled fractures exert varying degrees of capillary pressure at different saturation levels.

Relative permeability and capillary pressure are described as continuous functions of effective liquid saturation, following the expressions given by the van Genuchten-Mualem model (van Genuchten 1980 [DIRS 100610], pp. 892-893) as implemented in the iTOUGH2 code [User's Manual (UM) for iTOUGH2 V5.0 (BSC 2002 [DIRS 161066], Section 4.3.2)]. The applicability of relative permeability and capillary pressure functions is appropriate also for fractures that are rough-walled and/or partially filled with porous material. The constant of proportionality-relative permeability-is saturation-dependent because porous-medium continuum laws also apply to water flow through fractures filled with porous material, and in the absence of fracture fillings, the thickness of the water film and connectivity of liquid islands on the fracture surface are saturation dependent (Tokunaga and Wan 1997 [DIRS 139195]).

Capillary strength (represented by the $1 / \alpha$ parameter) and permeability are considered uncorrelated. The functional relationship describing the potential correlation between permeability and capillary strength is unknown. An increase in the effective (continuum) permeability of a fracture block may be attributed to either larger fracture apertures (which would reduce capillary strength) or to an increase in fracture density (which would not affect capillary strength). The capillary-strength parameter $1 / \alpha$ is taken to be constant for a given test bed, and will be estimated by inverse modeling.

The van Genuchten-Mualem model is the standard model used in the suite of UZ models; it is appropriate for modeling of unsaturated flow and seepage (as discussed in Section 5.3) and was chosen in this work to ensure consistency. The mountain-scale models may use a modified version of the van Genuchten-Mualem functions to account for the fact that unsaturated flow is restricted to a limited number of (active) fractures and that flow within a fracture is likely to be channelized. Both effects lead to different effective saturations determining capillary pressure and relative permeability, and they reduce fracture-matrix interaction. This revised model was 
developed by Liu et al. [“An Active Fracture Model for Unsaturated Flow and Transport in Fractured Rocks” (1998 [DIRS 105729])] and is referred to as the Active Fracture Model (AFM). For drift-scale seepage models under ambient conditions, the standard van Genuchten-Mualem model is employed rather than the AFM, because (1) flow segregation into active and inactive portions of the fracture network is a large-scale effect not engaged during the short-distance liquid-release tests; (2) flow channeling within fractures is partially accounted for through explicit modeling of small-scale heterogeneity; (3) the correction of the fracture-matrix interface area (the main effect captured by the AFM) is insignificant for seepage because of insignificant matrix imbibition during the calibration period (see Section 6.3.3.2); and (4) the potential impact of AFM effects on seepage are automatically reflected in the observed seepagerate data, which are used to estimate an effective capillary-strength parameter suitable for simulations with a conceptually consistent seepage-prediction model.

This general model conceptualization is consistent with that of the UZ Model. The calibration process and the consistent conceptualization in the downstream models (specifically the SMPA) make this a valid and reasonable approach.

\subsubsection{Factors and Properties Affecting Seepage During Liquid-Release Tests}

Seepage is a process that occurs at the interface between the natural and engineered systems. Consequently, seepage is not only affected by hydrogeologic factors (such as formation properties and flow conditions in the natural environment), but also by the engineered system itself. This second set of factors affecting the amount and distribution of seepage includes the design of the repository and waste emplacement drifts (location and geometry), the method of construction (excavation effects, drift surface roughness, ground support, backfill), and the conditions within the drifts (heat load and ventilation, which determine the relative humidity, evaporation potential, and the extent of the dry-out zone).

The engineered barriers in the waste emplacement drift (specifically the drip shield and waste packages) will be exposed to seeping water only if (1) a flow channel exists that carries water through the (potentially dry) zone around the drift, (2) the local percolation flux in this flow channel is high enough to overcome the local seepage threshold, and (3) the water droplets forming at the drift wall do not evaporate or dissipate in a water film flowing along the surface.

The following subsections describe in more detail the key factors affecting drift seepage and how they are included in the base-case conceptual model.

Based on theoretical insights discussed in the scientific literature [see, e.g., Philip et al. (1989 [DIRS 105743]); "Modeling Studies and Analysis of Seepage into Drifts at Yucca Mountain" (Birkholzer et al. 1999 [DIRS 105170]); "Seepage into Drifts with Mechanical Degradation" (Li and Tsang 2003 [DIRS 163714])] as well as the sensitivity analyses presented in Section 6.6.3.1, the most important factors affecting seepage are the magnitude of the local percolation flux in relation to the formation's permeability, the strength of the capillary forces in the fractures, the connectivity of the fracture network in the boundary layer, the local topography of the rough drift wall, and the thermodynamic conditions in the drift. 


\subsubsection{Percolation Flux}

\section{General Description}

The magnitude of the percolation flux is a key factor determining seepage. Seepage is initiated if the local percolation fluxes in individual flow channels and their accumulation near the drift ceiling exceeds the diversion capacity of the capillary barrier (which is caused by the presence of the drift), the evaporation potential of the atmosphere in the drift, and the capacity of water films to carry water along the drift surface. Because the local-rather than average-percolation flux controls the onset of seepage, the distribution of flow channels on all scales becomes a critical aspect for drift seepage. Flow focusing could concentrate water onto a particular drift segment and lead to a flux that exceeds the seepage threshold. On the other hand, if flow is concentrated in one location, flow will be reduced in other areas (potentially below the prevalent seepage threshold), leading to overall less seepage. Therefore, the distribution of flow channels, their frequency, width, and hydrologic properties determine the seepage probability and seepage amounts.

The spatial distribution of flow channels may change with the average percolation flux and potentially with time. The flux in a flow channel may be near steady state or episodic with a wide spectrum, ranging from high-frequency fluctuations triggered by flow instabilities, to intermediate variabilities in percolation fluxes in response to changing weather conditions, to long-term variations from climate changes.

In summary, the local (rather than average) percolation flux reaching the drift is the most important factor determining whether seepage occurs, the seepage rate, and the spatial and temporal distribution of seepage events.

\section{Model Conceptualization}

The actual percolation flux and its distribution cannot be measured directly. Estimates of the average, steady-state percolation fluxes at the locations of the liquid-release tests are taken from the UZ Model (see Section 6.6.2.3) and applied at the top of the corresponding drift seepage models. Note that large-scale redistribution of infiltration and percolation fluxes is captured in the mountain-scale UZ Model; intermediate-scale flow concentration is accounted for in the TSPA calculations through the use of a probabilistic flow focusing factor (BSC 2004 [DIRS 169131], Section 6.6.4.2). Small-scale flow concentration is included in the SCM by explicitly modeling small-scale heterogeneities (see Section 6.6.2.1).

The transient SCM simulations capture the time-dependent boundary conditions, saturation, and seepage-rate changes induced by the intermittent water release during seepage testing. Potential occurrence of small-scale, high-frequency episodic flow events is reflected in the seepage-rate data used for calibration. The cumulative effect of these episodic events on seepage is therefore appropriately captured in the estimation of an effective capillary-strength parameter. Low-frequency fluctuations in the background percolation flux on account of weather-condition or climate changes are insignificant because of the comparatively short duration of the liquid-release tests. In summary, the high-frequency episodic flow events are captured in the effective, seepage-relevant capillary-strength parameter, whereas the low-frequency transient 
events are accounted for in the UZ Model, which provides a time-dependent percolation flux as input to the seepage TSPA calculations. Additional issues related to the amount, variability, and uncertainty of percolation flux, lateral flow diversion, as well as large- and intermediate-scale flow concentration are also addressed by the UZ Model, seepage abstraction, and TSPA calculations.

\subsubsection{Formation Properties}

\section{General Description}

The key formation properties determining the effectiveness of the capillary barrier are (1) the capillary strength and (2) the tangential conductivity in the boundary layer near the drift wall. Geologic formations with strong capillarity and high tangential conductivity exhibit a high seepage threshold (i.e., low seepage), whereas a weak capillary barrier effect (i.e., high seepage) is expected if water retention is small or if the tangential permeability is insufficient to promote flow diversion.

Porous formations with strong capillarity tend to have low permeability and vice versa, which is a correlation that reduces the probability of encountering parameter combinations conducive to extreme (low or high) seepage behavior, making seepage relatively uniform across different geologic units. However, this negative correlation between conductivity and capillary strength may not apply to a fractured system, specifically if considering the seepage process. A certain hydraulic conductivity may result from a network consisting of a few, large fractures or, alternatively, many small, well-connected fractures. The first network would exhibit weak capillarity, whereas the second network has strong capillarity, i.e., capillarity is not necessarily correlated to permeability. Moreover, if the predominant fracture orientation happens to be aligned with the drift axis (see Figure 6-1a), little or no tangential conductivity is available, flow diversion is reduced or prevented, and seepage is increased. Even if fractures are normal to the drift axis, they may be too small or poorly connected, i.e., they would not be able to facilitate a continuous flow path from the apex of the drift to its spring line. For flow diversion to occur, the fracture system must have sufficient connectivity and permeability to provide the necessary effective conductivity in tangential direction around the drift.

In the repository units, matrix permeability is low, and the potential for imbibition of substantial amounts of water into the matrix is limited because of relatively low porosity and relatively high initial liquid saturation. In a fracture-matrix system, the transient effects from matrix imbibition are restricted to intermediate times, i.e., they are insignificant (1) for a short-term liquid-release test with insufficient time for matrix imbibition, and (2) for a long-term seepage experiment, when near-steady late-time data are no longer affected by matrix imbibition. Most liquid-release tests analyzed in this Model Report are sufficiently long to yield near-steady seepage rates that are insignificantly affected by potential matrix imbibition. Finally, potential seepage from the matrix during a liquid-release test is captured by the seepage-rate data used for calibration, and is thus reflected in the effective, seepage-relevant parameter.

Heterogeneities in formation properties impact seepage as they promote flow concentration and increase the probability of locally breaching the capillary barrier. 


\section{Model Conceptualization}

Seepage-related fracture properties on all relevant scales are not available and cannot be reliably derived from fracture-trace maps, considering that the mapped geometric characteristics and hydraulic properties are not related in a simple or unique way. However, as discussed in Sections 6.3.2 and 6.4.1 and demonstrated by Finsterle (2000 [DIRS 151875]), adequate average seepage prediction on the scale of a waste package does not require a discrete fracture network model.

In this work, the capillarity and the conductivity are conceptualized as effective properties that are specifically determined for their intended use in a drift seepage model. The corresponding model parameters must represent the average hydraulic characteristics of individual fractures as well as the connectivity, density, geometry, and orientation of the fracture network as it relates to the geometry and orientation of the underground opening. Moreover, they must account for seepage processes that cannot be explicitly implemented in the conceptual model (such as film flow and small-scale roughness in the drift ceiling), and compensate for certain artifacts related to the finite discretization of the numerical model. Model calibration using data that reflect all relevant seepage processes is the approach relied upon to determine these effective parameters.

The SCM is conceptualized as a heterogeneous fracture continuum model (see also Section 6.3.2). Given the specifics of the seepage process, the overall modeling approach, the purpose of the SCM, and the consistency with the downstream model (the SMPA), a single-continuum representation of the fractured formation is appropriate. (Note that the impact of the rock matrix may not be ignored when considering other processes; a dual-continuum model is selected in these instances.)

The seepage-relevant capillary-strength parameter is determined by calibrating the model against seepage-rate data from liquid-release tests (see Section 6.5.3). These data reflect the seepage process and contain information about seepage-relevant capillary properties of the fractured formation in the vicinity of an open drift. Thus, the inversely determined effective capillary-strength parameter is considered pertinent and appropriate for the intended use of the model.

The simulated seepage can be increased by decreasing capillary strength or permeability. Consequently, the two parameters are negatively correlated if inversely determined from seepage-rate data. Because only seepage data are available for calibration, the parameters are expected to be strongly correlated. That is, it is unlikely that they can be determined independently from one another and with a reasonably low estimation uncertainty. To reduce correlations and to improve the conditioning of the inverse problem, only the capillary-strength parameter is estimated through inverse modeling, whereas the permeability is fixed during the inversion. The choice of this calibration parameter is further discussed in Section 6.6.3.1.

The permeability field is considered the result of a stochastic process. The geostatistical properties of the field are determined from air-injection tests (see Section 6.5.2). Multiple realizations of the permeability field are generated and used in the inversions of data from the lower lithophysal zone. 
The permeability fields generated for simulations with the SCM are representative of the conditions currently encountered at the test locations of Yucca Mountain. Therefore, thermally and geochemically induced property changes do not need to be considered in this Model Report. They are addressed by the TH Seepage Model (BSC 2004 [DIRS 170338]) and the Thermal-Hydrologic-Chemical (THC) Seepage Model [Drift-Scale Coupled Processes (DST and THC Seepage) Models (BSC 2004 [DIRS 168848])].

\subsubsection{Drift Geometry}

\section{General Description}

The overall drift size and geometry impact the seepage threshold and the seepage amount. Generally, a larger drift exhibits a significantly lower seepage threshold because more water accumulates in the boundary layer as it migrates over a longer diversion distance around the wide opening. Because of the nonlinear impact of cavity size on seepage (Philip et al. 1989 [DIRS 105743]), seepage into large openings cannot be easily inferred from cumulative seepage into small cavities.

The effectiveness of a capillary barrier is highest if the shape of the cavity follows an equipotential surface. In a homogeneous medium, parabolic cavities are more efficient in preventing seepage than circular or flat-roofed openings. Breakouts in the drift ceiling, as a result of rock fall and general drift degradation, may change the overall drift geometry and lead to local topographic lows, which may trap water, reduce or prevent flow diversion, and thus initiate seepage. In addition, small-scale surface roughness tends to increase seepage if the amplitude of the irregularity is on the order of boundary-layer thickness. The latter is determined by the capillary strength of the formation.

In a heterogeneous, fractured formation, the importance of drift shape and drift geometry may be diminished relative to that of flow channeling and local ponding conditions (see Birkholzer et al. (1999 [DIRS 105170], pp. 372-379) and Section 6.4.2).

\section{Model Conceptualization}

The impact of the overall geometry of the underground opening (ECRB Cross-Drift or niche) on seepage is accounted for through explicit discretization of the cavity. The ECRB Cross-Drift is approximated as being cylindrical, with a diameter of $5.0 \mathrm{~m}$. The overall geometry of the niches is taken from survey data, thus including some medium-scale roughness from rock fall and large lithophysal cavities.

Small-scale roughness is indirectly included through a discretization effect. The length of the last vertical connection from the gridblocks representing the formation and the interface denoting the drift surface is $0.05 \mathrm{~m}$ (see Appendix C, Appendix D, and Appendix E; see also related discussion in Section 6.6.1.2). The choice of this nodal distance affects seepage because (in the model) no horizontal flow diversion can occur closer than $0.05 \mathrm{~m}$ from the drift wall. Since water is laterally diverted only if capillary suction is on the order of $0.05 \mathrm{~m}$ or higher, the discretization has an effect similar to that of (1) drift-wall roughness of amplitude of $0.05 \mathrm{~m}$, with troughs at the gridblock centers and ridges along the gridblock interfaces, or (2) short fractures cutting into the opening, with a distance to the next fracture intersection of $0.05 \mathrm{~m}$. 
Consequently, the effective capillary-strength parameter estimated by inverse modeling depends on the chosen discretization; it contains a geometric component related to the length of the nodal distance between the formation and the drift. The estimate is thus model-related, and the discretization between the calibration model and the prediction model must be consistent.

In summary, the geometric factors affecting seepage are accounted for through (1) explicit discretization of the opening (which includes the overall shape as well as medium-scale roughness from break-outs lithophysal cavities), (2) by preventing flow diversion in a $0.05 \mathrm{~m}$ thick layer around the drift (mimicking small-scale surface roughness with a $0.05 \mathrm{~m}$ amplitude of the irregularities), and (3) the estimation of an effective capillary-strength parameter. The inclusion of small-scale surface roughness (exceeding an amplitude of 0.05 meters) and discrete effects from small fractures into an effective capillary-strength parameter is appropriate because their impact on seepage rates is directly related to capillarity.

Note that the nominal diameter of a repository drift is $5.5 \mathrm{~m}$, which is slightly larger than that of the ECRB Cross-Drift (5.0 m). This difference is of no significance, because the seepage-related parameters are determined using a model with the correct diameter $(5.0 \mathrm{~m})$ to be used for the analysis of liquid-release tests in the ECRB Cross-Drift. These parameters are then applied in the prediction model, which simulates seepage into an opening with a $5.5 \mathrm{~m}$ diameter. The impact of drift-shape changes as a result of drift degradation is discussed in Seepage Model for PA Including Drift Collapse (BSC 2004 [DIRS 167652]).

\subsubsection{Evaporation Conditions}

\section{General Description}

Reduced relative humidity in the underground opening leads to evaporation of water at the drift surface and the development of a dry-out zone in the vicinity of the cavity. Part or all of the water reaching the ceiling of the opening during a liquid-release test may evaporate, depending on the evaporation potential in the drift and the wet area exposed to evaporation. The evaporation potential depends on the relative humidity in the opening and the thickness of a diffusive boundary layer at the drift surface, which in turn is governed by the air velocity in the ventilated drift.

The size of the wet spot developing at the drift ceiling as a result of liquid release above the drift depends on the formation properties, the spreading mechanism along the drift surface, and evaporation itself. As water injected during a liquid-release test reaches the opening, it spreads along the surface on account of capillary tension within the rough drift wall. As a result, water potentially seeping into the opening may not only form droplets or lines of water along fracture traces with a small surface area, but may spread across the drift surface over a relatively large area. This phenomenon is qualitatively confirmed by the geometry of the wet spot observed at the niche ceiling during seepage experiments (BSC 2004 [DIRS 170004], Section 6.2.1.3.4, Figure 6.2.1-7; Trautz and Wang 2002 [DIRS 160335], Figures 7 and 9). The geometry of the wet spot does not have a clear correlation with the visible fracture traces. Even though water first appears along fracture traces (Trautz and Wang 2002 [DIRS 160335], Figure 10), the wet spot grows in an areal fashion. It is obvious from the short arrival time and the average speed at which the leading edge of the plume moves across the ceiling that the water is not transmitted 
through the matrix, but spreads along the ceiling as a surface film, possibly supported by flow through microfractures. Evaporation from such wet areas is similar to evaporation from a free water surface, where the evaporation rate is governed by one-dimensional vapor diffusion across a relatively thin boundary layer of linearly decreasing vapor concentration. Temporal shrinkage of the wet spot can be correlated to increased evaporation as a result of changed ventilation regime, highlighting the coupled nature of the process.

In a closed-off and humidified niche, potential evaporation at the wall or in the capture system is expected to be small compared to the amount of water being released. Seepage experiments in the middle nonlithophysal zone of the Topopah Spring welded unit were conducted in niches that were closed off by a bulkhead, which leads to comparatively high relative humidity and low air circulation. Moreover, a humidifier was used in some of the experiments to ensure high relative humidity. For these conditions, Ho (1997 [DIRS 141521]) and Or and Ghezzehei (2000 [DIRS 144773]) provide a detailed description of evaporation mechanisms on the scale of individual water droplets within fractures or emerging from fractured formations. The evapo-infiltration threshold calculated by Ho (1997 [DIRS 141521], p. 2670) is significantly lower than the applied injection rates, suggesting a very minor influence of evaporation on measured seepage rates in experiments conducted in the niches.

\section{Model Conceptualization}

Evaporation effects are included in the modeling of liquid-release tests performed in the ventilated ECRB Cross-Drift as well as in Niche 5. Evaporation effects are neglected in the modeling of liquid-release tests conducted in the closed-off niches in the middle nonlithophysal zone, i.e., Niches 2, 3, and 4. As demonstrated in Section 6.7, the impact of slight evaporation in a closed-off and moisturized niche on seepage rates - and thus on the estimation of seepage-relevant parameters—is minor.

Evaporation effects are accounted for in the model by prescribing the measured relative humidity in the opening as a temporally varying water-potential boundary condition. Evaporation is calculated as a function of the water-potential gradient at the drift surface, the vapor diffusion coefficient, and the thickness of the diffusive boundary layer, which is estimated from evaporation pan measurements. A detailed description of the corresponding conceptual and mathematical model and the estimation of the evaporation boundary-layer thickness is given in Sections 6.6.1.3 and 6.6.1.4.

Predictions of long-term seepage using the SMPA are based on the presumption of 100 percent relative humidity in the waste emplacement drifts, yielding higher seepage estimates than those expected in a ventilated environment.

\subsubsection{Lithophysal Cavities}

\section{General Description}

The impact of lithophysal cavities on flow and seepage is twofold: (1) lithophysal cavities are essentially obstacles to water flow because they act as capillary barriers, focusing the water that flows around them; (2) lithophysal cavities intersected by the drift lead to a rough drift wall, 
potentially creating seepage points at local topographic lows. Both effects tend to promote seepage.

\section{Model Conceptualization}

The effect of lithophysal cavities on seepage can be captured through the estimation of an effective capillary-strength parameter, making the explicit inclusion of lithophysal cavities into the process model unnecessary. This approach is considered appropriate for the following reasons: (1) omitting lithophysal cavities in the process model used for inverse modeling yields lower estimates of the capillary-strength parameter; (2) consistency between the calibration model (the SCM) and the prediction model (the SMPA) removes the impact of a potential estimation bias; (3) the approach allows for the development of a single SMPA conceptual model for both the middle nonlithophysal and lower lithophysal zones, yielding a single look-up table for TSPA to sample from; and (4) explicit modeling of lithophysal cavities is not warranted because of insufficient information regarding their location, shape, and frequency. Note that the impact of lithophysal cavities on surface roughness in Niche 5 is accounted for through explicit discretization of the niche's geometry, based on survey data (see Appendix E).

\subsubsection{General Modeling and Data-Analysis Approach}

The key element of the approach chosen to simulate seepage and determine seepage-relevant parameters is the reliance on inverse modeling. Given the complexity of the seepage process in a fractured porous medium, it is considered unfeasible to develop a detailed process model with a deterministic calculation of unsaturated water flow, through a fracture network that exhibits multiscale variabilities in hydraulic properties. Such a model would also require an accurate representation of the seepage process, which includes effects from small-scale roughness and small-scale heterogeneities, film flow within fractures and along the drift surface, drop formation and detachment, and other processes. The necessary characterization data needed to carry out such a detailed simulation are not available. As discussed in the following paragraph, such a detailed simulation is not necessary for an adequate treatment of the issue.

The difficulties mentioned above can be effectively overcome by recognizing that (1) detailed simulation of individual seeps is not necessary to estimate average seepage rates into waste emplacement drifts, (2) certain factors affecting seepage can be lumped into an effective parameter, (3) calibrating a model against data from seepage experiments ensures that the model captures the relevant processes, (4) estimating effective parameters partly compensates for processes and features that are not explicitly considered in the model, and (5) the estimated parameters are optimal and can be directly used in the prediction model.

The main advantage of this approach is that it relies directly on seepage-rate data, which inherently contain information about the relevant processes. Moreover, the calibration data (seepage rates on the scale of a drift section) are very similar to the measure of interest for the subsequent predictions. The consistency between the calibration model used to derive seepage-relevant parameters and the prediction model used to forecast seepage minimizes potential conceptual differences and large systematic errors. The advantages of the selected method over alternative approaches are further evaluated in Section 6.4. 
The SCM is conceptualized as a three-dimensional, heterogeneous continuum model. The continuum mainly represents the dense fracture network that dominates the seepage process. The SCM is conceptually consistent with the site-scale model of the unsaturated zone at Yucca Mountain and submodels thereof, specifically the SMPA and TH Seepage Model (BSC 2004 [DIRS 170338]). This makes it straightforward to embed the SCM into the current modeling framework.

As will be discussed in Section 6.6.3.2, the SCM is calibrated against late-time seepage-rate data from liquid-release tests. Early-time seepage data are discarded because they are affected by storage effects and the properties of a few fractures connecting the injection interval with the opening. These fractures are not necessarily representative of the fracture network that is engaged in flow diversion around the entire opening under steady-state conditions. Late-time data are more representative of near-steady conditions and are less influenced by storage effects. Moreover, the relatively large amount of released water at late time has likely encountered a significant portion of the capillary barrier. As a result, the late-time seepage data better reflect average conditions on the scale of interest.

The duration of the liquid-release tests is on the order of days and weeks, whereas the calibrated parameters are intended to be used in a steady-state prediction model (the SMPA). Nevertheless, the late-time seepage-rate data are considered suitable for calibrating a model that subsequently will be used for the prediction of long-term seepage behavior. The approach is appropriate for the following reasons. First, any data that are sensitive to the parameters of interest are generally adequate for model calibration. There is no inherent requirement that the data used for model calibration have to reflect steady-state conditions if the ultimate purpose of the model is to predict steady-state behavior. If the model is capable of capturing the transient effects occurring during the liquid-release tests, no unwanted bias is introduced; such a bias would only be introduced if a steady-state model were calibrated against non-steady-state data. The SCM is a transient model that simulates time-dependent liquid release, flow, storage, and seepage processes. If the SCM can be successfully calibrated and validated, the parameters determined by inverse modeling are not affected by the transient nature of the underlying data, and thus they are also suitable for the prediction of steady-state seepage. Second, the late-time seepage-rate data used for model calibration show near-steady behavior, i.e., they do not change significantly with time. They closely reflect the processes governing steady-state seepage and are thus suitable as calibration data for a prediction model of long-term seepage into waste emplacement drifts.

The capillary-strength parameter will be determined by calibrating the model against multiple tests using different liquid-release rates. Some of these release rates induced a local percolation flux above the seepage threshold, i.e., water dripped into the opening and yielded seepage-rate data valuable for calibration. However, the joint inversion of multiple data sets also included data from tests performed below the seepage threshold. Moreover, the model was validated against tests conducted above and below the seepage threshold. That is, the system is probed and the model will be calibrated and validated for the critical range of percolation rates about the seepage threshold. Seepage predictions for natural percolation fluxes, that are even lower than the low fluxes (below the seepage threshold) induced during the low-rate tests, will yield the correct result, namely zero seepage. As a result of a high-infiltration climate or strong flow focusing, the natural percolation flux may be high and exceed the seepage threshold. This would 
be the critical scenario for performance. Obviously, the parameters estimated from the liquid-release tests would be most suitable for those critical circumstances, because they were determined under similar high-rate conditions. In summary, the parameters determined from relatively high-rate liquid-release tests are appropriate and provide a solid basis for seepage predictions under low and higher natural percolation fluxes.

Liquid-release tests directly supporting the SCM were conducted in two different hydrogeologic units, in multiple test beds, boreholes, and intervals. Each test event probes a different portion of the rock and a different section of the underground opening. The question arises how the available data should be combined to yield suitable averages and reasonable measures of variability and uncertainty, which are needed for model validation and the subsequent PA calculations. The goal is to obtain a probability density function of the seepage-relevant parameters that reflects both estimation uncertainty and spatial variability. These two aspects are discussed separately in the following paragraphs.

Parameter estimates determined by inverse modeling are uncertain because they are derived from limited data, which exhibit random and potentially systematic measurement errors, and because the model is a simplification of the real system, which introduces systematic and random modeling errors. As discussed above, estimating model-related parameters mitigates the impact of some of the residual systematic errors. Estimation uncertainty as a result of random noise in the seepage data is relatively minor (see Sections 6.6.3.3 and 8.2). However, there remains irreducible uncertainty because of small-scale heterogeneity that affects individual seepage tests. The details of these small-scale heterogeneities are unknown (i.e., they cannot be described deterministically) and vary from location to location (i.e., they are spatially variable). Consequently, they are considered the result of a stochastic process that must be described by geostatistical parameters and modeled by performing multiple geostatistical simulations. Each seepage data set is obtained from a certain test bed (niche or section of the ECRB Cross-Drift); it can be considered one realization from a number of statistically similar geologic systems. The lack of knowledge regarding the details of this specific realization makes the inversely determined parameter estimate uncertain. This uncertainty is examined by performing multiple inversions of the same data set using different realizations of the underlying heterogeneous permeability field, yielding a distribution of estimated capillary-strength parameters rather than a single value. In addition to capturing the random nature of the permeability field and its impact on seepage, each realization will induce some ergodic fluctuations, which reflect the fact that the model statistics are inferred from sparse air-permeability sampling (i.e., they are not deemed exactly representative of the population statistics). The average of all inversions performed with different permeability fields for a given interval yields one estimate representative of that location.

The average parameters obtained from multiple simultaneous inversions of one or more seepage events conducted in a certain test interval are considered independent, each reflecting the seepage-relevant properties at a given location on the drift scale. These estimates are then combined to yield a parameter distribution for the entire hydrogeologic unit. This distribution reflects spatial variability. By sampling from the distribution of the resulting parameter estimates, probabilistic predictions of seepage across the repository horizon can capture the spatial variability of average seepage on the scale of the $5 \mathrm{~m}$ long drift segment. Uncertainty in this average seepage rate as a result of small-scale heterogeneity is calculated based on multiple 
seepage prediction runs by the SMPA, using multiple realizations of the underlying permeability field.

A comparison of seepage predictions with observable data (such as seepage data from transient liquid-release tests involving a finite amount of water) is a necessary step in model development and confidence building. However, models are often developed-and most usefully - to infer behavior that cannot be directly observed (such as long-term near-steady seepage under naturally low percolation fluxes). The appropriateness of such an extrapolation of the model beyond its tested grounds needs to be assessed. While rigorous model testing is fundamentally not possible ["Verification, Validation, and Confirmation of Numerical Models in the Earth Sciences" (Oreskes et al. 1994 [DIRS 152512])], validation of the model for a limited purpose can be accomplished. The SCM is partially tested against observable data from seepage experiments that were not used for model calibration. The purpose of this validation exercise is to determine whether the model is appropriate and adequate for its intended use. Remaining uncertainty will be quantified during the seepage abstraction process and propagated through the PA models. Additional remarks about model validation can be found in Section 7.1.

The development of the SCM involves the following steps (note that this is a general description; details about the implementation and execution of these steps can be found in Sections 6.6.2, 6.6.3, and the appendices):

1. Geostatistical parameters of the permeability field are determined from the results of air-injection test data.

2. Multiple realizations of the permeability field are generated, each being consistent with the geostatistical properties of the measured air permeabilities.

3. A numerical mesh is generated. This step involves (a) making a primary 3-D grid, (b) translating coordinates to center the mesh, (c) mapping the permeability field onto the mesh, (d) cutting out the opening (niche or drift) from the mesh, (e) adding top and bottom boundary elements as well as an evaporation boundary in the opening, and (f) modifying elements representing injection intervals.

4. An input file defining the forward problem is prepared. This step involves (a) assembling parameters representing hydrogeologic properties, (b) assigning appropriate properties to elements representing the excavation and borehole intervals, (c) extracting the background percolation flux from the UZ Model, (d) assigning appropriate initial and boundary conditions, and (e) selecting computational parameters and program options.

5. Simulations with the background percolation flux applied at the top of the model are run to steady state to obtain initial conditions for the subsequent simulation of transient seepage experiments.

6. Injection rates are specified as time-dependent source terms.

7. Test events are selected for calibration. Seepage rates are calculated from the cumulative seepage data. 
8. An input file defining the inverse problem is prepared. This step involves (a) selecting the parameters to be estimated and their initial guesses, (b) selecting points in time at which calibration should occur, (c) specifying the data against which calibration should occur, and (d) selecting computational parameters and program options.

9. Seepage-relevant, model-related parameters are determined by automatic model calibration using iTOUGH2 V4.0 (LBNL 1999 [DIRS 139918]) and V5.0 (LBNL 2002 [DIRS 160106]). In each inversion, seepage-rate data from multiple test events are jointly inverted.

10. The model is tested by comparing predicted seepage rates to observed data from seepage experiments not used during model calibration. Prediction uncertainty is calculated by iTOUGH2 V4.0 (LBNL 1999 [DIRS 139918]) and V5.0 (LBNL 2002 [DIRS 160106]) using first-order-second-moment (FOSM) uncertainty propagation analysis and Monte Carlo simulations.

\subsection{ALTERNATIVE CONCEPTUAL MODELS}

The following subsections contain short descriptions of potential alternative ways to evaluate seepage into waste emplacement drifts at Yucca Mountain. These alternative conceptual models are discussed in a qualitative manner, and references to more detailed analyses are given, if available. No quantitative evaluations of these alternative conceptual models are presented in this Model Report.

Natural analogues for seepage also support the concepts of the base-case model; they are briefly reviewed in Section 7.2.1.

In general, the choice of a conceptual model should be based on a careful consideration of the study objectives, the available database in comparison with the data needs, the uncertainty in the input parameters and the corresponding prediction uncertainties and computational aspects.

\subsubsection{Discrete Fracture Network Model}

A discrete fracture network model (DFNM) is an alternative conceptual model to the heterogeneous continuum model used in this Model Report ["Alternative Concepts and Approaches for Modeling Flow and Transport in Thick Unsaturated Zones of Fractured Rocks” (Pruess et al. 1999 [DIRS 117112], pp. 307-309)]. A high-resolution DFNM is capable of generating channelized flow and discrete seepage events, as demonstrated by Finsterle (2000 [DIRS 151875], Plate 1) and Liu et al. (2002 [DIRS 160230], Figure 5). Note that two-dimensional DFNMs (such as those shown in Figure 6-2 and Figure 6-3) make the implicit assumption that the fractures are oriented parallel to the drift axis. This assumption exaggerates the discreteness of the flow and seepage behavior as flow diversion within the fracture plane is not possible (see also Figure 6-1 and related discussion in Section 6.3.2).

In a DFNM, an individual fracture is discretely represented by appropriately small computational grid blocks. This is often considered the defining feature of such a model. (Note, however, that the flow equations solved in and between grid blocks are essentially identical to those solved by a continuum model. As outlined in Section 6.3.2, in-plane flow diversion is the key mechanism 
characterizing the capillary barrier effect and determining the seepage threshold. In comparison, the geometrical details and discreteness of fracture-to-fracture flow are secondary aspects for seepage.)

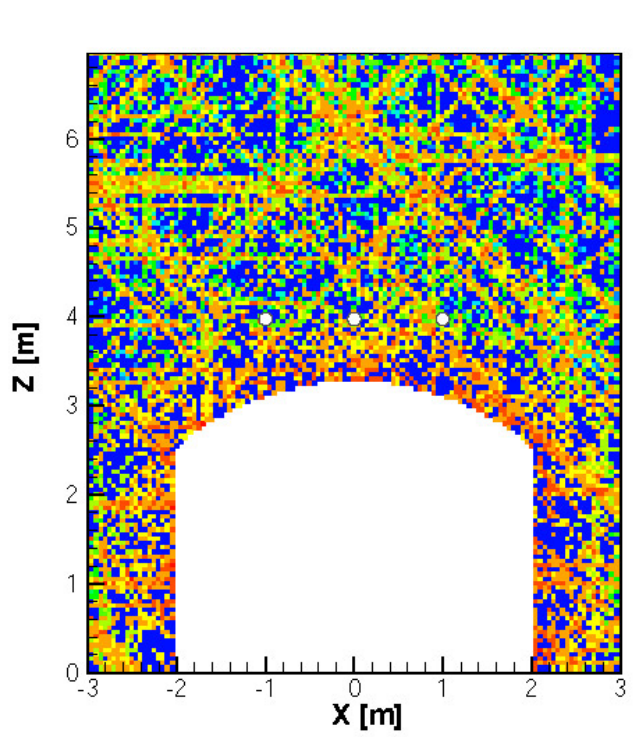

(a) High-Resolution Permeability Field Behavior
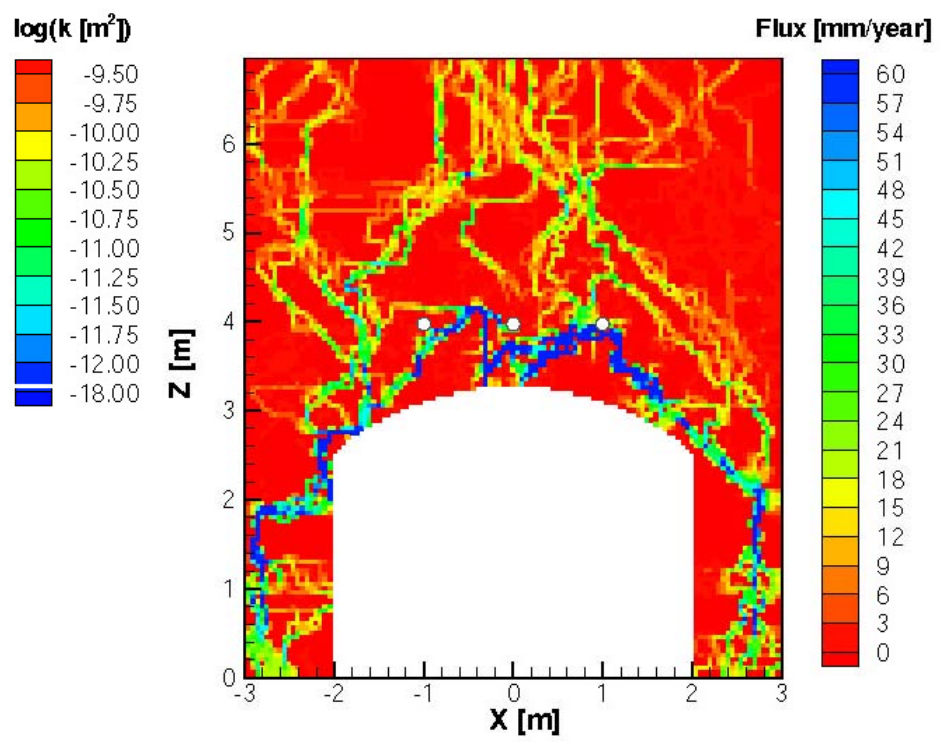

b) Discrete Flow Path and Discrete Seepage

Source: Modified from Finsterle (2000 [DIRS 151875], Plate 1).

Figure 6-2. Two-Dimensional Discrete Feature Model

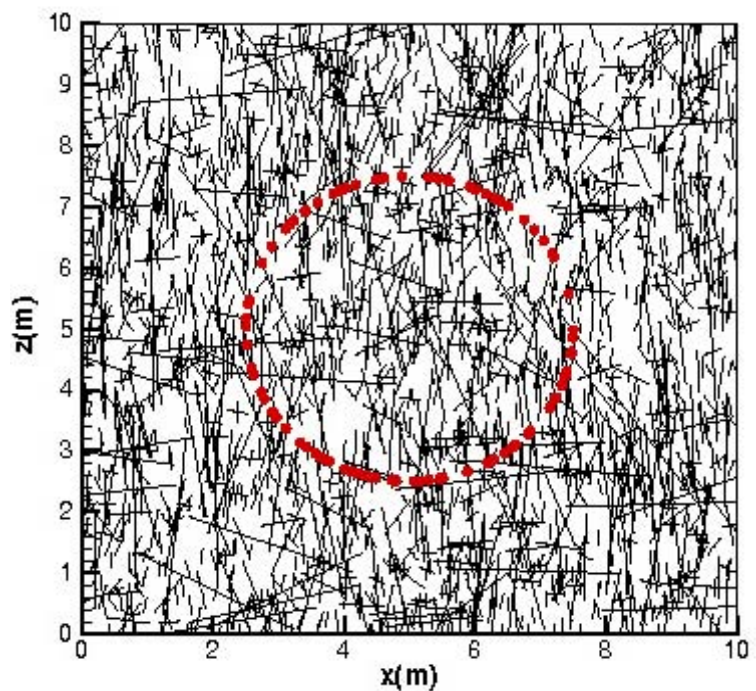

(a) Fracture Network

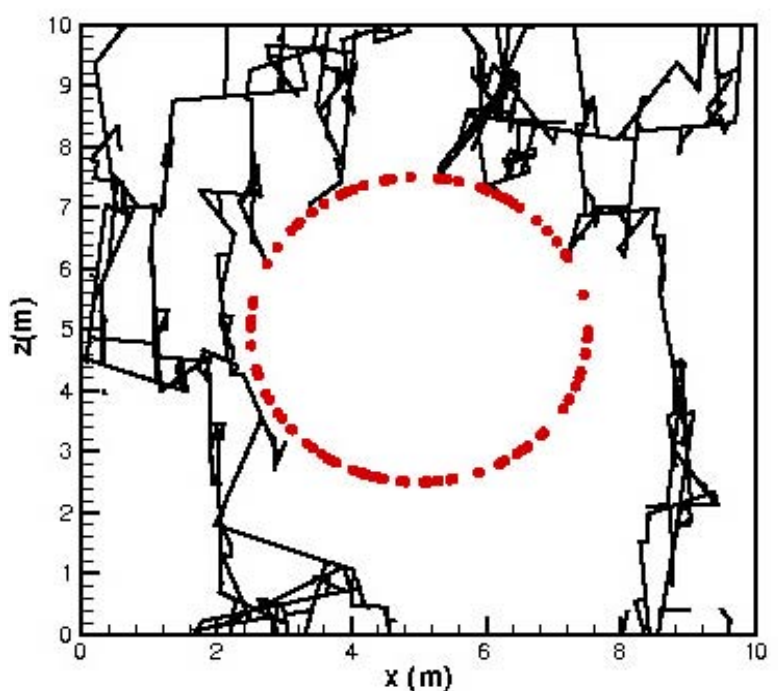

(b) Flow Paths

Source: Modified from Liu et al. (2002 [DIRS 160230], Figures 1 and 2).

Figure 6-3. Two-Dimensional Discrete Fracture Network Model 
The development of a defensible DFNM requires collecting a very large amount of geometric and hydrologic data. While part of the required geometric information can be obtained from fracture mappings, the description of the network remains incomplete and potentially biased towards fractures of a certain orientation and a certain size. Moreover, unsaturated hydrological parameters on the scale of individual fractures are required, along with conceptual models and simplifying assumptions regarding unsaturated flow within fractures and across fracture intersections. The databases required to develop a defensible DFNM are currently not available and are generally difficult or even impossible to obtain for site-specific simulations. The cumulative effect of the input uncertainties is likely to outweigh the apparent advantage of a detailed representation of the fracture network, specifically since the DFNM must be calibrated against hydrogeologic data to reduce prediction uncertainty - that is, an approach very similar to that outlined in Section 6.3.4 must be followed.

The appropriateness of using a continuum model for the prediction of average seepage quantities was demonstrated by Finsterle (2000 [DIRS 151875]). In that study, seepage predictions with a calibrated fracture continuum model were compared to those of a DFNM, yielding consistent results even when applied outside the range of calibration. Given these results, the parsimony of the continuum model is considered a key advantage over the complexity of the DFNM, which is difficult to support or justify despite its visual appeal. Moreover, a two-dimensional DFNM is not capable of capturing flow diversion within the fracture plane, a mechanism appropriately represented by a 2-D (or 3-D) continuum model.

For the reasons outlined above, the full development of a DFNM as a potential alternative to the base-case continuum model was considered unwarranted, infeasible, and unnecessary. While seepage calculations with a calibrated DFNM are likely to corroborate the findings of this Model Report, this approach is not further considered.

\subsubsection{Seepage Governed by Ponding Probability}

As an alternative conceptual model to a seepage process model, Birkholzer et al. (1999 [DIRS 105170], pp. 372-379) related seepage to the local ponding probability, which was derived from the variability of the permeability field. Their approach assumed that-in strongly heterogeneous formations - seepage is predominantly affected by pressure variations governed by local heterogeneity rather than the presence and geometry of the capillary barrier. This is different from the behavior in a homogeneous system, where the geometry of the capillary barrier has a strong impact on seepage (Philip et al. 1989 [DIRS 105743]). Strong medium- to small-scale heterogeneities tend to increase seepage because they increase channeling and local ponding. This effect is included in the current seepage process models through the estimation of effective, seepage-specific parameters for a heterogeneous medium with a heterogeneous permeability field. While the approach presented by Birkholzer et al. (1999 [DIRS 105170], pp. 372-379) may provide guidelines for how to extrapolate seepage predictions to other units or drift geometries, it nonetheless requires a calibration step similar to that described in this Model Report. The approach is therefore not further considered. Nevertheless, the concept that ponding probability affects seepage is consistent with and thus corroborates the base-case model, which produces random seepage locations as a result of local ponding in a stochastic permeability field. 


\subsubsection{Inferring Seepage from Geochemical Data}

Observations of calcite and opal in lithophysal cavities could be used to estimate long-term seepage rates into these small openings [Analysis for Geochemical Data for the Unsaturated Zone (BSC 2003 [DIRS 168343], Section 6.10.1)]. Calcite is assumed to precipitate from downward-percolating meteoric water because of (1) evaporation, (2) $\mathrm{CO}_{2}$ outgassing as a result of the geothermal gradient, and (3) interaction with a gas phase containing less $\mathrm{CO}_{2}$ than the gas with which the water was last equilibrated. Considering these calcite-precipitation mechanisms and assuming certain water-to-calcite ratios, seepage into lithophysal cavities can be estimated from calcite-deposition data. The analysis of calcite and opal precipitation data shows that (1) not all lithophysal cavities encountered seepage, and (2) seepage flux derived from mineral deposits is a very small fraction of percolation flux ["Estimation of Past Seepage Volumes from Calcite Distribution in the Topopah Spring Tuff, Yucca Mountain, Nevada” (Marshall et al., 2003 [DIRS 162891], Section 5)]. Both conclusions corroborate the general concept of a capillary barrier reducing seepage below the value of the percolation flux.

The advantage of using geochemical information to infer seepage is the fact that calcite and opal were deposited over a long period of time under natural percolation conditions. The disadvantage of this approach is that (1) seepage is inferred in an indirect manner, requiring a number of geochemical models with their associated assumptions-in addition to hydrogeologic model assumptions; (2) the calcite depositions on lithophysal cavity floors may not originate from dripping water (i.e., seepage); in fact, there is a lack of evidence of dripping from cavity ceilings (absence of stalactites or stalagmites), even where fractures containing coatings intersect lithophysae ceilings ["Physical and Stable-Isotope Evidence for Formation of Secondary Calcite and Silica in the Unsaturated Zone” (Whelan et al. 2002 [DIRS 160442], p. 744)]; (3) the data reflect seepage into (small) cavities instead of seepage into a (large) waste emplacement drift; since the size of the underground opening impacts seepage in a nonlinear fashion, a hydrological, physically based process model is required to estimate seepage on the scale of interest; (4) seepage into lithophysal cavities does not include potential impacts from the excavationdisturbed zone around a mechanically constructed drift; and (5) the historic record and the approach does not allow making predictions into the future under changed conditions.

As shown by Marshall et al. ["Seepage Flux Conceptualized from Secondary Calcite in Lithophysal Cavities in the Topopah Spring Tuff, Yucca Mountain, Nevada” (2000 [DIRS 151018], Figure 1), the seepage rates estimated from the calcite-deposition data are significantly lower than those predicted by TSPA using data derived from the SMPA, which is based on the methodology outlined in this Model Report. Inferring seepage from secondary mineral depositions in lithophysal cavities is not further considered as an approach to quantitatively estimate seepage into waste emplacement drifts.

\subsubsection{Inferring Seepage Threshold Directly From Liquid-Release Tests}

Trautz and Wang (2002 [DIRS 160335], Section 5) estimated the seepage threshold directly from the liquid-release test data, based on a number of simplifying assumptions (with regard to the cross-sectional area of the flow path between the borehole and the ceiling, evaporation, and the steady-state flow field). Once the seepage threshold was determined, a capillary-strength parameter was derived assuming seepage into a cylindrical cavity excavated from a 
homogeneous porous medium (Trautz and Wang 2002 [DIRS 160335], Section 6). The basecase model outlined in this Model Report relies on fewer assumptions than the simplified alternative conceptual model and predicts a lower seepage threshold; the base-case model described in this Model Report is therefore the preferred conceptualization.

\subsection{DESCRIPTION OF SEEPAGE EXPERIMENTS}

\subsubsection{Test Location and Borehole Configuration}

The data used for the development, calibration, and validation of the SCM were collected as part of the ESF Drift Seepage Test and Niche Moisture Study, an ongoing field-testing program. Drift-scale seepage tests were initiated in 1997 to investigate potential seepage into an underground opening representing a waste emplacement drift. Short drifts ranging from $6.3 \mathrm{~m}$ to $15.0 \mathrm{~m}$ in length were constructed at various locations along the ESF and the ECRB Cross-Drift. Boreholes were installed prior to and after the drifts were excavated to facilitate characterization of the rock using air-injection tests and investigation of seepage processes using liquid-release tests. The short excavations are called "niches," and the drift-scale seepage tests are collectively referred to as the Niche Study. In Niche 5, a horizontal slot on the side of the niche (also referred to as "batwing") was excavated to obtain direct evidence of the flow-diversion capability of the capillary barrier (see Section 6.8).

A second study referred to as the Systematic Borehole Testing Program was initiated in 2000 to complement the niche seepage experiments. The purpose of the program is to provide broad, systematic coverage and characterization of the lower lithophysal zone (Tptpll) of the Topopah Spring welded unit (TSw). Systematic characterization of the Tptpll is accomplished by performing air-injection and liquid-release tests in approximately $20 \mathrm{~m}$ long boreholes drilled into the ceiling approximately every $30 \mathrm{~m}$ along the ECRB Cross-Drift.

The data used in this Model Report are a subset of seepage tests from the Niche Studies and the Systematic Borehole Testing Program. A few tests failed and their data are not used in this Model Report (see discussion of Table 6-5 below). Data include air permeabilities and seepage-rate values from tests conducted at three niche sites located along the Main Drift of the ESF, one niche in the ECRB Cross-Drift, and in three systematic testing boreholes drilled into the ceiling of the Cross-Drift (see Figure 6-4). The first three niche sites are located along the west side of the ESF in the Tptpmn and they were selected for study based on fracture and hydrologic data collected in the ESF. The first niche site at construction station (CS) 31+07 (Niche 3107, hereafter referred to as Niche 3) consists of a $6.3 \mathrm{~m}$ long drift located in an area of relatively low fracture density. Niche 3 is located in close proximity to CS 30+62, where the Cross-Drift crosses over the Main Drift of the ESF. The second niche site, at CS 36+50 (Niche 3650, hereafter referred to as Niche 2), consists of a $9 \mathrm{~m}$ long drift located in a competent rock mass exhibiting relatively moderate fracture density. The third niche site, at CS 47+88 (Niche 4788, hereafter referred to as Niche 4), consists of an $8.2 \mathrm{~m}$ long drift located in a $950 \mathrm{~m}$ long exposure of an intensely fractured zone. Fractures in this zone are not uniformly spaced, but instead they occur in clusters of closely spaced fractures. The $15.0 \mathrm{~m}$-long Niche 5 is located on the south side of the ECRB Cross-Drift in the Tptpll. 


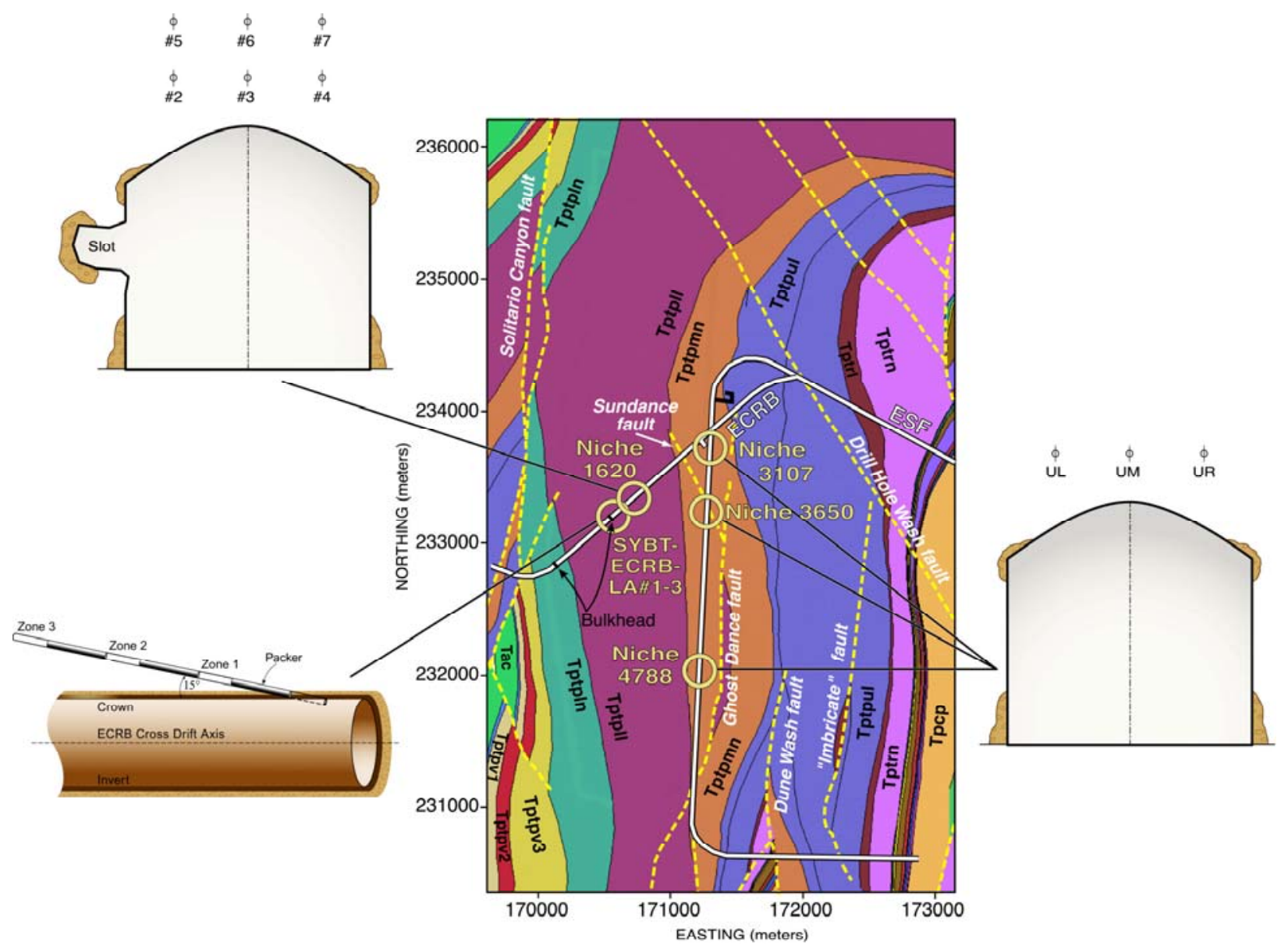

NOTE: The shape of the openings is approximate.

Figure 6-4. Schematic Geologic Map Showing Approximate Location of Niches and Systematic Testing Boreholes SYBT-ECRB-LA\#1-3

Prior to niche excavation, horizontal boreholes were drilled to gain access to the rock for testing and monitoring purposes. The boreholes above each niche are approximately one meter apart and within the same horizontal plane. Table 6-3 provides the correlation between the borehole designations shown in the schematic cross sections of Figure 6-4 (and used throughout this document) and their respective designations in the survey DTN. Note that throughout Project documents, the systematic testing boreholes are designated as either SYBT-ECRB-LA\#x or ECRB-SYBT-LA\#x; these designations are unambiguous and thus interchangeable without loss of traceability. The format SYBT-ECRB-LA\#x is used in this Model Report, consistent with most DTN entries. 
Table 6-3. Borehole Designations in Niches

\begin{tabular}{|c|c|c|l|}
\hline Niche & Borehole & Designation in DTN & \multicolumn{1}{|c|}{ DTN of Borehole Survey } \\
\hline 3107 & UL & ESF-MD-NICHE 3107 \#5 & MO0002GSC00064.000 \\
(Niche 3) & UM & ESF-MD-NICHE 3107 \#6 & [DIRS 152625] \\
& UR & ESF-MD-NICHE 3107 \#7 & \\
\hline 3650 & UL & ESF-MD-NICHE 3650 \#1 & MO0002GSC00076.000 \\
(Niche 2) & UM & ESF-MD-NICHE 3650 \#2 & [DIRS 152623] \\
& UR & ESF-MD-NICHE 3650 \#3 & \\
\hline 4788 & UL & ESF-MD-NICHE 4788 \#5 & MO0107GSC01069.000 \\
(Niche 4) & UM & ESF-MD-NICHE 4788 \#6 & [DIRS 156941] \\
& UR & ESF-MD-NICHE 4788 \#7 & \\
\hline 1620 & $\# 2$ & ECRB-NICHE 1620 \#2 & MO0312GSC03176.000 \\
(Niche 5) & $\# 3$ & ECRB-NICHE 1620 \#3 & [DIRS 169532] \\
& $\# 4$ & ECRB-NICHE 1620 \#4 & \\
& $\# 5$ & ECRB-NICHE 1620 \#5 & \\
& $\# 6$ & ECRB-NICHE 1620 \#6 & \\
& $\# 7$ & ECRB-NICHE 1620 \#7 & \\
\hline
\end{tabular}

NOTE: No liquid-release tests were performed in Niche 3566 (Niche 1).

DTN=Data Tracking Number; UL=upper left; UM=upper middle; UR=upper right

The boreholes listed in Table 6-3 are approximately parallel to the niche axis. Air-injection tests were conducted in several, $1 \mathrm{ft}(0.3 \mathrm{~m})$ long, packed-off intervals, both prior to and after niche excavation, to determine the permeability distribution of the formation, as well as to study potential permeability changes as a result of stress relief during niche excavation. After niche construction, water was injected at a specified rate into intervals of the same boreholes to observe, document, and quantify any water migrating to and seeping into the niche.

The systematic testing boreholes SYBT-ECRB-LA\#1, 2, and 3 are drilled from the ECRB and located in the moderately to densely welded, devitrified, and vapor-phase altered lower lithophysal zone (Tptpll).

Borehole SYBT-ECRB-LA\#1 is collared from the drift crown at ECRB construction station CD $17+49$. It is upward-inclined at nominal $15^{\circ}$ from the drift axis. Packers are set to isolate an injection zone between $10 \mathrm{ft}(3.0 \mathrm{~m})$ and $16 \mathrm{ft}(4.9 \mathrm{~m})$ (zone 2) from the collar (DTN: LB0110ECRBLIQR.002 [DIRS 156879]). Borehole SYBT-ECRB-LA\#2 is collared from the drift crown at ECRB construction station CD 17+26. It is upward-inclined at nominal $15^{\circ}$ from the drift axis. Packers are set to isolate three $6 \mathrm{ft}(1.8 \mathrm{~m})$ long injection zones between $17 \mathrm{ft}(5.2 \mathrm{~m})$ and $23 \mathrm{ft}(7.0 \mathrm{~m})$ (zone 1), $33 \mathrm{ft}(10.1 \mathrm{~m})$ and $39 \mathrm{ft}(11.9 \mathrm{~m})$ (zone 2), and $49 \mathrm{ft}$ $(15.0 \mathrm{~m})$ and $55 \mathrm{ft}(16.8 \mathrm{~m})$ (zone 3) from the collar (DTN: LB00090012213U.002 [DIRS 153154]). Borehole SYBT-ECRB-LA\#3 is collared from the drift crown at ECRB construction station CD 16+95. It is upward-inclined at nominal $15^{\circ}$ from the drift axis. Packers are set to isolate three $6 \mathrm{ft}(1.8 \mathrm{~m})$ long injection zones between $18 \mathrm{ft}(5.5 \mathrm{~m})$ and $24 \mathrm{ft}(7.3 \mathrm{~m})$ (zone 1), $34 \mathrm{ft}(10.4 \mathrm{~m})$ and $40 \mathrm{ft}(12.2 \mathrm{~m})$ (zone 2), and $50 \mathrm{ft}(15.2 \mathrm{~m})$ and $56 \mathrm{ft}(17.1 \mathrm{~m})$ (zone 3) from the collar (DTN: LB0203ECRBLIQR.001 [DIRS 158462]). 


\subsubsection{Air-Injection Tests}

The purpose of the air-injection tests was to estimate permeabilities as a basis for the stochastic generation of heterogeneous permeability fields. The tests were performed by isolating a short section of the boreholes $(1 \mathrm{ft}[0.3 \mathrm{~m}]$ in niches, $6 \mathrm{ft}$ [1.8 $\mathrm{m}]$ in systematic testing borehole SYBT-ECRB-LA\#2), using an inflatable packer system, and then injecting compressed air at a constant rate into the isolated injection interval. The pressure buildup in the injection interval and in nearby observation intervals was monitored with time until steady-state conditions were reached, which typically occurred within a few minutes. Air injection was terminated after reaching steady-state pressures, and the decline in air pressure was then monitored as it recovered to its initial pre-test condition. Air-permeability values were derived from the steady-state pressure data (BSC 2004 [DIRS 170004], Section 6.1.2) based on a commonly used analytical solution [Pneumatic Testing in 45-Degree-Incline Boreholes in Ash-Flow Tuff Near Superior, Arizona (LeCain 1995 [DIRS 101700], p. 10, Eq. (15))].

The air permeabilities around the niches and the ECRB Cross-Drift are affected by excavation (BSC 2004 [DIRS 170004], Section 6.1.2.2; "Permeability Changes Induced by Excavation in Fractured Tuff” (Wang and Elsworth 1999 [DIRS 104366]), pp. 752-756). Since seepage is determined by the formation properties in the immediate vicinity of the opening, it is reasonable to use post-excavation air-permeability data for seepage calculations. Note that the perturbation of the permeability in the drift vicinity depends on the excavation method. A tunnel-boring machine is used for the excavation of the ECRB, whereas a road header is used to mine out the niches. Since local post-excavation air-permeability values are directly used for the analysis of seepage-rate data, no bias is introduced. The permeabilities used during TSPA-LA are sampled from a distribution that describes variability and uncertainty, including uncertainty induced by excavation effects (BSC 2004 [DIRS 169131], Section 6.6).

These permeabilities are considered representative of the absolute permeability of the excavation-disturbed zone around the opening, because the post-excavation air-injection tests were conducted in a network of essentially dry fractures, i.e., no empirical relative permeability function is needed to translate air conductivity into absolute permeability. Since air-injection tests are a standard method to obtain permeability values, the use of these values during both calibration and prediction of seepage ensures consistency.

The distributions representing variability and uncertainty in permeability (BSC 2004 [DIRS 169131], Section 6.6) were developed also based on air-permeability data. This consistency reduces the impact of a potential bias. Data that are located outside the footprint of the niches were removed from the data set (Ahlers 2002 [DIRS 161045], p. 20; Trautz 2001 [DIRS 161044], p. 20) because they represent a separate population of air permeabilities performed in an area of relatively undisturbed, lower-permeability rock. Mean and standard deviations for each of the four locations are summarized in Table 6-4. Here, standard deviations reflect spatial variability within the test bed. The number of log-permeability values available is indicated in the last column. Mean permeabilities and their spatial variability as calculated for the three niches located in the middle nonlithophysal zone are consistent with one another. Permeability in the lower lithophysal zone is approximately one order of magnitude larger. The variability as measured in Niche 5 is significantly larger than that obtained in borehole SYBTECRB-LA\#2. This is partly a result of the injection intervals of borehole SYBT-ECRB-LA\#2 
being six times longer than those in Niche 5 are. Note no air-permeability data are available from boreholes SYBT-ECRB-LA\#1 and SYBT-ECRB-LA\#3 because of equipment problems during air-injection testing.

Table 6-4. Mean and Standard Deviation of Post-Excavation Log-Air-Permeability Values

\begin{tabular}{|c|c|c|c|c|c|}
\hline Location & Input DTN & Scientific Notebook Reference & $\begin{array}{c}\text { Mean } \\
\log \\
\left(k\left[\mathrm{~m}^{2}\right]\right)\end{array}$ & $\begin{array}{l}\text { Std. } \\
\text { Dev. }\end{array}$ & $N^{\mathrm{a}}$ \\
\hline Niche 2 & $\begin{array}{l}\text { LB0011AIRKTEST.001 } \\
\text { [DIRS 153155] }\end{array}$ & Trautz 2001 [DIRS 161044], pp. 19-25 & -11.66 & 0.72 & 84 \\
\hline Niche 3 & $\begin{array}{l}\text { LB990601233124.001 } \\
\text { [DIRS 105888] }\end{array}$ & Ahlers 2002 [DIRS 161045], pp. 39-40 & -12.14 & 0.80 & 78 \\
\hline Niche 4 & $\begin{array}{l}\text { LB990601233124.001 } \\
\text { [DIRS 105888] }\end{array}$ & Ahlers 2002 [DIRS 161045], pp. 15-21 & -11.79 & 0.84 & 63 \\
\hline Niche 5 & $\begin{array}{l}\text { LB0110AKN5POST.001 } \\
\text { [DIRS 156904] }\end{array}$ & $\begin{array}{c}\text { Wang } 2003 \text { [DIRS 161456], } \\
\text { SN-LBNL-SCI-223-V1, pp. 19-20 }\end{array}$ & -10.95 & 1.31 & 61 \\
\hline SYBT-ECRB-LA\#2 & $\begin{array}{l}\text { LB00090012213U.001 } \\
\text { [DIRS 153141] }\end{array}$ & Finsterle 2002 [DIRS 161043], pp. 54-55 & -10.73 & 0.21 & 6 \\
\hline
\end{tabular}

a Number of log-permeability values

DTN=Data Tracking Number; Std Dev=Standard Deviation

\subsubsection{Liquid-Release Tests}

Multiple liquid-release tests were performed in the niches and the ECRB Cross-Drift to characterize seepage into a large underground opening (BSC 2004 [DIRS 170004], Sections 6.2 and 6.11). The tests were performed by sealing a short section of the borehole above the opening using an inflatable packer system and then releasing water at a specified rate into the isolated test interval. Any water that migrated from the borehole to the ceiling and dripped into the opening was captured and weighed. Only a small amount of water (approximately one liter per test event) was released during testing at Niche 2, and only the total amount of water that seeped into the capture system was recorded. Seepage experiments at Niches 3, 4, 5, and in the systematic testing boreholes SYBT-ECRB-LA\#1-3 involved significantly more water, which was injected over longer periods, and cumulative seepage was recorded as a function of time.

In many intervals, multiple liquid-release tests were conducted using different injection rates with different lengths of inactivity between individual test events. The reason for using different injection rates and different injection schedules was to collect data that are sensitive to percolation rate and water storage effects. While the inverse modeling approach pursued in this Model Report does not require data above and below the seepage threshold, increasing the sensitivity of the data to seepage-related effects improves the identifiability of seepage-relevant parameters.

Table 6-5 summarizes the test events used for the calibration and validation of the SCM. The approximate release rate (defined as the injection rate minus the return flow) is indicated in Column 4. As shown in Column 5, 53 out of 90 test events led to seepage into the capture system. Potential seepage was not recorded in two cases (Events 5 and 46) because of an equipment failure. While no data are available to be used for calibration or validation from these 
three test events, the injections that occurred were nevertheless modeled because the released water has a potential impact on subsequent test events. Column 6 indicates whether a specific test event was used for calibration (C) or validation (V). The selection of each test event for calibration or validation purposes is discussed in detail in Section 6.6.3.2. A few additional seepage tests were conducted in Niche 2 that were not used, because only a very small amount of water was released and generally, no seepage was observed. Injection attempts at zone 3 of borehole SYBT-ECRB-LA\#3 (Event 77) failed because the zone was too tight. A few test events in Niche 5 were not analyzed because of various difficulties (Events 79 and 80: packer problem; Event 82: seepage partially bypassed capture system; Event 83: pump problem). During Events 87 and 88 in borehole SYBT-ECRB-LA\#5, water from Events 83 and 85 (conducted in the neighboring borehole SYBT-ECRB-LA\#3) entered the seepage collection system, interfering with the test results (see detailed discussion of Figure 6-17 below).

The events without any seepage cannot be used for calibration (unless jointly inverted with other tests that exhibit seepage), because the corresponding inverse problem would be ill posed. These tests (along with tests showing seepage) are therefore used for validation of the SCM. The small amount of water released during the short-term tests performed in Niche 1 makes it difficult to reliably estimate seepage parameters on the drift scale. If used for calibration, these tests yield small-scale parameter values that are biased towards the properties of the few fractures connecting the release point with the niche ceiling. These fractures may not be representative of the fracture network taking part in the diversion of water around the entire niche, which is the behavior to be modeled under steady-state flow conditions. Moreover, storage effects are significant in short-term tests but are also poorly identifiable. For these reasons, the Niche 2 liquid-release tests are used for validation purposes only.

The calculation of seepage rates from cumulative seepage data is described in Appendix F.

Table 6-5. Liquid-Release Test Events, Approximate Release Rate, Occurrence of Seepage, and Their Use for Calibration or Validation Purposes

\begin{tabular}{|c|c|c|c|c|c|}
\hline Event & $\begin{array}{c}\text { Starting Date } \\
\text { of Test }\end{array}$ & Borehole, Interval & $\begin{array}{c}\text { Approximate } \\
\text { Release Rate } \\
\text { [ml/min] }\end{array}$ & Seepage? & $\begin{array}{c}\text { Calibration, } \\
\text { Validation }\end{array}$ \\
\hline \multicolumn{6}{|c|}{ Niche 2, DTN: LB980001233124.004 [DIRS 136583] } \\
\hline 13 & $12 / 11 / 97$ & UL, 5.18-5.49 m & 4.7 & No & $\mathrm{V}$ \\
\hline 14 & $02 / 12 / 98$ & UL, 5.18-5.49 m & 0.4 & No & $\mathrm{V}$ \\
\hline 15 & $12 / 11 / 97$ & UL, 5.79-6.10 m & 12.1 & No & $\mathrm{V}$ \\
\hline 16 & $12 / 11 / 97$ & UL, $6.40-6.71 \mathrm{~m}$ & 12.7 & No & $\mathrm{V}$ \\
\hline 17 & $12 / 10 / 97$ & UL, 7.01-7.32 m & 116.9 & Yes & $\mathrm{V}$ \\
\hline 18 & 01/06/98 & UL, 7.01-7.32 m & 11.4 & No & $\mathrm{V}$ \\
\hline 19 & $11 / 13 / 97$ & UM, 4.27-4.57 m & 121.1 & Yes & $\mathrm{V}$ \\
\hline 20 & $12 / 03 / 97$ & UM, 4.27-4.57 m & 30.2 & Yes & $\mathrm{V}$ \\
\hline 21 & $12 / 03 / 97$ & UM, 4.27-4.57 m & 30.4 & Yes & $\mathrm{V}$ \\
\hline 22 & 01/07/98 & UM, 4.27-4.57 m & 2.8 & Yes & $\mathrm{V}$ \\
\hline 23 & $02 / 10 / 98$ & UM, 4.27-4.57 m & 1.0 & No & $\mathrm{V}$ \\
\hline 24 & $11 / 12 / 97$ & UM, 4.88-5.18 m & 173.5 & Yes & $\mathrm{V}$ \\
\hline
\end{tabular}


Table 6-5. Liquid-Release Test Events, Approximate Release Rate, Occurrence of Seepage, and their Use for Calibration or Validation Purposes (Continued)

\begin{tabular}{|c|c|c|c|c|c|}
\hline Event & $\begin{array}{c}\text { Starting Date } \\
\text { of Test }\end{array}$ & Borehole, Interval & $\begin{array}{c}\text { Approximate } \\
\text { Release Rate } \\
\text { [ml/min] }\end{array}$ & Seepage? & $\begin{array}{c}\text { Calibration, } \\
\text { Validation }\end{array}$ \\
\hline 25 & $12 / 04 / 97$ & UM, $4.88-5.18 \mathrm{~m}$ & 30.4 & Yes & $\mathrm{V}$ \\
\hline 26 & $12 / 05 / 97$ & UM, 4.88-5.18 m & 8.6 & Yes & $\mathrm{V}$ \\
\hline 27 & $01 / 08 / 98$ & UM, $4.88-5.18 \mathrm{~m}$ & 2.8 & No & $\mathrm{V}$ \\
\hline 28 & $03 / 06 / 98$ & UM, 4.88-5.18 m & 0.8 & No & $\mathrm{V}$ \\
\hline 29 & $11 / 13 / 97$ & UM, 5.49-5.79 m & 124.1 & Yes & $\mathrm{V}$ \\
\hline 30 & $12 / 04 / 97$ & UM, 5.49-5.79 m & 30.2 & Yes & $\mathrm{V}$ \\
\hline 31 & 01/09/98 & UM, $5.49-5.79 \mathrm{~m}$ & 3.5 & Yes & $\mathrm{V}$ \\
\hline 32 & $02 / 11 / 98$ & UM, $5.49-5.79 \mathrm{~m}$ & 0.8 & No & $\mathrm{V}$ \\
\hline 33 & $11 / 13 / 1997$ & UM, $6.10-6.40 \mathrm{~m}$ & 30.8 & No & $\mathrm{V}$ \\
\hline 34 & $12 / 04 / 1997$ & UM, $6.10-6.40 \mathrm{~m}$ & 11.5 & No & $\mathrm{V}$ \\
\hline 35 & 01/12/1998 & UM, $6.10-6.40 \mathrm{~m}$ & 47.5 & No & $\mathrm{V}$ \\
\hline 36 & 01/14/1998 & UR, $4.27-4.57 \mathrm{~m}$ & 11.9 & Yes & $\mathrm{V}$ \\
\hline 37 & 02/05/1998 & UR, $4.27-4.57 \mathrm{~m}$ & 3.3 & No & $\mathrm{V}$ \\
\hline 38 & 01/15/1998 & UR, $4.88-5.18 \mathrm{~m}$ & 11.4 & Yes & $\mathrm{V}$ \\
\hline 39 & 02/06/1998 & UR, $4.88-5.18 \mathrm{~m}$ & 3.2 & No & $\mathrm{V}$ \\
\hline \multicolumn{6}{|c|}{ Niche 3, DTN: LB0010NICH3LIQ.001 [DIRS 153144] } \\
\hline 1 & 03/10/99 & UL, $5.49-5.80 \mathrm{~m}$ & 1.5 & No & $\mathrm{V}$ \\
\hline 2 & $03 / 30 / 99$ & UL, $5.49-5.80 \mathrm{~m}$ & 2.0 & No & $\mathrm{V}$ \\
\hline 3 & $09 / 17 / 99$ & UL, $5.49-5.80 \mathrm{~m}$ & 1.5 & No & $\mathrm{V}$ \\
\hline 4 & $03 / 04 / 99$ & UM, $4.88-5.18 \mathrm{~m}$ & 0.9 & No & $\mathrm{C}$ \\
\hline 5 & $04 / 07 / 99$ & UM, $4.88-5.18 \mathrm{~m}$ & 5.8 & $-{ }^{a}$ & $-{ }^{a}$ \\
\hline 6 & $04 / 27 / 99$ & UM, $4.88-5.18 \mathrm{~m}$ & 2.4 & Yes & $\mathrm{C}$ \\
\hline \multicolumn{6}{|c|}{ Niche 3, DTN: LB0010NICH3LIQ.001 [DIRS 153144] (Continued) } \\
\hline 7 & $04 / 30 / 99$ & UM, 4.88-5.18 m & 0.8 & No & $\mathrm{V}$ \\
\hline 8 & $05 / 06 / 99$ & UM, 4.88-5.18 m & 5.4 & Yes & $\mathrm{C}$ \\
\hline 9 & $09 / 21 / 99$ & UM, $4.88-5.18 \mathrm{~m}$ & 5.0 & Yes & $\mathrm{V}$ \\
\hline 10 & $09 / 23 / 99$ & UM, $4.88-5.18 \mathrm{~m}$ & 5.3 & Yes & $\mathrm{V}$ \\
\hline 11 & $09 / 27 / 99$ & UM, $4.88-5.18 \mathrm{~m}$ & 5.4 & Yes & $\mathrm{V}$ \\
\hline 12 & $10 / 11 / 99$ & UM, $4.88-5.18 \mathrm{~m}$ & 5.4 & Yes & $\mathrm{V}$ \\
\hline \multicolumn{6}{|c|}{ Niche 4, DTN: LB0010NICH4LIQ.001 [DIRS 153145] } \\
\hline 40 & $11 / 03 / 1999$ & UL, $7.62-7.93 \mathrm{~m}$ & 5.5 & Yes & $\mathrm{V}$ \\
\hline 41 & $11 / 30 / 1999$ & UL, $7.62-7.93 \mathrm{~m}$ & 3.1 & Yes & $\mathrm{C}$ \\
\hline 42 & $01 / 24 / 2000$ & UL, $7.62-7.93 \mathrm{~m}$ & 0.5 & No & $\mathrm{V}$ \\
\hline 43 & $06 / 26 / 2000$ & UL, $7.62-7.93 \mathrm{~m}$ & 1.2 & Yes & $\mathrm{C}$ \\
\hline 44 & $11 / 16 / 1999$ & UM, $6.10-6.40 \mathrm{~m}$ & 5.5 & Yes & $\mathrm{V}$ \\
\hline 45 & $12 / 10 / 1999$ & UM, $6.10-6.40 \mathrm{~m}$ & 2.3 & Yes & $\mathrm{C}$ \\
\hline 46 & $02 / 09 / 2000$ & UM, $6.10-6.40 \mathrm{~m}$ & 0.5 & $-{ }^{a}$ & $-{ }^{\mathrm{a}}$ \\
\hline 47 & $03 / 14 / 2000$ & UM, $6.10-6.40 \mathrm{~m}$ & 0.5 & No & $\mathrm{V}$ \\
\hline 48 & $06 / 08 / 2000$ & UM, $6.10-6.40 \mathrm{~m}$ & 1.2 & Yes & $\mathrm{C}$ \\
\hline 49 & $12 / 07 / 1999$ & UR, $5.18-5.48 \mathrm{~m}$ & 5.5 & Yes & $\mathrm{V}$ \\
\hline
\end{tabular}


Table 6-5. Liquid-Release Test Events, Approximate Release Rate, Occurrence of Seepage, and their Use for Calibration or Validation Purposes (Continued)

\begin{tabular}{|c|c|c|c|c|c|}
\hline Event & $\begin{array}{c}\text { Starting Date } \\
\text { of Test }\end{array}$ & Borehole, Interval & $\begin{array}{c}\text { Approximate } \\
\text { Release Rate } \\
{[\mathrm{ml} / \mathrm{min}]}\end{array}$ & Seepage? & $\begin{array}{c}\text { Calibration, } \\
\text { Validation }\end{array}$ \\
\hline 50 & $01 / 05 / 2000$ & UR, 5.18-5.48 m & 2.4 & Yes & $\mathrm{C}$ \\
\hline 51 & $02 / 14 / 2000$ & UR, $5.18-5.48 \mathrm{~m}$ & 0.5 & Yes & $\mathrm{C}$ \\
\hline \multicolumn{6}{|c|}{ SYBT-ECRB-LA\#2, DTN: LB00090012213U.002 [DIRS 153154] } \\
\hline 52 & $05 / 11 / 2000$ & LA\#2, zone 1 & $>450$ & Yes & $\mathrm{V}$ \\
\hline 53 & $05 / 17 / 2000$ & LA\#2, zone 1 & 34.9 & Yes & $\mathrm{V}$ \\
\hline 54 & $05 / 23 / 2000$ & LA\#2, zone 1 & 26.3 & Yes & $\mathrm{V}$ \\
\hline 55 & $05 / 23 / 2000$ & LA\#2, zone 2 & 29.5 & Yes & $\mathrm{V}$ \\
\hline 56 & $06 / 01 / 2000$ & LA\#2, zone 2 & 31.6 & Yes & $\mathrm{V}$ \\
\hline 57 & $05 / 17 / 2000$ & LA\#2, zone 3 & 16.8 & No & $\mathrm{V}$ \\
\hline 58 & $05 / 23 / 2000$ & LA\#2, zone 3 & 26.1 & No & $\mathrm{V}$ \\
\hline 59 & $06 / 01 / 2000$ & LA\#2, zone 3 & 35.6 & No & $\mathrm{V}$ \\
\hline 60 & $06 / 14 / 2000$ & LA\#2, zone 3 & 37.8 & Yes & $\mathrm{V}$ \\
\hline \multicolumn{6}{|c|}{ SYBT-ECRB-LA\#2, DTN: LB0110SYST0015.001 [DIRS 160409] } \\
\hline 61 & $10 / 23 / 2000$ & LA\#2, zone 2 & 33.0 & Yes & $\mathrm{C}$ \\
\hline 62 & $11 / 27 / 2000$ & LA\#2, zone 2 & 35.3 & Yes & $\mathrm{C}$ \\
\hline 63 & $10 / 23 / 2000$ & LA\#2, zone 3 & 38.0 & Yes & C \\
\hline 64 & $11 / 27 / 2000$ & LA\#2, zone 3 & 40.8 & Yes & $\mathrm{C}$ \\
\hline \multicolumn{6}{|c|}{ SYBT-ECRB-LA\#1, DTN: LB0110ECRBLIQR.002 [DIRS 156879] } \\
\hline 65 & $02 / 28 / 2001$ & LA\#1, zone 2 & 17.0 & No & $\mathrm{C}$ \\
\hline 66 & $04 / 03 / 2001$ & LA\#1, zone 2 & 41.2 & Yes & $\mathrm{C}$ \\
\hline 67 & $04 / 09 / 2001$ & LA\#1, zone 2 & 43.9 & Yes & $\mathrm{C}$ \\
\hline 68 & $04 / 17 / 2001$ & LA\#1, zone 2 & 44.5 & Yes & $\mathrm{C}$ \\
\hline 69 & $04 / 25 / 2001$ & LA\#1, zone 2 & 43.1 & Yes & $\mathrm{C}$ \\
\hline \multicolumn{6}{|c|}{ SYBT-ECRB-LA\#3, DTN: LB0203ECRBLIQR.001 [DIRS 158462] } \\
\hline 70 & $05 / 17 / 2001$ & LA\#3, zone 1 & 36.4 & No & $\mathrm{C}$ \\
\hline 71 & $05 / 23 / 2001$ & LA\#3, zone 1 & 24.7 & Yes & $\mathrm{C}$ \\
\hline 72 & $05 / 17 / 2001$ & LA\#3, zone 2 & 71.2 & No & $\mathrm{V}$ \\
\hline 73 & $06 / 20 / 2001$ & LA\#3, zone 2 & 31.2 & No & $\mathrm{V}$ \\
\hline 74 & $07 / 05 / 2001$ & LA\#3, zone 2 & 65.7 & No & $\mathrm{V}$ \\
\hline 75 & $07 / 13 / 2001$ & LA\#3, zone 2 & 47.9 & No & $\mathrm{V}$ \\
\hline 76 & $07 / 16 / 2002$ & LA\#3, zone 2 & 32.4 & No & $\mathrm{V}$ \\
\hline 77 & $05 / 17 / 2001$ & LA\#3, zone 3 & $0.0^{\mathrm{b}}$ & No & $-{ }^{\mathrm{b}}$ \\
\hline \multicolumn{6}{|c|}{ Niche 5, DTN: LB0207NICH5LIQ.001 [DIRS 160408] } \\
\hline 78 & $05 / 06 / 2002$ & $\# 5,28-29 \mathrm{ft}$ & 72.0 & Yes & $\mathrm{V}$ \\
\hline 79 & $05 / 06 / 2002$ & $\# 2,21-22 \mathrm{ft}$ & 120.0 & No & $-{ }^{c}$ \\
\hline 80 & $05 / 17 / 2002$ & $\# 2,21-22 \mathrm{ft}$ & 120.0 & No & $-^{\mathrm{c}}$ \\
\hline 81 & 05/16/2002 & $\# 5,28-29 \mathrm{ft}$ & 60.0 & Yes & $\mathrm{V}$ \\
\hline 82 & $05 / 21 / 2002$ & $\# 5,28-29 \mathrm{ft}$ & 72.0 & Yes & $-{ }^{d}$ \\
\hline
\end{tabular}


Table 6-5. Liquid-Release Test Events, Approximate Release Rate, Occurrence of Seepage, and their Use for Calibration or Validation Purposes (Continued)

\begin{tabular}{|c|c|c|c|c|c|}
\hline Event & $\begin{array}{c}\text { Starting Date } \\
\text { of Test }\end{array}$ & Borehole, Interval & $\begin{array}{c}\text { Approximate } \\
\text { Release Rate } \\
\text { [ml/min] }\end{array}$ & Seepage? & $\begin{array}{c}\text { Calibration, } \\
\text { Validation }\end{array}$ \\
\hline \multicolumn{7}{|c|}{ Niche 5, DTN: LB0209NICH5LIQ.001 [DIRS 160796] } \\
\hline 83 & $07 / 17 / 2002$ & $\# 3,21-22 \mathrm{ft}$ & 55.0 & Yes & $-^{\mathrm{e}, \mathrm{f}}$ \\
\hline 84 & $07 / 29 / 2002$ & $\# 3,21-22 \mathrm{ft}$ & 33.0 & Yes & $-^{\mathrm{f}}$ \\
\hline 85 & $08 / 14 / 2002$ & $\# 3,21-22 \mathrm{ft}$ & 9.0 & Yes & $-^{\mathrm{g}}$ \\
\hline 86 & $07 / 15 / 2002$ & $\# 5,28-29 \mathrm{ft}$ & 25.8 & Yes & $\mathrm{C}$ \\
\hline 87 & $07 / 31 / 2002$ & $\# 5,28-29 \mathrm{ft}$ & 25.8 & Yes & $\mathrm{V}$ \\
\hline 88 & $08 / 05 / 2002$ & $\# 5,28-29 \mathrm{ft}$ & 11.3 & Yes & $\mathrm{V}$ \\
\hline \multicolumn{7}{|c|}{ Niche 5, DTN: LB0211NICH5LIQ.001 [DIRS 160792] } \\
\hline 89 & $09 / 17 / 2002$ & $\# 4,10-11 \mathrm{ft}$ & 9.9 & Yes & $\mathrm{C}$ \\
\hline 90 & $10 / 01 / 2002$ & $\# 4,10-11 \mathrm{ft}$ & 4.8 & No & $\mathrm{V}$ \\
\hline
\end{tabular}

${ }^{a}$ Events 5 and 46: Potential seepage could not be determined because of an equipment failure

${ }^{\mathrm{b}}$ Event 77: Return flow from injection interval indicates that no water was released to the formation

c Events 79 and 80: Packer problem

${ }^{d}$ Event 82: Seepage partially bypassed capture system

e Event 83: Pump problem

$f$ Events 83 and 84: Test interference (see discussion of Figure 6-17)

${ }^{g}$ Event 85: Test too short for analysis

UL=upper left; UM=upper middle UL=upper left; UM=upper middle

\subsubsection{Relative Humidity and Evaporation Rate Measurements}

Reduced relative humidity in the ESF Main Drift, the ECRB Cross-Drift, and the niches lead to partial evaporation of the water that reaches the opening, effectively reducing seepage. Note that a conservative treatment of a process in a forward model is nonconservative in an inverse model (and vice versa). Specifically, neglecting evaporation effects in a seepage prediction model (forward model) leads to higher seepage rates and is thus conservative. However, an overestimation of seepage in a model used for parameter determination (inverse model) is compensated by an increase in the estimated capillary-strength parameter, which is nonconservative if this parameter is subsequently used for seepage predictions. Following the recommendations made to address the evaporation issue [Seepage Calibration Model and Seepage Testing Data (CRWMS M\&O 2001 [DIRS 153045], Section 7.5)], humidity in the closed-off Niches 3 and 4 was artificially increased to reduce the evaporation potential, and relative humidity was monitored (BSC 2004 [DIRS 170004], Figures 6-27 and 6-28). In the systematic testing area, additional curtains were installed on the two ends of the V-shaped seepage capture PVC curtains to reduce air circulation in the ventilated ECRB Cross-Drift (after June 2000). In addition, relative humidity and evaporation rates from an open pan were measured (see, for example, In Situ Field Testing of Processes (BSC 2004 [DIRS 170004], Figure 6-139). Relative humidity and evaporation rate were also measured in Niche 5 (DTN: LB0207NICH5LIQ.001 [DIRS 160408] and DTN: LB0211NICH5LIQ.001 [DIRS 160792]). 
The evaporation-rate data will be used to estimate the thickness of the diffusive boundary layer (see Section 6.6.1.4). The relative-humidity data will be applied as a time-dependent boundary condition determining the water potential in the opening.

\subsection{MODEL FORMULATION}

\subsubsection{Mathematical Model}

The mathematical model for unsaturated flow is based on the conceptual model outlined in the previous sections. The basic theoretical foundation for unsaturated flow in a continuum is outlined first, with a short discussion of the capillary pressure curve and its relevance for seepage (Sections 6.6.1.1 and 6.6.1.2). The incorporation of evaporation from a wetted porous surface is described in Sections 6.6.1.3 and 6.6.1.4. Section 6.6.1.5 contains a summary description of the inverse modeling methodology.

\subsubsection{Unsaturated Flow}

Flow in unsaturated porous or fractured media is described by the rate of change in liquid saturation and the flow rate at any given point. The continuum concept (see Section 6.3.2) stipulates the following equation of continuity, which describes the rate at which liquid saturation changes at a given point (Bear 1972 [DIRS 156269], pp. 496, Eq. 9.4.39):

$$
\phi \rho \frac{\partial}{\partial} S=\frac{\partial}{\partial x} q_{x}+\frac{\partial}{\partial y} q_{y}+\frac{\partial}{\partial z} q_{z}
$$

Here, $t$ [s] is time, $\phi$ [dimensionless] is porosity, $S$ [dimensionless] is liquid saturation, $\rho$ [kg $\left.\mathrm{m}^{-3}\right]$ is liquid density, and $q\left[\mathrm{~kg} \mathrm{~m}^{-2} \mathrm{~s}^{-1}\right]$ is the flow rate along the principal axes $(x, y$, and $z$ ). Considering that liquid flow is driven by gravity and pressure gradients (see Section 6.3.2), the liquid-flow rate is described by the Buckingham-Darcy law as follows (after Bear 1972 [DIRS 156269], pp. 487-488, Eqs. 9.4.20 and 9.4.21):

$$
q_{x}=\frac{k_{r} \rho}{\mu} k_{x} \frac{\partial P_{c}}{\partial x}, q_{y}=\frac{k_{r} \rho}{\mu} k_{y} \frac{\partial P_{c}}{\partial y} \text {, and } q_{z}=\frac{k_{r} \rho}{\mu} k_{z} \frac{\partial}{\partial z}\left(P_{c}+\rho g z\right)
$$

Here, $k_{x}\left[\mathrm{~m}^{2}\right], k_{y}\left[\mathrm{~m}^{2}\right]$, and $k_{z}\left[\mathrm{~m}^{2}\right]$ are the absolute permeabilities along the three coordinate axes $x[\mathrm{~m}], y[\mathrm{~m}]$, and $z[\mathrm{~m}]$ (where $z$ is positive upward), $k_{r}$ [dimensionless] is relative permeability, $\mu[\mathrm{Pa} \cdot \mathrm{s}]$ is liquid viscosity, $g\left[\mathrm{~m} \mathrm{~s}^{-2}\right]$ is gravitational acceleration, and $P_{c}[\mathrm{~Pa}]$ is the capillary pressure defined as the difference between the liquid and gas pressure. Substituting Eq. 6-2 into Eq. 6-1 leads to the governing equation of flow in unsaturated porous media (after Bear 1972 [DIRS 156269], p. 496, Eq. 9.4.41):

$$
\phi \rho \frac{\partial}{\partial} S=\operatorname{div}\left[k \frac{k_{r} \rho}{\mu} \nabla\left(P_{c}+\rho \mathbf{g} z\right)\right]
$$


In Richards' equation, the relative permeability $\left(k_{r}\right)$ and capillary pressure $\left(P_{c}\right)$ are functions of liquid saturation as given, for example, by van Genuchten's model (after van Genuchten 1980 [DIRS 100610], after Eqs. [8] and [3]):

$$
\begin{gathered}
k_{r}=S_{e}^{1 / 2}\left[1-\left(1-S_{e}^{1 / m}\right)^{m}\right]^{2} \\
P_{c}=-\frac{1}{\alpha}\left[S_{e}^{-1 / m}-1\right]^{1-m}
\end{gathered}
$$

In van Genuchten's equations, the effective saturation, $S_{e}$, is defined as

$$
S_{e}=\frac{S-S_{l r}}{1-S_{l r}}
$$

where $S_{l r}$ is residual liquid saturation, and $1 / \alpha>0[\mathrm{~Pa}$ ] and $0<m<1$ [dimensionless] are fitting parameters. The roles of the parameters in the capillary pressure and relative permeability functions are illustrated in Figure 6-5. The parameter $1 / \alpha$ describes the point of inflection in the capillary-pressure function (Eq. 6-5) shown in Figure 6-5a. The factor $1 / \alpha$ scales the capillary pressure curve and is therefore referred to as the capillary-strength parameter.

The parameter $m$ determines the slopes of the capillary pressure and relative permeability functions. It is a measure of the spread of the effective pore size distribution; a large $m$ value implies a narrow pore size distribution. The use of continuous relative-permeability and capillary-pressure functions, which apply to porous media, is considered appropriate also for small fracture segments that are rough-walled and/or partially filled with porous material. 

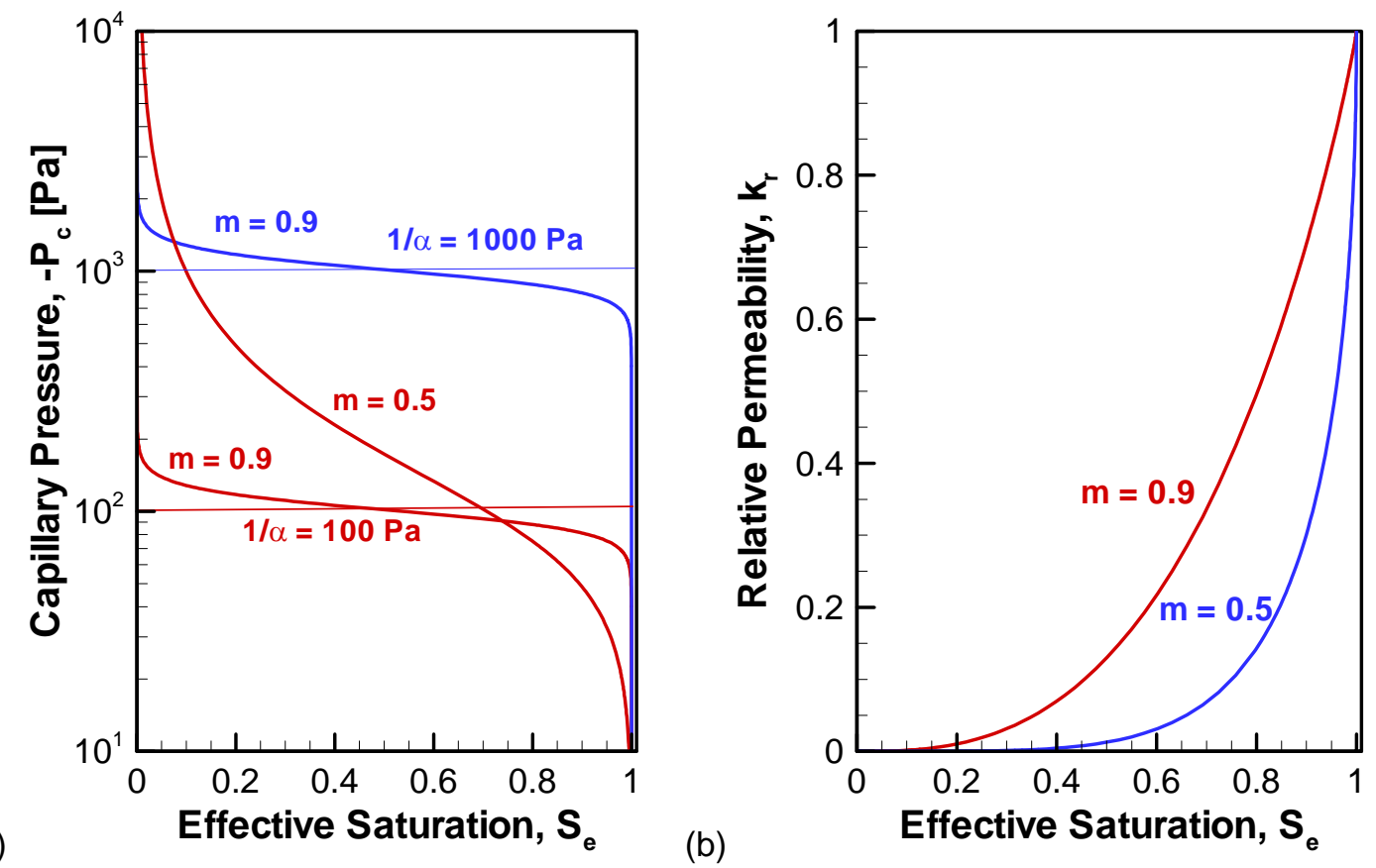

Figure 6-5. (a) Capillary-Pressure Curves and (b) Relative-Permeability Curves for Different Illustrative van Genuchten Parameters.

\subsubsection{Onset of Seepage}

For a circular opening in a homogeneous medium, the threshold for liquid entry into the cavity is full saturation at the apex (Philip et al. 1989 [DIRS 105743]). For the liquid that enters the opening to form a drop at the opening wall and detach (see definition of seepage in Section 6.1.2), a positive pressure that offsets the drop pressure is required (Or and Ghezzehei 2000 [DIRS 144773], pp. 390-392).

For a numerical model in which the continuum is subdivided into discrete gridblocks, the condition for seepage is determined by the total water-potential gradient at the connection between the fractured medium and the opening as depicted in Figure 6-6. From Eq. 6-2 it follows that downward seepage in a discrete numerical mesh, $q_{z}>0$, occurs only when the following condition is satisfied:

$$
P_{c}+\rho g \Delta z>0
$$

where $P_{c}$ is the capillary pressure at the last node adjacent to the opening. Given that the capillary pressure in the opening is zero, the numerical threshold capillary pressure is defined as $P_{c}{ }^{*}=-\rho g \Delta z$, where $\Delta z$ is the distance between the last node and the opening. The numerical threshold capillary pressure $P_{c}{ }^{*}$ therefore depends on the nodal distance between the last node and the opening. The opening surface does not need to be fully saturated for seepage to commence as given by the analytical solutions of Philip et al. (1989 [DIRS 105743]). As indicated in Figure 6-6, given a numerical grid, the seepage-threshold liquid saturation is lower 
for larger $\Delta z$ and for lower capillary strength $(1 / \alpha)$. Consequently, $1 / \alpha$ parameter determines whether liquid that reaches the surface seeps or is diverted around the opening (effectiveness of the capillary barrier). Note that the relative permeability function (Eq. 6-4) does not depend on $1 / \alpha$. Hence, the capillary-strength parameter is the main subject of the SCM presented in this report (see also discussion in Section 6.6.3.1). The fact that the seepage threshold depends on the length of the nodal distance to the opening makes the values of the estimated capillary-strength parameter $(1 / \alpha)$ applicable only to numerical models of comparable discretization (see Point 0 of Section 8.4).

Figure 6-6 shows that a reasonable variation in the $m$ parameter has only a limited effect on the seepage threshold saturation; a stronger effect is seen for a change in $1 / \alpha$, which tends to vary more than $m$. Therefore, fixing the parameter $m$ appears reasonable as confirmed by the formal sensitivity analysis (see Section 6.6.3.1 below). Moreover, any potential variability of $m$ is accounted for in the calibrated $1 / \alpha$ parameter. The relative sensitivity and potential identifiability of seepage-relevant parameters are further discussed in Section 6.6.3.1.
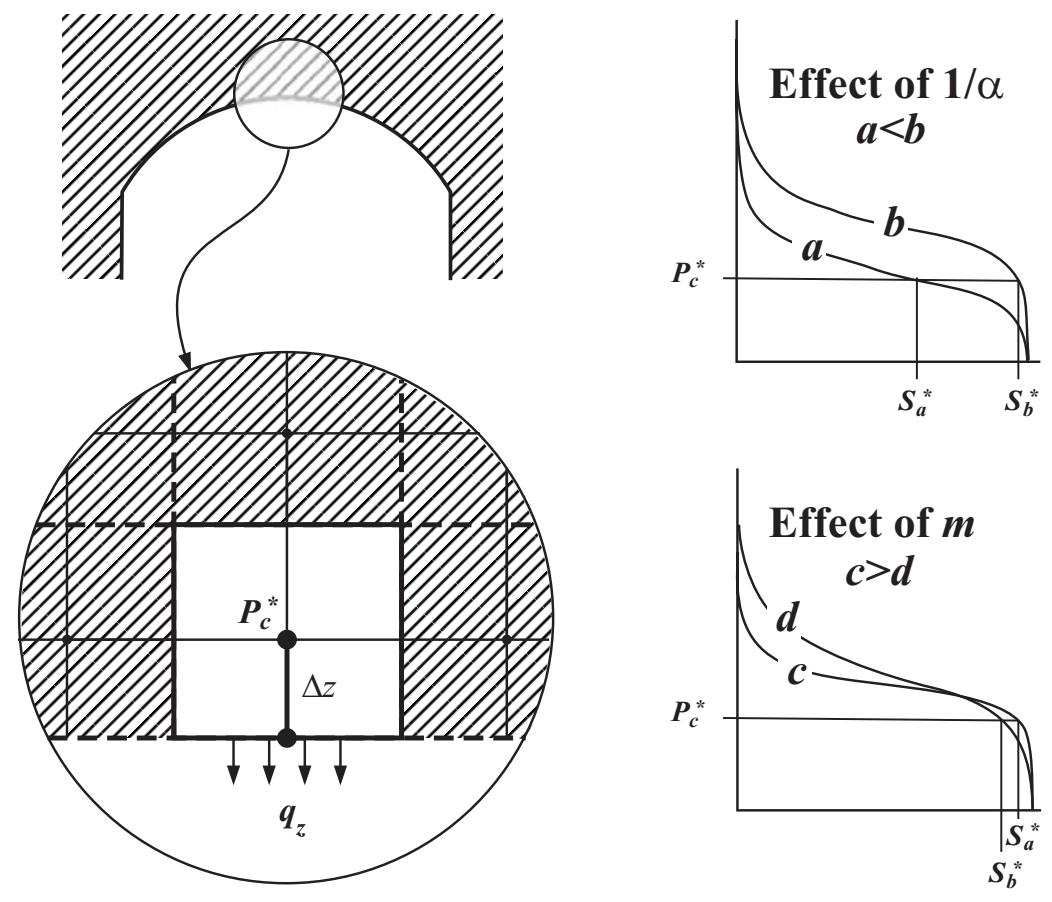

NOTE: A change in $1 / \alpha$ has a greater impact on the seepage threshold saturation than a change in $m$.

Figure 6-6. Schematic Description of Seepage Condition

\subsubsection{Incorporation of Evaporation Effects}

Part of the liquid that reaches the surface of the underground opening evaporates by virtue of the vapor concentration gradient at the surface. Considering mass transfer from evaporation as an 
isothermal diffusive process, the evaporative flux $\left(q_{e}\left[\mathrm{~kg} \mathrm{~m}^{-2} \mathrm{~s}^{-1}\right]\right)$ applied at the wall of the opening is given by:

$$
q_{e}=D \frac{\mathrm{d} C}{\mathrm{~d} x}
$$

where $D\left[\mathrm{~m}^{2} \mathrm{sec}^{-1}\right]$ is the vapor diffusion coefficient and $C\left[\mathrm{~kg} \mathrm{~m}^{-3}\right]$ is the vapor concentration. The vapor concentration at the surface of the opening $\left(C^{\circ}\right)$ is related to the capillary pressure by Kelvin's equation (after Campbell and Norman [An Introduction to Environmental Biophysics (1998 [DIRS 150929], Eqs. 3.11 and 3.17)]):

$$
C^{o}=\frac{M_{w} P_{s a t}}{R T} \exp \left[\frac{P_{c} M_{w}}{\rho R T}\right]
$$

where $M_{w}\left[0.01802 \mathrm{~kg} \mathrm{~mol}^{-1}\right]$ is the molecular mass of water, $R$ [8.314 J K $\mathrm{mol}^{-1}$ ] is the universal gas constant, $P_{\text {sat }}[\mathrm{Pa}]$ is the saturated vapor pressure, $T[\mathrm{~K}]$ is the temperature, and the expression $\exp \left[P_{c} M_{w} /(\rho R T)\right]$ denotes the relative humidity (Ho 1997 [DIRS 141521], Eq. 10). The vapor concentration of bulk air of the opening $\left(C^{\infty}\right)$ is related to the relative humidity $h$ by

$$
C^{\infty}=\frac{P_{s a t} M_{w} h}{R T}
$$

The vapor concentration undergoes a gradual transition from $C^{o}$ to $C^{\infty}$ within a finite distance away from the opening surface, here referred to as the evaporative boundary layer, whose thickness $(\delta)$ is inversely related to the airflow velocity (e.g., [Heat, Mass, and Momentum Transfer (Rohsenow and Choi 1961 [DIRS 158324], pp. 36-40)]. The vapor concentration gradient is presumed linear within the boundary layer. Then, Eq. 6-8 can be rewritten as:

$$
q_{e}=D \frac{C^{o}-C^{\infty}}{\delta}
$$

The vapor diffusion coefficient depends on temperature and pressure as given in [TOUGH User's Guide (Pruess 1987 [DIRS 100684], pp. 5-6)]:

$$
D=D^{o}\left(\frac{10^{5}}{P}\right)\left(\frac{T}{273.15}\right)^{1.8}
$$

where $D^{o}=2.13 \times 10^{-5} \mathrm{~m}^{2} \mathrm{~s}^{-1}$ is the vapor diffusion coefficient at standard conditions of $T=273.15 \mathrm{~K}$ and $P=10^{5} \mathrm{~Pa}$.

The implementation of evaporation effects into iTOUGH2 V5.0 (LBNL 2002 [DIRS 160106]) is described in detail in Requirements Document (RD) for iTOUGH2 V5.0-00 (BSC 2002 [DIRS 161067], Section 1.2). 


\subsubsection{Estimation of Evaporative Boundary-Layer Thickness}

The thickness of the evaporative boundary layer ( $\delta$, see Eq. 6-11) can be estimated by calibration using evaporation data measured under known vapor concentration and temperature conditions. The $\delta$ values employed in this Model Report were obtained by calibration using free-water evaporation data collected inside and outside of Niche 5 (DTN: LB0207NICH5LIQ.001 [DIRS 160408]) (see also Section 6.5.4). The vapor concentration at the surface of free water is given by Eq. 6-9 with $P_{c}=0 \mathrm{~Pa}$.

The available evaporation data are grouped into three classes based on airflow velocity: (1) outside of Niche 5 with active ventilation, (2) outside of Niche 5 without active ventilation (the regime usually encountered during nights and weekends), and (3) inside the closed-off Niche 5, with little or no air flow. In Figure 6-7 and Figure 6-8, the relative humidity, temperature and measured and fitted evaporation rates are plotted for outside and inside of Niche 5, respectively (Wang 2003 [DIRS 161456], SN-LBNL-SCI-223-V1, pp. 22-25).

The objective of calibrating the evaporation model against evaporation measurements conducted outside of Niche 5 (see Figure 6-7) is to estimate the boundary-layer thickness that represents the open ECRB. The airflow velocity in the ECRB Cross-Drift is influenced by natural airflow and active ventilation. Fluctuations in airflow velocity translate into fluctuations in the diffusive boundary-layer thickness, and (together with fluctuations in relative humidity) determine the time-varying evaporation potential. While relative humidity was measured as a function of time, corresponding airflow velocity data are not available. For the purposes of this evaluation, a change in airflow velocity is adequately accounted for by simply relating it to the prevailing ventilation condition, which was categorized into (a) periods of active ventilation (during working days), and (b) periods without active ventilation (nights and weekends). Short-term fluctuations in airflow velocity are not accounted for; their effect on the average evaporation potential prevailing during the length of a liquid-release test is considered small.

Evaporation-rate data from the beginning of Day 139 to the end of Day 141 were excluded, because they appear to have been affected by higher than average ventilation conditions. The boundary-layer thicknesses were increased and reduced by $1 \mathrm{~mm}$ (green lines in Figure 6-7) to show the impact of this parameter on the calculated evaporation rates; this provides an indication of the uncertainty in the estimated value. 

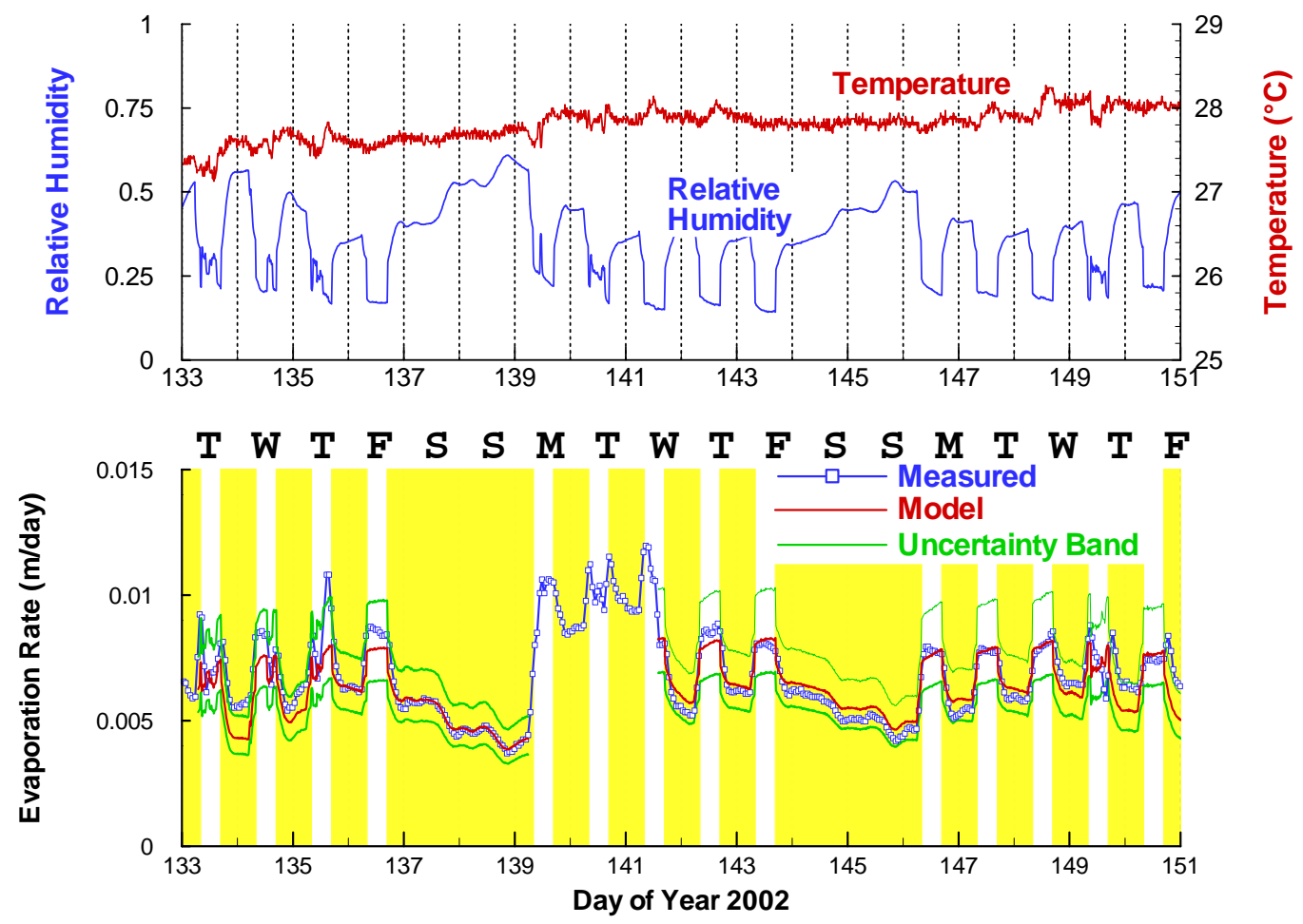

Source: DTN: LB0207NICH5LIQ.001 [DIRS 160408].

NOTE: Relative humidity is higher during nights and weekends, and evaporation is decreased accordingly (shaded).

Figure 6-7. Relative Humidity, Temperature, and Measured and Fitted Evaporation Rates from Experiments Conducted outside Niche 5

The objective of calibrating the evaporation model against evaporation measurements conducted inside Niche 5 is to estimate the boundary-layer thickness that represents the closed-off niche environment. Therefore, evaporation data that appear to have been affected by occasional opening of the bulkhead (as evidenced by sudden drops in relative humidity and temperature as well as rapid rise in evaporation rate) were excluded from the calibration exercise. The evaporation rate data that were not used for calibration are greater than $0.0075 \mathrm{~mm} /$ day (marked by a horizontal black line in Figure 6-8). The sensitivity analysis with boundary-layer thicknesses of $15 \mathrm{~mm}$ and $25 \mathrm{~mm}$ (green lines in Figure 6-8) shows the impact of this parameter on the calculated evaporation rates, and thus gives an indication of the uncertainty in the estimated value. 

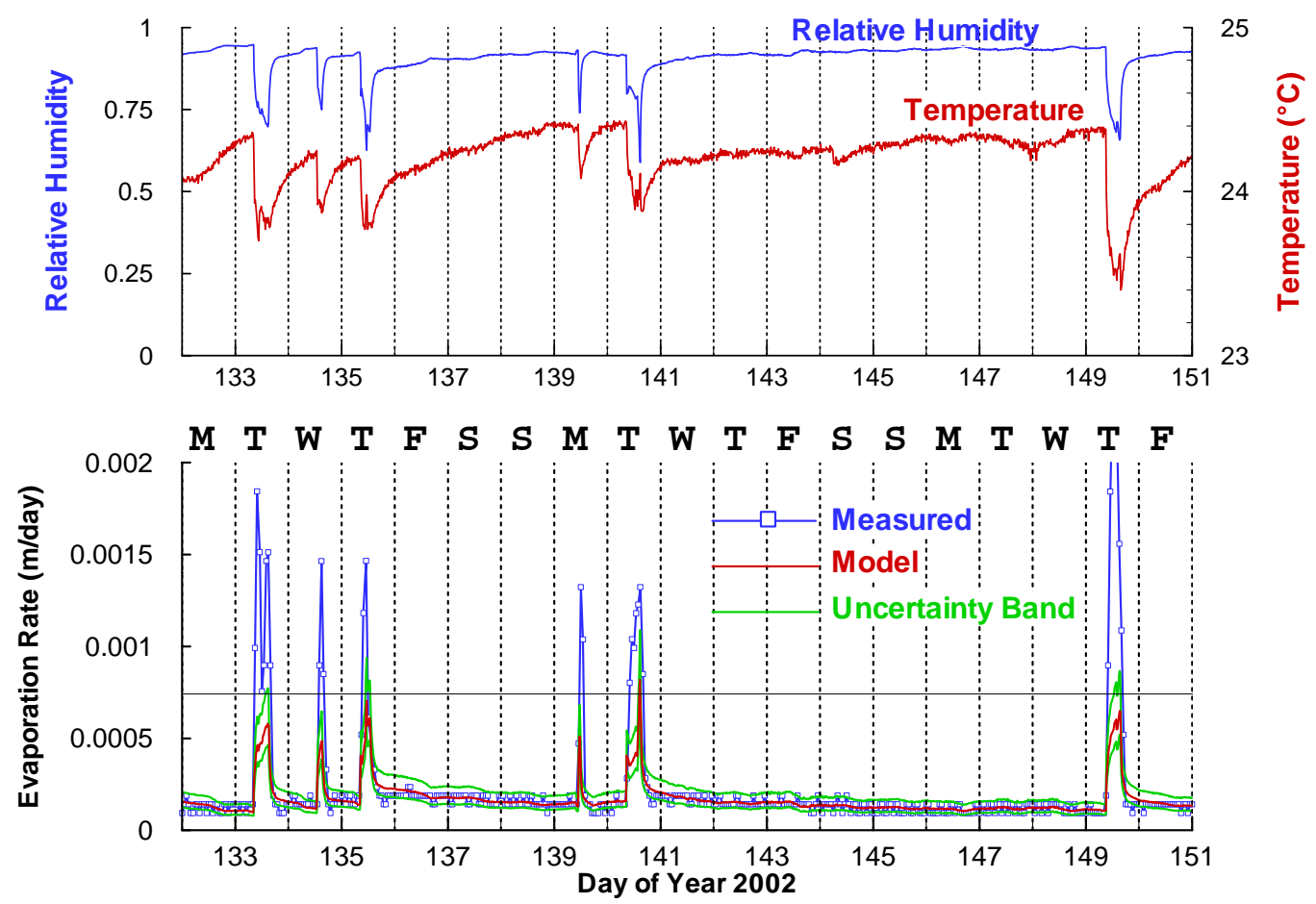

Source: DTN: LB0207NICH5LIQ.001 [DIRS 160408].

Figure 6-8. Relative Humidity, Temperature, and Measured and Fitted Evaporation Rates from Experiments Conducted inside Niche 5

The boundary-layer thickness was estimated by performing a least-squares fit of Eq. 6-11 to the evaporation data (Wang 2003 [DIRS 161456], SN-LBNL-SCI-223-V1, pp. 22-25); the estimated values are listed in Table 6-6.

Table 6-6. Boundary-Layer Thickness Estimated Using Eq. 6-11 and Relative Humidity, Temperature, and the Evaporation Data from a Free Water Surface

\begin{tabular}{|l|c|c|}
\hline \multicolumn{1}{|c|}{ Location of Evaporation Experiment } & $\begin{array}{c}\text { Boundary-layer } \\
\text { thickness (mm) }\end{array}$ & $\begin{array}{c}\text { Used For Simulation of } \\
\text { Liquid-Release Tests in... }\end{array}$ \\
\hline Inside Niche 5 & 20.0 & Niche 5 (Niche 1620) \\
\hline Outside Niche 5, Weekdays (ventilation on) & 5.0 & ECRB (no end curtains) \\
\hline Outside Niche 5 Weekends (ventilation off) & 7.5 & ECRB (with end curtains) \\
\hline
\end{tabular}

Output DTNS: LB0302SCMREV02.002, LB0302SCMREV02.001.

NOTE: $\quad$ See Figure 6-7 and Figure 6-8 for relative humidity, temperature, and evaporation data.

$\mathrm{ECRB}=$ enhanced characterization of repository block

An evaporative boundary-layer thickness $\delta=0.02 \mathrm{~m}$ was used for the simulation of liquid-release tests in Niche 5. Some of the liquid-release tests performed in the open drift of the ECRB Cross-Drift were exposed to ventilation; a boundary-layer thickness $\delta=0.005 \mathrm{~m}$ was used for these simulations. In more recent tests, additional curtains were installed at the two ends of the V-shaped seepage capture curtains to reduce air circulation and thus partly protect the seepage section of the drift from ventilation effects; a boundary-layer thickness $\delta=0.0075 \mathrm{~m}$ was used for these simulations. 


\subsubsection{Summary Description of Inverse Modeling Methodology}

The inverse modeling approach follows the concept described by Carrera and Neuman ["Estimation of Aquifer Parameters Under Transient and Steady State Conditions" (1986 [DIRS 104368])] and Finsterle [iTOUGH2 User's Guide (1999 [DIRS 104367])]. It is based on the classical weighted least-squares method, which consists of minimizing the objective function

$$
S=\mathbf{r}^{T} \mathbf{C}_{z z}^{-1} \mathbf{r}
$$

The residual vector $\mathbf{r}$ contains the differences between the measured seepage rate, $z^{*}$, and the corresponding model prediction, $z(\mathbf{p})$, which is a function of the unknown, $n$-dimensional parameter vector $\mathbf{p}$, i.e., $r_{i}=\left(z_{i}^{*}-z(\mathbf{p})_{i}\right), i=1 \ldots m$, where $m$ is the number of calibration points. The inverse of the covariance matrix $\mathbf{C}_{z z}$, which holds the expected variances of the final residuals on its diagonal, is used as a weighting matrix. The objective function is a measure of the misfit between the model output and the measured data. The objective function is automatically minimized using the Levenberg-Marquardt algorithm implemented in iTOUGH2 V5.0 (Finsterle 1999 [DIRS 104367], Section 2.7.4).

The covariance matrix of the estimated parameters is asymptotically given by:

$$
\mathbf{C}_{p p}=s_{0}^{2}\left(\mathbf{J}^{T} \mathbf{C}_{z z}^{-1} \mathbf{J}\right)^{-1}
$$

where $\mathbf{J}$ is an $m \times n$ Jacobian matrix holding the partial derivatives of the predicted seepage with respect to the unknown parameters, $J_{i j}=\partial z_{i} / \partial p_{j}$, and $s_{0}^{2}$ is the estimated error variance, which represents the variance of the mean weighted residual; it is an aggregate measure of goodness-of-fit:

$$
s_{0}^{2}=\frac{\mathbf{r}^{T} \mathbf{C}_{z z}^{-1} \mathbf{r}}{m-n}
$$

The impact of parameter uncertainty (expressed through matrix $\mathbf{C}_{p p}$ ) on model predictions can be evaluated by means of first-order-second-moment uncertainty propagation analysis. The covariance matrix of the model prediction, $\mathbf{C}_{\hat{z} \hat{z}}$, is calculated based on a linearity and normality assumption using

$$
\mathbf{C}_{\hat{z} \hat{z}}=\mathbf{J C}_{p p} \mathbf{J}^{T}
$$

The inverse modeling methodology and its numerical implementation are described in detail in the iTOUGH2 software documentation, specifically Finsterle (1999 [DIRS 104367], Section 2).

\subsubsection{Development of Forward Model}

The numerical model constructed to simulate liquid-release tests and seepage into the underground openings is referred to as the forward model. Different forward models were created for the different test locations and liquid-release events. During the inversion, the seepage rates calculated by the forward model are compared to the measured seepage rates at discrete points in time. (If the calibration time does not coincide with a data collection time, the comparison occurs against a value linearly interpolated between the measurements). The discrepancies between the two rates are then used to automatically update the input parameters of 
the forward model. The solution to both the forward and inverse problem is calculated by iTOUGH2 V4.0 (LBNL 1999 [DIRS 139918]) and V5.0 (LBNL 2002 [DIRS 160106]).

\subsubsection{Generation of Permeability Field}

Air-injection tests performed in borehole intervals at the experimental sites were used to estimate effective permeabilities (see Section 6.5.2, Table 6-4). The spatial structure of the permeability data was analyzed, and the resulting geostatistical parameters were used to generate spatially correlated permeability fields (for details, see Appendix C, Appendix D, and Appendix E). For seepage models representing the lower lithophysal zone, multiple realizations of the permeability field were simulated by changing the seed number of the random-number generator of the software SISIM V1.203 (LBNL 1999 [DIRS 134136]) and V1.204 (LBNL 2000 [DIRS 153100]) (see Figure C-5). To reduce the computational burden, only one permeability field is produced and examined for each of the niches in the middle nonlithophysal unit, which hosts a significantly smaller fraction of the repository. The permeability fields were eventually mapped onto the numerical grid (see Section 6.6.2.2). The support scale of the air-permeability data (see Section 6.5.2) is appropriately consistent with the gridblock size (see Section 6.6.2.2).

The GSLIB modules GAMV2 V1.201 (LBNL 1999 [DIRS 134139]) and GAMV3 V1.201 (LBNL 2000 [DIRS 153099]) were used to analyze spatial correlation of, respectively, two-dimensional and three-dimensional, irregularly spaced, log-transformed air-permeability data. Sequential indicator simulation [GSLIB Geostatistical Software Library and User's Guide (Deutsch and Journel 1992 [DIRS 100567], p. 151)] as implemented in the GSLIB modules SISIM V1.203 (LBNL 1999 [DIRS 134136]) and V1.204 (LBNL 2000 [DIRS 153100]) was used to generate spatially correlated, random fields of log-transformed permeability modifiers (see Figure C-2).

\section{Borehole SYBT-ECRB-LA\#2, Lower Lithophysal Zone}

Six air-injection tests were performed in $6 \mathrm{ft}$ (approximately $1.8 \mathrm{~m}$ ) long intervals of borehole SYBT-ECRB-LA\#2 (DTN: LB00090012213U.001 [DIRS 153141]), providing an estimate of mean log-permeability at the experimental site of -10.73 (corresponding to a permeability of $1.86 \times 10^{-11} \mathrm{~m}^{2}$ ) with a standard deviation of 0.21 (see Table 6-4). Variability in permeability on the scale of a gridblock (which is $1 \mathrm{ft}$ long) is expected to be higher than the standard deviation reported in Table 6-4. For generating a heterogeneous field, permeability is taken to be log-normally distributed with a standard deviation of one order of magnitude. The number of data points was insufficient to reveal the spatial correlation structure of the permeability field. A weak spatial correlation with a correlation length of $0.2 \mathrm{~m}$ was prescribed (consistent with the geostatistical results from air-permeability data in the middle nonlithophysal zone, see below). Multiple realizations of the permeability field were generated.

\section{Niche 5, Lower Lithophysal Zone}

A total of 61 air-injection tests were conducted in three boreholes (boreholes \#2, \#3, and \#5) above Niche 5 (DTN: LB0110AKN5POST.001 [DIRS 156904]). The length of the injection interval was $1 \mathrm{ft}$. The mean and standard deviation of the log-transformed permeability values 
are provided in Table 6-4. The permeability values are approximately log-normally distributed as shown in Figure 6-9.

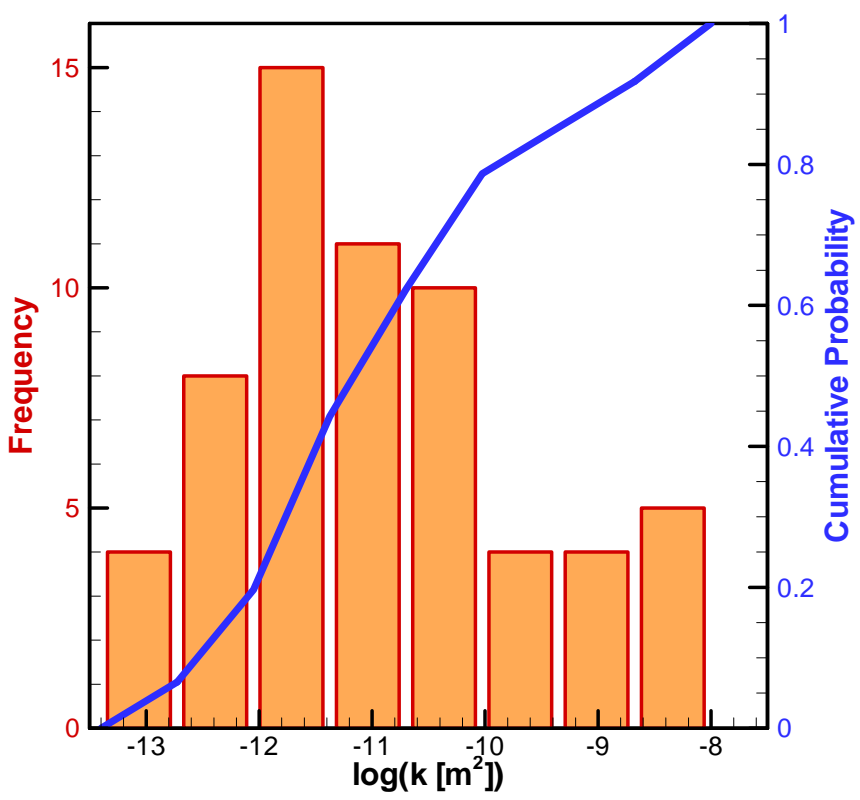

Source: Permeability data from DTN: LB0110AKN5POST.001 [DIRS 156904].

Output: Histogram and cumulative probability distribution in output DTN: LB0302SCMREV02.001.

Figure 6-9. Cumulative Frequency Distribution of the Log-Transformed Permeability Values and Corresponding Cumulative Normal Probability Density Function for Niche 5

The post-excavation air-permeability data were geostatistically analyzed using the software GAMV3 V1.201 (LBNL 2000 [DIRS 153099]) to calculate the empirical semivariogram specific to Niche 5. The nugget effect, correlation length, and sill values were determined by fitting a spherical semivariogram (Deutsch and Journel 1992 [DIRS 100567], p. 23) to the empirical semivariogram (Wang 2003 [DIRS 161456], SN-LBNL-SCI-223-V1, p. 16). Figure 6-10 shows the empirical semivariogram and corresponding theoretical spherical semivariogram of Niche 5. The geostatistical parameters are provided in Table 6-7 below. The generated spatially correlated permeability field is conditioned on the measured post-excavation air-permeability data as shown in Figure 6-11. The stochastic simulation approach may generate permeability values that are considerably different from those at the neighboring conditioning points, i.e., the field is more heterogeneous than one created by means of an interpolation technique. Multiple realizations were generated. 


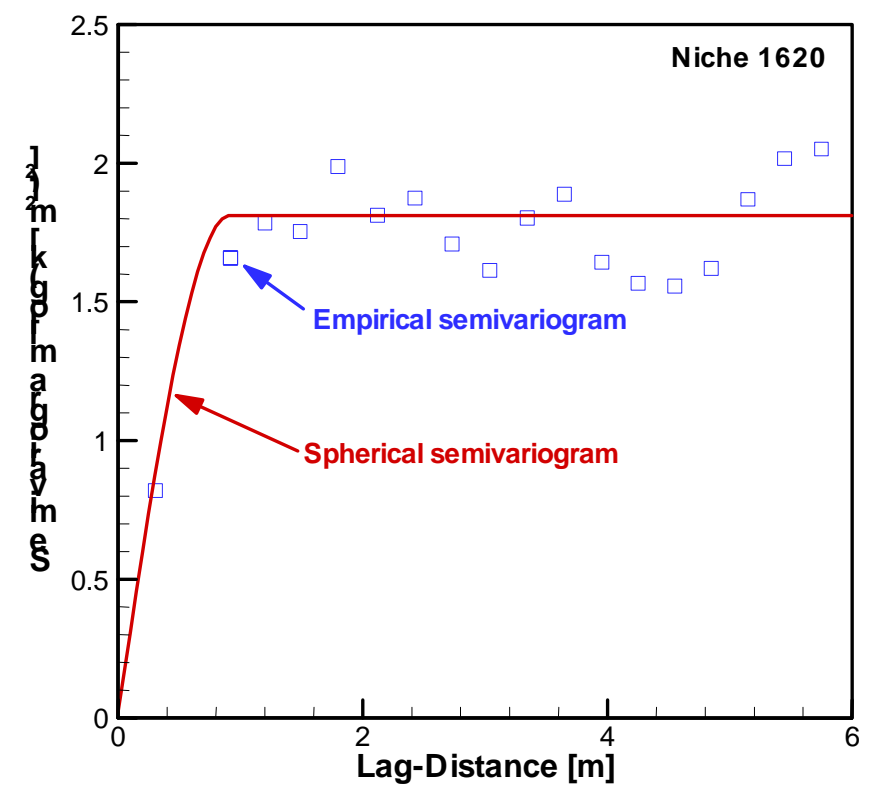

Source: Permeability data from DTN: LB0110AKN5POST.001 [DIRS 156904].

Output: Semivariogram in output DTN: LB0302SCMREV02.001.

NOTE: $\quad$ See Table 6-7 for geostatistical parameters of the spherical semivariogram model.

Figure 6-10. Empirical Post-Excavation Air-Permeability Semivariograms and Spherical Semivariogram Model for Niche 5

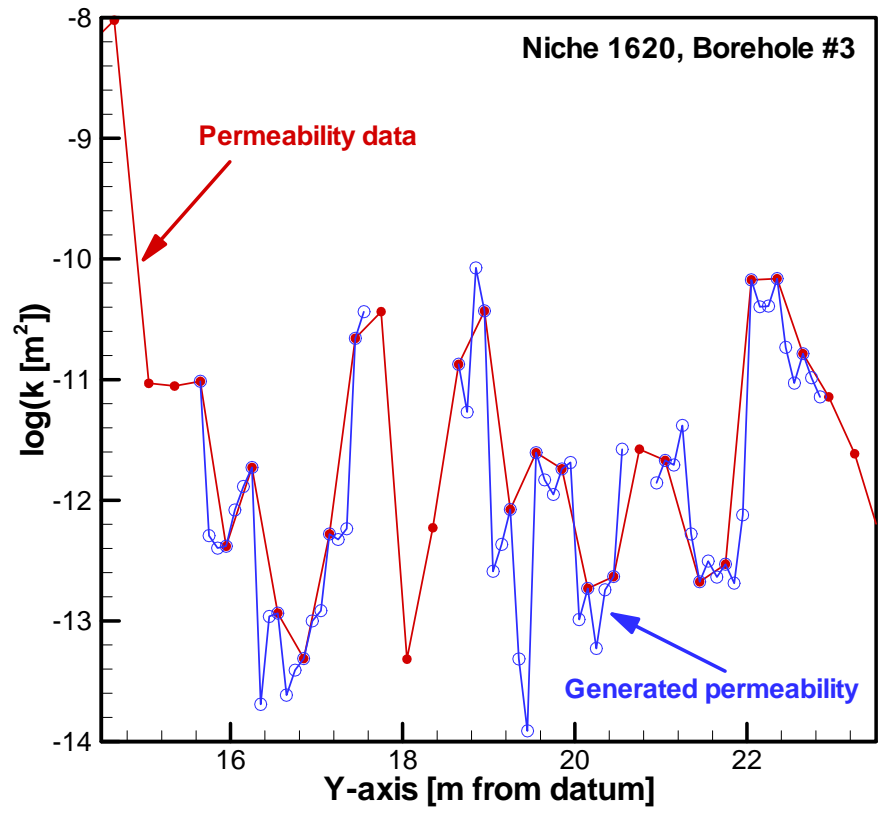

Source: Permeability data from DTN: LB0110AKN5POST.001 [DIRS 156904].

Output: Generated permeabilities in output DTN: LB0302SCMREV02.001.

Figure 6-11. Post-Excavation Permeability Data of Niche 5, Borehole \#3 and the Corresponding Generated Permeability Values from One Representative Realization, which Honors the Measured Data 
Niches 2, 3, and 4, Middle Nonlithophysal Zone

A total of 225 air-injection tests were performed in 10 boreholes above Niche 2 (DTN: LB0011AIRKTEST.001 [DIRS 153155]), Niche 3 (DTN: LB990601233124.001 [DIRS 105888]), and Niche 4 (DTN: LB990601233124.001 [DIRS 105888]). The mean, standard deviation, and number of air-permeability data for each niche are shown in Table 6-4.

For Niche 2, the software GAMV2 V1.201 (LBNL 1999 [DIRS 134139]) was used to calculate the empirical semivariogram, given that all intervals in boreholes UL, UM, and UR lie within a two-dimensional plane. The appropriateness of this presumption was confirmed by surveyed borehole alignments for Niche 2 (DTN: MO0002GSC00076.000 [DIRS 152623]). For Niches 3 and 4, the software GAMV3 V1.201 (LBNL 2000 [DIRS 153099]) was used to calculate the empirical semivariogram. The three-dimensional coordinates of the permeability data were taken from the detailed borehole alignment surveys (DTN: MO0002GSC00064.000 [DIRS 152625] and DTN: MO0107GSC01069.000 [DIRS 156941]).

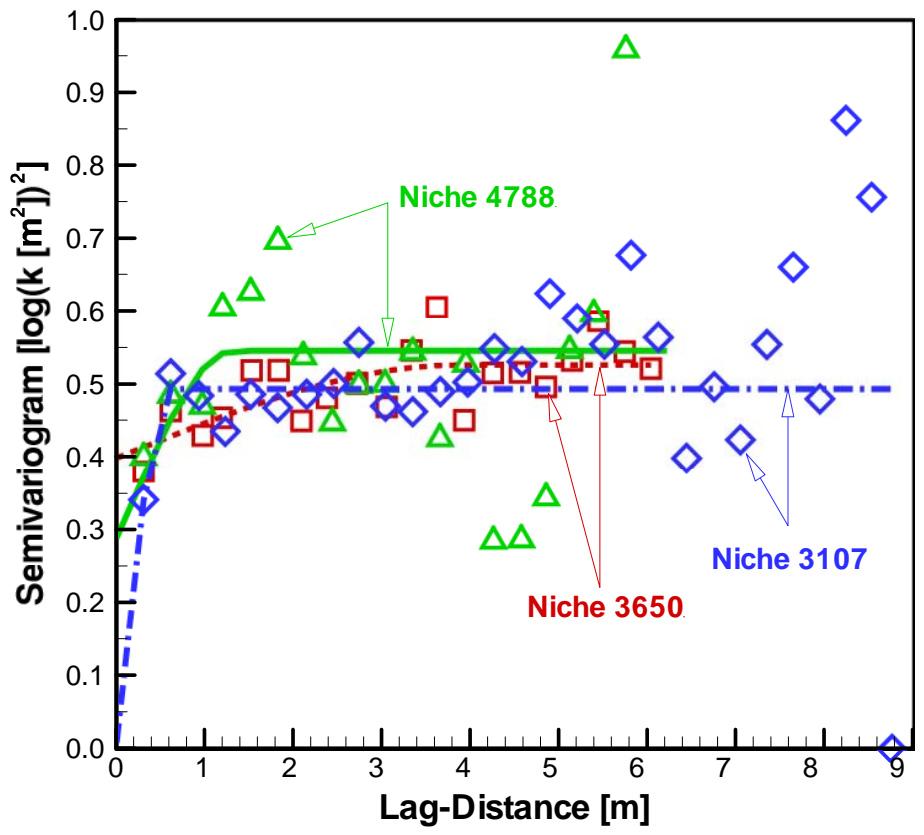

Source: Permeability data from DTN: LB990601233124.001 [DIRS 105888] and DTN: LB0011AIRKTEST.001 [DIRS 153155].

Output: Semivariograms in output DTN: LB0010SCMREV01.001.

NOTE: See Table 6-7 for geostatistical parameters of the spherical semivariogram models.

Figure 6-12. Empirical Post-Excavation Air-Permeability Semivariograms and Fitted Spherical Semivariogram Models for Niches 2, 3, and 4

Spherical semivariogram models (Deutsch and Journel 1992 [DIRS 100567], p. 23) with the geostatistical parameters shown in Table 6-7 are used to represent the empirical log-permeability semivariograms. The empirical semivariograms (symbols) and the corresponding spherical semivariogram models (lines) are shown in Figure 6-12. Note that the relatively large correlation length obtained for Niche 2 should not be misinterpreted as suggesting that the 
permeability field is strongly correlated. All three semivariograms shown in Figure 6-12 exhibit either a short correlation length (i.e., on the order of 1 meter or less) or a nugget effect that is close to the sill value. It can therefore be concluded that the permeability is random without a noticeable or significant spatial correlation. No nugget effect is evident for the Niche 3 data, resulting in a permeability field that is slightly spatially correlated (see Figure 6-16c below).

Table 6-7. Geostatistical Parameters of Spherical Semivariogram Models

\begin{tabular}{|l|c|c|c|}
\hline Niche & $\begin{array}{c}\text { Nugget effect } \\
{\left[\log (\mathbf{k})^{2}\right]}\end{array}$ & $\begin{array}{c}\text { Correlation length } \\
{[\mathbf{m}]}\end{array}$ & $\begin{array}{c}\text { Sill value } \\
{\left[\log (\mathbf{k})^{2}\right]}\end{array}$ \\
\hline Niche 2 & 0.40 & 3.87 & 0.53 \\
\hline Niche 3 & 0.01 & 0.61 & 0.49 \\
\hline Niche 4 & 0.29 & 1.31 & 0.55 \\
\hline Niche 5 & 0.02 & 0.91 & 1.81 \\
\hline
\end{tabular}

Output DTN: LB0302SCMREV02.002.

The spherical semivariogram models, along with the cumulative distribution functions shown in Figure 6-13, are used as input to the software SISIM V1.203 (LBNL 1999 [DIRS 134136]) for Niches 3 and 4; the software SISIM V1.204 (LBNL 2000 [DIRS 153100]) is used for Niche 2. The random permeability field is conditioned on the measured post-excavation air-permeability data. For Niches 3 and 4, coordinates are added to the permeability field using software AddCoord V1.0 (LBNL 2000 [DIRS 152814]). The resulting permeability fields are mapped onto the numerical grid of the SCM for each of the niches, as described below in Section 6.6.2.2. Only one permeability field is produced for the niches in the middle nonlithophysal unit. The generation of permeability fields is documented in Scientific Notebooks Finsterle (1999 [DIRS 153448], p. 139) and Ahlers (2002 [DIRS 161045], pp. 13, 15-19, 21, 39-40, 58).

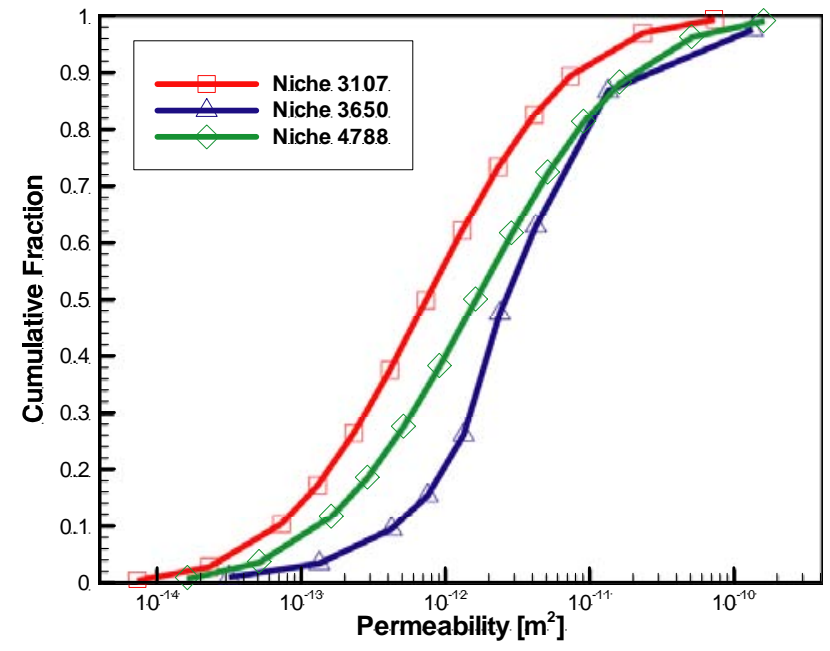

Source: Permeability data from DTN: LB990601233124.001 [DIRS 105888] and DTN: LB0011AIRKTEST.001 [DIRS 153155].

Output: Cumulative distribution function in output DTN: LB0010SCMREV01.001.

Figure 6-13. Cumulative Distribution Functions of Air Permeabilities for Niches 2, 3, and 4 


\subsubsection{Mesh Generation}

Three-dimensional meshes of a section of the ECRB Cross-Drift and Niches 2, 3, 4, and 5 were created in several steps. The following general steps were followed for all the meshes. Detailed and specific descriptions pertaining to the Cross-Drift and different niches are provided in Appendix C, Appendix D, and Appendix E.

1. A primary 3-D mesh is generated, consisting of regular gridblocks. The Y-axis is aligned with the drift or niche axis.

2. Constants are added to the coordinates of the primary mesh using software MoveMesh V1.0 (LBNL 2000 [DIRS 152824]) to shift the origin of the mesh to an appropriate datum.

3. A random, spatially correlated field of log-permeability modifiers is generated using software SISIM V1.203 and SISIM V1.204 (LBNL 1999 [DIRS 134136]; LBNL 2000 [DIRS 153100]) as described in Section 6.6.2.1. Multiple realizations are created for locations in the lower lithophysal zone.

4. The heterogeneous field of log-permeability modifiers is mapped onto the mesh using software Perm2Mesh V1.0 (LBNL 2000 [DIRS 152826]).

5. For the tests in the ECRB Cross-Drift, a cylindrical drift is cut from the primary mesh using the software CutDrift V1.0 (LBNL 2000 [DIRS 152816]); for Niche 2, a smooth niche is cut using software CutNiche V1.3 (LBNL 2000 [DIRS 152828]); for Niches 3,4 , and 5, an irregularly shaped niche is cut using the software CutNiche V1.2 (LBNL 2000 [DIRS 152815]).

6. Software AddBound V1.0 (LBNL 2000 [DIRS 152823]) is used to attach boundary elements at the top and bottom of the model domain. The bottom boundary gridblock is assigned to a special material domain to allow specifying a free-drainage boundary condition.

7. Gridblocks along the boreholes are modified to represent the injection intervals. For the inclined boreholes in the ECRB Cross-Drift, software AddBorehole V1.0 (LBNL 2000 [DIRS 152822]) was used for this task.

8. The drift or niche gridblocks are assigned a large volume so that Dirichlet boundary conditions can be specified. Flux into these gridblocks represents seepage. 
9. For the tests in the ECRB Cross-Drift and Niche 5, evaporation gridblocks are added and connected to the same formation elements as the drift and niche gridblocks, respectively. The nodal distance from the formation gridblocks to the evaporation gridblocks is set to the diffusive boundary-layer thickness (see Table 6-6). Flux into these elements represents evaporation.

10. A single time step is performed using a generic TOUGH2 input onestep file (as input to iTOUGH2 V4.0 or V5.0; see Figure C-4) to test the mesh and to obtain cross-referencing information.

Typical meshes created for the simulation of liquid-release tests in the ECRB Cross-Drift, Niche 5, and Niches 2, 3, and 4 are shown in Figure 6-14, Figure 6-15, and Figure 6-16, respectively. Only half of the ECRB Cross-Drift is simulated because of geometrical symmetry (see Figure 6-14). Consequentially, the heterogeneous permeability field is also symmetric. Given the small correlation length and thus local impact of heterogeneity on flow, the artifact of having a symmetric field is not expected to affect the seepage behavior significantly.

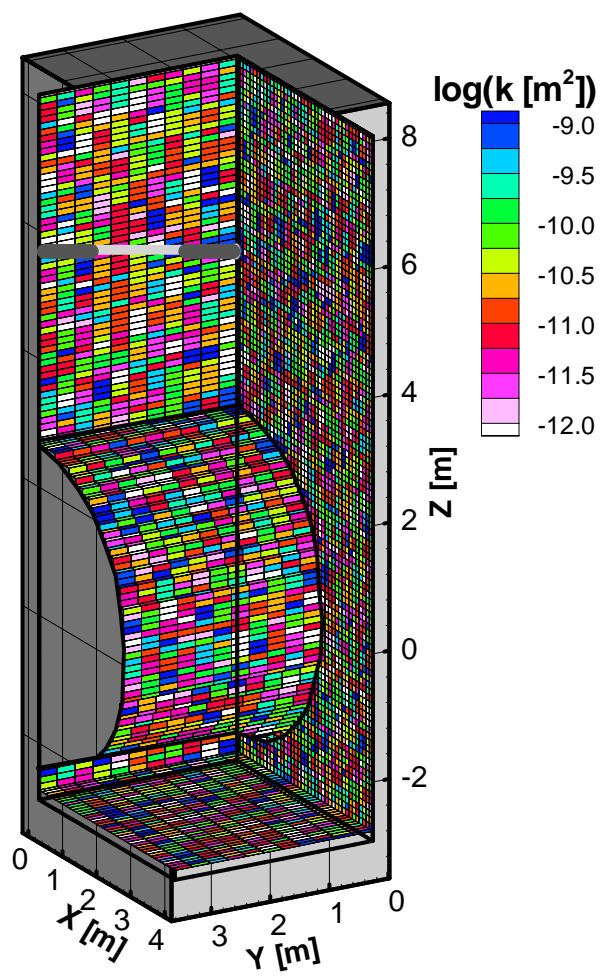

Output DTN: LB0302SCMREV02.001.

NOTE: Only half of the drift is simulated because of symmetry. The vertical position of the injection interval (indicated as an inclined gray line at an elevation of approximately $6 \mathrm{~m}$ ) is appropriately adjusted for the simulation of seepage experiments conducted in other test zones. Multiple realizations of the permeability field were generated.

Figure 6-14. Numerical Grid with one Realization of the Permeability Field Used for the Simulation of Liquid-Release Tests Conducted in Zone 2 of Borehole SYBT-ECRB-LA\#2 

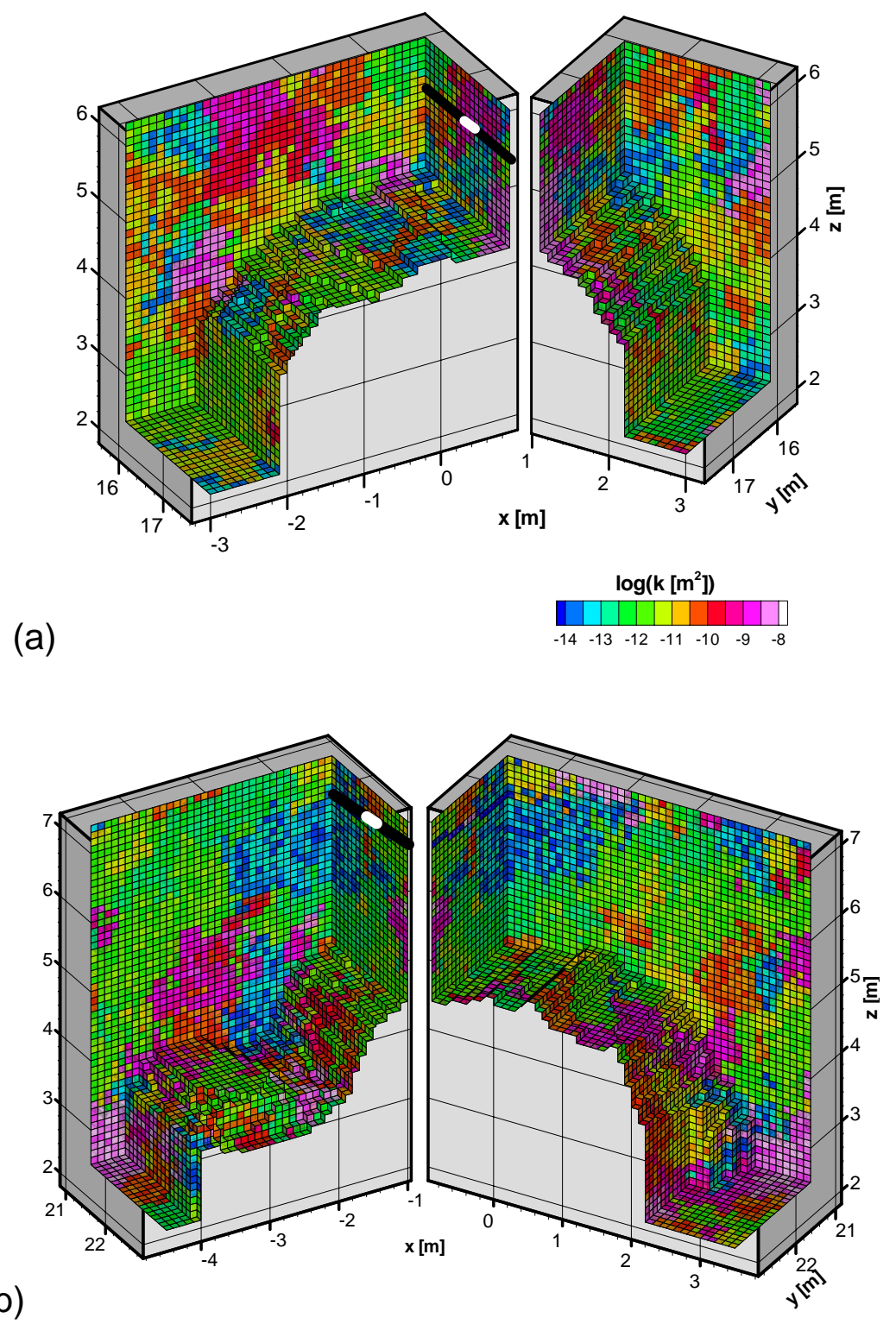

(b)

Output DTN: LB0302SCMREV02.001.

NOTE: (a) Borehole \#4, (b) Borehole \#5. In this visualization, the meshes are split into two parts to expose the boreholes (indicated by thick black lines) and the injection interval (thick white lines). Multiple realizations of the permeability field were generated. Note the rough ceilings as well as the left slot (for $X<\sim 2.5 \mathrm{~m}$ ) of Mesh (b).

Figure 6-15. Numerical Grid with one Realization of the Permeability Field Used for the Simulation of Liquid-Release Tests Conducted in Niche 5 
(a)

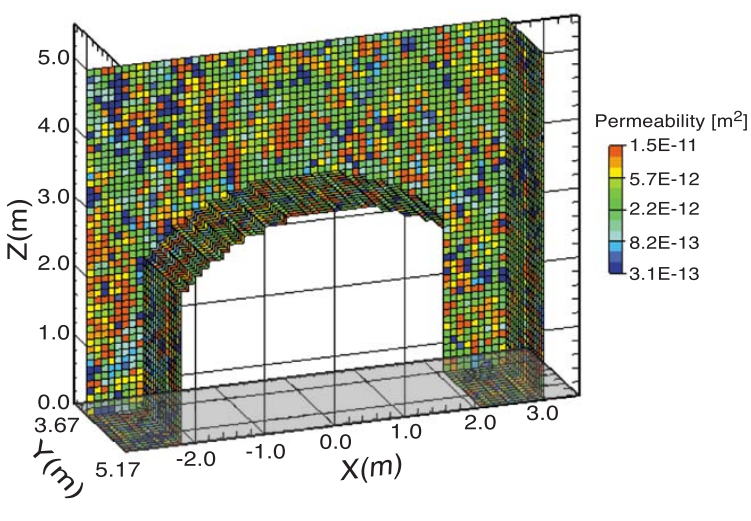

(c)

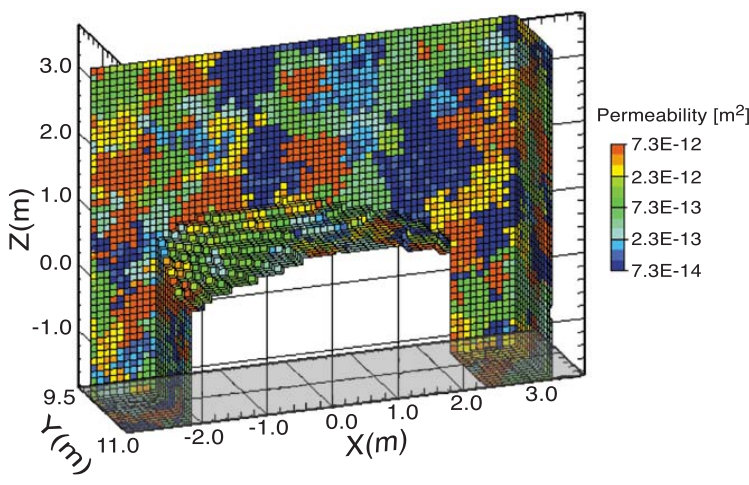

(b)

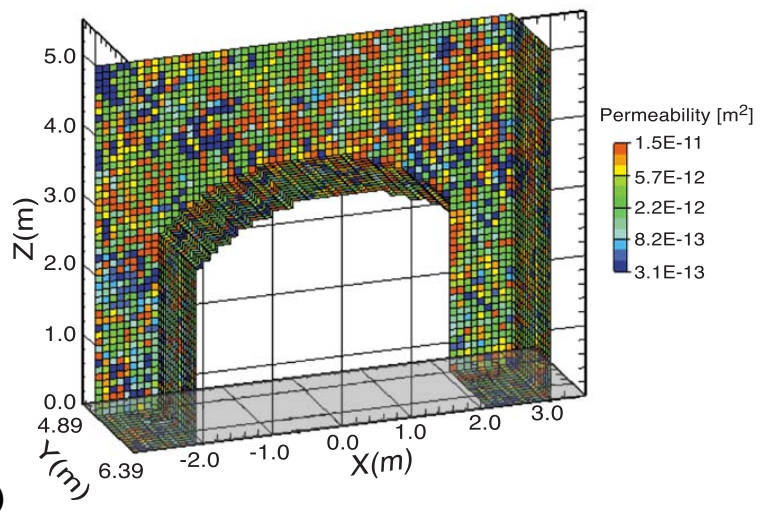

(d)

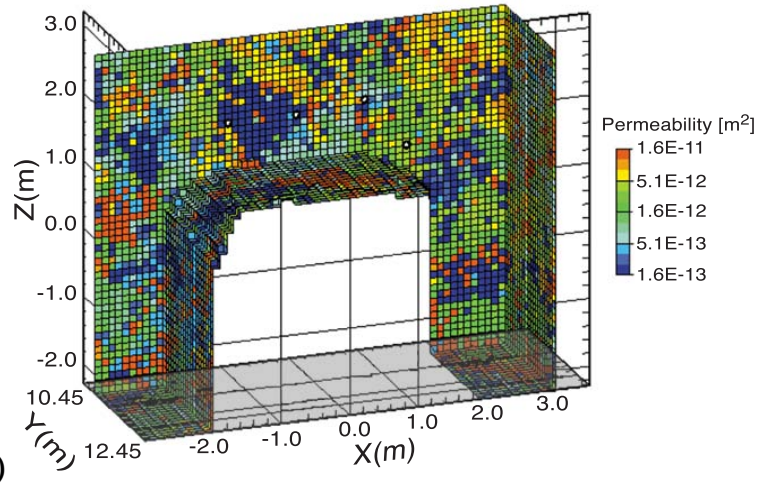

Output DTN: LB0010SCMREV01.001.

NOTE: (a) Niche 2, centered $4.42 \mathrm{~m}$ from the collar of borehole UM, (b) Niche 2, centered $5.64 \mathrm{~m}$ from the collar of borehole UM, (c) Niche 3, and (d) Niche 4. Note that the meshes are shown from an angle below horizontal to display the ceiling roughness incorporated into Meshes (c) and (d).

Figure 6-16. Computational Meshes and Permeability Field for 3-D Seepage Calibration Model Used for the Analysis of Seepage Data

\subsubsection{Boundary Conditions}

No-flow boundary conditions are specified at the left, right, front, and back sides of the model. A free-drainage boundary condition [iTOUGH2 Verification and Validation Report (Finsterle 1998 [DIRS 103783], pp. 14-15)] is applied at the bottom to prevent an unphysical capillary boundary effect. Elements representing large openings (i.e., borehole intervals, drift sections, or niches) are assigned a zero-capillary pressure independent of saturation. The evaporation elements are set at a capillary pressure equivalent to the prevailing relative humidity $h$ according to Kelvin's equation,

$$
p_{c}=-\frac{R T}{M_{w}} \rho_{w} \ln (h)
$$

as discussed in Section 6.6.1.3. Water is allowed to enter, but prevented from exiting the drift or niche. 
A constant flux boundary condition is applied at the top of the model to represent background percolation. The percolation flux at the experimental site is taken from the UZ Model (DTN: LB990801233129.003 [DIRS 122757]). (Note that slight changes in the calculated percolation flux as a result of future revisions of the UZ Model will not impact the estimates and conclusions presented in this Model Report). Software ECRB-XYZ V.03 (CRWMS M\&O 1999 [DIRS 147402]) is used to calculate the coordinates of Cross-Drift construction station CS 1726 (Hinds 2001 [DIRS 155955], p. 124). The gridblock closest to these coordinates and those of Niches 2, 3, and 4 are identified from the UZ Model mesh file (DTN: LB990701233129.001 [DIRS 106785]), and the corresponding percolation flux for the present-day, mean infiltration scenario is extracted from the UZ Model output file (DTN: LB990801233129.003 [DIRS 122757]) (Ahlers 2002 [DIRS 161045], pp. 29-31, 45, 55).

The calculated percolation flux of approximately $13.6 \mathrm{~mm} / \mathrm{year}$ is injected into a single boundary element connected to all gridblocks across the top of the ECRB Cross-Drift and Niche 5 model domains. Percolation fluxes of approximately $2.80 \mathrm{~mm} /$ year for Niche 2, $2.54 \mathrm{~mm} /$ year for Niche 3, and $2.02 \mathrm{~mm} /$ year for Niche 4 are injected at the top of the respective model domains. Niche 5 and the tested section of the ECRB Cross-Drift are closer to the high-infiltration zone near the crest of Yucca Mountain, explaining the higher percolation fluxes at these locations compared to the fluxes for the niches in the ESF. Note that the inflow into the model is non-uniform as a result of the heterogeneity in the permeability field.

As evident from Figure 6-18 below, the average background percolation flux is significantly less than the local flux induced by releasing water from the injection intervals. The impact of the background percolation flux on simulated seepage rates is thus very limited.

For the simulation of liquid-release tests, release rates and test durations are determined for each event shown in Table 6-5 and applied to the gridblocks representing the injection interval (Ahlers 2002 [DIRS 161045], pp. 8-10, 34-35, 47; Finsterle 2002 [DIRS 161043], p. 57; Wang 2003 [DIRS 161456], SN-LBNL-SCI-228-V1, pp. 16-17, 19-20).

\subsubsection{Initial Conditions}

The initial saturation distribution is calculated from the steady-state flow field obtained for background percolation, followed by a simulation of reduced relative humidity, which creates a dry-out zone around the ventilated opening (Niche 5 and ECRB Cross-Drift only).

The initial saturation distribution in the fracture continuum is generally low but nonuniform. Initial saturation is not expected to have a significant impact on simulation results. The variability in the initial saturation distribution is a result of formation heterogeneities and the presence of the underground opening and a dry-out zone (if evaporation is simulated). Since the steady-state flow field changes if the input parameters are updated during the inversion, a steady-state run precedes each transient liquid-release test simulation performed as part of the inversion process.

Details about the steady-state simulations performed to create initial conditions for the subsequent simulation of liquid-release tests can be found in Appendix G. 


\subsubsection{Inversion}

The software iTOUGH2 V4.0 (LBNL 1999 [DIRS 139918]) and V5.0 (LBNL 2002 [DIRS 160106]) was used to automatically calibrate the forward models against seepage-rate data. The iTOUGH2 V5.0 (LBNL 2002 [DIRS 160106]) program was used for calibrating liquid-release tests performed in the lower lithophysal zone (Tptpll; Niche 5 and systematic seepage testing in the ECRB Cross-Drift); these models include evaporation effects (see Sections 6.3.3.4, and 6.6.1.3). The iTOUGH2 V4.0 (LBNL 1999 [DIRS 139918]) program was used for the analysis of tests conducted in closed-off Niches 3 and 4 located in the middle nonlithophysal zone (Tptpmn), where evaporation was significantly reduced and thus not considered (see Sections 6.3.3.4 and 6.7). The parameters and data selected for model calibration are described below in Sections 6.6.3.1 and 6.6.3.2, respectively. The results of the inversions are discussed in Section 6.6.3.3.

\subsubsection{Parameter Selection}

Inverse modeling requires selecting one or more parameters that are considered unknown or uncertain and that are to be adjusted to match the model calculations to the observed data. All the other input parameters to the numerical model, including model-domain geometry as well as initial and boundary conditions, are fixed during the inversion and are thus by definition part of the model structure. The estimated parameters are optimal for and depend on this model structure.

The selection of the parameter to be estimated can be based on (1) the physical understanding of the system behavior as it relates to the observed data, (2) a sensitivity analysis, or (3) a synthetic inversion using a derivative-based algorithm, which reveals both the sensitivity coefficients and parameter correlations. In the first step, the parameters most likely to affect seepage rates are selected, based on the understanding of the physical system behavior. Subsequently, these parameters are subjected to a synthetic inversion to identify the most sensitive parameters and their correlation structure. Finally, a selection of the parameters to be estimated is made based on their overall sensitivity, relative independence, and the availability and reliability of prior knowledge.

The seepage process and impact of parameterized hydrogeologic properties on seepage rates has been discussed in Section 6.3.3. To summarize, the seepage rates observed during liquid-release tests are most strongly affected by the following parameters:

1. Parameters of the capillary pressure function are expected to affect seepage rates because they determine the effectiveness of the capillary barrier. The two parameters of interest are the van Genuchten capillary-strength parameter $1 / \alpha$ and $m$, which is related to the pore size distribution index. Both parameters have been discussed in Section 6.6.1.1.

2. Effective permeability impacts the flow-diversion capability of the fractured formation and thus seepage rates. 
3. Porosity can be interpreted as an effective parameter capturing storage effects. Storage effects may be significant at early times, for short-duration experiments, and if only a small amount of water is injected (as in the liquid-release tests conducted in Niche 2).

A synthetic inversion (using the layout and test conditions of the liquid-release test conducted in zone 2 of borehole SYBT-ECRB-LA\#2) was conducted to determine the sensitivities and correlation structure of the four parameters $(1) \log (1 / \alpha)$, where $1 / \alpha[\mathrm{Pa}]$ is the van Genuchten capillary-strength parameter, (2) $n$ [dimensionless], which is related to the van Genuchten parameter $m$ by $n=1 /(1-m)$, (3) $\log (k)$, where $k\left[\mathrm{~m}^{2}\right]$ is the reference permeability of the heterogeneous permeability field, and $(4) \log (\phi)$, where $\phi$ [dimensionless] is the effective porosity. The residual liquid saturation (another parameter of the relative-permeability and capillary-pressure functions) is expected to be much less important as seepage is initiated near full saturation. A separate sensitivity study was performed to examine the impact of the evaporation boundary-layer thickness $\delta$ (see Section 6.6.1.4) on the estimated parameters. The key parameter $\log (1 / \alpha)$ was estimated using boundary-layer thicknesses of $0.50 \mathrm{~cm}, 0.75 \mathrm{~cm}$, and $2.00 \mathrm{~cm}$ (see Table 6-6).

The sensitivity measure reported below is the sum of the absolute values of the sensitivity coefficients, which is defined as the partial derivative of the calculated seepage rate with respect to the parameter of interest. The correlation coefficients are obtained from the parameter covariance matrix given by Eq. 6-14. Because the inverse problem is highly nonlinear, the results of this synthetic analysis depend on the a priori parameter values. The values used are sufficiently close to the best estimates obtained by the actual inversion, i.e., there is no need to repeat the sensitivity analysis after calibration. This analysis should be considered qualitative in nature.

The results from the synthetic inversion (Wang 2003 [DIRS 161456], SN-LBNL-SCI-228-V1, pp. 33, 35-36) and from the sensitivity analysis regarding the evaporation boundary-layer thickness (Wang 2003 [DIRS 161456], SN-LBNL-SCI-228-V1, pp. 24-25) can be summarized as follows:

1. The capillary-strength parameter $\log (1 / \alpha)$ has the largest impact on calculated seepage rates. Provided that $\log (1 / \alpha)$ tends to vary less than $\log (k)$, both parameters are about equally important for seepage predictions.

2. The two parameters, $\log (1 / \alpha)$ and $\log (k)$, are strongly negatively correlated, i.e., an increase in seepage rates by a reduction of $\log (1 / \alpha)$ can almost be completely compensated by an appropriate increase in $\log (k)$.

3. Overall, $\log (k)$ is the parameter most strongly correlated to all other parameters, i.e., permeability is difficult to estimate from seepage-rate data alone. Permeability should be derived from independent information; this independent information is available from the air-injection tests (see Section 6.5.2). 
4. The van Genuchten parameter $n$ (and thus $m$, see van Genuchten 1980 [DIRS 100610], Eq. [9]) is relatively insensitive and at the same time strongly correlated to all the other parameters.

5. Porosity is the least-sensitive parameter. However, since its impact is restricted to only a portion of the data (i.e., the onset of seepage and early-time seepage rates), it is the least-correlated parameter. If the available data are potentially influenced by storage effects (e.g., data from short-term liquid-release tests with small injection volumes), porosity could be included in the estimation process.

6. Changes in the evaporation boundary-layer thickness $\delta$ within the range considered have a limited impact on the estimated parameter $\log (1 / \alpha)$. Choosing a thin boundary layer of $0.75 \mathrm{~cm}$ (an estimate based on evaporation and relative-humidity data in an open drift section, see Section 6.6.1.4) leads to a relatively $\operatorname{low} \log (1 / \alpha)$ value, because reducing the boundary layer thickness increases evaporation and thus leads to a reduction in the calculated seepage rate, which is compensated for by reducing the capillary strength parameter.

The sensitivity analysis and correlation structure inferred from the synthetic inversion provides guidance for the final selection of parameters to be subjected to estimation by automatic model calibration.

The following decisions regarding parameter selection have been made:

1. As few parameters as possible should be selected to avoid overparameterization. If the observed seepage rates can be successfully reproduced by the calibrated model and the estimated model parameters can be considered reasonable, the relative parsimony of the model and the small number of adjustable parameters provides confidence that the physical processes governing seepage are appropriately represented by the model.

2. The capillary-strength parameter $\log (1 / \alpha)$ is selected as the primary target parameter to be estimated by calibrating the SCM against seepage-rate data from the liquid release tests. Capillarity is the main process behind the seepage exclusion phenomenon, as confirmed by the large sensitivity of the calculated seepage rate to changes in the key parameter of the capillary pressure-saturation relationship. The seepage-relevant capillary-strength parameter on the drift scale cannot be derived from standard laboratory or field measurements, or inferred from secondary information (such as fracture trace maps and aperture measurements). The parameter is suitable for the inclusion of a number of small-scale features and effects (such as surface roughness, film flow, drop detachment), and even numerical artifacts, such as increased seepage induced by discretization effects. It is important to realize that all the effects lumped into the $\log (1 / \alpha)$ parameter are related or analogous to a capillarity effect, justifying the approach.

3. Permeability as the second important parameter affecting drift seepage is not estimated from seepage-rate data, but is taken from and conditioned on the air-permeability data. Fixing permeability at values that are determined independently from seepage-rate 
data is a reasonable means to resolve the non-uniqueness issue that arises from the strong correlation of permeability to all the other parameters. The support scale of the air-permeability data is consistent with that of the numerical grid. It allows determination and inclusion of heterogeneity into the model, which is an important feature affecting seepage. The stochastic nature and uncertainty in the heterogeneous permeability field is accounted for by performing multiple inversions using different realizations of the simulated permeability field.

4. Porosity is used as an effective parameter to capture storage effects. Porosity is only estimated in those liquid-release tests that involved little water, and where evaporation effects (which have an impact similar to increased storage) are not explicitly accounted for, affecting the early-time seepage-rate data. The analysis of liquid-release tests performed in the middle nonlithophysal zone (Niches 3 and 4) include the estimation of porosity; the tests conducted in the lower lithophysal zone (Niche 5 and systematic seepage testing area in the ECRB Cross-Drift) use a fixed value for porosity of 0.96 percent (DTN: LB0205REVUZPRP.001 [DIRS 159525]) and include only the estimation of $\log (1 / \alpha)$. Note that the estimated porosity value does not affect the subsequent prediction of steady-state seepage into waste emplacement drifts. It is only determined here to avoid an unwanted bias in the concurrently estimated $\log (1 / \alpha)$ parameter, to which it is negatively correlated.

5. All other parameters are fixed at the values given in Table 4-2. They become part of the model structure along with boundary and initial conditions (see Sections 6.6.2.3 and 6.6.2.4, respectively), and spatial discretization (specifically the length of the nodal distance to the drift element, see Sections 6.3.3.3, 6.6.1.2, and Point 0 of Section 8.4). Since the estimated parameters are likely to be correlated to these fixed parameters and would change if the model structure were modified, the estimated values are to be considered model-related.

In summary, the logarithm of the capillary-strength parameter $1 / \alpha$, which enters the van Genuchten capillary-pressure function (see Eq. 6-5), is estimated as an effective, seepage relevant, model-related parameter through automatic calibration of the SCM against seepage-rate data from liquid-release tests. For tests conducted in the middle nonlithophysal zone, porosity is also determined to be an effective parameter, accounting for storage effects.

\subsubsection{Data Selection}

As described in the report In Situ Field Testing of Processes (BSC 2004 [DIRS 170004], Sections 6.2 and 6.11) and summarized in Section 6.5.3, an automatic data acquisition system was set up to monitor the cumulative amount of water seeping into the capture system installed within the niches and the ECRB Cross-Drift. Taking the derivative of these cumulative seepage data (see Appendix F) yields the seepage rates to be used for calibration. Note that measurement noise in the cumulative seepage data induces fluctuations in the calculated seepage rates. If no or little seepage occurs, these fluctuations may lead to negative seepage-rate values. These nonphysical data points are of no concern, because the numerical model (which always produces physically correct, non-negative seepage rates) does not attempt to track the high-frequency fluctuations from measurement noise (the random component of the data are described by the 
stochastic model of the inversion). Instead, the model follows the smooth, deterministic component of the seepage-rate data, which is non-negative.

Seepage rates are used instead of cumulative seepage data because an error in the prediction of the early-time seepage behavior leads to a shift in the cumulative seepage curve. Such a shift induces a bias in the estimated parameters, even if only late-time data were used in the inversion. In general, early-time seepage data are relatively strongly affected by storage effects. Moreover, they reflect the properties of only a few fractures that connect the injection interval with the point at the drift surface where seepage is initiated. These fractures may not be representative of the drift-scale properties of the fracture network engaged in the seepage process under near-steady-state conditions. These few fractures are likely to be conceptually different from the larger-scale network providing connectivity for flow diversion around the drift. Consequently, matching early-time data potentially leads to an unwanted bias in the estimated parameters. Late-time, near-steady data are less affected by storage effects, allowing for a more representative estimation of $\log (1 / \alpha)$.

The following paragraphs discuss the data sets used for calibration (see also Table 6-5).

Borehole SYBT-ECRB-LA\#1, Lower Lithophysal Zone DTN: LB0110ECRBLIQR.002 [DIRS 156879]

Only one borehole interval (zone 2) was available for liquid-release testing in borehole SYBT-ECRB-LA\#1 (BSC 2004 [DIRS 170004], Sections 6.11.2.5 and 6.11.2.6). Starting on February 28, 2001, water was released for a period of almost a month at an average rate of approximately $17 \mathrm{ml} / \mathrm{min}$. No seepage was induced. In the following month, four tests with approximate release rates between $41 \mathrm{ml} / \mathrm{min}$ and $45 \mathrm{ml} / \mathrm{min}$ were performed, interrupted by phases of inactivity that lasted from a few hours to approximately 6 days. These higher-rate tests led to seepage. Seepage-rate data from all five tests (Events 65-69 of Table 6-5) are used for calibration. During the two-month testing period, the relative humidity in the drift varied between about 10 percent and 60 percent (BSC 2004 [DIRS 170004], Figure 6.11.2-11c). Data preparation is described in Appendix F and Wang 2003 [DIRS 161456], SN-LBNL-SCI-228-V1, pp. 15-17).

Borehole SYBT-ECRB-LA\#2, Lower Lithophysal Zone DTN: LB00090012213U.002 [DIRS 153154], DTN: LB0110SYST0015.001 [DIRS 160409]

Borehole SYBT-ECRB-LA\#2 was tested twice, in May/June 2000 and October/November 2000. Humidity in the drift was not controlled or monitored during the earlier tests; these tests will therefore not be used for calibration, but for validation with an assumed relative humidity. During the second test period starting October 23, 2000, long-term liquid-release tests were conducted in zones 2 and 3 (Events 61-64 of Table 6-5) with approximate release rates ranging between $33 \mathrm{ml} / \mathrm{min}$ and $41 \mathrm{ml} / \mathrm{min}$. The relative humidity in the testing area (partly protected from air circulation by curtains installed at the two ends of the V-shaped seepage capture curtains) varied between approximately 30 percent and 90 percent (BSC 2004 [DIRS 170004], Figure 6.11.2-8). Data preparation is described in Finsterle (2002 [DIRS 161043], p. 133) and Wang (2003 [DIRS 161456], SN-LBNL-SCI-228-V1, pp. 18-21). 
Borehole SYBT-ECRB-LA\#3, Lower Lithophysal Zone DTN: LB0203ECRBLIQR.001 [DIRS 158462]

Test events 70 and 71 (see Table 6-5) were conducted in zone 1 of borehole SYBT-ECRB-LA\#3, starting on May 17, 2001. Despite the higher release rate of approximately $36 \mathrm{ml} / \mathrm{min}$ during the first test, which lasted for about 4 days, no seepage was observed. A long-term test (26 days) at an average rate of approximately $25 \mathrm{ml} / \mathrm{min}$ produced erratic seepage, with seepage rates reaching approximately $10 \mathrm{ml} / \mathrm{min}$, but decreasing during the last 10 days of the test. Relative humidity varied between 10 percent and 50 percent. Data preparation is described by Wang (2003 [DIRS 161456], SN-LBNL-SCI-228-V1, pp. 15-17).

Niche 5, Lower Lithophysal Zone

DTN: LB0209NICH5LIQ.001 [DIRS 160796] and DTN: LB0211NICH5LIQ.001 [DIRS 160792]

During test events 86 and 87 (see Table 6-5), water was released at an approximate rate of $26 \mathrm{ml} / \mathrm{min}$ from interval 28-29 ft of borehole \#5; the tests started July 15, 2002 (Day 195 since January 01, 2002) and continued until August 5, 2002 (Day 216). In concurrently conducted tests, water was released from interval 21-22 ft of borehole \#3 between July 17, 2002 (Day 197) and July 19, 2002 (Day 199; Event 83), and again between July 29, 2002 (Day 208) and August 9, 2002 (Day 221; Event 84; shaded zones in Figure 6-17). It is apparent from Figure 6-17 that part of the water released in borehole \#3 was captured in the trays intended to collect seepage from the liquid-release tests conducted in borehole \#5. Because of this test interference, only the late-time data of Event 86 up to July 30, 2002 (Day 209) are considered for calibration. During Event 89 (Table 6-5), water was released at an almost constant rate of approximately $9.9 \mathrm{ml} / \mathrm{min}$ from interval 10-11 ft of borehole \#4; the test started September 17, 2002 and continued until October 1, 2002. Seepage started on September 19, 2002 and increased gradually until it reached almost steady state on September 24, 2002. Data preparation is described by Wang (2003 [DIRS 161456], SN-LBNL-SCI-223-V1, pp. 30-34). 

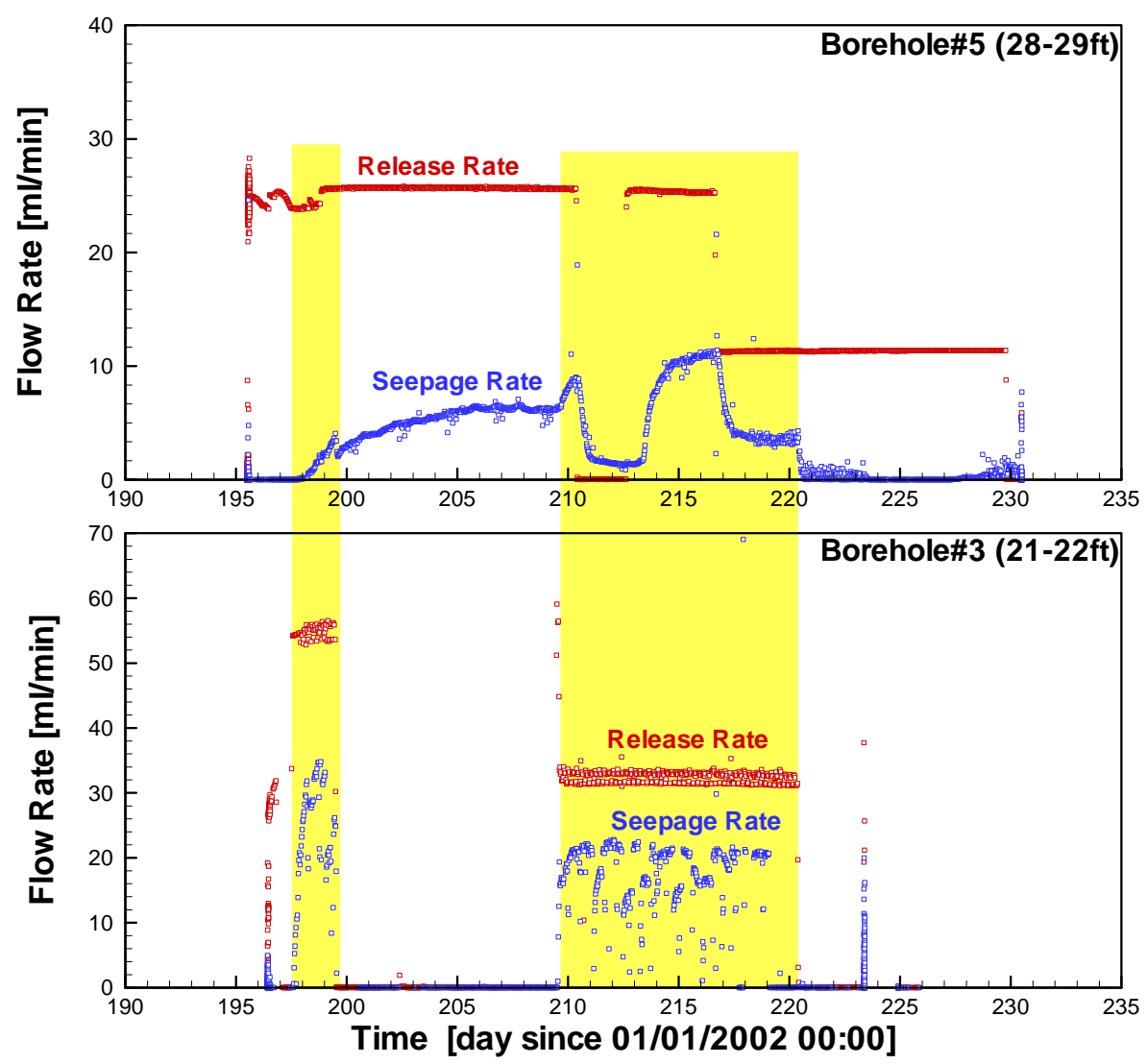

Source: DTN: LB0209NICH5LIQ.001 [DIRS 160796]

NOTE: July 15, 2002 is Day 195.

Figure 6-17. Interference between Concurrent Liquid-Release Tests in Borehole \#3 (21-22 ft) and Borehole \#5 (28-29 ft) in Niche 5

Niche 3, Middle Nonlithophysal Zone

DTN: LB0010NICH3LIQ.001 [DIRS 153144]

Two intervals were tested in Niche 3. However, only test events in one interval (UM 4.88-5.18) resulted in seepage (see Events 6, 8-12 in Table 6-5). The tests in the other interval (UL 5.495.80) are not useable for calibration, as no seepage was observed (see Events 1-3), which would lead to an ill-posed inverse problem. Nevertheless, these data will be used for validation purposes. Of the nine tests performed in interval UM 4.88-5.18, three are selected for model calibration because of their variety in injection and seepage rates. The tests starting on March 4, 1999, April 27, 1999, and May 6, 1999 are characteristic of all the tests performed in this interval. The March 4, 1999 test (Event 4) was conducted at a low injection rate of approximately $0.9 \mathrm{ml} / \mathrm{min}$, resulting in no seepage. The April 27, 1999 test (Event 6) used a medium rate of about $2.4 \mathrm{ml} / \mathrm{min}$ and resulted in a small amount of seepage. Finally, the May 6, 1999 test (Event 8) was performed with a higher rate of approximately $5.4 \mathrm{ml} / \mathrm{min}$, which resulted in substantial seepage. The remaining tests (Events 7, 9-12) in this interval are reserved for validation. Data preparation is described by Ahlers (2002 [DIRS 161045], pp. 41, 47-48). 
Niche 4, Middle Nonlithophysal Zone

DTN: LB0010NICH4LIQ.001 [DIRS 153145]

Three intervals were tested in Niche 4, all tests leading to seepage. Each test performed in a given interval was conducted with a different release rate (except in interval UM 6.10-6.40, where three low-rate tests were performed; only the test on March 14, 2000 was a long-term test). In each interval, the low- and medium-rate tests that resulted in seepage were selected for model calibration (Events 41, 43, 45, 48, 50, and 51 in Table 6-5). The highest-rate and lowest-rate seepage tests are reserved for validation (Events 40, 42, 44, 47, 49) to determine whether seepage model predictions can be successfully extrapolated to conditions beyond the calibration range. Data preparation is described by Ahlers (2002 [DIRS 161045], pp. 26-27, 34-36).

\subsubsection{Calibration Results}

The software iTOUGH2 V4.0 (LBNL 1999 [DIRS 139918]) for tests without significant evaporation effects, or iTOUGH2 V5.0 (LBNL 2002 [DIRS 160106]) for tests with evaporation effects, was used to match the transient seepage-rate data (see Section 6.6.3.2) by automatically updating the parameters of interest (see Section 6.6.3.1). The inverse modeling approach follows the concept described by Carrera and Neuman (1986 [DIRS 104368]) and Finsterle (1999 [DIRS 104367]). The misfit between calculated and measured seepage is evaluated using the least-squares objective function (Eq. 6-13). The objective function is minimized using the Levenberg-Marquardt algorithm (Finsterle 1999 [DIRS 104367], pp. 44-45).

The inversion results are presented as follows. First, the simulated system behavior obtained with the calibrated model is qualitatively described for selected tests and points in time. Second, the match between the simulated and observed seepage-rate data is shown. Third, the estimated parameters are discussed. Finally, the results from the individual inversions are combined and summarized (see Section 6.6.4) to obtain a parameter distribution for subsequent model validation. Input and output files from a representative inversion are discussed in Appendix G.

\section{Borehole SYBT-ECRB-LA\#1, Lower Lithophysal Zone}

The overall simulated system behavior during liquid-release tests from inclined boreholes drilled from the ECRB Cross-Drift is qualitatively visualized in Figure 6-18 (and-for other boreholes in the ECRB Cross-Drift and niches-in Figure 6-21, Figure 6-26, Figure 6-28, and Figure 6-30). Figure 6-18a shows the calculated flux distribution at the end of the testing period. The flow field above the injection point represents the natural background percolation flux; with flow channeling occurring as a result of explicitly modeled small-scale heterogeneity. It is apparent that flow channels are established within a short distance below the top boundary. The injection interval (zone 2 of borehole SYBT-ECRB-LA\#1) is relatively close to the crown of the drift. Local flux below the water release point is very high. Water is partly diverted around the opening. The low relative humidity (less than 50 percent) leads to substantial evaporation, extracting most of the injected water from the formation before it reaches the spring line of the drift. Flow diversion around the drift and the removal of water that seeped into the capture system leads to reduced fluxes below the drift, an effect referred to as the shadow zone. 
The calculated saturation distribution at the end of seepage testing (Event 69 of Table 6-5) shows that the fracture continuum is essentially dry (less than 10 percent) under natural percolation conditions (Figure 6-18). Injecting at rates on the order of $40 \mathrm{ml} / \mathrm{min}$ increases saturation without completely saturating the pore space, i.e., the flow regime remains unsaturated. As a result of the capillary-barrier effect, saturations are highest in the immediate vicinity of the drift, which induces a capillary-pressure gradient promoting flow diversion. Seepage and evaporation removes water from the formation as it flows around the drift, explaining why no significant saturation increase can be observed at the spring line. In contrast, during the liquid-release tests performed in the closed-off niches, where evaporation is significantly reduced, water reaches the spring line and drains to depth as shown, for example, in Figure 6-26a and Figure 6-28a, and evidenced by seepage into the horizontal slot excavated from the side of Niche 5 (see also Section 6.7). Additional discussions of the flow and seepage behavior will be given below for tests in borehole SYBT-ECRB-LA\#2.
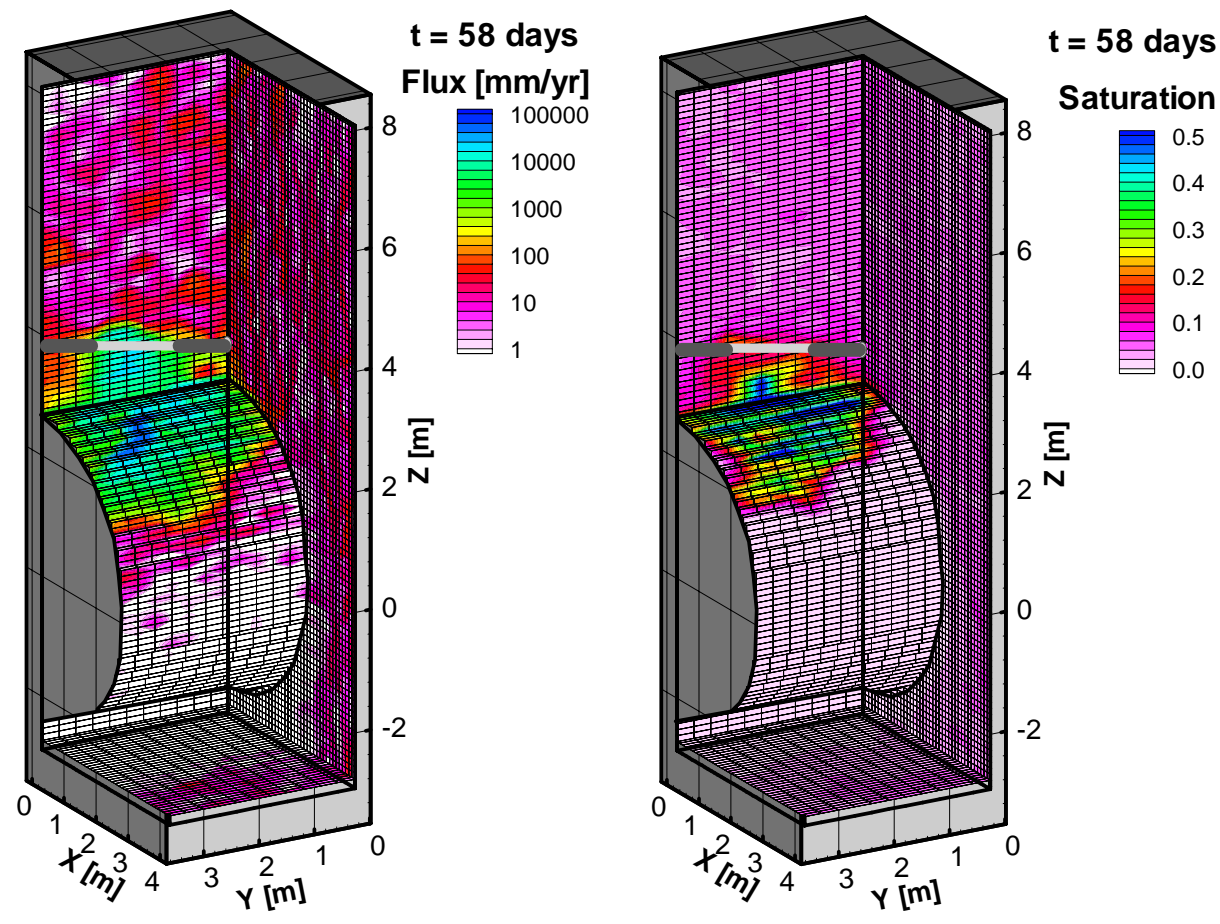

(a)

(b)

Output DTN: LB0302SCMREV02.001.

Figure 6-18. (a) Flux and (b) Saturation Distribution at the End of Liquid-Release Testing in Zone 2 of Borehole SYBT-ECRB-LA\#1

The match of the calculated seepage rates (red line) to the observed data (blue symbols) for this test is shown in Figure 6-19, along with the measured and modeled release rates (gray and black lines) and the relative-humidity data (green line). The model correctly replicates the initial, 34-day long no-seepage period. The increase in release rates induces seepage, the magnitude of which is well reproduced by the calibrated model. After each test interruption, seepage rates are reestablished more quickly in the model than observed in the field. The discrepancy between 
model and data is more pronounced after longer periods of inactivity (i.e., for the test events starting at 34 and 40 days, which followed interruptions of approximately 5 1/4 and 3 3/4 days, respectively). This suggests that a storage mechanism (e.g., storage in the injection lines and borehole intervals, imbibition into the dried-out matrix, filling of lithophysal cavities, and/or storage within the capture system, i.e., between the trays or capture curtain and the balance measuring cumulative seepage) is not appropriately accounted for. The discrepancies in these early-time data, however, are minor and are not expected to significantly bias the parameter estimate. Because transient system responses introduced by test interruptions and rate changes are reproduced by specifying time-varying boundary conditions, their potential impact on seepage is appropriately captured.

A total of 17 inversions were performed, each with a different realization of the underlying, heterogeneous permeability field. The quality of the matches obtained with each inversion is consistent, as shown in Figure 6-20.

(Note that each solution of the inverse problem performed to evaluate the impact of the underlying permeability field requires many solutions of the forward problem, each consisting of a steady-state simulation (to achieve initial conditions), followed by a transient simulation of a sequence of liquid-release tests. The central processing unit time required for these calculations is intensive, limiting the number of realizations that can be analyzed. The number of realizations analyzed is different for each location (see fourth column of Table 6-8 below), because the simulated test sequences have different durations and thus different central processing unit time requirements.)

The $1 / \alpha$ estimate has a mean, standard deviation, and standard error of 534 Pascals $(\mathrm{Pa}), 57 \mathrm{~Pa}$, and $14 \mathrm{~Pa}$, respectively (see Table 6-8 below). (Note that the statistics are performed for $1 / \alpha$ instead of $\log (1 / \alpha)$. Using the backtransformed values is justified by the small standard deviation of the estimates.) The estimation uncertainty of an individual inversion (given by Eq. 6-14) is on the order of a few Pascals. This estimation uncertainty accounts for the residual misfit of the calibrated model to the data and the sensitivity of the calculated seepage rates with respect to $1 / \alpha$. This uncertainty measure is not propagated through the suite of seepage models, because it is significantly less than the uncertainty stemming from small-scale heterogeneities (which is examined by performing multiple inversions with multiple realizations of the permeability field, amounting to $57 \mathrm{~Pa}$ in this case) and spatial variability (which is examined by inverting data from tests conducted at different locations, amounting to approximately $100 \mathrm{~Pa}-$ see Section 6.6.4). 


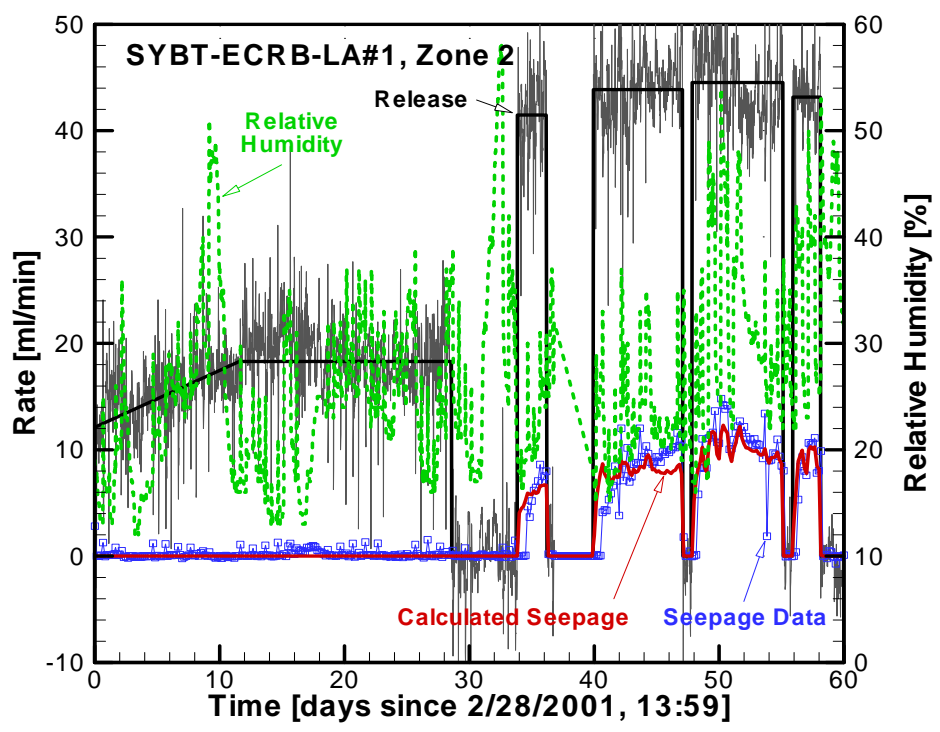

Source: DTN: LB0110ECRBLIQR.002 [DIRS 156879].

Output DTN: LB0302SCMREV02.001.

NOTE: Blue symbols represent measured data; the red line is the calculated seepage rate. The measured release rates are shown in dark gray; the black solid line shows the injection rate used in the model. Relative-humidity data are shown as a green dashed line.

Figure 6-19. Calibration of Seepage-Rate Data from Liquid-Release Tests in Zone 2 of Borehole SYBTECRB-LA\#1

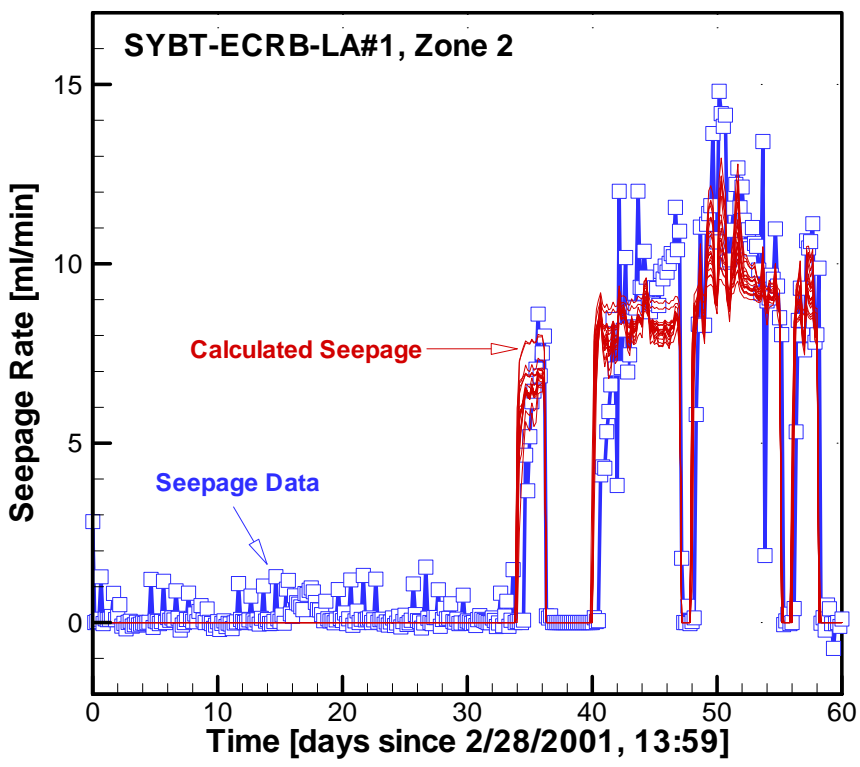

Source: Seepage-rate data derived from DTN: LB0110ECRBLIQR.002 [DIRS 156879].

Output: Calculated seepage in output DTN: LB0302SCMREV02.001.

NOTE: Blue symbols represent measured seepage-rate data; the red lines are the results obtained with 17 calibrated models, each using a different realization of the underlying heterogeneous permeability field.

Figure 6-20. Calibration of Seepage-Rate Data from Liquid-Release Tests in Zone 2 of Borehole SYBTECRB-LA\#1 


\section{Borehole SYBT-ECRB-LA\#2, Lower Lithophysal Zone}

Multiple liquid-release tests were performed in zones 2 and 3 of borehole SYBT-ECRB-LA\#2. The propagation of the liquid plume from the tests in zone 2 is visualized in Figure 6-21. After 10 days of injection (Figure 6-21b), water is diverted around the drift approximately to the elevation of the spring line. After 20 days (Figure 6-21c), however, the plume has shrunk significantly as a result of increased evaporation (see discussion of Figure 6-22 below). Increased relative humidity prior to the 30-day time mark reduces evaporation and thus enables water to flow around the drift. Figure 6-21d also highlights the shadow zone created by flow diversion around the drift.

Figure 6-21 suggests that horizontal spreading of the liquid plume is partly restricted by the limited extension of the model domain in the Y-direction. This boundary effect increases seepage. The impact of the lateral no-flow boundary on the estimated $1 / \alpha$ value was evaluated by inverting data using an expanded model. The effect is minor compared to the parameter's uncertainty (Wang 2003 [DIRS 161456], SN-LBNL-SCI-228-V1, p. 32).

Despite the SCM being a continuum model, seepage occurs at only a few discrete locations (indicated by triangles), consistent with qualitative observations of drip locations. Seepage locations are affected by heterogeneity. In the current realization, some seepage occurs near the crown of the drift; however, most water enters the drift from a location approximately halfway between the crown and the spring line (see Figure 6-21d).

Comparisons between measured and calculated seepage rates for the tests in zones 2 and 3 are shown in Figure 6-22 and Figure 6-23, respectively. Fluctuations in both data sets can be correlated to the drastic changes in relative humidity, which drives evaporation. The model captures this evaporation effect reasonably well, tracking increases in measured seepage rates as relative humidity increases and vice versa. These results provide confidence that the conceptual model represents the key processes and their interactions appropriately, including:

1. Unsaturated flow using a continuum representation of fracture flow based on Richards’ equation (see Section 6.6.1.1);

2. Seepage into the opening, accounting for the capillary-barrier effect (see Section 6.6.1.2);

3. Vaporization of water from the drift surface, using a simplified evaporation model (see Section 6.6.1.3).

The rather complex system behavior, which includes expansion and shrinkage of the liquid plume along the drift surface, signifies the importance of handling unsaturated flow, seepage, and evaporation in a fully coupled manner. 
(a)
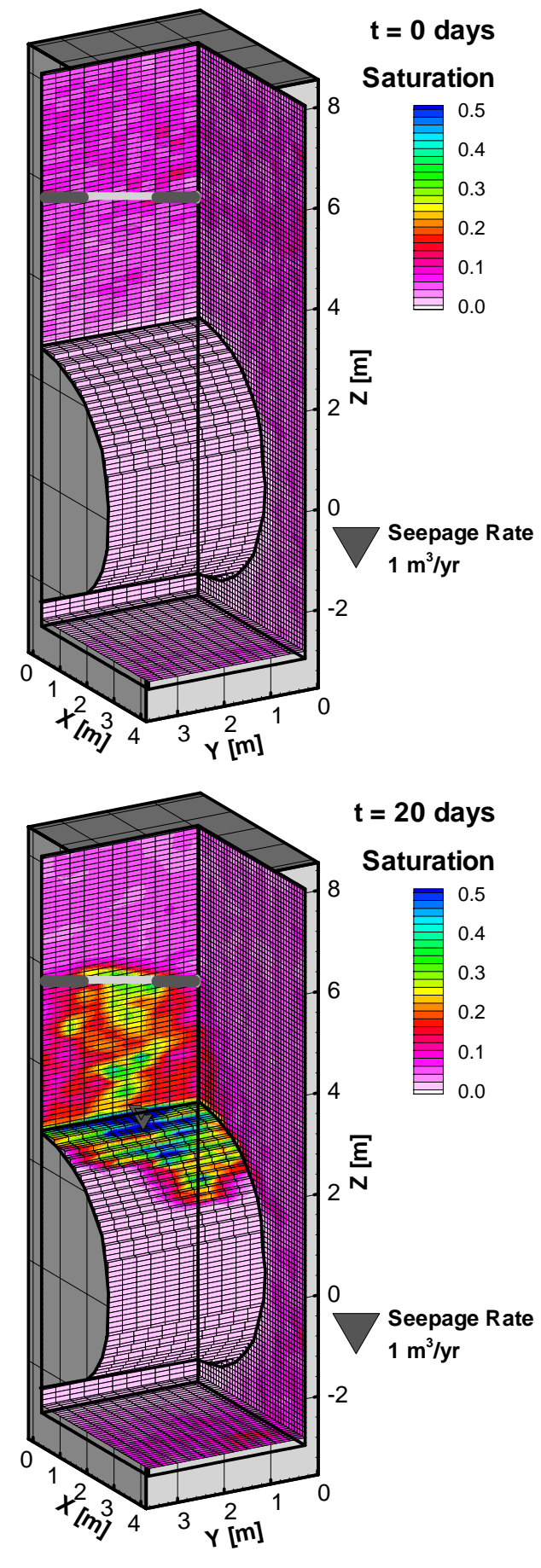

(b)

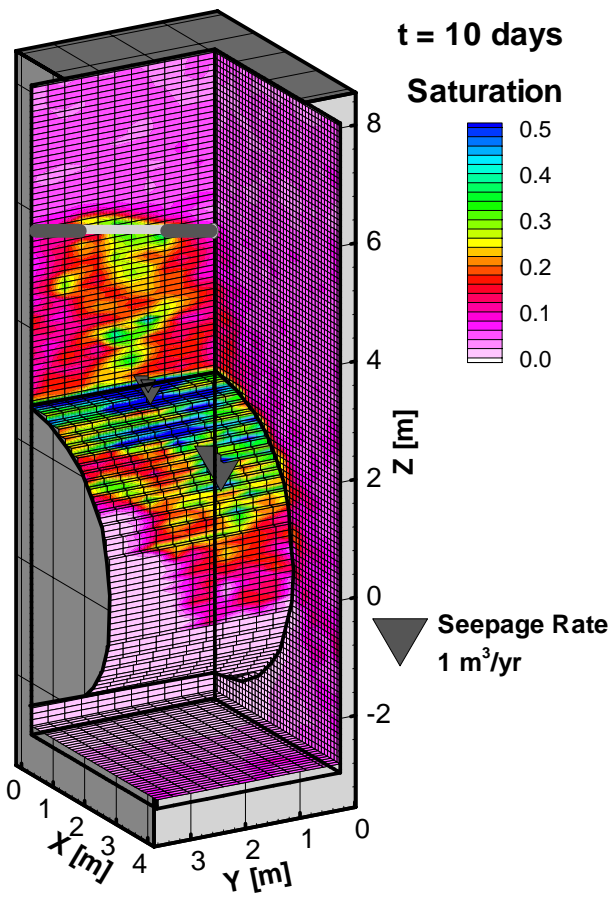

(d)

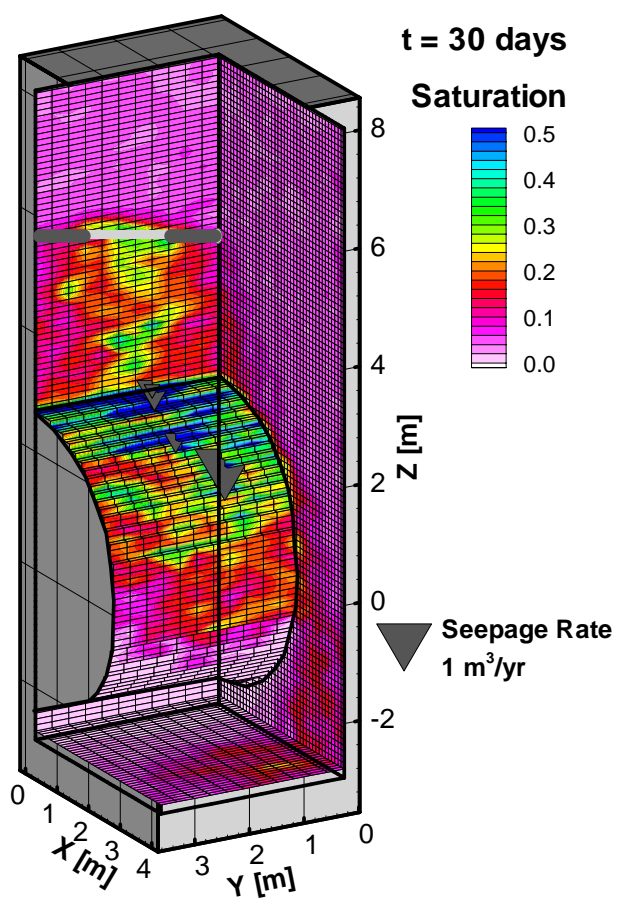

Output DTN: LB0302SCMREV02.001.

NOTE: (a) initial distribution, (b) after 10 days, (c) 20 days, and (d) 30 days. Triangles indicate seep locations and seepage amount.

Figure 6-21. Saturation Distribution Simulated With Model Calibrated against Seepage-Rate Data from Liquid-Release Tests Conducted in Zone 2 of Borehole SYBT-ECRB-LA\#2 


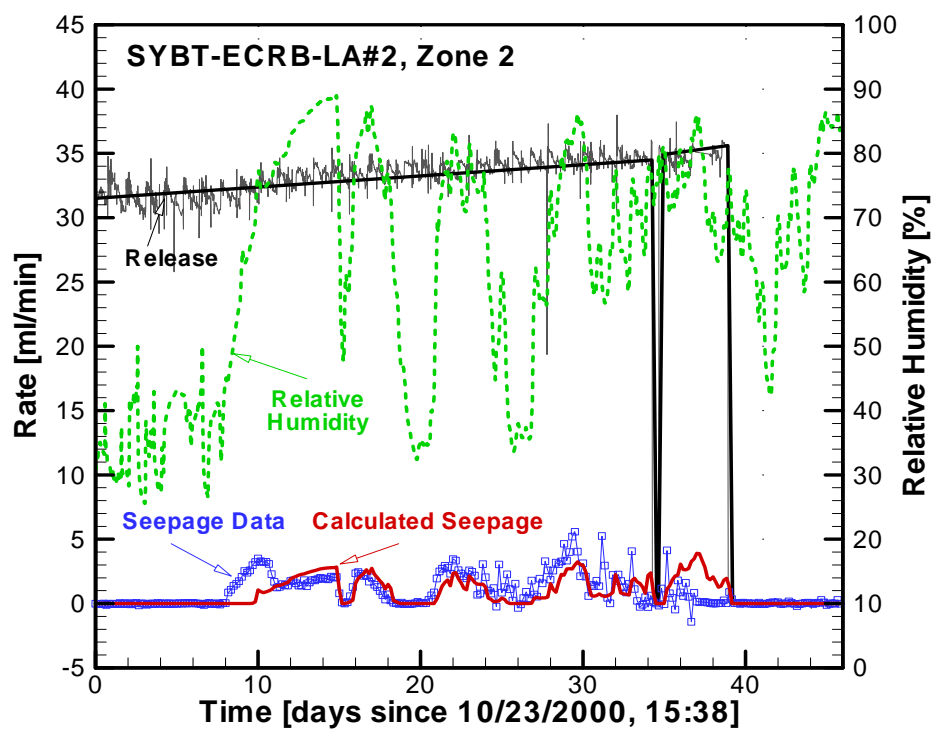

Source: DTN:LB0110SYST0015.001 [DIRS 160409].

Output DTN: LB0302SCMREV02.001.

NOTE: Blue symbols represent measured data; the red line is the calculated seepage rate. The measured release rates are shown in dark gray; the black solid line shows the injection rate used in the model. Relative-humidity data are shown as a green dashed line.

Figure 6-22. Calibration of Seepage-Rate Data from Liquid-Release Tests Conducted in Zone 2 of Borehole SYBT-ECRB-LA\#2

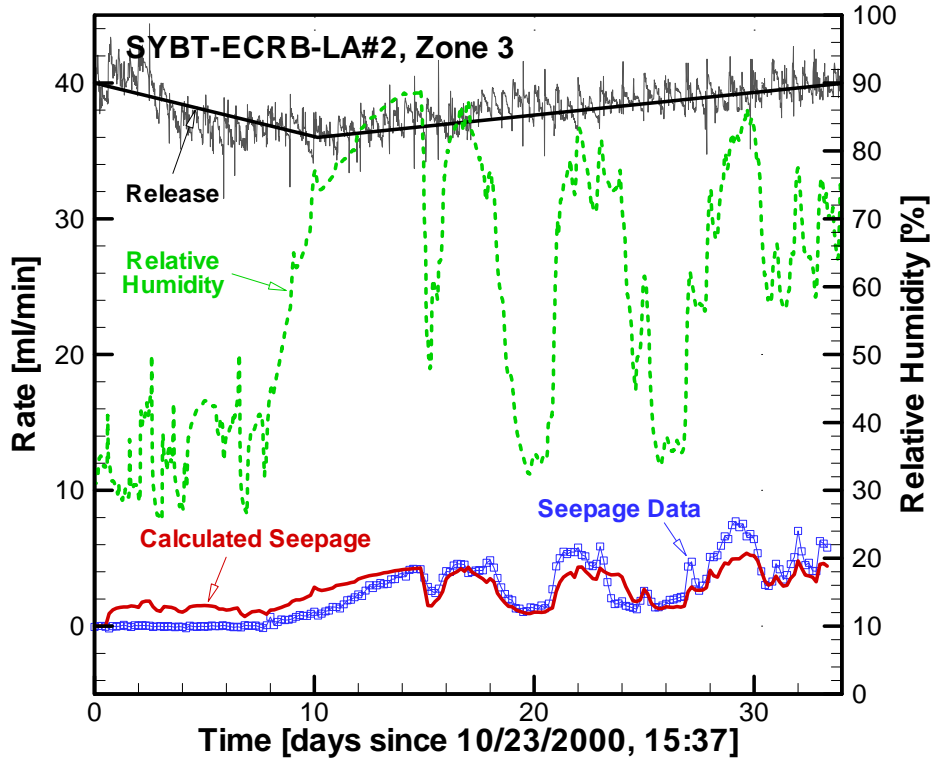

Source: DTN: LB0110SYST0015.001 [DIRS 160409].

Output DTN: LB0302SCMREV02.001.

NOTE: Blue symbols represent measured data; the red line is the calculated seepage rate. The measured release rates are shown in dark gray; the black solid line shows the injection rate used in the model. Relative-humidity data are shown as a green dashed line.

Figure 6-23. Calibration of Seepage-Rate Data from Liquid-Release Tests Conducted in Zone 3 of Borehole SYBT-ECRB-LA\#2 
The capillary-strength parameter $1 / \alpha$ was determined based on 21 inversions of seepage-rate data from zone 2, and 19 inversions of data from zone 3. The means and standard deviations (557 \pm 56 Pa for zone 2 and $535 \pm 58$ Pa for zone 3; see Table 6-8 below) are consistent with those obtained in borehole SYBT-ECRB-LA\#1.

\section{Borehole SYBT-ECRB-LA\#3, Lower Lithophysal Zone}

The calibration of liquid-release tests from zone 1 of borehole SYBT-ECRB-LA\#3 revealed some systematic inconsistencies between the data and the model. As shown in Figure 6-24, the model produces considerable seepage during the simulation of the first test event, while no seepage was observed in the field despite the high release rate. Furthermore, the model predicts a relatively uniform seepage rate for the second test event, whereas the data show a continuous increase in seepage for approximately 10 days, followed by a decrease. Nevertheless, the inversion yields a reasonable reproduction of the average seepage rate. The mean $1 / \alpha$ value of $452 \pm 55 \mathrm{~Pa}$ (based on 23 inversions; see Table 6-8 below) is lower than the previous estimates.

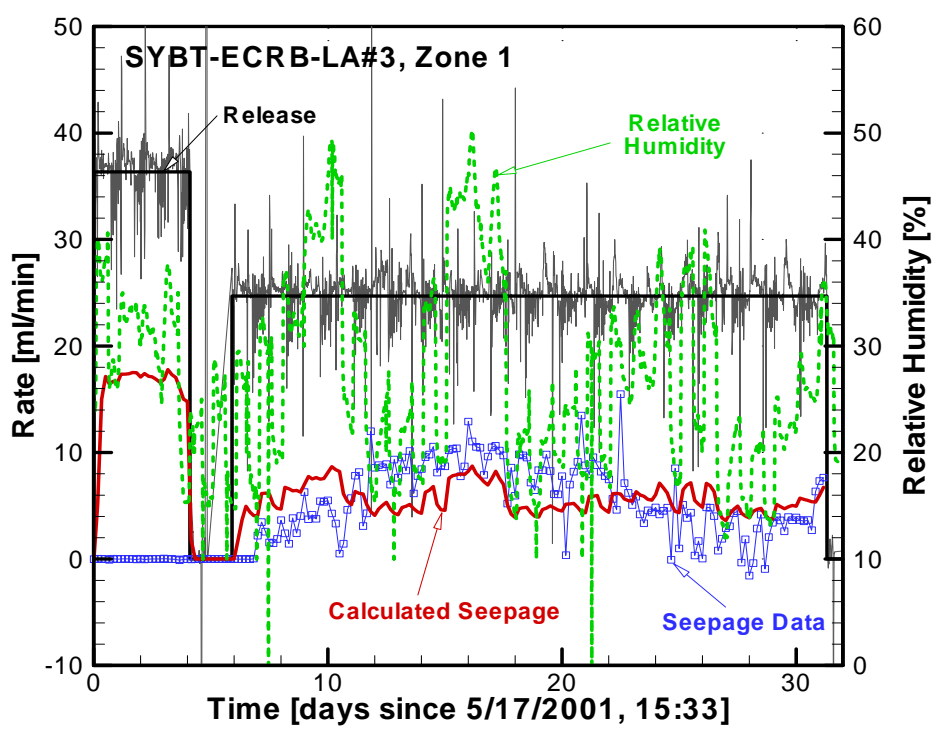

Source: DTN: LB0203ECRBLIQR.001 [DIRS 158462].

Output DTN: LB0302SCMREV02.001.

NOTE: Blue symbols represent measured data; the red line is the calculated seepage rate. The measured release rates are shown in dark gray; the black solid line shows the injection rate used in the model. Relative-humidity data are shown as a green dashed line.

Figure 6-24. Calibration of Seepage-Rate Data from Liquid-Release Tests Conducted in Zone 1 of Borehole SYBT-ECRB-LA\#3 
Niche 5, Borehole \#4, Interval 10-11 ft, Lower Lithophysal Zone

During Test Event 89, liquid was released at a fairly constant rate. Seepage was observed after two days and continued to increase for four days, reaching almost steady state on the sixth day.

The test was simulated with a constant release rate of $9.9 \mathrm{ml} / \mathrm{min}$ and a constant relative humidity of 85 percent. The model produced seepage 12 hours after liquid release started, and reached a constant seepage rate after 36 hours (see Figure 6-25). The modeled saturation and flux at the end of the test (see Figure 6-26) show that there is significant diversion of injected liquid around the niche. Thirty inversions with 30 different realizations of the underlying heterogeneous permeability field were performed, resulting in a calibrated capillary-strength parameter $1 / \alpha$ of $671 \pm 223 \mathrm{~Pa}$. The standard error of the mean is $41 \mathrm{~Pa}$.

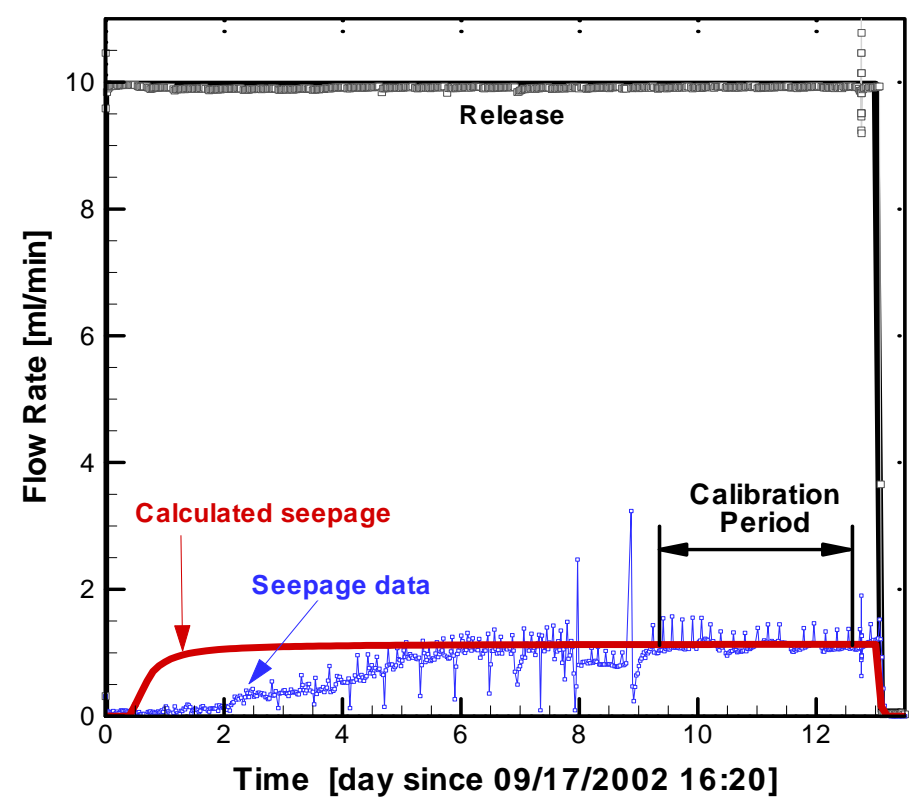

Source: DTN: LB0211NICH5LIQ.001 [DIRS 160792].

Output DTN: LB0302SCMREV02.001.

NOTE: Blue symbols represent measured data; the red line is the calculated seepage rate. The measured release rates are shown in dark gray; the black solid line shows the injection rate used in the model.

Figure 6-25. Calibration of Seepage-Rate Data from Liquid-Release Tests Conducted in Interval 10-11 $\mathrm{ft}$ of Borehole \#4 in Niche 5 


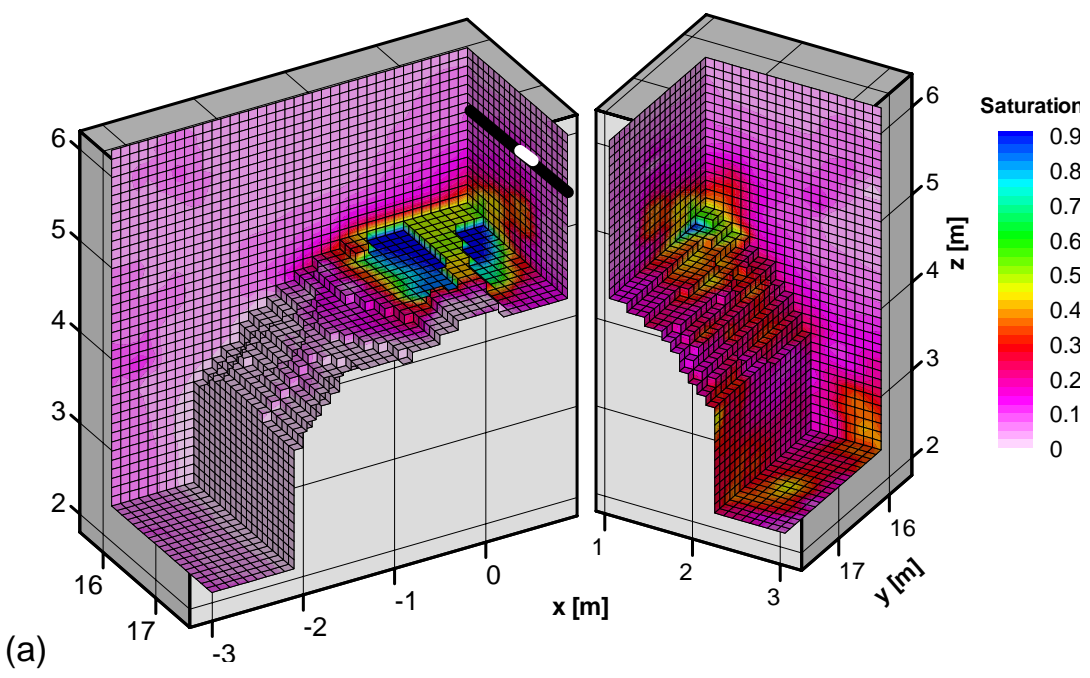

(b)

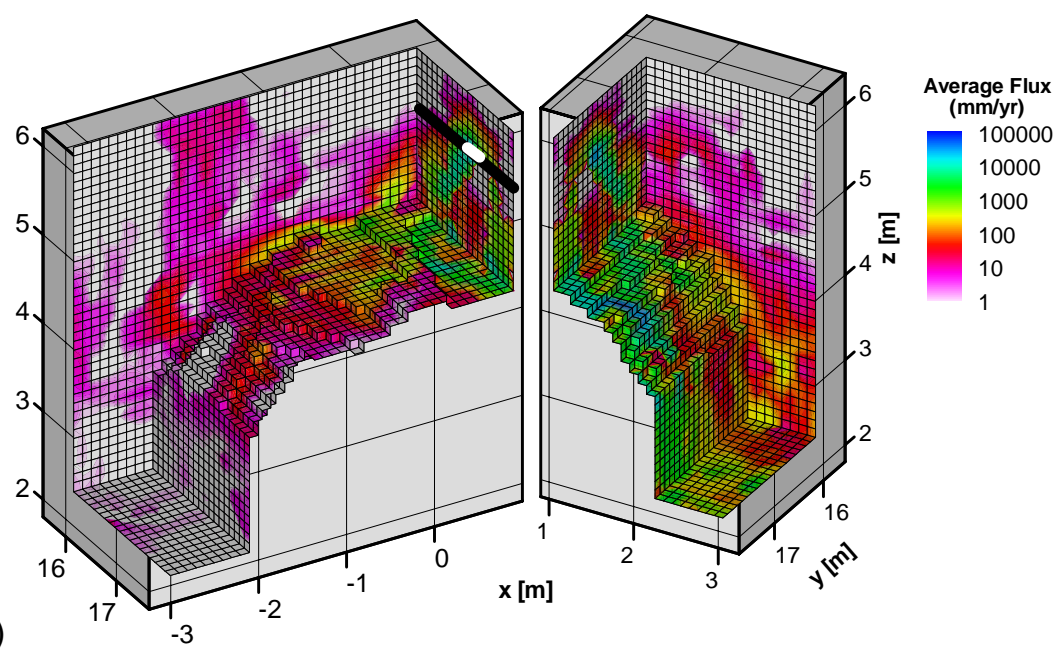

Output DTN: LB0302SCMREV02.001.

Figure 6-26. Simulated (a) Saturation And (b) Flux Distribution at the End of Liquid-Release Testing (After 13 Days) in Interval 10-11 ft of Borehole \#4 in Niche 5

Niche 5, Borehole \#5, Interval 28-29 ft, Lower Lithophysal Zone

In Test Event 86, water was released at a rate of approximately $25.8 \mathrm{ml} / \mathrm{min}$. The slight fluctuations in the release data that occurred during the first four days were reproduced in the seepage model. Seepage started on the second day and continued at an increasing rate, until it reached a constant rate on the tenth day (see Figure 6-27). The slight interference from Event 83, which occurred during the third day of Event 86, affected only the transient stage of the seepage data and was considered insignificant in the calibration process (see also discussion of Figure 6-17). The simulated relative humidity was kept constant at 85 percent, consistent with the averaged observed relative humidity during the test. The saturation and flux at the end of the test (see Figure 6-28) show that there is significant flow diversion of injected liquid around the niche towards the left slot. (See Section 6.7 for a detailed discussion on the significance of seepage into the slot in confirming the capillary-barrier concept.) Twenty-four inversions with 
different realizations of the underlying heterogeneous permeability field were performed, resulting in a calibrated capillary-strength parameter $1 / \alpha$ of $740 \pm 339 \mathrm{~Pa}$. The standard error of the mean is $69 \mathrm{~Pa}$ (see Table 6-8 below).

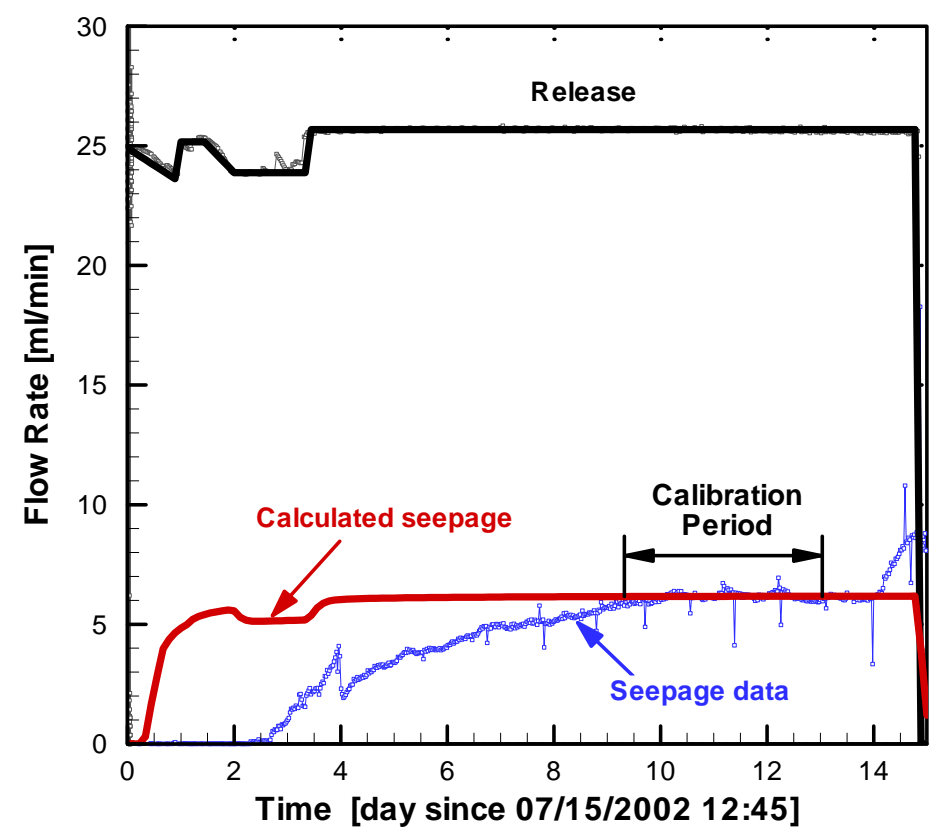

Source: DTN: LB0209NICH5LIQ.001 [DIRS 160796].

Output DTN: LB0302SCMREV02.001.

NOTE: Blue symbols represent measured data; the red line is the calculated seepage rate. The measured release rates are shown in dark gray; the black solid line shows the injection rate used in the model.

Figure 6-27. Calibration of Seepage-Rate Data from Liquid-Release Tests Conducted in Interval 28-29 $\mathrm{ft}$ of Borehole \#5 in Niche 5 


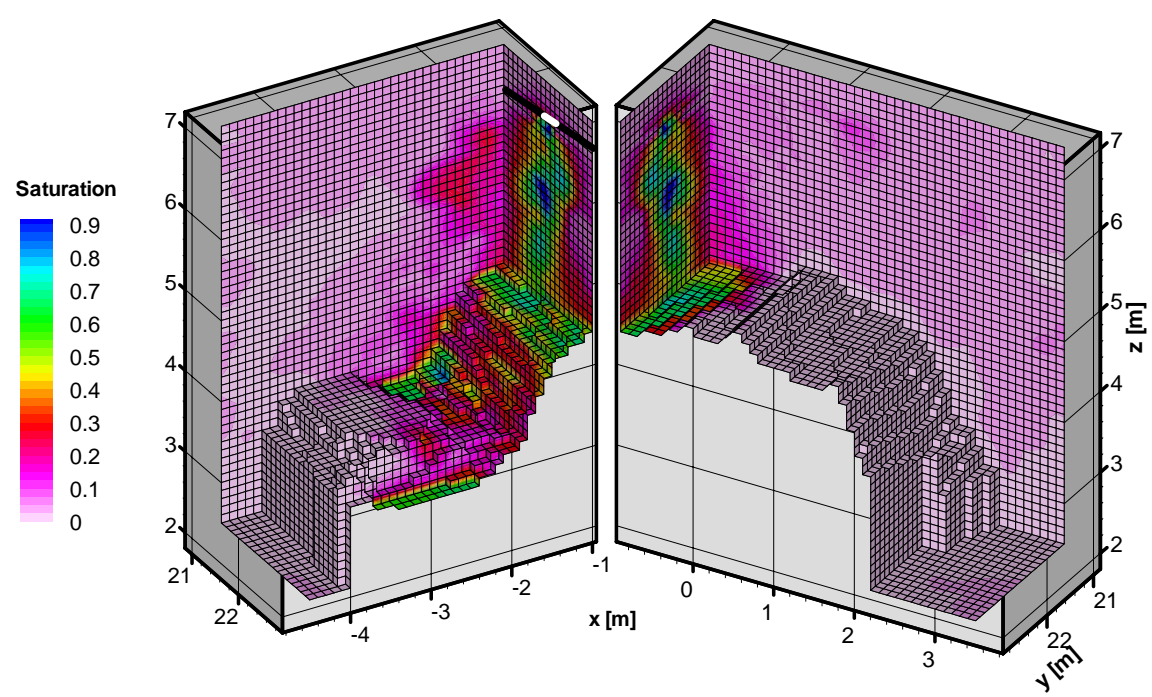

(a)

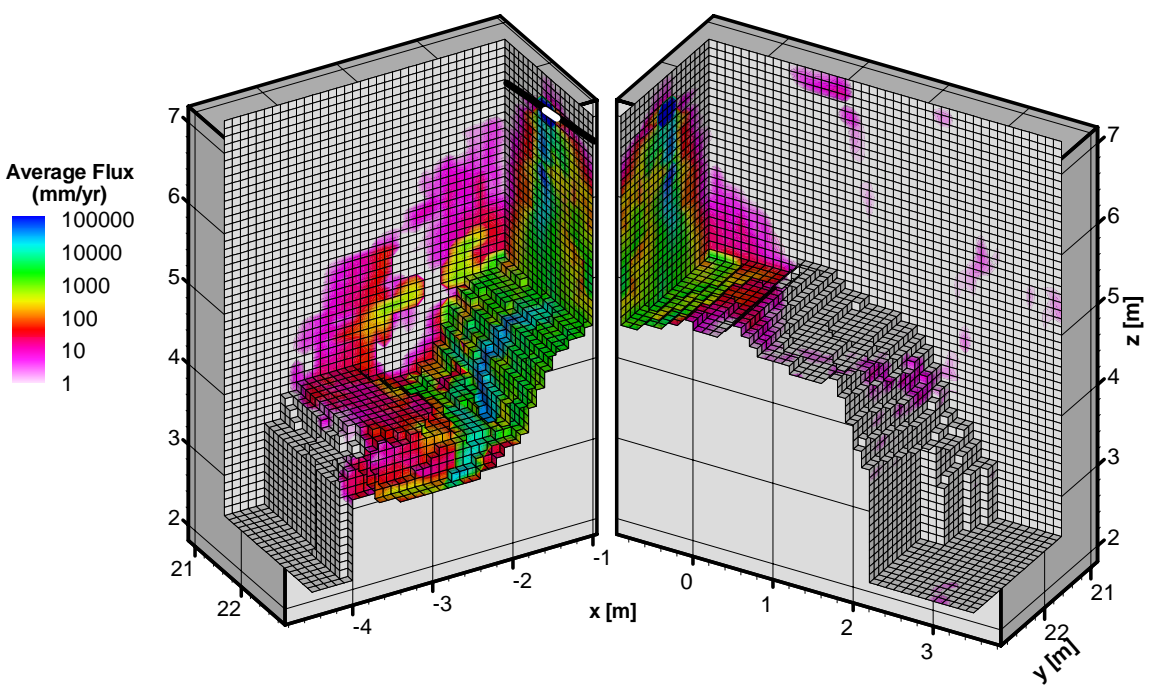

Output DTN: LB0302SCMREV02.001.

Figure 6-28. Simulated (a) Saturation and (b) Flux Distribution at the End of Liquid-Release Testing (After 13 Days) in Interval 28-29 ft of Borehole \#5 in Niche 5

Niche 3, Middle Nonlithophysal Zone

Data from three liquid-release tests performed in the center borehole UM (see inset in Figure 6-4) were inverted simultaneously. The inversions are based on one realization of the underlying heterogeneous permeability field. The match between the measured and calculated seepage rates is shown in Figure 6-29. The first low-rate test did not yield seepage. The seepage-rate data of the test conducted with the intermediate rate were considered less reliable, and a smaller weight was assigned to these data for the inversion. As a result, the model slightly overpredicts these data, whereas the other two jointly inverted test events were well matched. A relatively high $1 / \alpha$ estimate of $741 \mathrm{~Pa}$ was obtained. The estimate will be combined with those obtained from Niche 4 to yield a single value for the middle nonlithophysal zone (see Section 6.6.4). 

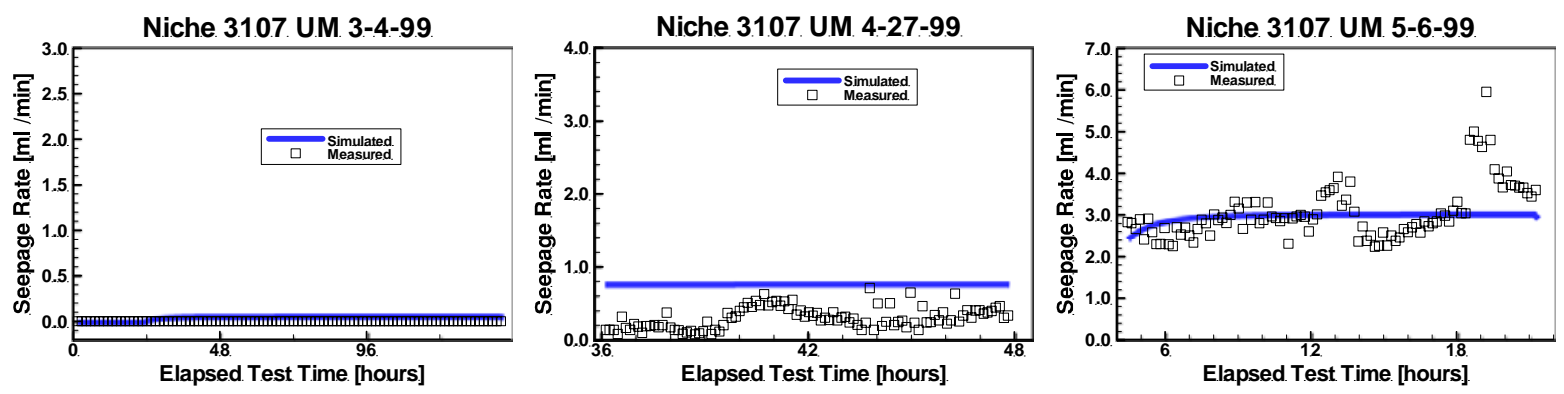

Source: DTN: LB0010NICH3LIQ.001 [DIRS 153144].

Output DTN: LB0010SCMREV01.001.

Figure 6-29. Comparison Between Simulated and Measured Seepage Rates from Three Liquid-Release Tests Conducted in Interval UM 4.88-5.18 of Niche 3.

\section{Niche 4, Middle Nonlithophysal Zone}

Calibrated parameters are produced separately for each interval tested in Niche 4. The horizontal separation distance between adjacent borehole intervals is greater than the vertical distance between the injection intervals and the ceiling of the niche. Since water flow is predominantly gravity driven, test interference is unlikely. Additionally, flow is diverted around the niche on different (albeit overlapping) paths. The water injected into the intervals on the side boreholes (UL and UR, see insert in Figure 6-4) is expected to be diverted to the respective sides of the niche, testing the flow system and capillary barrier on either side of the niche. The water injected into the center borehole (UM) encounters the flow system near the crown of the niche as well as on the sides. Figure 6-30 shows the simulated late-time saturations from liquid-release tests in each of the three boreholes above Niche 4 . The relative independence of the flow systems in Niche 4 leads to a strategy of estimating a separate $1 / \alpha$ parameter for each interval (intervals UL 7.62-7.93, UM 6.10-6.40, and UR 5.18-5.48).

The calibrated model matches the data reasonably well (see Figure 6-31) given that multiple test events performed with different injection rates were inverted simultaneously (note the different scales on the $\mathrm{Y}$-axes). The model overpredicts the seepage rates from the test performed in borehole UM on 12-10-99. In this case, the minimization algorithm was likely trapped in a local minimum. The $1 / \alpha$ estimates (based on one realization of the underlying heterogeneous permeability field) for the three boreholes UL, UM, and UR are $646 \mathrm{~Pa}, 603 \mathrm{~Pa}$, and $427 \mathrm{~Pa}$, respectively. These three estimates will be combined with that from Niche 3 to yield an average value for the middle nonlithophysal zone (see Section 6.6.4). Additional information on calibrations of the tests conducted in the middle nonlithophysal zone can be found the scientific notebook by Ahlers (2002 [DIRS 161045], pp. 38-39, 49).

Note that effective porosity values were also estimated from the seepage-rate data measured in Niches 3 and 4 . They represent storage effects during the transient liquid-release tests. The estimated mean of approximately 0.7 percent (DTN: LB0010SCMREV01.001) is a reasonable value for an effective storage parameter. Because porosity is insignificant for the prediction of steady-state seepage rates and is thus not used in downstream seepage models, the porosity estimates are not further discussed. 
(a)

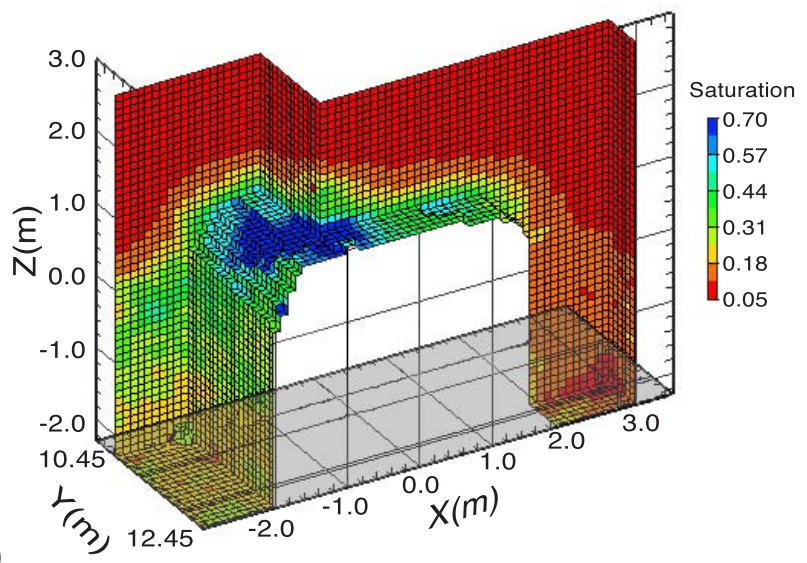

(b)

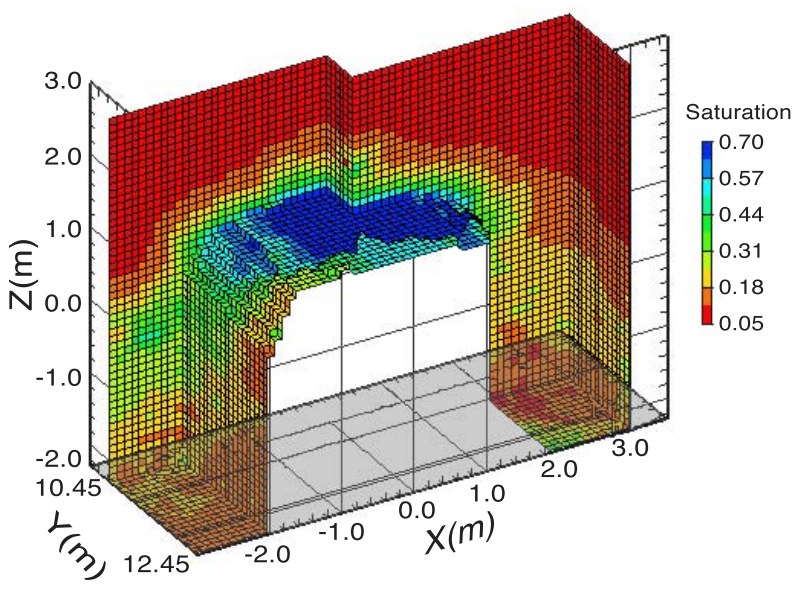

(c)

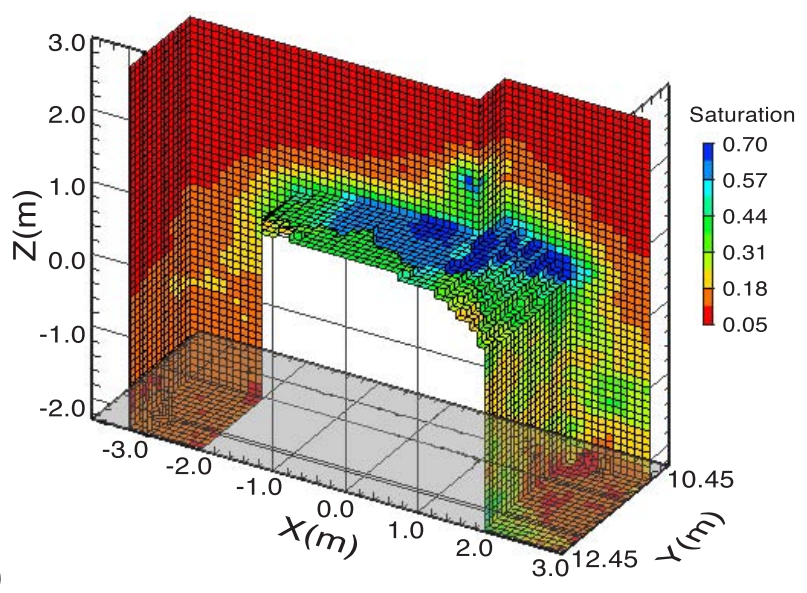

Output DTN: LB0010SCMREV01.001.

NOTE: The step in the displayed grid contains the injection interval.

Figure 6-30. Simulated Late-Time Saturation Distribution for Liquid-Release Tests in Niche 4, Intervals (a) UL 6.72-7.93 (November 3, 1999), (b) UM 6.10-6.40 (November 16, 1999), and (c) UR 5.18-5.48 (December 7, 1999) 

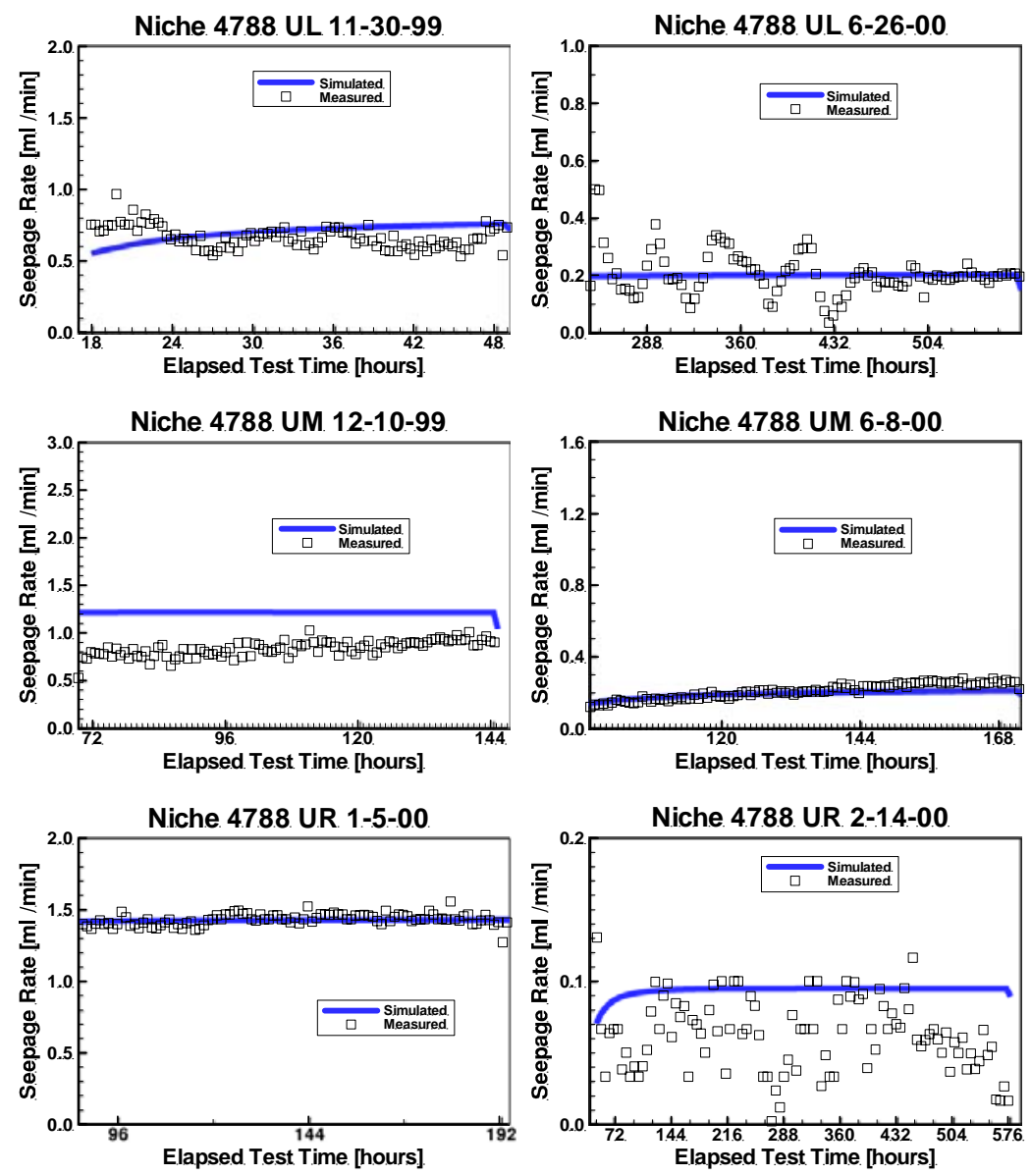

Source: DTN: LB0010NICH4LIQ.001 [DIRS 153145].

Output DTN: LB0010SCMREV01.001.

NOTE: Data from a given interval are inverted simultaneously. Note the different ranges of the $Y$-axes.

Figure 6-31. Comparison between Simulated and Measured Seepage Rates from Six Liquid-Release Tests Conducted in Three Different Borehole Intervals of Niche 4

\subsubsection{Summary and Compilation of Results}

Multiple three-dimensional, heterogeneous models representing niche locations and sections of the ECRB Cross-Drift were developed. The permeability fields were constructed and conditioned on local air-permeability data (see Section 6.6.2.1). Seepage-rate data from multiple test events, using different liquid-release rates, were inverted simultaneously. Inversions for the main repository host unit (the lower lithophysal zone) were repeated for multiple realizations of the underlying stochastic permeability field to capture the uncertainty induced by local heterogeneity. A total of 22 test events were used for model calibration (13 from tests conducted in the lower lithophysal zone and 9 in the middle nonlithophysal zone). Seepage-relevant capillary-strength values (parameter $1 / \alpha$ of the van Genuchten capillary pressure-saturation relationship—see Eq. 6-5) were estimated for each location.

A summary is provided in Table 6-8 and visualized in Figure 6-32 (see also Wang (2003 [DIRS 161456], SN-LBNL-SCI-223-V1, p. 37) and Wang (2003 [DIRS 161456], SN-LBNL-SCI-228- 
V1, p. 31)). Since multiple inversions with different realizations of the underlying heterogeneous permeability field were performed for test locations in the lower lithophysal zone, the capillary-strength parameter $1 / \alpha$ is calculated as the average for all inverse modeling results at that location, and a standard deviation $\sigma$ representing the related uncertainty is given. The standard error of the mean is calculated as $\bar{\sigma}=\sigma / \sqrt{i}$, where $i$ is the number of inversions performed. To reduce the computational burden, the estimates for the minor repository host unit (the middle nonlithophysal zone) are based on a single inversion, i.e., no estimation uncertainty as a result of uncertainty in small-scale heterogeneity can be given. The estimation uncertainty stemming from the misfit between the calibrated model and the data, and the sensitivity of the calculated seepage rates with respect to $1 / \alpha$ (see Eq. 6-14), is on the order of a few pascals, i.e., significantly less than the uncertainty from small-scale heterogeneity (which is greater than $50 \mathrm{~Pa}$ ) or spatial variability (which is on the order of $100 \mathrm{~Pa}$ ); this contribution to the estimation uncertainty is therefore ignored.

An average capillary-strength parameter for each of the two units is calculated from the estimates at the different locations within a given unit. The related standard deviation is considered a measure of spatial variability in $1 / \alpha$. In summary, the $1 / \alpha$ parameter of the lower lithophysal zone is about $580 \mathrm{~Pa}$ with a variability of approximately $100 \mathrm{~Pa}$; the middle nonlithophysal zone has slightly a higher $1 / \alpha$ value of about $600 \mathrm{~Pa}$ and a variability of approximately $130 \mathrm{~Pa}$. These values can be used to derive a probability distribution for the capillary-strength parameter for each unit (see Figure 6-32); they will be used as a basis for probabilistic predictions during model validation (see Section 7.2). Note that such a distribution reflects spatial variability only. Multiple realizations of the underlying permeability field must be created to capture the uncertainty in predicted seepage rates, on account of uncertainty in stochastic small-scale heterogeneity.

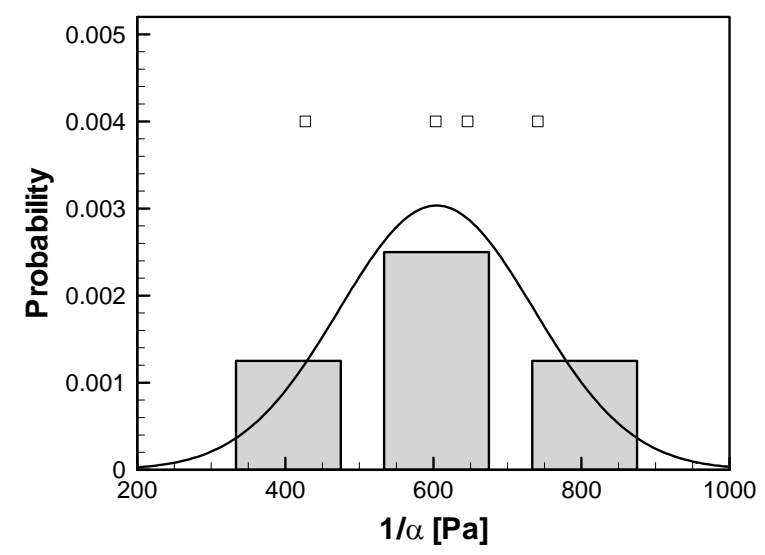

(a)

Output DTN: LB0302SCMREV02.002.

NOTE: These distributions represent spatial variability. The squares indicate the values obtained at individual locations. For the lower lithophysal zone, the squares represent means from multiple inversions, which are plotted along with the standard error of the mean. (The vertical position of the symbols is of no significance.)

Figure 6-32. Histograms and Related Normal Distributions of Van Genuchten Capillary-Strength Parameter $1 / \alpha$ for (a) the Middle Nonlithophysal Zone, and (b) the Lower Lithophysal Zone 
Table 6-8. Summary Statistics of Estimated Capillary-Strength Parameter for Lower Lithophysal Zone and Middle Nonlithophysal Zone

\begin{tabular}{|c|c|c|c|c|c|c|c|c|}
\hline \multicolumn{9}{|c|}{ Lower Lithophysal Zone (TptpII) } \\
\hline \multirow[b]{2}{*}{$\begin{array}{c}\text { Test } \\
\text { Event }^{\mathrm{a}}\end{array}$} & \multirow[b]{2}{*}{ Location } & \multirow[b]{2}{*}{ Interval } & \multirow[b]{2}{*}{$\begin{array}{l}\text { Number of } \\
\text { Inversions }\end{array}$} & \multicolumn{5}{|c|}{ Estimate $1 / \alpha[\mathrm{Pa}]$} \\
\hline & & & & Mean & $\begin{array}{l}\text { Std. } \\
\text { Dev. }\end{array}$ & $\begin{array}{l}\text { Std. } \\
\text { Error }^{d}\end{array}$ & Min. & Max. \\
\hline $65-69$ & SYBT-ECRB-LA\#1 & zone 2 & 17 & 534.3 & 56.8 & 13.8 & 447.7 & 674.1 \\
\hline 61,62 & SYBT-ECRB-LA\#2 & zone 2 & 21 & 557.1 & 56.4 & 12.3 & 457.1 & 676.1 \\
\hline 63,64 & SYBT-ECRB-LA\#2 & zone 3 & 19 & 534.8 & 57.8 & 13.3 & 443.1 & 645.7 \\
\hline 70,71 & SYBT-ECRB-LA\#3 & zone 1 & 23 & 452.0 & 54.7 & 11.4 & 382.8 & 616.6 \\
\hline 89 & Niche 5 & $\mathrm{BH} \# 4$ & 30 & 671.2 & 223.2 & 40.8 & 356.0 & 1197.0 \\
\hline 86 & Niche 5 & $\mathrm{BH} \# 5$ & 24 & 740.5 & 339.0 & 69.2 & 231.1 & 1840.7 \\
\hline & & & $\begin{array}{r}\text { Mean }{ }^{\mathrm{e}}= \\
\text { Std. Dev. }{ }^{\mathrm{f}}=\end{array}$ & $\begin{array}{l}581.6 \\
105.0\end{array}$ & & & & \\
\hline \multicolumn{9}{|c|}{ Middle Nonlithophysal Zone (Tptpmn) } \\
\hline $4,6,8$ & Niche 3 & UM & 1 & 741 & - & - & - & - \\
\hline 41,43 & Niche 4 & UL & 1 & 646 & - & - & - & - \\
\hline 45,48 & Niche 4 & UM & 1 & 603 & - & - & - & - \\
\hline 50,51 & Niche 4 & UR & 1 & 427 & - & - & - & - \\
\hline & & & $\begin{array}{r}\text { Mean }^{\mathrm{e}}= \\
\text { Std. Dev. }{ }^{\mathrm{f}}=\end{array}$ & $\begin{array}{l}604.3 \\
131.5 \\
\end{array}$ & & & & \\
\hline
\end{tabular}

Output DTN: LB0302SCMREV02.002.

a See Table 6-5 on Page 6-29. Data from all indicated test events were jointly inverted.

${ }^{b}$ Each inversion is based on a different realization of the heterogeneous permeability field.

${ }^{c}$ Represents estimation uncertainty on account of small-scale heterogeneity (not available for estimates for the middle nonlithophysal zone).

d Standard error of mean.

e Represents average for given hydrogeologic unit.

$\mathrm{f}$ Represents spatial variability.

$\mathrm{BH}=$ borehole; UM=upper middle; UL=upper left; UR=upper right

\subsection{IMPACT OF RELATIVE HUMIDITY ON SEEPAGE}

As outlined in Section 6.3.3.4, evaporation losses during the seepage experiments conducted in closed-off niches are expected to be insignificant and are thus neglected in the analyses of seepage data from Niches 3 and 4 . If evaporation were significant during liquid-release tests, measured seepage rates would be lower than those expected in a niche with 100 percent relative humidity. Analyzing these lower seepage rates with a model that assumes 100 percent relative humidity in the opening would lead to biased estimates, i.e., the estimated capillary-strength parameter $1 / \alpha$ would be increased to match the lower rates, compensating for the systematic modeling error, which is a result of a conceptual difference. Neglecting evaporation effects in an inverse model is thus nonconservative and requires justification. (Note, however, that assuming 100 percent relative humidity in the drift in a prediction model always yields seepage rates that are higher than those calculated with a model that includes evaporation effects; neglecting evaporation in a prediction model is thus conservative.) 
The SCM developed for the analysis of seepage data from liquid-release tests conducted in interval 10-11 ft of borehole \#4 in Niche 5 includes evaporation effects. This model is therefore suitable for examining the impact of evaporation on calculated seepage rates as relative humidity is reduced from near 100 percent to 85 percent (the value used in the inversions).

Figure 6-33 shows the calculated seepage and evaporation rates as a function of the relativehumidity boundary condition in the niche. Evaporation from the entire niche wall surface is relatively high and comparable to the amount of seepage. Evaporation decreases almost linearly as relative humidity increases, as expected. Nevertheless, the impact of evaporation on the calculated seepage rate is small for these high relative humidity values. Neglecting evaporation effects for the analysis of seepage-rate data from Niches 3 and 4, where relative humidity was close to 100 percent, is thus acceptable. Note that evaporation in the open, ventilated ECRB Cross-Drift is considered substantial and is thus incorporated into the respective seepage models.

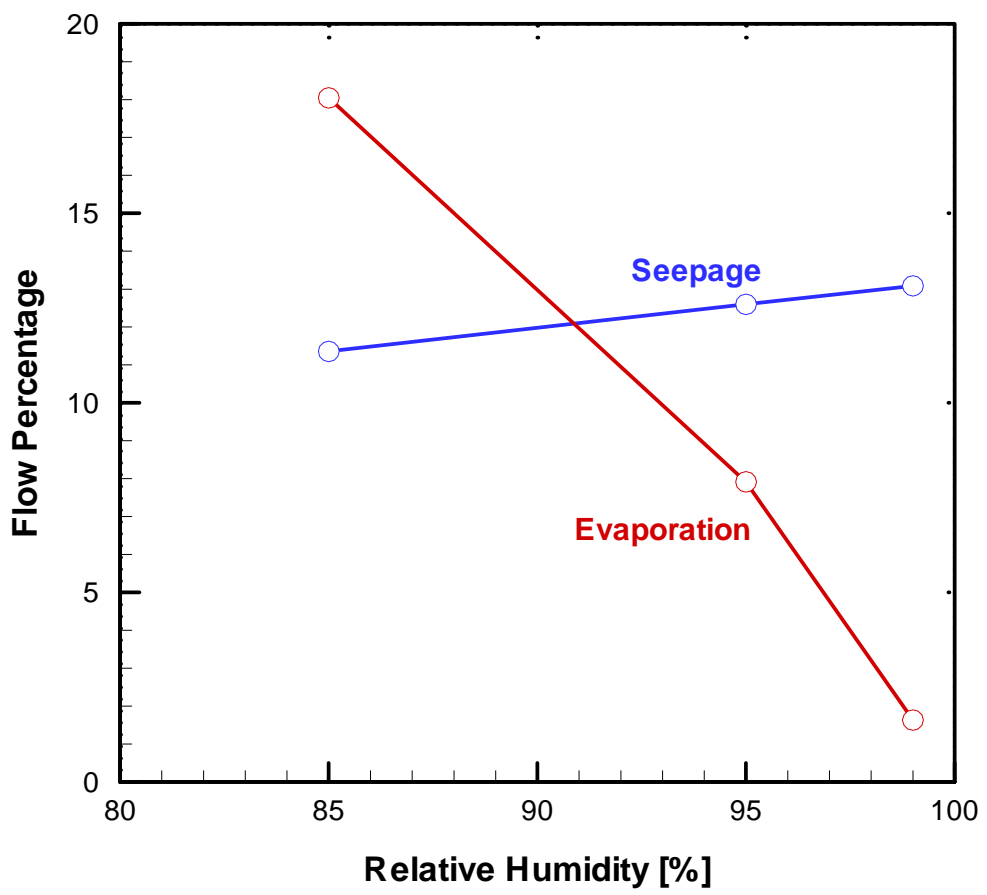

Output DTN: LB0302SCMREV02.001.

NOTE: $\quad$ Flow percentages are plotted 13 days after the start of liquid release. See Figure 6-34 for the seepage and evaporation rates as a function of time with relative humidity of 85 percent. Note that flow percentage is calculated relative to liquid-release rate.

Figure 6-33. Effect of Relative Humidity on Seepage and Evaporation Percentages, Based on the Simulation of a Liquid-Release Test in Interval 10-11 ft of Borehole \#4 in Niche 5

\subsection{DESCRIPTION OF BARRIER CAPABILITY}

In the unsaturated zone, percolation water encountering a waste emplacement drift is partly diverted around the opening on account of the capillary barrier effect. This effect is referred to as the seepage exclusion phenomenon (Philip et al. 1989 [DIRS 105743]). Seepage exclusion reduces the amount of water entering the waste emplacement drift or prevents dripping 
altogether, i.e., the seepage flux is always smaller than the percolation flux (see also discussion in Section 6.3). This barrier effect is an attribute of the natural system at Yucca Mountain, where unsaturated conditions prevail.

The seepage-exclusion phenomenon has been extensively described in the literature (see Philip et al. 1989 [DIRS 105743] and references therein). The related water diversion capability is exploited in practical applications for the protection of landfills and hazardous waste sites (the corresponding engineering designs are sometimes referred to as "Richards Barriers"). These standard engineering applications consider porous materials rather than fractured rocks. However, since the key factors affecting a capillary barrier are permeability and capillarity (see Section 6.3.3), which are properties of fractured rock, the same barrier effect can also be expected to apply at Yucca Mountain.

This hypothesis has been extensively tested through the in situ seepage experiments described in the reports, In Situ Field Testing Processes (BSC 2004 [DIRS 170004], Sections 6.2 and 6.11), Trautz and Wang (2002 [DIRS 160335]), and Section 6.5 above. These experiments show that the seepage rate is less than the injection rate. Because of storage effects and evaporation, the reduced seepage rate by itself does not conclusively prove that water is diverted around the opening, which would assess the barrier capability of the natural system at Yucca Mountain. Evidence that seepage exclusion and flow diversion occurs is provided by the numerical model, which accounts for storage and evaporation effects, and which is capable of reproducing the observed seepage data. The following mass balance can be formulated:

$$
M_{\text {release }}=M_{\text {seepage }}+M_{\text {storage }}+M_{\text {evaporation }}+M_{\text {diversion }}
$$

The cumulative amounts of water that was released $\left(M_{\text {release }}\right)$ and that seeped into the capture system ( $\left.M_{\text {seepage }}\right)$ are known from measurements. Cumulative evaporation $\left(M_{\text {evaporation }}\right)$ is calculated by the model. The rest of the water is either stored in the formation above the opening ( $M_{\text {storage }}$ ) or was diverted around the drift on account of the capillary barrier effect or bypassed the opening through known or unknown geologic features and percolated to depth ( $M_{\text {diversion }}$ ). Both terms can be inferred from the calibrated model. A similar balance can be written for steady-state rates (where the storage term drops out) instead of cumulative amounts of water. The rate balance for the simulation of a typical sequence of liquid-release tests in Niche 5 (Events 86-88 of Table 6-5) is shown in Figure 6-34. 


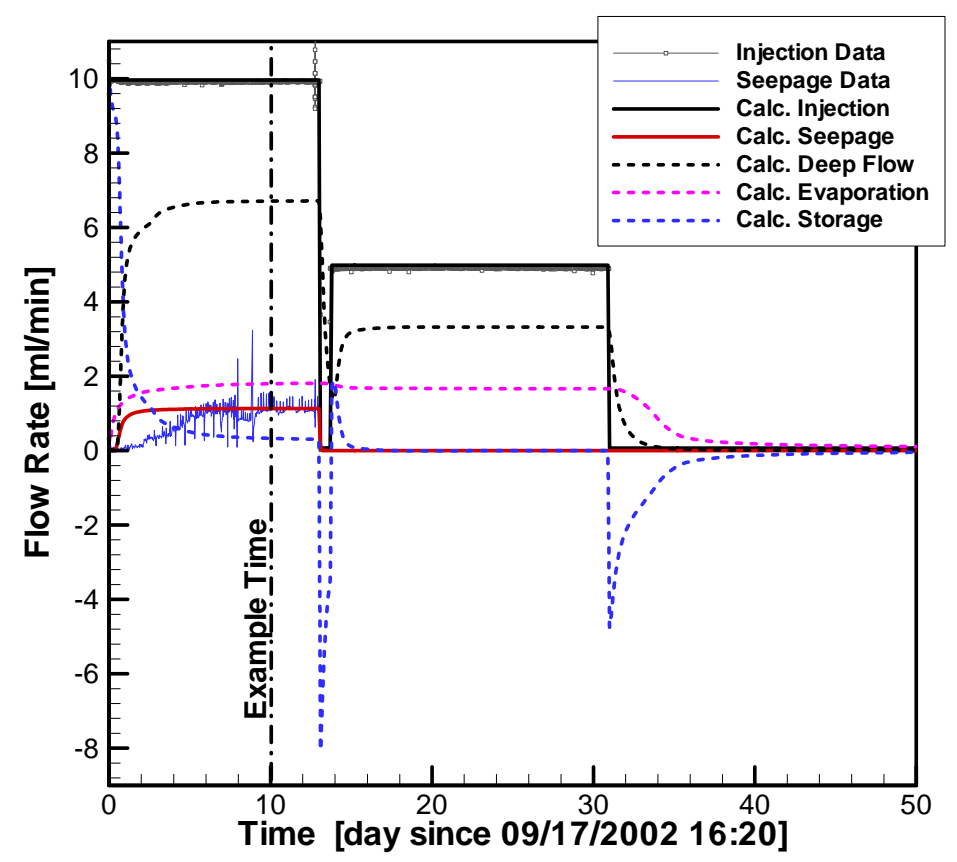

Source: DTN: LB0211NICH5LIQ.001 [DIRS 160792].

Output DTN: LB0302SCMREV02.001.

NOTE: $\quad$ A detailed rate balance on Day 10 (denoted by "Example Time") is given in Table 6-9. "Deep Flow" refers to water diverted around the opening, escaping to depth.

Figure 6-34. Rates of Water Released, Evaporated, Diverted around the Niche, Stored in the Formation above the Niche, and Captured in the Seepage Collection System as a Function of Time

Measured and calculated flow rates for typical liquid-release test in borehole \#4 of Niche 5, on Day 10 (since September 27, 2002 16:20) are summarized in Table 6-9.

Table 6-9. Mass Balance for Typical Seepage Test in Borehole \#4 of Niche 5, on September 27, 2002 at 16:20 (Day 10).

\begin{tabular}{|c|c|c|c|c|}
\hline & \multicolumn{2}{|c|}{ Measured Flow Rate $(\mathrm{ml} / \mathrm{min})$} & \multicolumn{2}{|c|}{ Calculated Flow Rate $(\mathrm{ml} / \mathrm{min})$} \\
\hline Release & 9.915 & $(100.00 \%)$ & 9.967 & $(100.00 \%)$ \\
\hline Seepage & 1.130 & $(11.40 \%)$ & 1.132 & $(11.36 \%)$ \\
\hline Diversion & & - & 6.707 & $(67.30 \%)$ \\
\hline Evaporation & & - & 1.798 & $(18.04 \%)$ \\
\hline Storage & & - & 0.329 & $(3.30 \%)$ \\
\hline
\end{tabular}

Source: DTN: LB0211NICH5LIQ.001 [DIRS 160792].

Output DTN: LB0302SCMREV02.001.

NOTE: The model release includes an ambient infiltration rate of $2.20 \mathrm{~mm} / \mathrm{year}$ $(0.067 \mathrm{ml} / \mathrm{min})$ 
The mass balance indicates that a substantial amount of water is diverted around the opening, confirming the seepage exclusion phenomena and barrier potential of the unsaturated zone at Yucca Mountain.

The mass-balance calculation presented above includes measured values and quantities inferred from the calibrated model. The key quantity of interest demonstrating the barrier capability of the natural system ( $M_{\text {diversion }}$ ) was obtained from the model. To obtain direct evidence that flow diversion occurs during liquid-release tests, a horizontal slot (also referred to as "batwing"; see schematic in Figure 6-4) was excavated from the side of Niche 5. Water released near the center above the niche and eventually collected in the slot at the spring line (Figure 6-35) must have been diverted around the opening, corroborating the barrier capability of the seepage-exclusion effect known to exist in unsaturated formations.

In summary, partial or complete diversion of water around underground openings on account of the capillary barrier effect reduces seepage or even prevents water from dripping into a waste emplacement drift. This effective barrier at the interface between the natural and engineered system has the potential to significantly reduce corrosion, waste dissolution, mobilization of radionuclides and their transport from the invert of the waste emplacement drift to the accessible environment. In addition, the extent of the "shadow zone" beneath the drift and its effectiveness in delaying radionuclide transport is strongly related to the seepage-exclusion phenomenon. (For a discussion of the shadow zone, see Philip et al. (1989 [DIRS 105743])). The barrier capability of flow diversion around underground openings in unsaturated fractured formations has been established theoretically, through modeling and extensive field testing at Yucca Mountain. The Seepage Model for Performance Assessment (SMPA) examines the effectiveness of the seepage barrier for a multitude of conditions. Uncertainty and spatial variability in the seepage-relevant model parameters have been quantified and will be propagated through the downstream seepage models. 


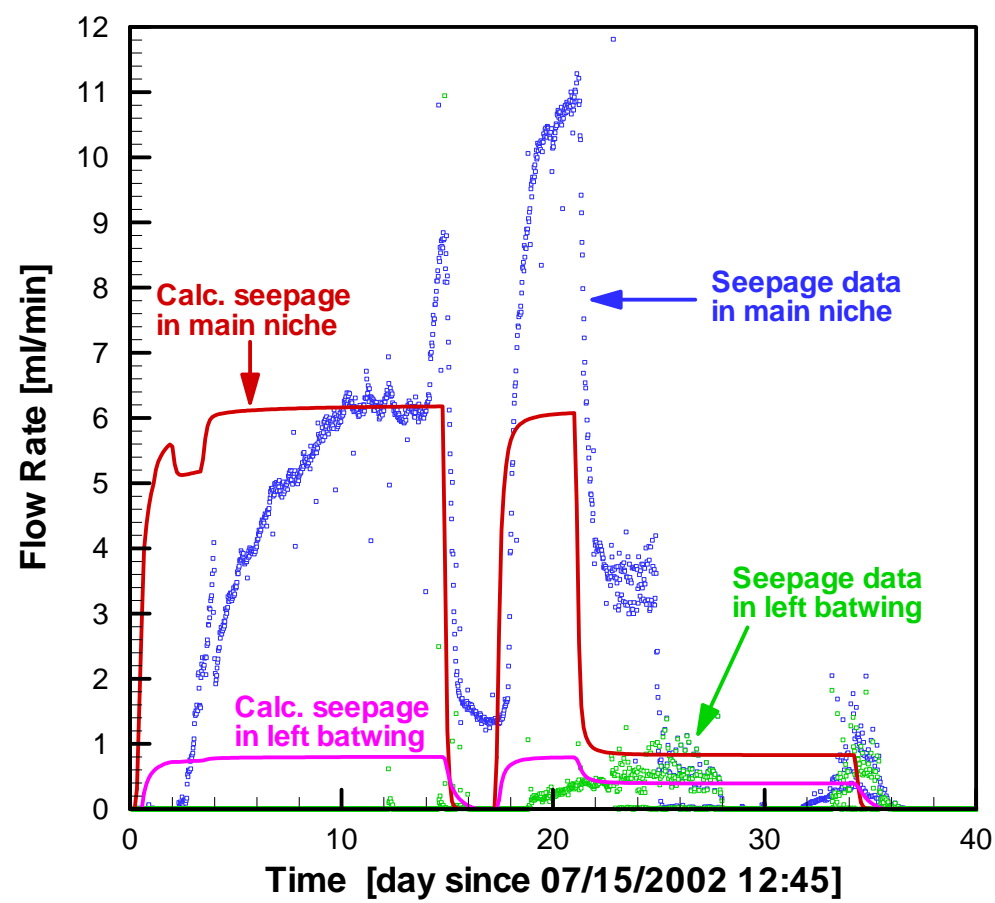

Source: DTN: LB0209NICH5LIQ.001 [DIRS 160796],

Output DTN: LB0302SCMREV02.001.

NOTE: $\quad$ Liquid was released in interval $28-29 \mathrm{ft}$ of borehole \#5. Note that the significant under-prediction of seepage after Day 15 is a result of test interference, as shown in Figure 6-17 and the related discussion.

Figure 6-35. Water Collected in the Slot on the Side of Niche 5 Confirming Flow Diversion around the Opening 


\section{VALIDATION}

\subsection{LEVEL OF RELATIVE MODEL IMPORTANCE}

According to AP-SIII.10Q, Models, Section 3.13, model validation is "a process used to establish confidence that a mathematical model and its underlying conceptual model adequately represent with sufficient accuracy the system, process, or phenomenon in question.” The model validation process also includes developing a level of confidence as stated in AP.SIII.10Q, Models, Section 5.3: "Validate the model to the level of confidence required in accordance with the TWP and Paragraph 5.3.2c) of AP.SIII.10Q.”

While rigorous model testing is fundamentally not possible (Oreskes et al. 1994 [DIRS 152512]), confidence can be gained that the Seepage Calibration Model (SCM) is adequate for its intended purpose to the level of confidence required by the model's relative importance to the potential performance of the repository system. The scientific basis for the model is considered adequate if (1) the model implements the current scientific understanding of unsaturated flow and capillary barrier behavior (see Sections 6.3 and 6.6.1), (2) the model is capable of reproducing available, seepage-relevant data during model calibration (see Section 6.6.3.3), (3) the model is capable of predicting available seepage-relevant data within a predefined level of accuracy considered acceptable for the intended use of the model (see Sections 7.2 and 7.4), and (4) the model is not inconsistent with alternative, viable conceptualizations (see Section 6.4).

The intended use of the SCM is twofold (BSC 2004 [DIRS 169654], Section 2.1.1.9):

The primary purpose of the SCM is to provide the conceptual basis and a general modeling framework for the development of the Seepage Model for Performance Assessment (SMPA). The purpose of the SMPA is to provide predicted seepage rates over a large range of conditions (BSC 2004 [DIRS 169654], Section 2.1.1.8). These seepage rates will be further abstracted and used in a probabilistic performance assessment (PA) calculation.

A secondary purpose of the SCM is to provide seepage-relevant $1 / \alpha$ estimates. This information will be used in the seepage abstraction process for the development of probabilistic parameter distributions. However, additional data and assumptions enter the development of these distributions: the PA calculations do not rely solely on the $1 / \alpha$ values provided by the SCM, but may use broader sampling distributions to reflect additional uncertainties and variabilities.

The relative importance of the SCM to the potential performance of the repository system has been evaluated based on sensitivity analyses as documented in Risk Information to Support Prioritization of Performance Assessment Models (BSC 2003 [DIRS 168796]). These sensitivity analyses indicate that seepage rate does not significantly change the mean annual dose estimate for the nominal scenario (BSC 2003 [DIRS 168796], Section 3.3.2). For the igneous activity groundwater release scenario, which is dominated by the solubility-limited radionuclides ${ }^{239} \mathrm{Pu}$ and ${ }^{240} \mathrm{Pu}$, the annual dose is affected by the amount of flow contacting the waste. Nevertheless, it was concluded that the details of the seepage model do not play a significant role in the estimate of mean annual dose. Consequently, the lowest level of validation (Level I) for the TSPA seepage model and the process models supporting it (such as the SCM) was considered appropriate (BSC 2003 [DIRS 168796], Section 4.3), requiring a demonstration that basic physical principles are appropriately represented. 


\subsection{VALIDATION ACTIVITIES AND CONFIDENCE EVALUATION CRITERIA}

The model validation activities and acceptance criteria presented in the remainder of this section follow those of the TWP for this Model Report (BSC 2004 [DIRS 169654], Section 2.2.1) and in the related planning document Technical Work Plan for: Performance Assessment Unsaturated Zone (BSC 2004 [DIRS 167969], Section I-4-1); these model validation activities exceed the Level I validation activities outlined in Risk Information to Support Prioritization of Performance Assessment Models (BSC 2003 [DIRS 168796], Section 4.3) and Scientific Processes Guidelines Manual (BSC 2002 [DIRS 160313], p. B-1). The guidelines of the Scientific Processes Guidelines Manual are consistent with the Level I validation activities described in AP-2.27Q, Planning for Science Activities, Attachment 3, and AP-SIII.10Q, Models, Paragraph 5.3.2c). Confidence in the adequacy of the SCM for its intended purpose has been gained during the model development process as well as through pre-test predictions of seepage experiments and rigorous post-development model testing as outlined in the TWP for this Model Report (BSC 2004 [DIRS 169654], Section 2.2.1).

\subsubsection{Confidence Building during Model Development to Establish the Scientific Bases and Accuracy for Intended Use}

For Level I validation, the Technical Work Plan for: Unsaturated Zone Flow Analysis and model Report Integration (BSC 2004 [DIRS 169654], Section 2.2.1) refers to Technical Work Plan for: Performance Assessment Unsaturated Zone (BSC 2004 [DIRS 167969], Section I-4-1) where model validation activities for the SCM were planned. Consistent with this planning, the development of the SCM has been conducted according to the following criteria:

1. Selection of input parameters and/or input data, and a discussion of how the selection process builds confidence in the model [AP-SIII.10Q 5.3.2(b) (1) and AP-2.27Q Attachment 3 Level I (a)]

The types and quality of the data selected as input builds confidence in the model. The inputs to the SCM have all been obtained from the TDMS, a controlled source. Section 4.1 identifies the data and design parameters used. Discussions of parameter ranges and uncertainties are covered in Sections 6.3 through 6.6. Model assumptions have been described in Section 5. During model development, input data and parameters were carefully selected (1) to best represent the conditions encountered at the liquid-release test sites, (2) to be compatible with the general modeling approach and parameters from upstream models, and (3) to provide a useful conceptual basis and mathematical model for the downstream modeling activities. Thus, this requirement can be considered satisfied.

2. Description of calibration activities, and/or initial boundary condition runs, and/or run convergences, simulation conditions set up to span the range of intended use and avoid inconsistent outputs, and a discussion of how the activity or activities build confidence in the model. Inclusion of a discussion of impacts of any non-convergence runs [(AP-SIII.10Q 5.3.2(b)(2) and AP-2.27Q Attachment 3 Level I (e)] 
Calibration activities for the SCM are described in Sections 6.3 and 6.6.3.1. The model is calibrated using a minimum number of adjustable parameters (see Section 6.6.3.1). Being able to match seepage-rate data by adjusting only one or two parameters provides confidence that the model appropriately represents the relevant physical processes and features at the experimental site. Sensitivity analyses have been performed in support of the parameter selection process and to test the appropriateness of certain model simplifications. Detailed discussion of the model domain and boundary conditions for the SCM can be found in Sections 6.6.2.2 and 6.6.2.3. All simulations converged; therefore, discussion about non-convergence runs is not relevant for this Model Report.

3. Discussion of the impacts of uncertainties to the model results including how the model results represent the range of possible outcomes consistent with important uncertainties [(AP-SIII.10Q 5.3.2(b)(3) and AP-2.27Q Attachment 3 Level 1 (d) and (f)]

Uncertainties in the characteristics of the natural system are explicitly considered in the SCM development. Uncertainty associated with initial parameterization and in the inverse modeling and data-analysis approach is described in Sections 6.3.3 and 6.3.4, respectively. The parameter ranges are technically defensible and reasonably account for system uncertainties and variabilities. The results are discussed in Section 6.6.4.

The simulations were carried out using a well-established numerical simulator (see also Section 6.6.1), which ensures mass conservation at each time step. Nevertheless, an explicit mass-balance calculation has been performed (see Section 6.8) to demonstrate that "basic physical principles such as conservation of mass” (BSC 2003 [DIRS 168796], p. 4-2) are appropriately represented. Model assumptions and simplifications have been described in Sections 5 and 6.6. Boundary and initial conditions are discussed in Sections 6.6.2.3 and 6.6.2.4, respectively.

The main activity presented in this Model Report is the calibration of the SCM against seepagerate data from liquid-release tests conducted at Yucca Mountain. Development of the SCM is closely coupled with seepage testing in niches and along boreholes of the systematic hydrologic characterization program. The iteration between testing and modeling leads to improvements in test design and confidence in the modeling approach. As outlined in Section 6.3.4, the approach ensures that the estimated drift-scale parameters are site-specific, seepage-relevant, and model-related, and therefore suitable for the prediction of seepage into waste emplacement drifts using the conceptually compatible Seepage Model for Performance Assessment, thus avoiding inconsistencies in the outputs. All simulation runs converged to a solution, which are described in Section 6.6.3.3. A summary discussion of the adequacy of the approach can be found in Section 8.3 below.

The uncertainty and spatial variability of seepage were evaluated and described by means of a parameter distribution (see Section 6.6.4), which is provided as input to the seepage abstraction process. A summary discussion on uncertainties and their impact is given in Section 8.2.

Natural analogues as those reported in Natural Analogue Synthesis Report (BSC 2004 [DIRS 169218], Section 8) provide evidence that the concept of seepage exclusion describes a process that actually occurs in caves, lava tubes, rock shelters and buildings. The qualitative 
evidence for seepage exclusion and flow diversion was substantiated by quantitative seepage measurements in limestone caves. These studies show that seepage is considerably smaller than the pertinent percolation flux (BSC 2004 [DIRS 169218], Section 8.2), corroborating the seepage testing and modeling results at Yucca Mountain. Although examples exist where large amounts of seepage can be observed (e.g., the Mission Tunnel through the Santa Ynez Mountains near Santa Barbara, California, and the Mitchell Caverns, located on the eastern slope of the Providence Mountains in the East Mojave National Preserve, California), and cave minerals formed by water are common in unsaturated environments, these hydrogeologic settings are significantly different (i.e., shallow depth; high percolation flux; different geologic formation) from those at Yucca Mountain and, thus, are not appropriate analogues (BSC 2004 [DIRS 169218], Sections 8.4 and 15.7.5). Calcite-deposition data in lithophysal cavities (see Section 6.4.3) further corroborate the seepage exclusion concept.

\subsubsection{Confidence Building after Model Development to Support the Scientific Basis of the Model}

For confidence building after model development, the planning document (BSC 2004 [DIRS 167969], Section I-4-1-1) imposes the requirement that the SCM be validated by one or more of the following methods:

1. AP-SIII.10Q, Section 5.3.2(c), Method 1; Corroboration with Experimental Data (see Section 7.2.2.1)

2. AP-SIII.10Q, Section 5.3.2(c), Method 7, Corroboration of Pre-Test Predictions to Data (see Section 7.2.2.2)

3. AP-SIII.10Q, Section 5.3.2(d), Technical Review through Publication in a Refereed Professional Journal (see Section 7.2.2.3)

\subsubsection{Corroboration with Data from Field Experiments}

Blind predictions of seepage rates were performed with the calibrated SCM, simulating tests that were not used for model calibration, and that involve a different portion of the fracture system and a different section of the drift or niche. The DTNs containing the data used for model validation are identical to those listed in Table 4-1, Table 4-2, and Table 4-3. In addition, Table 6-5 identifies the test event used for validation purposes. Moreover, each DTN is listed below along with the discussion of individual validation test cases.

If seepage rates were successfully predicted (according to an acceptance criterion discussed below), confidence was gained that the seepage process is adequately conceptualized in the SCM. The proposed modeling approach is therefore reasonable and can be used as the basis for the development of the predictive SMPA. This addresses the primary purpose of the SCM.

Given the probabilistic nature of the TSPA calculations, a probabilistic acceptance criterion is adopted to ensure that prediction uncertainty is included in the validation process as well as in future model predictions. This addresses the secondary purpose of the SCM. The acceptance criteria were defined in the TWP (BSC 2004 [DIRS 169654], Section 2.2.1). The SCM will be considered validated if one of the following acceptance criteria is met: 
(1) Ninety-five percent of the measured late-time seepage-rate data fall within the 95 percent confidence region predicted by the model. Note that since the prediction model uses a parameter set that is related to an entire hydrogeologic unit (rather than separate parameter sets for individual test locations), this acceptance criterion shall be applied to the combined test data in a given unit rather than to data from individual liquid-release tests. A poor prediction of early-time seepage data is considered acceptable, because the intended use of the model does not include the accurate simulation of short-term, transient seepage events. Seepage will be calculated in response to steady percolation flux predictions.

(2) The model overpredicts seepage.

(3) An explanation can be found for why the observed and predicted seepage rates deviate significantly for a residual that fails to meet Criteria (1) and (2), and this explanation does not concern and thus invalidate the general approach.

The combination of Criteria (1) and (2) implies that the 95 percent confidence region should be regarded as one-sided, i.e., 95 percent of the measured seepage-rate data should be less than the upper bound of the uncertainty band. Figure 7-1 through Figure 7-9 show a two-sided error band where 90 percent of the Monte Carlo simulations fall within that band, and 95 percent are between zero seepage (the physical minimum) and the upper bound.

Note that these acceptance criteria are stricter than the general acceptance criterion of BSC (2003 [DIRS 168796], p. 4-2), which only requires a demonstration that "basic physical principles such as conservation of mass” are appropriately represented.

If any of the acceptance criteria are met, the SCM can be considered validated for its primary and secondary purpose, according to the definition in Section 3.16 of AP-SIII.10Q, Models.

Several methods can be employed to assess the uncertainty of model predictions as a result of input parameter uncertainty. When computationally feasible, Monte Carlo simulations (Finsterle 1999 [DIRS 104367], pp. 76-79) are the method of choice because they automatically account for nonlinearities in the model. A simplified linear uncertainty-propagation analysis can be chosen in cases where running many simulations is prohibitive. The first-order-second-moment (FOSM) uncertainty propagation analysis (see Eq. 6-16) is valid for predicting uncertainties that can be approximated by a normal distribution (Finsterle 1999 [DIRS 104367], pp. 74-76).

Both methods require that probability distributions be determined for each input parameter considered variable or uncertain. Since the seepage experiments used for validation were conducted at locations different from those used for calibration, input parameters other than the ones estimated during calibration can be considered variable or uncertain. Selecting $1 / \alpha$ as the only parameter reduces the prediction uncertainty, i.e., it is more difficult for the SCM to pass the validation acceptance criteria. The approach followed here is therefore conservative.

The van Genuchten parameter $1 / \alpha$ is both spatially variable and uncertain. A measure of spatial variability was obtained by analyzing data from liquid-release tests performed at multiple locations. The resulting distribution is discussed in Section 6.6.4 and visualized in Figure 6-32. 
Small-scale heterogeneity has been identified as the key source of estimation uncertainty. For the validation of the model and parameters for the lower lithophysal zone, the combined impact of spatial variability and uncertainty was propagated through the prediction models by means of Monte Carlo simulations. In each simulation, the van Genuchten parameter $1 / \alpha$ was sampled from a normal distribution (with a mean of $580 \mathrm{~Pa}$, a standard deviation of $100 \mathrm{~Pa}$, and an admissible parameter range from $280 \mathrm{~Pa}$ to $880 \mathrm{~Pa}$ ) and a new realization of the random permeability field was generated. For the prediction of seepage rates (and their uncertainty bands) from liquid-release tests conducted in Niches 3 and 4 (middle nonlithophysal zone), linear uncertainty-propagation analysis was used. These FOSM analyses only consider spatial variability in the input parameters (standard deviations for $\log (1 / \alpha)$ and $\log (\mathrm{k})$ were set to reasonable values of 0.1 , and for $\log (\varphi)$ to 0.3 based on DTN: LB0010SCMREV01.001); uncertainty as a result of small-scale heterogeneity is not included. (Note that while the model itself is heterogeneous, only one realization can be considered in a FOSM analysis.) This approach is conservative because it reduces the range of predicted seepage rates, making it more difficult for the SCM to meet the stringent validation criteria outlined above.

In general, 100 Monte Carlo simulations were performed for each validation test case. This sample size is considered sufficient to obtain the output statistics of interest. Specifically, the mean of the predicted seepage rate is accurately identified from a sample of 100 values, and a sufficiently accurate estimate of the prediction uncertainty can be derived from the histogram consisting of 100 data points. Only 50 Monte Carlo realizations were examined for the tests conducted in Niche 2, which is considered sufficient given the limited usefulness of these short-term liquid-release tests for validation purposes.

\subsubsection{Corroboration through Comparison of Data with Pre-Test Model Predictions}

Pre-test predictions of seepage rates were made for a representative seepage test planned for Niche 5 as planned (Test Plan for: Niche 5 Seepage Testing (BSC 2001 [DIRS 158200])). These predictions were based on the proposed conceptual model, but using preliminary parameters, which were derived from testing in a single systematic testing borehole (SYBT-ECRB-LA\#2) in the Tptpll unit [see previous revision of Seepage Calibration Model and Seepage Testing Data, (CRWMS M\&O 2001 [DIRS 153045])]. The pre-test predictions were submitted to the TDMS under DTN: LB0207PRESCMN5.001 [DIRS 160410] and DTN: LB0207PRESCMN5.002 [DIRS 161192]. These predictions were qualitatively compared with seepage data collected in Niche 5. It is important to realize that these pre-test predictions were made based on a preliminary understanding of seepage behavior in the Tptpll unit.

The Seepage Calibration Model will be considered corroborated by pre-test predictions if (1) 95 percent of the measured data fall within the 95 percent confidence region predicted by the model using linear uncertainty-propagation analysis, (2) if the model overpredicts seepage, or (3) if an explanation can be found for why the observed and predicted seepage rates deviate significantly.

\subsubsection{Corroboration Through Technical Review by Publication in Refereed Journals}

The general modeling approach has been reviewed and published in a number of scientific journals (Birkholzer et al. 1999 [DIRS 105170]; Finsterle 2000 [DIRS 151875]; Salve et al. 
2002 [DIRS 161318]; Doughty et al. 2002 [DIRS 161320]; Finsterle and Trautz 2001 [DIRS 161148]; Trautz and Wang 2002 [DIRS 160335]).

\subsection{RESULTS OF MODEL VALIDATION ACTIVITIES}

In this section, the range of predicted seepage rates is compared to seepage-rate data collected from liquid-release tests that were not used for model calibration. The range was evaluated by means of Monte Carlo simulations (all tests in lower lithophysal zone and short-term tests in Niche 2) and using FOSM error propagation analyses (tests in Niches 3 and 4, middle nonlithophysal zone). The indicated range contains 90 percent of the Monte Carlo simulation results, or -if FOSM error propagation analysis is used-represents the 90 percent confidence band. Considering that realizations below the lower bound of the confidence limit are acceptable (see Criterion (2) of Section 7.2.2.1), the range between zero seepage and the upper bound corresponds to a one-sided uncertainty band on the 95 percent significance level. Note that the linearity and normality assumption inherent in FOSM breaks down for large standard deviations and for experiments near or below the seepage threshold, where nonlinearities prevail. If no seepage is predicted with the mean parameter set, the uncertainty band vanishes. Furthermore, FOSM may assign a certain probability to negative seepage rates. This specific artifact of the normality assumption inherent in FOSM is of no concern because it only affects the lower bound of the predicted seepage rates.

\section{SYBT-ECRB-LA\#2, Lower Lithophysal Zone}

Three liquid-release tests (Events 52-54 of Table 6-5) were performed in zone 1 of borehole SYBT-ECRB-LA\#2. No data from this zone have been used for model calibration. Starting May 11, 2000, 09:30, approximately 652 liters of water were released at a very high average rate of approximately $464 \mathrm{ml} / \mathrm{min}$. A second test was conducted starting May 17, 2000, 11:39, in which about 20 liters of water were released at an approximate rate of $35 \mathrm{ml} / \mathrm{min}$. The final, long-term seepage test started on May 23, 2000, 14:22, releasing approximately 334 liters of water at an average rate of $26 \mathrm{ml} / \mathrm{min}$ (Finsterle 2002 [DIRS 161043], p. 74). Input files for simulating this test sequence are created analogous to the procedure described in Section 6.6.2 (Finsterle 2002 [DIRS 161043], pp. 82-83). The software iTOUGH2 V5.0 (LBNL 2002 [DIRS 160106]) is used to perform 100 Monte Carlo simulations. The resulting predictions of seepage rates into the drift are shown in Figure 7-1.

The calibrated SCM predicts seepage rates for the first test event that are higher than the observed data (Figure 7-1a). This result is expected because the high release rate caused an unknown amount of the seepage water to bypass the capture system, i.e., the measured seepage rates are known to be too low. This test event therefore cannot be used for rigorous model validation, but it does serve to qualitatively corroborate the SCM predictions.

As shown in Figure 7-1b and Figure 7-1c, the measured seepage-rate data for the lower-rate test events lie within the band containing 90 percent of the Monte Carlo simulations. Noise in the data causes some measurements to exceed this band; however, the time-averaged seepage is within the prediction-uncertainty band. Thus, an interpretation of probabilistic seepage predictions made with the calibrated SCM would not lead to erroneous statements about seepage, meeting the validation acceptance criterion. 
(a)
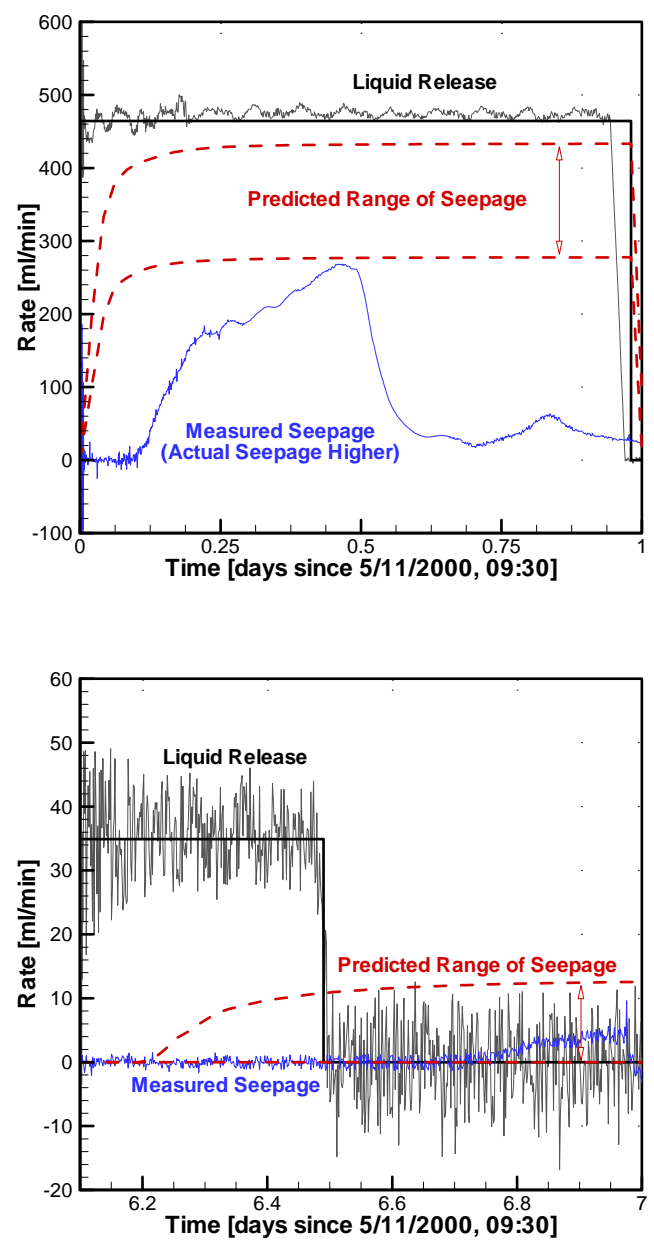

(b)

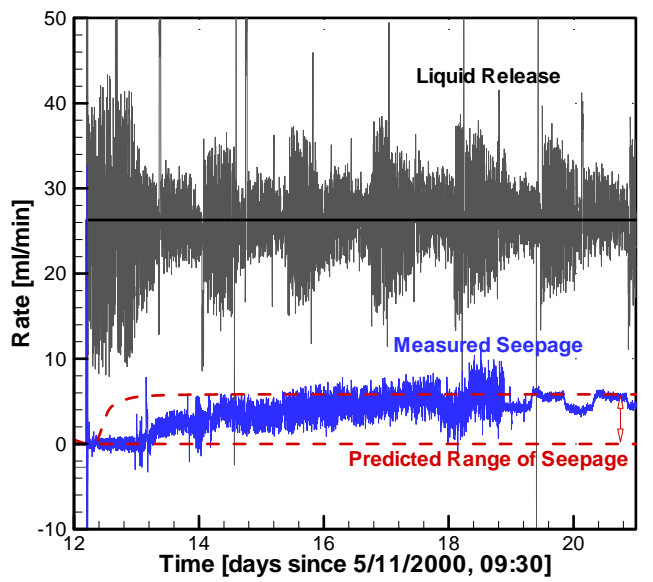

(c)

Source: DTN: LB00090012213U.002 [DIRS 153154].

Output DTN: LB0302SCMREV02.001.

NOTE: (a) Event 52 (the actual seepage is higher than the measured seepage, because part of the seepage water bypassed the capture system), (b) Event 53, and (c) Event 54.

Figure 7-1. Liquid-Release Rates, Measured Seepage Rates, and Range of Predicted Seepage Rates Containing 90 Percent of the 100 Monte Carlo Simulations of the Experiment Conducted in Zone 1 of Borehole SYBT-ECRB-LA\#2 
A long-term liquid-release test was conducted in zone 2 of borehole SYBT-ECRB-LA\#2, starting May 11, 2000, 05:20 (Events 55 and 56 of Table 6-5). Figure 7-2 shows the liquidrelease rate, the measured seepage rate, and the range of predicted seepage rates containing 90 percent of 100 Monte Carlo simulations. Water release occurs at a rate of approximately $30 \mathrm{ml} / \mathrm{min}$ for more than two weeks. (The noise seen in the release and seepage-rate data changes with time as the water tank is emptied or filled, respectively.) It takes about 9 days for the water to migrate to the drift ceiling and to build up sufficient saturation for seepage to occur. The fluctuations in the observed seepage rates reflect the change in ventilation conditions (ventilation is on during daytime, and off during nighttime and weekends). This ventilation regime is approximately implemented in the model by changing the water potential in the drift, accounting for both the reduction in relative humidity and the reduction in the evaporative boundary-layer thickness during active ventilation (for details, see Finsterle (2002 [DIRS 161043], pp. 134-135)). The data fall within the uncertainty band of the model prediction, meeting the validation acceptance criterion.

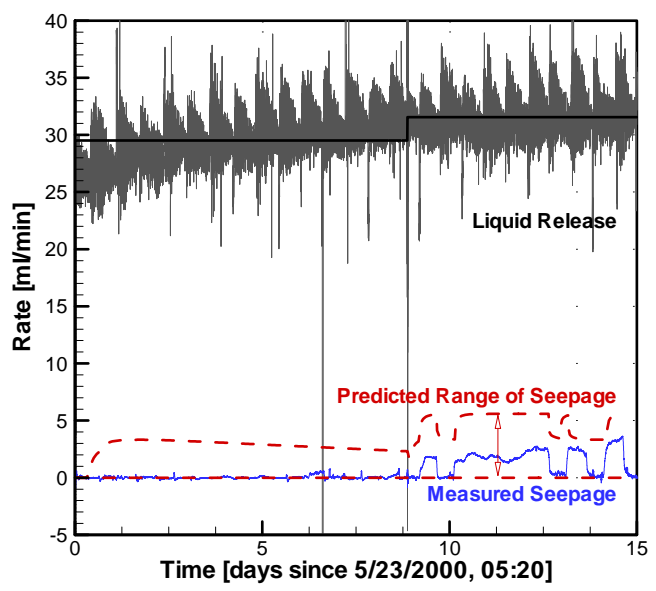

Source: DTN: LB00090012213U.002 [DIRS 153154].

Output DTN: LB0302SCMREV02.001.

Figure 7-2. Liquid-Release Rates, Measured Seepage Rates, and Range of Predicted Seepage Rates Containing 90 Percent of the 100 Monte Carlo Simulations of the Experiment Conducted in Zone 2 of Borehole SYBT-ECRB-LA\#2

Four consecutive liquid-release tests (Events 57-60 of Table 6-5) were performed in zone 3 of borehole SYBT-ECRB-LA\#2. Starting May 17, 2000, 11:39, more than 1000 liters of water were released during the 41-day testing period. However, seepage occurred only during the last $1 \frac{1}{2}$ days of testing (see Figure 7-3), i.e., shortly before the test was terminated on June 27, 2000, 09:37 because of an operational conflict in the ECRB. Only about 1 liter seeped into the drift. Furthermore, the early-time seepage rate is highly dependent on the formation storage capacity, which again is of no relevance for the ultimate purpose of the SCM. The calibrated SCM predicts early seepage initiation and a seepage rate that is slightly higher than the observed values. Nevertheless, the data lie within the simulation uncertainty band, i.e., the acceptance criterion for model validation is met. 


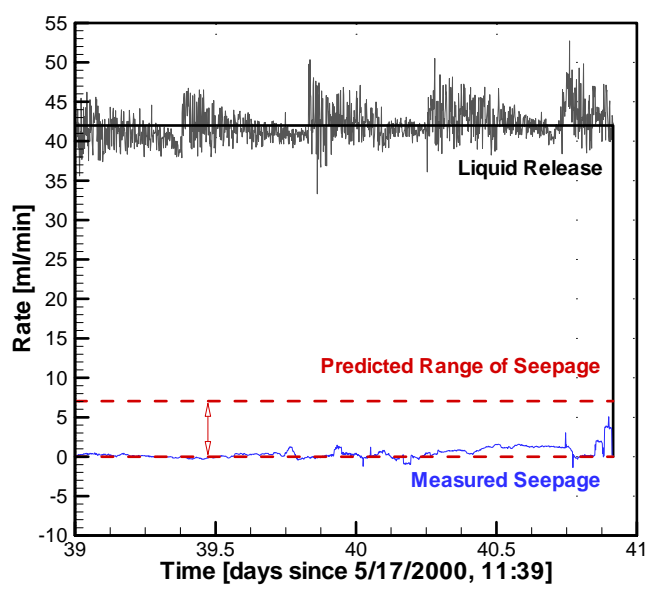

Source: DTN: LB00090012213U.002 [DIRS 153154].

Output DTN: LB0302SCMREV02.001.

Figure 7-3. Liquid-Release Rates, Measured Seepage Rates, and Range of Predicted Seepage Rates Containing 90 Percent of the 100 Monte Carlo Simulations of the Experiment Conducted in Zone 3 of Borehole SYBT-ECRB-LA\#2

\section{SYBT-ECRB-LA\#3, Lower Lithophysal Zone}

Water was released from zone 2 of borehole SYBT-ECRB-LA\#3 at various rates over a period of 2 months (Events 72-76 of Table 6-5) without inducing any observable seepage. No data from this zone have been used for model calibration. While most of the 100 Monte Carlo simulations resulted in zero seepage, the upper bound of the confidence band is determined by the few realizations that promote seepage (see Figure 7-4). The validation test obviously meets the acceptance criteria.

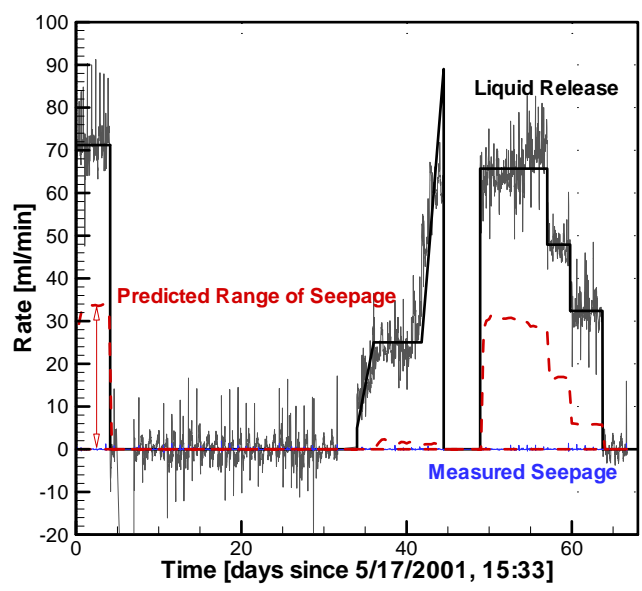

Source: DTN: LB0203ECRBLIQR.001 [DIRS 158462].

Output DTN: LB0302SCMREV02.001.

Figure 7-4. Liquid-Release Rates, Measured Seepage Rates, and Range of Predicted Seepage Rates Containing 90 Percent of the 100 Monte Carlo Simulations of the Experiment Conducted in Zone 2 of Borehole SYBT-ECRB-LA\#3. 
Niche 5, Borehole \#5, Interval 28-29 ft, May 6, 2002, Lower Lithophysal Zone

Water was released from interval 28-29 ft of borehole \#5 in Niche 5 starting on May 6, 2002 at different rates for 4 days (Event 78 of Table 6-5). Testing resumed on May 16, 2002 at a rate of approximately $60 \mathrm{ml} / \mathrm{min}$ for 5 days, resulting in observable seepage (Event 81) as shown in Figure 7-5. These test data were not used for calibration. During the first 4 days, the release rate fluctuated significantly, and the test was terminated due to data-logger problems while the seepage rate was still increasing (before it reached near-steady-state conditions). Because the calibrations were performed to match the late-time response (see Section 6.6.3.2), the model prediction during this initial 4 days overestimated the observed seepage rates, meeting the validation acceptance criteria. The release rate during the second period (after May 16, 2002) was relatively constant and allowed enough time for the seepage rate to reach an approximately constant rate. The late-time seepage-rate data in this period fall within the uncertainty band of the model prediction, meeting the validation acceptance criteria.

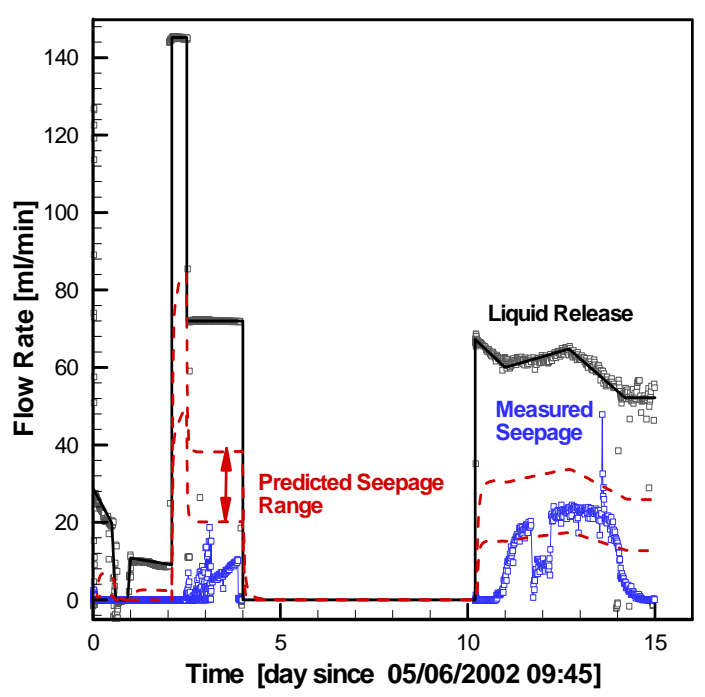

Source: DTN: LB0207NICH5LIQ.001 [DIRS 160408].

Output DTN: LB0302SCMREV02.001.

Figure 7-5. Liquid-Release Rates, Measured Seepage Rates, and Range of Predicted Seepage Rates Containing 90 Percent of the 100 Monte Carlo Simulations of the Experiment Conducted in Interval 28-29 ft of Borehole \#5 in Niche 5, Starting on May 6, 2002.

Niche 5, Borehole \#5, Interval 28-29 ft, July 15, 2002, Lower Lithophysal Zone

Water was released from interval 28-29 ft of borehole \#5 in Niche 5 starting on July 15, 2002 at different rates for 34 days, resulting in observable seepage (Events 86-88 of Table 6-5). The seepage data of the first 14 days were used for calibration (see Figure 6-27). Water released from interval 21-22 ft of borehole \#3 between July 31, 2002 (Day 15) and August 14, 2002 (Day 25) was partially collected by the capture system intended for borehole \#5 (see Figure 6-17, Days 210 through 221). Therefore, only data between Day 25 and Day 35 is used for validation. Most of the 100 Monte Carlo simulations resulted in zero seepage during this validation period. The 
observed seepage rate falls within the 90 percent confidence interval and thus meets the acceptance criteria (see Figure 7-6).

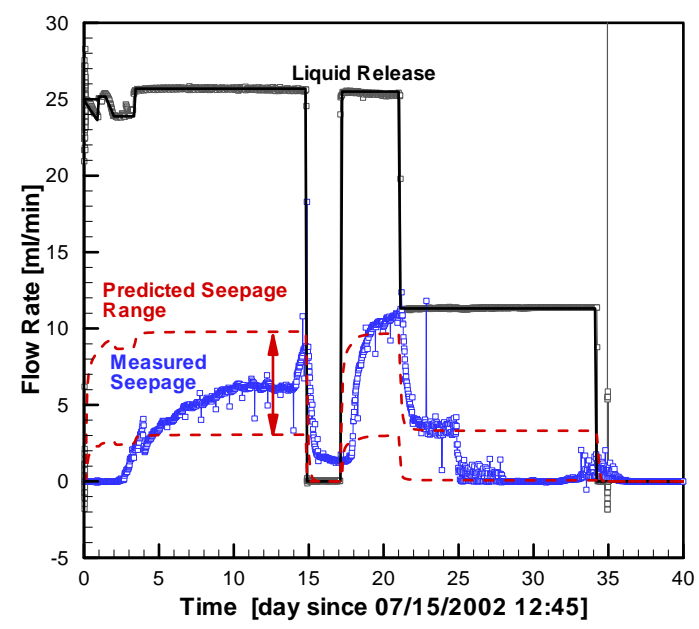

Source: DTN: LB0209NICH5LIQ.001 [DIRS 160796].

Output DTN: LB0302SCMREV02.001.

NOTE: Effective validation period is between Day 25 and Day 35.

Figure 7-6. Liquid-Release Rates, Measured Seepage Rates, and Range of Predicted Seepage Rates Containing 90 Percent of the 100 Monte Carlo Simulations of the Experiment Conducted in Interval 28-29 ft of Borehole \#5 in Niche 5, Starting July 15, 2002.

Niche 5, Borehole \#4, Interval 10-11 ft, Lower Lithophysal Zone

Water was released from interval 10-11 ft of Borehole \#4 in Niche 5 starting on September 17, 2002 and lasting for approximately one month. Two rates were applied; Event 89 (see Table 6-5) (Day 0 to Day 13) resulted in observable seepage and was used for calibration (see Figure 6-25); Event 90 (Day 14 to Day 31) did not result in observable seepage and is used for validation. While most of the 100 Monte Carlo simulations resulted in zero seepage during this validation period, a few simulations yielded seepage and thus a non-zero upper bound of the confidence region. The validation meets the acceptance criteria (see Figure 7-7). 


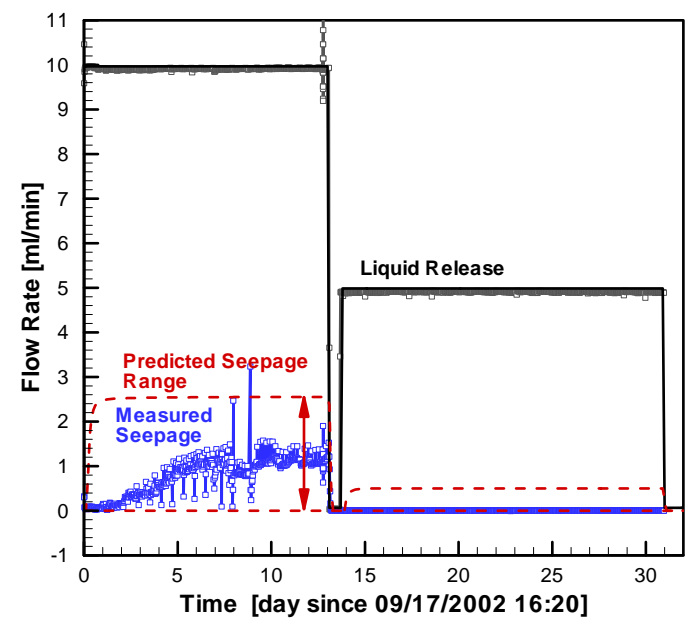

Source: DTN: LB0211NICH5LIQ.001 [DIRS 160792].

Output DTN: LB0302SCMREV02.001.

NOTE: $\quad$ Data for Days 1 through 13 were used for calibration; validation period is between Day 14 and Day 31.

Figure 7-7. Liquid-Release Rates, Measured Seepage Rates, and Range of Predicted Seepage Rates Containing 90 Percent of the 100 Monte Carlo Simulations of the Experiment Conducted in Interval 10-11 ft of Borehole \#4 Niche 5

\section{Niche 3, Middle Nonlithophysal Zone}

Predictions of seepage rates from eight liquid-release tests performed in Niche 3 were performed. The prediction uncertainty as a result of spatial variability in the input parameters is evaluated using FOSM uncertainty-propagation analysis.

Figure 7-8 shows the observed seepage-rate data, the predicted seepage rates, and the simulation uncertainty bands for the eight liquid-release tests performed in interval UM 4.88-5.18 and interval UL 5.49-5.80 of Niche 3. Based on the acceptance criteria outlined in Section 7.2, seven of the eight tests are considered acceptable, even when applied to individual tests. [Since the prediction model uses a parameter set that is related to the entire Tptpll unit (rather than separate parameter sets for each individual test), the first acceptance criterion outlined in Section 7.2 shall be applied to the entire data set for this unit rather than to data from an individual liquid-release test at a single location.] In Test UM 4.88-5.18 (Event 12 of Table 6-5), which started October 11, 1999, the observed late-time seepage rates are slightly larger than the relatively narrow uncertainty band. The tests would be considered acceptable if the chosen uncertainty in the input parameters were marginally increased (e.g., to account for uncertainty as a result of the stochastic nature of the underlying heterogeneous permeability field). Such an increase takes place during seepage abstraction (BSC 2004 [DIRS 169131], Section 6.6). 

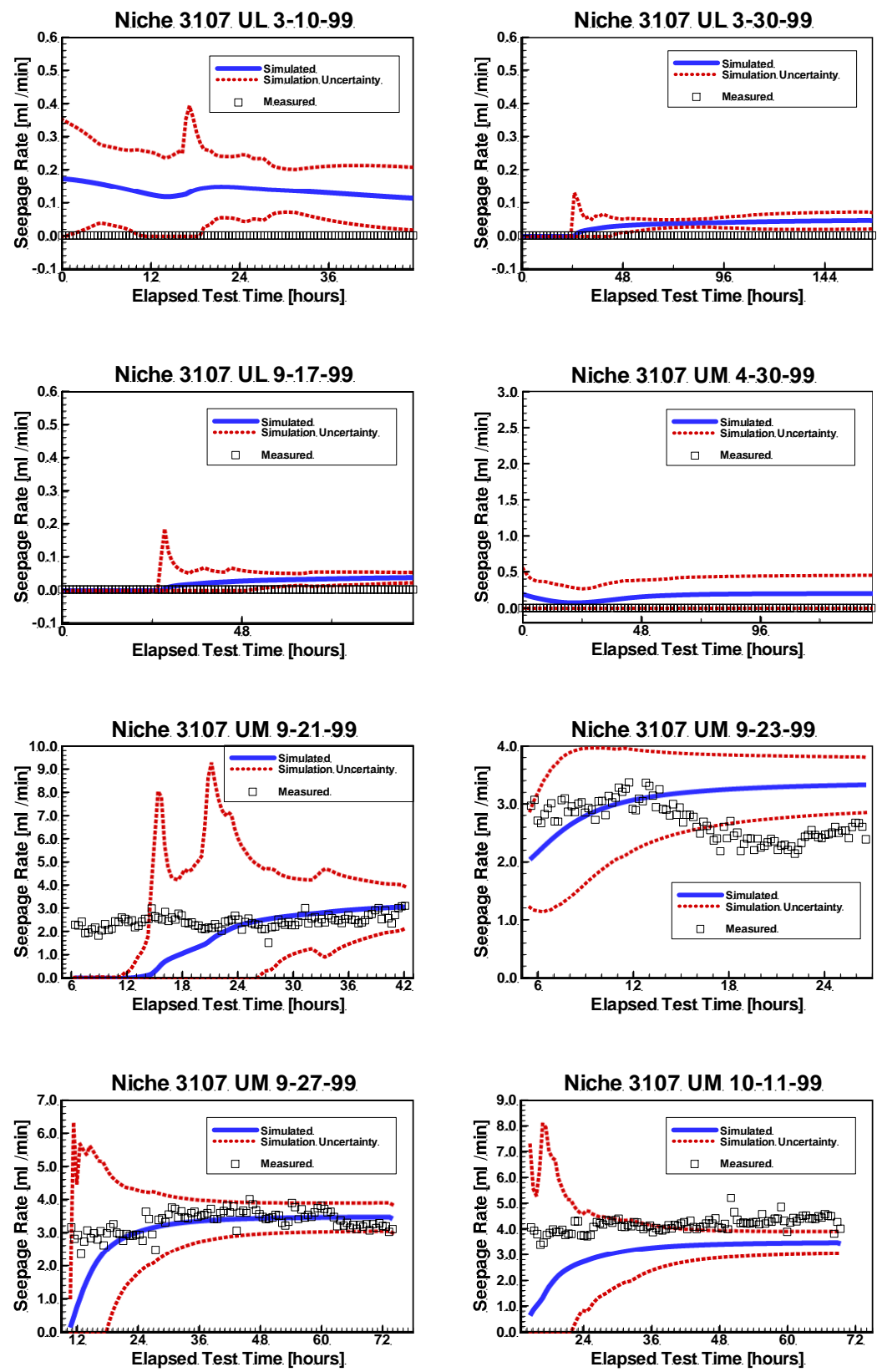

Source: DTN: LB0010NICH3LIQ.001 [DIRS 153144].

Output DTN: LB0010SCMREV01.001.

NOTE: Linear uncertainty propagation analysis was used to calculate the uncertainty band of the model predictions.

Figure 7-8. Validation of Seepage Calibration Model and Tptpmn Seepage-Relevant Parameters Using Data From Niche 3 (Events 1, 2, 3, 7, 9, 10, 11, 12 of Table 6-5) 


\section{Niche 4, Middle Nonlithophysal Zone}

Predictions of seepage rates from five liquid-release tests performed in Niche 4 were conducted. The prediction uncertainty as a result of uncertainty in the input parameters is evaluated using FOSM error propagation analysis.

Figure 7-9 shows the observed seepage-rate data, the predicted seepage rates, and the simulation uncertainty bands for five liquid-release tests performed in interval UL 7.62-7.93, interval UM 6.10-6.40, and interval UR 5.18-5.48 of Niche 4. Based on the acceptance criteria outlined in Section 7.2.2.1, four of the five tests are considered acceptable. In Test UL 7.62-7.93 (Event 40 of Table 6-5), which started November 3, 1999, the observed late-time seepage rates are slightly larger than the relatively narrow uncertainty band. The tests would be considered acceptable if the chosen uncertainty in the input parameters were slightly increased, e.g., to account for aleatory uncertainty.

The seepage-rate data from the test in interval UL 7.62-7.93, starting November 3, 1999, show some outliers that appear to be random, possibly caused by a disturbance of the balance measuring cumulative seepage mass. The seepage-rate data from the test in interval UR 5.18-5.48, starting December 7, 1999, shows a spike approximately 60 hours after water release. The cause for this erratic behavior is unknown. Note, however, that despite these outliers, 95 percent of the observed data are within the predicted range. 

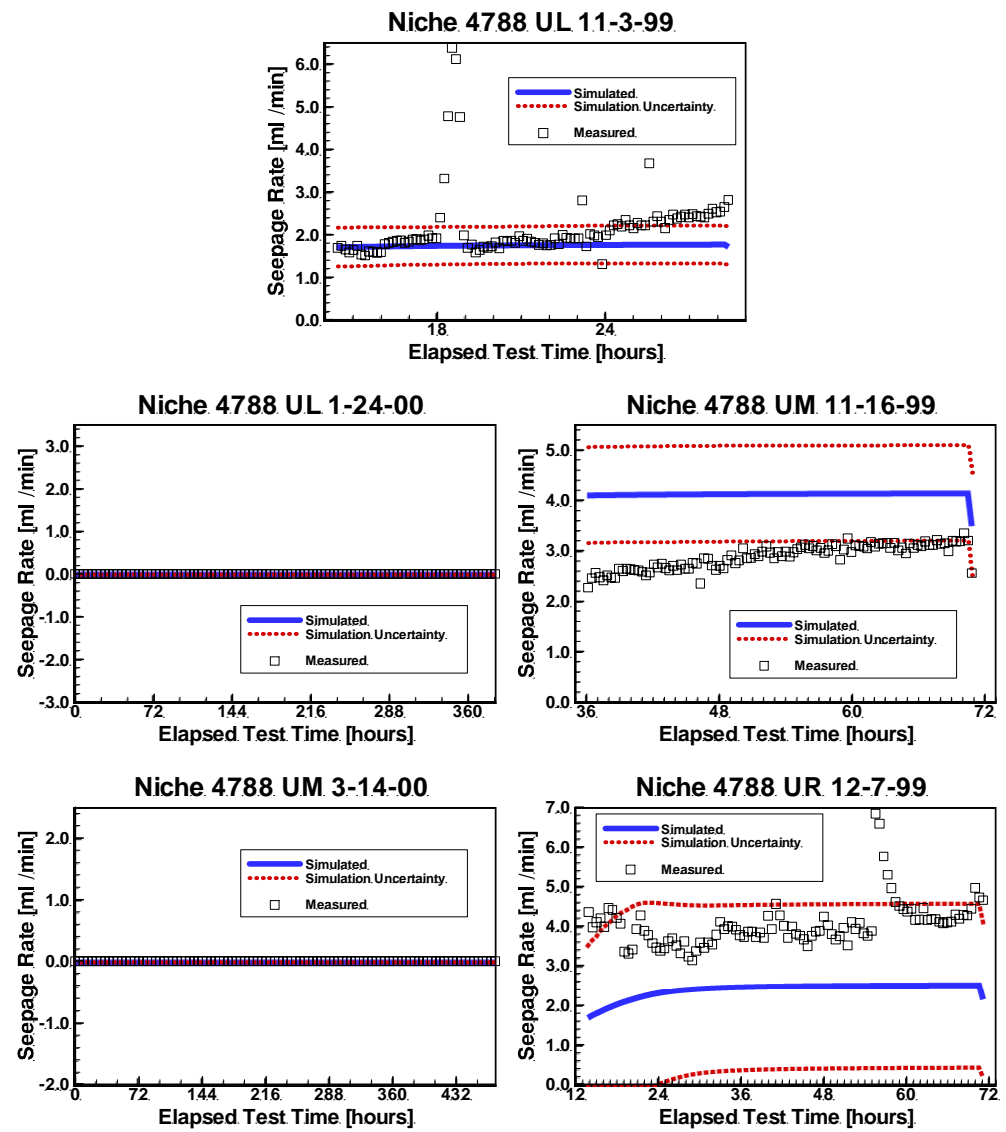

Source: DTN: LB0010NICH4LIQ.001 [DIRS 153145].

Output DTN: LB0010SCMREV01.001.

NOTE: Linear uncertainty propagation analysis was used to calculate the uncertainty band of the model predictions

Figure 7-9. Validation of Seepage Calibration Model and Tptpmn Seepage-Relevant Parameters Using Data from Niche 4 (Events 40, 42, 44, 47, and 49 of Table 6-5)

Niche 2, Middle Nonlithophysal Zone

Twenty-seven liquid-release tests were performed in Niche 2 (DTN: LB980001233124.004 [DIRS 136583]), thirteen resulting in seepage (see Table 6-5, Events 13-39). The short-term tests are very sensitive to storage effects and the properties of a few fractures connecting the injection interval to the niche opening. Therefore, information derived from these tests is considered much less reliable than the long-term tests discussed before. Unlike in all the other tests, only the total seepage amount at the end of the experiment was recorded.

These tests, while providing qualitative seepage information, were not used for calibration purposes to avoid a potential bias in the estimates. A similar bias renders them unsuitable for stringent model validation; the data and model predictions are shown here for completeness only. 
Their weight in the overall evaluation of the model validation activities should be considered minimal.

Fifty Monte Carlo simulations were performed for the prediction of seepage rates in Niche 2 (Ahlers 2002 [DIRS 161045], p. 57). Figure 7-10 shows the results of the Monte Carlo simulations. The measured cumulative seepage mass falls outside the range defined by the Monte Carlo simulations in only three of the 27 test events. All three cases (Events 19, 20, and 22) concern data from interval UM 4.27-4.57. In a fourth test event conducted in the same interval (Event 21), the observed data point is near the upper bound of the predicted seepage range. Conditions in this interval seem to be specific and significantly different from those encountered elsewhere in Niche 2 and the other two niches in the middle nonlithophysal zone. In several other intervals, the simulations show (minor) seepage where no seepage was observed.

As mentioned earlier, the short-term, small-volume liquid-release tests provide only limited insight into the long-term seepage behavior, because (1) the tests involved only a small portion of the fracture system, which is not representative of the fracture system to be engaged in flow diversion around the underground opening, and (2) the seepage mass is affected by storage effects, which are of no significance for steady-state seepage. As a result, the comparison between measured and calculated cumulative seepage has limited usefulness for validating or invalidating the seepage model. Nevertheless, as shown in Figure 7-6, the model is overall not inconsistent with the observed data, further corroborating the calibrated seepage prediction model. 


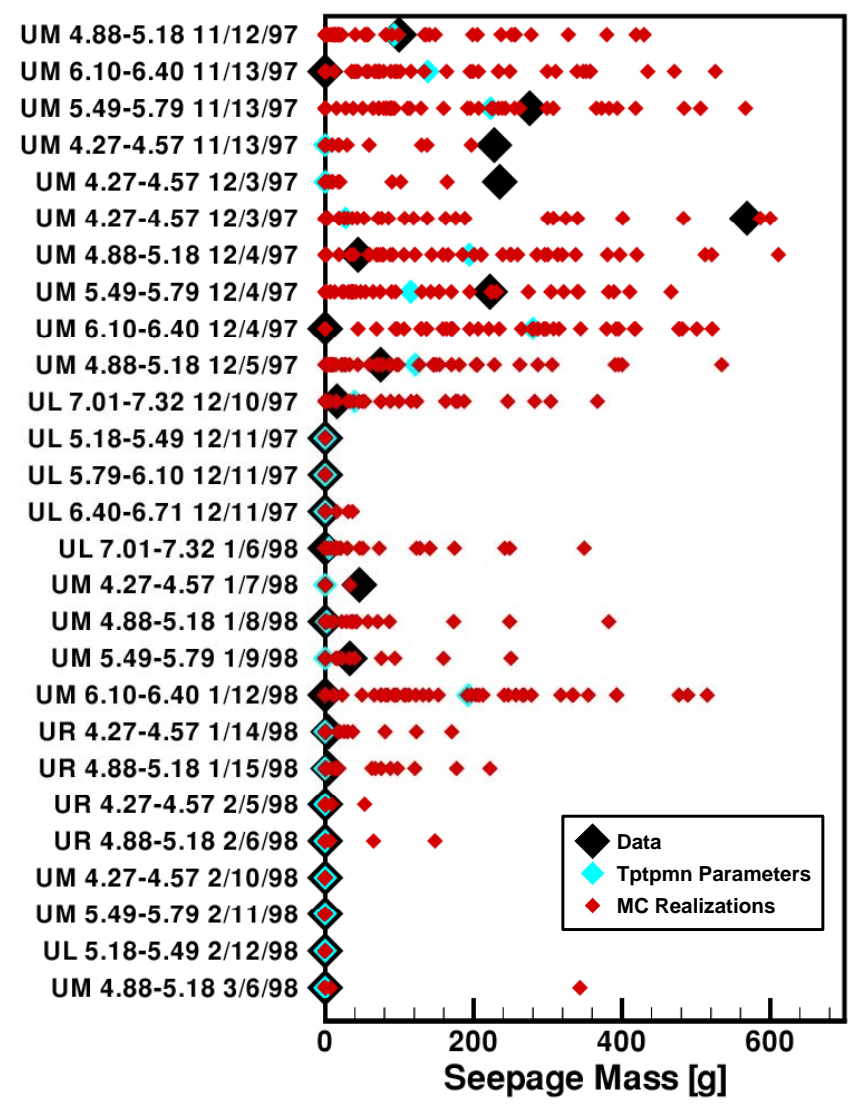

Source: DTN: LB980001233124.004 [DIRS 136583].

Output DTN: LB0010SCMREV01.001.

NOTE: Monte Carlo simulations were performed to estimate the prediction range. The blue symbols indicated the realization with the best-estimate parameter set for the Tptpmn unit.

Figure 7-10. Validation of Seepage Calibration Model and Tptpmn Seepage-Relevant Parameters Using Data from Niche 2

\section{Pre-Test Prediction}

A blind pre-test prediction of a representative liquid-release test with a rate of $30 \mathrm{ml} / \mathrm{min}$ was performed prior to actual testing in Niche 5. The predicted range of seepage rates (DTN: LB0207PRESCMN5.002 [DIRS 161192], Figure 1) is shown in Figure 7-11, along with the measured seepage-rate data from a liquid-release test in borehole \#5 of Niche 5 (using a rate of approximately $25 \mathrm{ml} / \mathrm{min}$ ).

The prediction cannot be directly compared to the data because of the different release rates. However, it is evident that the predicted rates are consistent with the seepage amounts actually observed during the test. The model overpredicted the seepage rates by a small amount, which was expected because of conservative assumptions made in that model. (Note that the seepage percentage - the ratio between the seepage and release rates-is not expected to be constant; it increases with the release rate. Also, note that the non-monotonic behavior of the upper limit of the predicted seepage rate is a result of rapidly changing sensitivity coefficients at the time of 
seepage initiation. These sensitivity coefficients, which form the basis for estimating the prediction uncertainty band, are evaluated for the base-case parameter set.)

In summary, the pre-test prediction of seepage rates performed with the preliminary Seepage Calibration Model meets the acceptance criteria outlined in Section 7.2 and thus provides confidence in the appropriateness of the general modeling approach.

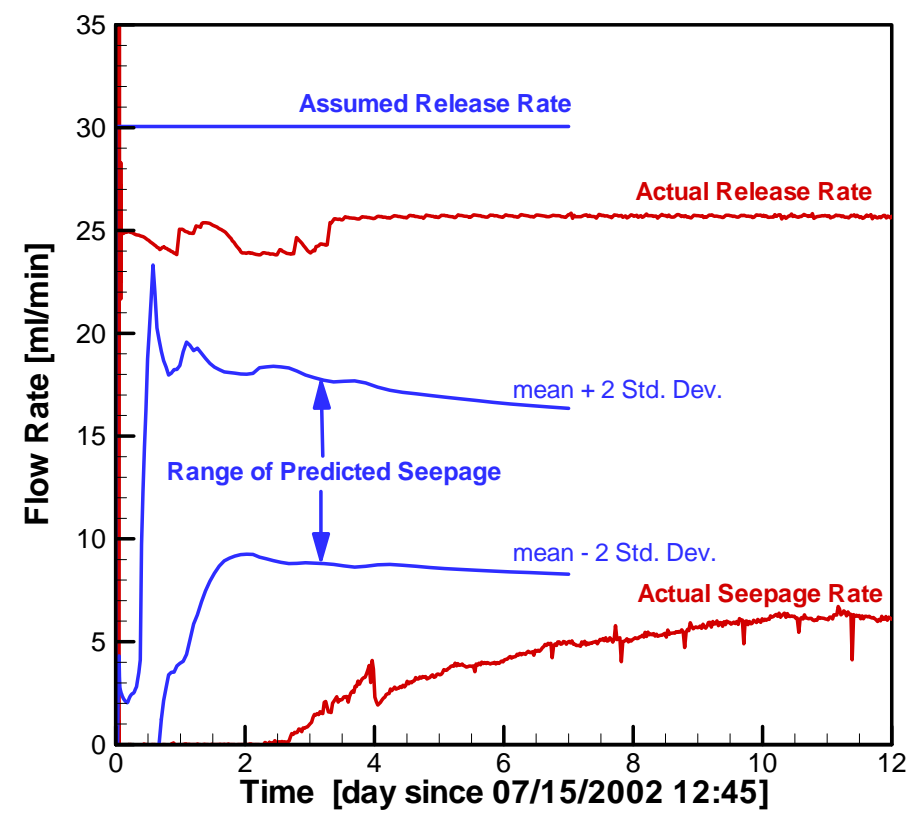

Source: DTN: LB0207PRESCMN5.002 [DIRS 161192].

Output DTN: LB0209NICH5LIQ.001.

NOTE: The range of predicted seepage covers the uncertainty band approximately on the 95 percent confidence level.

Figure 7-11. Comparison between Pre-Test Seepage-Rate Prediction with Preliminary Seepage Calibration Model and Seepage-Rate Data Observed in Niche 5

\subsection{SUMMARY OF MODEL VALIDATION}

As outlined in Section 7.1, the intended use of the SCM calls for Level I validation activities that demonstrate that the basic physical principles are appropriately represented in the model. Confidence building during model development is described in Section 7.2.1. Post-development activities include several validation methods; they are discussed in Section 7.2.2 and summarized below.

Criteria for confidence building during model development have been satisfied. Estimates of the seepage-relevant van Genuchten parameter $1 / \alpha$ for the lower lithophysal zone and the middle nonlithophysal zone of the Topopah Spring welded unit were obtained by calibration of a process model against seepage-rate data collected in the ECRB Cross-Drift and in Niches 3, 4 and 5. As outlined in Section 7.2.1, the development and calibration of the models is fully documented (see specifically Section 7.2.2 and the supporting references and scientific notebooks), generating 
confidence in the conceptual and mathematical model used as a basis for the analysis of seepage data.

Next, the calibrated parameter values obtained at different locations were compiled and described by means of a statistical distribution to represent spatial variability within a given hydrogeologic unit (see Section 6.6.4). Small-scale heterogeneity was identified as the main source of estimation uncertainty. The combined impact of spatial variability and uncertainty was propagated through the prediction models during model post-development validation by means of Monte Carlo simulations, in which the van Genuchten parameter $1 / \alpha$ was sampled from the respective statistical distribution, and a new realization of the random permeability field was generated for each simulation. (Note that this approach is identical to that used in the downstream seepage models - the Seepage Model for Performance Assessment, which uses multiple realizations of the underlying heterogeneous permeability field to account for uncertainty, and the sampling strategy employed during TSPA calculations, which makes use of an abstracted statistical distribution representing spatial variability.)

According to AP-SIII.10Q, Section 5.3.2 (c) (1), the model was corroborated by comparing predicted seepage rates with measured data not previously used for model calibration. The observed late-time seepage-rate data (1) fell within the range of predicted seepage rates in all test cases for the lower lithophysal zone, and in almost all test cases for the middle nonlithophysal zone, or (2) were lower than the predicted seepage rates in a few cases, i.e., the model prediction was conservative. The data were marginally higher in two longer-term tests (Events 12 and 40) and in three short-term tests in Niche 2 (Events 19, 20, and 22), which are considered of minor relevance.

According to AP-SIII.10Q, Section 5.3.2 (c) (7), a preliminary version of the model was used for a pre-test prediction of a representative liquid-release test planned for Niche 5 . The predicted seepage rates were consistent with the associated test observations, corroborating the appropriateness of the conceptual model.

Finally, according to AP-SIII.10Q, Section 5.3 .2 (d), the conceptual basis and mathematical model of the Seepage Calibration Model has been presented to the technical community through publication in refereed scientific journals, passing the review process.

Based on the evidence presented in Section 7.3, the conceptual and mathematical basis of the Seepage Calibration Model and the parameters derived from calibrating the model against seepage-rate data are considered adequate for the intended purpose and to the level of confidence required by the model's relative importance to the postclosure performance of the proposed repository system. No further activities are needed to complete the validation of the SCM for its intended use. 


\section{CONCLUSIONS}

\subsection{SUMMARY AND CONCLUSIONS}

Seepage into waste emplacement drifts affects the performance of the proposed high-level nuclear waste repository at Yucca Mountain, Nevada. Theoretical analyses, numerical modeling studies, and field experiments suggest that seepage into underground openings excavated in unsaturated formations is smaller than the percolation flux at the given location. Reduced inflow is mainly a result of capillary pressures holding water in the formation, diverting it around the cavity, and preventing it from entering the underground opening. The effectiveness of this capillary barrier depends on the percolation flux, the hydrogeologic properties of the formation, the geometry of the drift, the properties of the drift surface, and the evaporation potential determined by in-drift conditions.

This Model Report describes the development, calibration, and validation of the Seepage Calibration Model (SCM). The purpose of the SCM is to provide the conceptual basis for the Seepage Model for Performance Assessment (SMPA), which calculates seepage into waste emplacement drifts for a variety of hydrogeologic conditions. The SCM was calibrated against in situ seepage-rate data to provide seepage-relevant, model-related parameters appropriate for use in a drift-scale process model with a comparable model structure (such as the SMPA). These parameters will be used as base-case parameters for certain SMPA sensitivity analyses and will contribute to the development of parameter probability distributions for subsequent Performance Assessment calculations.

Three-dimensional process models were developed, representing niche locations in the middle nonlithophysal zone of the Topopah Spring Tuff (Tptpmn) and one niche and three boreholes in the ECRB Cross-Drift, which are located in the lower lithophysal zone of the Topopah Spring Tuff (Tptpll). Air-permeability data were geostatistically analyzed to provide the basis for generating heterogeneous, spatially correlated permeability fields.

A total of 90 experiments using different release rates were performed (Table 6-5). Eighty-one of these test events were simulated with the SCM, a numerical process model that captures transient unsaturated flow through a heterogeneous fracture continuum and seepage into the underground openings. In addition, evaporation effects were accounted for when deemed significant. Measured seepage-rate data from 22 liquid-release tests were used to calibrate the SCM and to estimate the seepage-relevant van Genuchten capillary-strength parameter $1 / \alpha$ (see Section 6.6.3.3). The remainder of the seepage-rate data was used to validate the SCM, that is, to determine whether it is appropriate and adequate for its intended use (see Section 7.3).

The duration of the liquid-release tests is on the order of days and weeks, which is relatively short compared to the prediction period. Nevertheless, the late-time seepage-rate data are considered suitable for calibrating a model that subsequently will be used for the prediction of long-term seepage behavior, because (1) the SCM is a transient model that captures the test conditions and thus yields parameters that are not biased by the transient nature of the underlying data, and (2) the late-time seepage-rate data used for model calibration show near-steady behavior, closely reflecting the processes governing steady-state seepage. Consequently, the use of late-time, near-steady seepage-rate data provides an appropriate basis for calibrating a 
transient model that subsequently will be used for the prediction of steady-state seepage into waste emplacement drifts.

The capillary-strength parameter was determined by calibrating the model against multiple tests using different liquid-release rates. Some of these release rates induced a local percolation flux above the seepage threshold, i.e., water dripped into the opening and yielded seepage-rate data valuable for calibration. However, the joint inversion of multiple data sets also included data from tests performed below the seepage threshold. Moreover, the model was validated against tests conducted above and below the seepage threshold. That is, the system was probed and the model was validated for the critical range of percolation rates about the seepage threshold. Seepage predictions for natural percolation fluxes that are even lower than the low fluxes (below the seepage threshold) induced during the low-rate tests will yield the correct result, namely zero seepage. As a result of a high-infiltration climate or strong flow focusing, the natural percolation flux may be high and exceed the seepage threshold. Percolation fluxes that are above the seepage threshold are the critical scenario for performance. Obviously, the parameters estimated from the liquid-release tests would be most suitable for those critical circumstances, because they were determined under similar high-rate conditions. In summary, the parameters determined from relatively high-rate liquid-release tests are appropriate and provide a solid basis for seepage predictions under natural percolation fluxes.

The insignificant impact of reduced relative humidity on calculated seepage into closed-off niches in the middle nonlithophysal zone has been confirmed (see Section 6.7 and discussion in Section 6.3.3.4). Significant evaporation effects in the ventilated ECRB Cross-Drift have been addressed through moisture control, monitoring of relative humidity, and inclusion of evaporation in the numerical model.

The following general conclusions are drawn:

1. The testing and modeling approach documented in this Model Report is adequate for providing the conceptual basis and parameters for the TSPA seepage model. The approach consists of analyzing seepage by means of a numerical process model that is calibrated against seepage-rate data from liquid-release tests conducted within the repository host units.

2. The estimation of seepage-relevant, model-related, effective parameters on the appropriate scale is a methodology that reduces the risk of introducing significant systematic errors, provided that the structure of the prediction model (such as the SMPA) is consistent with the model used for calibration (the SCM).

3. Seepage properties are spatially variable. The variability has been examined by performing liquid-release tests at various sites along the ESF and the ECRB CrossDrift. Spatial variability in the estimated van Genuchten capillary-strength parameter $1 / \alpha$ is relatively strong when compared to the estimation uncertainty at a given location. The main contribution to the estimation uncertainty is small-scale heterogeneity that can only be described stochastically. Random fluctuations in seepage-rate data leads to insignificant uncertainty in the parameter estimates. 
4. The seepage-relevant van Genuchten capillary-strength parameter $1 / \alpha$ in the lower lithophysal zone is on the order of $580 \mathrm{~Pa}$, with a standard deviation, representing spatial variability, of approximately $100 \mathrm{~Pa}$. The corresponding values for the middle nonlithophysal zone are $600 \mathrm{~Pa}$ and $130 \mathrm{~Pa}$.

The general conclusions listed above must be viewed considering the caveats and limitations discussed throughout this Model Report and summarized in Section 8.2. Further justification for the modeling and analysis approach can be found in Section 8.3 below.

\subsection{MODEL OUTPUT, UNCERTAINTIES, AND LIMITATIONS}

As outlined in Sections 1 and 6.1.1, this Model Report produces (1) a methodological and conceptual basis for the subsequent development of the Seepage Model for Performance Assessment (SMPA), and (2) seepage-relevant parameters that will be used for drift seepage abstraction. The parameter distribution developed as a result of the abstraction process will then be used-in combination with the results from the SMPA-as input to the seepage TSPA model. The Seepage Calibration Model (SCM) is intended to be used only within this Model Report for parameter estimation purposes.

The two products from this Model Report — conceptual model and model-related parametersare described below.

\section{Conceptual Basis for Seepage Prediction Models}

The conceptual basis to be used for the SMPA or similar modeling efforts to predict seepage has been described in Section 6.3; recommendations for downstream users are summarized in Section 8.4. The SCM must be viewed as an integral element of a consistent approach involving data analysis, parameter estimation, model prediction, and abstraction. The adequacy of the approach is further discussed in Section 8.3. Alternative approaches were described in Section 6.4 .

\section{Seepage-Relevant van Genuchten Capillary-Strength Parameter}

The second output from this Model Report consists of model-related estimates of the van Genuchten capillary-strength parameter $1 / \alpha$. The estimates were obtained through calibration of the SCM against seepage-rate data from liquid-release tests; they are summarized inTable 8-1. The estimates from the different locations are combined to obtain seepage characteristics for the two hydrogeologic units Tptpll and Tptpmn. The standard deviations reported in Table 8-1 reflect spatial variability.

The estimates are uncertain because they are derived from limited data, which exhibit random and potentially systematic measurement errors, and because the model is a simplification of the real system, which introduces systematic and random modeling errors. Estimating model-related parameters mitigates the impact of some of the residual systematic errors. The following uncertainties have been evaluated:

1. The uncertainty as a result of undetermined details of small-scale heterogeneity was quantified for the $1 / \alpha$ estimates in the Tptpll (see Table 6-8) by performing multiple 
inversions with different realizations of the underlying heterogeneous permeability field. Note, that the impact of this uncertainty on seepage predictions can be directly evaluated using the Seepage Model for Performance Assessment (SMPA; BSC 2004 [DIRS 167652]), i.e., this uncertainty does not need to be incorporated in the parameter distribution used for sampling in TSPA calculations (BSC 2004 [DIRS 169131], Section 6.6.1.3).

2. Estimation uncertainty resulting from unexplained fluctuations in the seepage-rate data is propagated through the model and is evaluated using Eq. 6-14; its contribution to the overall parameter uncertainty is negligible (see Section 6.6.3.3).

3. A potential bias in the estimated parameters as a result of evaporation effects is minimized by an appropriate test design, moisture monitoring, and inclusion of evaporation effects into the model using site-specific relative humidity and evaporation-rate data. Sensitivity analyses were performed, demonstrating that residual uncertainty resulting from incomplete knowledge about the evaporative boundary-layer thickness in a ventilated drift and uncertainty in the relative humidity data is minor (see Sections 6.6.3.1 and 6.7).

4. Sensitivity analyses were performed to examine the potential impact of selected, uncertain parameters on the estimation of seepage-relevant parameters (see Section 6.6.3.1). These synthetic inversions also provided the correlation structure, indicating that a potential error in one (relatively insensitive) parameter can be partly compensated for by the estimation of the model-related parameters that are most sensitive.

Table 8-1. Mean and Standard Deviation of Capillary-Strength Parameter $1 / \alpha$ for Lower Lithophysal Zone and Middle Nonlithophysal Zone

\begin{tabular}{|c|c|c|c|c|c|}
\hline Unit & Location & Interval & $1 / \alpha[\mathrm{Pa}]$ & Mean $1 / \alpha[\mathrm{Pa}]$ & Std. Dev. $\underset{a}{[P a]}$ \\
\hline \multirow[t]{6}{*}{ Tptpll } & SYBT-ECRB-LA\#1 & zone 1 & 534 & \multirow[t]{6}{*}{582} & \multirow[t]{6}{*}{105} \\
\hline & \multirow[t]{2}{*}{ SYBT-ECRB-LA\#2 } & zone 2 & 557 & & \\
\hline & & zone 3 & 535 & & \\
\hline & SYBT-ECRB-LA\#3 & zone 1 & 452 & & \\
\hline & \multirow[t]{2}{*}{ Niche 5} & borehole \#4 & 671 & & \\
\hline & & borehole \#5 & 741 & & \\
\hline \multirow[t]{4}{*}{ Tptpmn } & Niche 3 & UM & 741 & \multirow[t]{4}{*}{604} & \multirow[t]{4}{*}{131} \\
\hline & \multirow[t]{3}{*}{ Niche 4} & UL & 646 & & \\
\hline & & UM & 603 & & \\
\hline & & UR & 427 & & \\
\hline
\end{tabular}

Output DTN: LB0302SCMREV02.002.

a Characterizes spatial variability; the impact of uncertainty from undetermined details of small-scale heterogeneity on seepage predictions is directly evaluated in the Seepage Model for Performance Assessment.

Std. Dev.=Standard Deviation; UL=upper left; UM=upper middle; UR=upper right 
The primary caveats and limitations for usage of the results from the SCM are as follows:

1. The seepage models described in this Model Report provide estimates of the seepage flux averaged over a drift segment of a certain length. The seepage models are not expected to accurately predict individual seepage events or the precise spatial seepage distribution along a waste emplacement drift. By definition, the derived parameters (see) are related to the specific model structure used, i.e., these parameters are only applicable to a conceptual and numerical model similar to the SCM. (Note that the SCM and the SMPA are compatible in this sense (BSC 2004 [DIRS 167652]).) The parameters are also process specific and scale dependent, i.e., while they can be considered optimal for seepage calculations on the drift scale, they are not necessarily applicable to other processes on different scales. If the downstream models cannot be developed to be fully compatible with the SCM (see Section 8.4), appropriate adjustments to the parameter values should be made.

2. The effective parameters derived in this Model Report capture many processes and features leading to dripping of formation water into a large underground opening. However, this does not include water dripping as a result of condensate accumulation on the drift surface or other in-drift moisture redistribution processes.

3. Seepage during the thermal period is examined separately in the TH Seepage Model [see Drift-Scale Coupled Processes (DST and TH Seepage) Models (BSC 2004 [DIRS 170338])].

\subsection{ADEQUACY OF INPUT DATA AND MODELING APPROACH}

The two key elements of the overall approach described in this Model Report are (1) the use of a physically based, numerical process model as the basis for predicting seepage into large underground openings and (2) the calibration of this model against data from in situ liquid-release experiments. This approach is considered appropriate for the following reasons:

1. Unsaturated flow and seepage into drifts are complex, highly nonlinear phenomena. Hydrological process modeling is the preferred means for predicting seepage, because (1) the key process relevant to seepage (i.e., flow of water under unsaturated conditions) is directly modeled based on established physical laws, (2) only a few presumptions need to be made, because the model directly simulates the seepage process of interest, (3) the approach has the potential to simulate conditions that cannot be observed in the field, (4) numerical models are flexible enough to accommodate the nonideal initial and boundary conditions as they occur during seepage experiments.

2. The SCM is based on a process model that is consistent and compatible with the conceptual and numerical models used for calculating flow and transport in the unsaturated zone at Yucca Mountain.

3. Seepage experiments provide calibration data that reflect the process of interest. The measured data automatically reflect the factors and features pertinent to seepage. The 
effective parameters are capable of reproducing observed seepage data and are thus likely to yield reasonable seepage predictions.

4. The experiments test the capillary-barrier effect on the scale of interest, i.e., no upscaling is required. The water encountering the niche or drift is partly diverted around the opening, engaging the relevant portion of the fracture network on the appropriate scale.

5. Water is released from a localized point or line source, simulating the arrival of focused percolation water. Since the injection point lies outside the region of saturation buildup caused by the capillary barrier effect, the (relatively short) flow distance from the release point to the opening does not significantly affect the seepage behavior.

6. The seepage experiments are conducted in the excavation-disturbed zone. The estimated parameters therefore reflect the seepage-relevant properties and conditions to be expected in the vicinity of a waste emplacement drift.

Confidence into the appropriateness of the proposed approach was obtained by meeting acceptance criteria during the validation exercises (Section 7). While alternative approaches are viable (see Section 6.4), they often require currently unavailable characterization data, additional model assumptions, or extensive computational resources. Moreover, they usually need a calibration step similar to that described in this Model Report-they suffer from the same potential limitations and caveats. The approach outlined in this Model Report is considered adequate for the intended purpose and for the use of the SCM and its results.

\subsection{RECOMMENDATIONS}

The modeling and data-analysis approach outlined in this Model Report are considered suitable for providing a solid basis and sufficient characterization data for predicting seepage into waste emplacement drifts in the repository host rock. The Seepage Calibration Model has been validated applying acceptance criteria that are stricter than those required based on an evaluation of the model's relative importance to the potential performance of the repository system. The recommendations provided below concern the use of the conceptual model for the seepage predictions to be performed by the Seepage Model for Performance Assessment (BSC 2004 [DIRS 167652]).

1. Seepage predictions should make use of a physically based process model capable of simulating unsaturated flow under viscous, capillary pressure, and gravitational forces.

2. A three-dimensional, heterogeneous continuum model should be developed. The computational grid should capture the overall shape of the drift; small-scale surface roughness should not be explicitly discretized; lithophysal cavities should not be explicitly discretized; the nodal distance between the formation and the drift element should be $0.05 \mathrm{~m}$; and gravity must be acting along those vertical connections. 
3. Seepage-relevant input parameters should be used that are specifically determined for this conceptual model, based on data that represent the key mechanism affecting drift seepage.

Multiple prediction runs with different realizations of the underlying heterogeneous permeability field should be performed and appropriately averaged.

\subsection{HOW THE ACCEPTANCE CRITERIA ARE ADDRESSED}

The following information describes how this model report addresses the acceptance criteria in the Yucca Mountain Review Plan (NRC 2003 [DIRS 163274], Sections 2.2.1.3.3.3 and 2.2.1.3.6.3). In most cases, the applicable acceptance criteria are not addressed solely by this report; rather, the acceptance criteria are fully addressed when this report is considered in conjunction with other analysis and model reports that describe flow paths in the unsaturated zone. Only those acceptance criteria that are applicable to this report (see Section 4.2) are discussed.

In Section 4.2, the U.S. Nuclear Regulatory Commission acceptance criteria considered applicable to this Model Report were identified. These include criteria in YMRP Section 2.2.1.3.3.3, Quality and Chemistry of Water Contacting Waste Packages and Waste Forms, and YMRP Section 2.2.1.3.6.3, Flow Path in the Unsaturated Zone. This section summarizes how those criteria are addressed in this report. References to pertinent report sections are included. Details about how data, parameter, and model uncertainties are propagated through the model abstraction are primarily discussed in the seepage abstraction model report (BSC 2004 [DIRS 169131]). This Model Report does not address the chemistry of seepage water, which is evaluated by the THC Seepage Model (BSC 2004 [DIRS 168848]).

\section{YMRP Section 2.2.1.3.3.3: Quality and Chemistry of Water Contacting Waste Packages and Waste Forms}

Acceptance Criterion 1, System Description and Model Integration are Adequate:

Subcriterion (2): The conceptual and related process models developed to describe the physical phenomena of liquid release, unsaturated flow, and seepage are described (see Sections 6.3 and 6.6). These descriptions demonstrate that the model is based on a clear understanding of the relevant seepage processes (see Section 6.3.3), supported by field data from the site (see Section 6.5), and sensitivity analyses (see Section 6.6.3.1). The approach and model are documented in a transparent and traceable manner.

Subcriterion (8): The physics of the seepage phenomenon is adequately incorporated into the model, either explicitly or through the estimation of site-specific, modelrelated, process-relevant effective parameters (see Section 6.3.4). The successful calibration and validation of the model (see Sections 6.6.3 and 7.2.2) demonstrate that the conceptual description and its implementation into a numerical process model are adequate. 


\section{Acceptance Criterion 2, Data are Sufficient for Model Justification:}

Subcriterion (1): Hydrological values used in the seepage model are adequately justified as they are based on site-specific, seepage-related data (see Sections 6.5 and 8.3), which were interpreted using a consistent modeling approach (see Sections 6.3.4 and 8.3) and synthesized into appropriate effective parameters (see Section 6.3.4).

Subcriterion (2): Section 6.5 describes how data were collected and shows that sufficient hydrological data reflecting the parameters and processes of interest, including (1) permeability (see Section 6.5.2), seepage behavior (see Section 6.5.3), and evaporation effects (see Section 6.5.4). These data were collected from the relevant repository units. Their use for the calibration and validation of the SCM has been justified, and a description of their interpretation and synthesis into seepage-relevant parameters has been provided (see Section 6.6.3). Seepage tests, data analyses, and the modeling approach were designed for the development of a conceptual model for seepage and the calibration and intended use of the related seepage process model (see Section 6.3.4).

\section{Acceptance Criterion 3, Data Uncertainty is Characterized and Propagated through the Model Abstraction:}

Subcriterion (1): The development of parameter estimates by inverse modeling shows that the parameter values in the SCM (1) are technically defensible (see Section 6.3.4), (2) reasonably account for uncertainties and variabilities (see Sections 6.6.3.3 and 8.2), and (3) do not result in an under-representation of the risk estimate, because the estimation of model-related parameters is conducted to mitigate the impact of residual systematic errors (see Section 8.3).

Subcriterion (2): The parameters used in and derived by the seepage process model are technically defensible and reasonable, because they are based on and consistent with available data from Yucca Mountain (see Sections 4.1, 6.5, and 6.6.3). Assumptions made are technically defensible (see Section 5). Seepage is analyzed using a combination of techniques, including direct interpretation of field data (see Sections 6.5, 6.6.1.4, 6.6.3.3, and 6.4.4), natural analogs (see Sections 6.4.3 and 7.2.1), and process modeling (see Section 6.6.2).

Subcriterion (4): Adequate representation of the heterogeneities of the unsaturated zone is provided for in the development of parameters by (1) analyzing seepage-test data from different hydrogeologic units, (2) analyzing seepage-test data conducted in different locations, boreholes, and test intervals, and (3) performing multiple inversions based on different realizations of small-scale heterogeneity. Uncertainties and variabilities are evaluated (see Sections 6.6.3.3 and 8.2); they are propagated through the seepage abstraction to TSPA-LA (BSC 2004 [DIRS 169131]). 


\section{Acceptance Criterion 4, Model Uncertainty is Characterized and Propagated through the Model Abstraction:}

Subcriterion (1): Alternative modeling approaches of features, events, and processes are considered (see Section 6.4).

Subcriterion (2): Alternative conceptual models and their limitations and uncertainties are discussed qualitatively (see Section 6.4). Four alternative conceptual models are discussed: (1) discrete fracture network model; (2) seepage inferred from ponding probability; (3) seepage inferred from geochemical data; and (4) seepage threshold directly inferred from liquid-release test data. Although a discrete fracture network model is a recognized, appropriate alternative, it is limited by (1) data limitations, (2) the need for many auxiliary submodels, and (3) computational difficulties. Moreover, calibrated discrete fracture network models are expected to give results comparable to those obtained from the base-case continuum model (see Section 6.4.1). Ponding effects are explicitly included in the current seepage process models, which calculate flow through a heterogeneous medium, which leads to local ponding (see Section 6.4.2). Observations of calcite and opal in lithophysal cavities could be used to estimate long-term seepage rates into small openings. However, there are uncertainties associated with (1) the process leading to secondary mineral depositions at cavity floors, (2) the geochemical model and the initial water composition, and (3) upscaling issues (see Section 6.4.3). Directly using short-term liquid-release test data yields non-conservative seepage threshold estimates because of unaccounted storage effects and the inherent steady-state assumption (see Section 6.4.4). This discussion, the calibration results (see Section 6.6.3.3), and model validation (see Section 7.2) show that the selected modeling approach is the one most consistent with available data and current scientific understanding.

Subcriterion(3): Model uncertainty is minimized by requesting consistency between the calibration and prediction model (see Sections 6.3.4 and 8.4). Moreover, limitations and uncertainties of the chosen model are discussed (see Sections 1, 6.3.4, and 8.2). Consideration of conceptual model uncertainty is consistent with available site characterization data (see Section 6.6.4).

YMRP Section 2.2.1.3.6.3, Flow Path in the Unsaturated Zone

Acceptance Criterion 1, System Description and Model Integration are Adequate:

Subcriterion (2): The aspects of geology, hydrology, physical phenomena, and couplings that may affect flow paths in the unsaturated zone are adequately considered through in situ testing (see Section 6.5), estimation of effective parameters (see Sections 6.6.1.4, 6.3.4, and 6.6.3), and process modeling (see Section 6.6). Important physical phenomena are adequately incorporated in the mathematical model for flow in the unsaturated zone in the vicinity of drifts (see Section 6.6.1). Flow is modeled mathematically using the basic theoretical foundation for unsaturated flow in a continuum (see Section 6.6.1.1). Capillarity and its relevance for seepage is addressed (see Section 
6.6.1.2). Evaporation from a wetted porous surface is incorporated (see Section 6.6.1.3). Model calibration is based on established inverse modeling procedures (see Section 6.6.1.5).

Subcriterion (6): Adequate spatial variability of model parameters and spatial and temporal variability of boundary conditions are employed to estimate seepage flux (see Sections 6.6.2.1, 6.6.2.2, 6.6.2.3, and 6.6.4).

Subcriterion (7): The average parameter estimates are representative of the spatial discretization considered in the model (see Sections 6.1.1, 6.3.4, 6.6.2.1, and 6.6.3.1).

\section{Acceptance Criterion 2, Data are Sufficient for Model Justification:}

Subcriterion (1): Hydrological values used in the seepage process model for simulating unsaturated flow above the underground opening are adequately justified (see Sections 4.1 and 6.6.2). Adequate descriptions of how the data were used, interpreted, and appropriately synthesized into the parameters are provided (see Sections 6.5.2, 6.6.1.4, 6.6.2, 6.6.3, and 8.3).

Subcriterion (3): Data on the hydrology of the unsaturated zone in the vicinity of drifts were developed based on appropriate techniques, which include air-injection tests (see Section 6.5.2) and liquid-release tests (see Section 6.5.3).

Subcriterion (5): Model validation and uncertainty analyses are performed to assess data sufficiency (see Sections 6.6.4 and 7.2.2).

Subcriterion (6): Accepted and well-documented procedures are used to construct and calibrate the numerical models (see Section 6.6.1).

Subcriterion (7): Reasonably complete process-level conceptual and mathematical models are used in the analyses (see Sections 6.3 and 6.6).

Acceptance Criterion 3, Data Uncertainty is Characterized and Propagated through the Model Abstraction:

Subcriterion (1): The parameters used in and derived by the seepage process model are based on and consistent with available data from Yucca Mountain (see Sections 4.1, 6.5, and 6.6.3). Assumptions made are technically defensible (see Section 5). Seepage is analyzed using a combination of techniques, including direct interpretation of field data (see Sections 6.5, 6.6.1.4, 6.6.3.3, and 6.4.4), and natural analogs (see Sections 6.4.3 and 7.2.1). Uncertainties and variabilities are evaluated (see Sections 6.6.3.3 and 8.2); they are propagated through the seepage abstraction to TSPA-LA (BSC 2004 [DIRS 169131]).

Subcriterion (4): Initial and boundary conditions are consistent with available data and the underlying conceptual model. The evaporation boundary condition in the drift is based on measured relative humidity data (see Sections 6.6.2.3), with the evaporative boundary-layer thickness used in the conceptual model (see Section 6.6.1.3) determined from evaporation rate measurements (see Section 6.6.1.4). The background percolation flux (see Section 6.6.2.3) and resulting 
saturation distribution (see Section 6.6.2.4) are consistent with the conceptual model of the unsaturated zone at Yucca Mountain.

Subcriterion (6): Uncertainties in the characteristics of the natural system are considered by performing multiple inversions using different realizations of the small-scale, random permeability field, and by evaluating the estimation error of seepagerelevant parameters (see Sections 6.6.4 and 8.2).

\section{Acceptance Criterion 4, Model Uncertainty is Characterized and Propagated through the Model Abstraction:}

Subcriterion (1): Alternative modeling approaches consistent with available data and scientific understanding are investigated (see Section 6.4). These alternate models include a discrete fracture network model (see Section 6.4.1), seepage governed by a ponding probability model (see Section 6.4.2), using geochemical information to infer seepage (see Section 6.4.3), and estimating the seepage threshold directly from liquid-release test data (see Section 6.4.4). Model, parameter, and data uncertainties are addressed through (1) the estimation of effective, model-related parameters (see Section 6.3.4), (2) determination of estimation uncertainty through inverse modeling (see Sections 6.6.4 and 8.2), and (3) ensuring consistency between calibration and prediction models (see Section 8.4). The results and limitations of these alternate models are addressed in the discussions.

\subsection{OUTPUT DTNS}

The computer files needed to reproduce the model results discussed in this Model Report were submitted to the Technical Data Management System (TDMS). Reproducibility by an appropriately qualified individual is possible by consulting this Model Report and the pertinent scientific notebook pages as listed in Table 6-1.

The analyses of seepage-rate data from liquid-release tests performed in the middle nonlithophysal zone were fully documented in an earlier revision (REV 01) of this report (CRWMS M\&O 2001 [DIRS 153045]), and all related files were previously submitted to the TDMS under DTN: LB0010SCMREV01.001.

The files supporting the analyses of data from the lower lithophysal zone are listed in Appendix A and are submitted under DTN: LB0302SCMREV02.001. Air-permeability data developed in this Model Report (see Table 6-4) and the $1 / \alpha$ estimates (see Table 8-1) were submitted to the TDMS under DTN: LB0302SCMREV02.002. 
INTENTIONALLY LEFT BLANK 


\section{INPUTS AND REFERENCES}

\subsection{DOCUMENTS CITED}

Ahlers, C.F. 2002. The Seepage Calibration Model (YMP-LBNL-DSM-CFA-1). 161045 Scientific Notebook SN-LBNL-SCI-180-V1. ACC: MOL.20020925.0108.

Bear, J. 1972. Dynamics of Fluids in Porous Media. Environmental Science Series. 156269 Biswas, A.K., ed. New York, New York: Elsevier. TIC: 217356.

Birkholzer, J. and Tsang, C.F. 1997. "Solute Channeling in Unsaturated 119397 Heterogeneous Porous Media." Water Resources Research, 33, (10), 2221-2238. Washington, D.C.: American Geophysical Union. TIC: 235675.

Birkholzer, J.; Li, G.; Tsang, C-F.; and Tsang, Y. 1999. "Modeling Studies and 105170 Analysis of Seepage into Drifts at Yucca Mountain." Journal of Contaminant Hydrology, 38, (1-3), 349-384. New York, New York: Elsevier. TIC: 244160.

BSC (Bechtel SAIC Company) 2001. Development of Numerical Grids for UZ Flow 159356 and Transport Modeling. ANL-NBS-HS-000015 REV 00 ICN 01. Las Vegas, Nevada: Bechtel SAIC Company. ACC: MOL.20020211.0002.

BSC (Bechtel SAIC Company) 2001. UZ Flow Models and Submodels. MDL158726 NBS-HS-000006 REV 00 ICN 01. Las Vegas, Nevada: Bechtel SAIC Company. ACC: MOL.20020417.0382.

BSC (Bechtel SAIC Company) 2001. Test Plan for: Niche 5 Seepage Testing. 158200 SITP-02-UZ-002 REV 00. Las Vegas, Nevada: Bechtel SAIC Company. ACC: MOL.20020117.0200.

BSC (Bechtel SAIC Company) 2002. Requirements Document (RD) for iTOUGH2 161067 V5.0-00. DI: 10003-RD-5.0-0. Las Vegas, Nevada: Bechtel SAIC Company. ACC: MOL.20020923.0143.

BSC (Bechtel SAIC Company) 2002. Scientific Processes Guidelines Manual. 160313 MIS-WIS-MD-000001 REV 01. Las Vegas, Nevada: Bechtel SAIC Company. ACC: MOL.20020923.0176.

BSC (Bechtel SAIC Company) 2002. User's Manual (UM) for iTOUGH2 V5.0. 161066 DI: 10003-UM-5.0-00. Las Vegas, Nevada: Bechtel SAIC Company. ACC: MOL.20020923.0147.

BSC (Bechtel SAIC Company) 2003. Errata for Analysis of Geochemical Data for the Unsaturated Zone. ANL-NBS-HS-000017 REV 00 ICN 02. Las Vegas, Nevada: Bechtel SAIC Company. ACC: MOL.20020314.0051; DOC.20031015.0006. 
BSC (Bechtel SAIC Company) 2003. Errata for Risk Information to Support

168796

Prioritization of Performance Assessment Models. TDR-WIS-PA-000009 REV 01

ICN 01. Las Vegas, Nevada: Bechtel SAIC Company. ACC: MOL.20021017.0045;

DOC.20031014.0003.

BSC (Bechtel SAIC Company) 2003. Total System Performance Assessment-

166296

License Application Methods and Approach. TDR-WIS-PA-000006 REV 00 ICN

01. Las Vegas, Nevada: Bechtel SAIC Company. ACC: DOC.20031215.0001.

BSC (Bechtel SAIC Company) 2004. Abstraction of Drift Seepage. MDL-NBS-

169131

HS-000019 REV 01. Las Vegas, Nevada: Bechtel SAIC Company.

BSC (Bechtel SAIC Company) 2004. Analysis of Hydrologic Properties Data. ANL- 170038

NBS-HS-000042, Rev. 00. Las Vegas, Nevada: Bechtel SAIC Company.

BSC (Bechtel SAIC Company) 2004. Drift-Scale Coupled Processes (DST and TH

170338

Seepage) Models. MDL-NBS-HS-000015. Rev. 01. Las Vegas, Nevada: Bechtel

SAIC Company.

BSC (Bechtel SAIC Company) 2004. Errata 002 for Drift-Scale Coupled Processes (DST and THC Seepage) Models. MDL-NBS-HS-000001 REV 02. Las Vegas,

Nevada: Bechtel SAIC Company. ACC: DOC.20030804.0004;

DOC.20040219.0002; DOC.20040405.0005.

BSC (Bechtel SAIC Company) 2004. Errata for Technical Work Plan for:

167969

Performance Assessment Unsaturated Zone. TWP-NBS-HS-000003 REV 02.

Las Vegas, Nevada: Bechtel SAIC Company. ACC: MOL.20030102.0108;

DOC.20040121.0001.

BSC (Bechtel SAIC Company) 2004. Features, Events, and Processes in UZ Flow 170012 and Transport. ANL-NBS-MD-000001 REV 03. Las Vegas, Nevada: Bechtel SAIC Company.

BSC (Bechtel SAIC Company) 2004. In Situ Field Testing of Processes. ANLNBS-HS-000005 REV 03. Las Vegas, Nevada: Bechtel SAIC Company.

BSC (Bechtel SAIC Company) 2004. Natural Analogue Synthesis Report. TDR- 169218 NBS-GS-000027 REV 01. Las Vegas, Nevada: Bechtel SAIC Company.

ACC: DOC.20040524.0008.

BSC (Bechtel SAIC Company) 2004. Q-List. 000-30R-MGR0-00500-000-000

168361

REV 00. Las Vegas, Nevada: Bechtel SAIC Company. ACC:

ENG.20040721.0007.

BSC (Bechtel SAIC Company) 2004. Seepage Model for PA Including Drift Collapse. MDL-NBS-HS-000002 REV 03. Las Vegas, Nevada: Bechtel SAIC Company. 
BSC (Bechtel SAIC Company) 2004. Technical Work Plan for: Regulatory

169653

Integration Evaluation of Analysis and Model Reports Supporting the TSPA-LA.

TWP-MGR-PA-000014 REV 00 ICN 01. Las Vegas, Nevada: Bechtel SAIC

Company. ACC: DOC.20040603.0001.

BSC (Bechtel SAIC Company) 2004. Technical Work Plan for: Unsaturated Zone

169654

Flow Analysis and Model Report Integration. TWP-MGR-HS-000001 REV 00.

Las Vegas, Nevada: Bechtel SAIC Company. ACC: DOC.20040701.0005.

Campbell, G.S. and Norman, J.M. 1998. An Introduction to Environmental

150929

Biophysics. 2nd Edition. New York, New York: Springer-Verlag. TIC: 243951.

Canori, G.F. and Leitner, M.M. 2003. Project Requirements Document. TERMGR-MD-000001 REV 02. Las Vegas, Nevada: Bechtel SAIC Company.

ACC: DOC.20031222.0006.

Carrera, J. and Neuman, S.P. 1986. "Estimation of Aquifer Parameters Under

104368

Transient and Steady State Conditions: 1. Maximum Likelihood Method

Incorporating Prior Information." Water Resources Research, 22, (2), 199-210.

Washington, D.C.: American Geophysical Union. TIC: 245915.

CRWMS M\&O 2000. Calibrated Properties Model. MDL-NBS-HS-000003 REV

00. Las Vegas, Nevada: CRWMS M\&O. ACC: MOL.19990721.0520.

CRWMS M\&O 2001. Seepage Calibration Model and Seepage Testing Data.

MDL-NBS-HS-000004 REV 01. Las Vegas, Nevada: CRWMS M\&O. ACC:

MOL.20010122.0093.

Deutsch, C.V. and Journel, A.G. 1992. GSLIB Geostatistical Software Library and 100567

User's Guide. New York, New York: Oxford University Press. TIC: 224174.

Doughty, C.; Salve, R.; and Wang, J.S.Y. 2002. "Liquid-Release Tests in

161320

Unsaturated Fractured Welded Tuffs: II. Numerical Modeling." Journal of Hydrology, 256, ([1-2]), 80-105. [New York, New York]: Elsevier. TIC: 253773.

Finsterle, S. 1998. ITOUGH2 V3.2 Verification and Validation Report. LBNL103783 42002. Berkeley, California: Lawrence Berkeley National Laboratory. ACC:

MOL.19981008.0014.

Finsterle, S. 1999. ITOUGH2 User's Guide. LBNL-40040. Berkeley, California: 104367 Lawrence Berkeley National Laboratory. TIC: 243018.

Finsterle, S. 1999. UZ Drift Scale Model. Scientific Notebook YMP-LBNL-SAF- 153448

1. ACC: MOL.19990723.0301. 
Finsterle, S. 2000. "Using the Continuum Approach to Model Unsaturated Flow in 151875 Fractured Rock." Water Resources Research, 36, (8), 2055-2066. [Washington, D.C.]: American Geophysical Union. TIC: 248769.

Finsterle, S. 2002. UZ Drift Scale Model (YMP-LBNL-SAF-2). Scientific

161043

Notebook SN-LBNL-SCI-171-V1. ACC: MOL.20021203.0495.

Finsterle, S. and Trautz, R.C. 2001. "Numerical Modeling of Seepage into

161148 Underground Openings." Mining Engineering, [53], ([9]), 52-56. [Littleton, Colorado: Society for Mining, Metallurgy and Exploration]. TIC: 253738.

Hedegaard, R. 2002. Niche Excavation; Liquid Flow Testing; Borehole Drilling and Pneumatic Testing; Drift Seepage Testing. Scientific Notebook YMP-LBNLRCT-RH-1. ACC: MOL.20020725.0450.

Hinds, J. 2001. Unsaturated Zone Modeling \& Synthesis. Scientific Notebook YMP-LBNL-YSW-JH-2. ACC: MOL.20010725.0216.

Ho, C.K. 1997. "Evaporation of Pendant Water Droplets in Fractures." Water

Resources Research, 33, (12), 2665-2671. Washington, D.C.: American Geophysical Union. TIC: 246969.

Jackson, C.P.; Hoch, A.R.; and Todman, S. 2000. "Self-Consistency of a 141523 Heterogeneous Continuum Porous Medium Representation of a Fractured Medium." Water Resources Research, 36, (1), 189-202. Washington, D.C.: American Geophysical Union. TIC: 247466.

LeCain, G.D. 1995. Pneumatic Testing in 45-Degree-Inclined Boreholes in Ash101700 Flow Tuff Near Superior, Arizona. Water-Resources Investigations Report 95-4073. Denver, Colorado: U.S. Geological Survey. ACC: MOL.19960715.0083.

Li, G. and Tsang, C-F. 2003. "Seepage into Drifts with Mechanical Degradation." 163714 Journal of Contaminant Hydrology, 62-63, 157-172. New York, New York: Elsevier. TIC: 254205.

Liu, H.H.; Bodvarsson, G.S.; and Finsterle, S. 2002. "A Note on Unsaturated Flow 160230 in Two-Dimensional Fracture Networks." Water Resources Research, 38, (9), 15-1 to 15-9. [Washington, D.C.]: American Geophysical Union. TIC: 253307.

Liu, H.H.; Doughty, C.; and Bodvarsson, G.S. 1998. "An Active Fracture Model 105729 for Unsaturated Flow and Transport in Fractured Rocks." Water Resources Research, 34, (10), 2633-2646. Washington, D.C.: American Geophysical Union. TIC: 243012. 
Marshall, B.D.; Neymark, L.A.; and Peterman, Z.E. 2003. "Estimation of Past 162891

Seepage Volumes from Calcite Distribution in the Topopah Spring Tuff, Yucca Mountain, Nevada." Journal of Contaminant Hydrology, 62-63, 237-247. [New York, New York]: Elsevier. TIC: 254210.

Marshall, B.D.; Neymark, L.A.; Paces, J.B.; Peterman, Z.E.; and Whelan, J.F. 2000. 151018 "Seepage Flux Conceptualized from Secondary Calcite in Lithophysal Cavities in the Topopah Spring Tuff, Yucca Mountain, Nevada." SME Annual Meeting, February 28-March 1, 2000, Salt Lake City, Utah. Preprint 00-12. [Littleton, Colorado]: Society for Mining, Metallurgy, and Exploration. TIC: 248608.

Mongano, G.S.; Singleton, W.L.; Moyer, T.C.; Beason, S.C.; Eatman, G.L.W.; 149850 Albin, A.L.; and Lung, R.C. 1999. Geology of the ECRB Cross Drift - Exploratory Studies Facility, Yucca Mountain Project, Yucca Mountain, Nevada. [Deliverable SPG42GM3]. Denver, Colorado: U.S. Geological Survey. ACC: MOL.20000324.0614.

NRC (U.S. Nuclear Regulatory Commission) 2003. Yucca Mountain Review Plan, 163274 Final Report. NUREG-1804, Rev. 2. Washington, D.C.: U.S. Nuclear Regulatory Commission, Office of Nuclear Material Safety and Safeguards. TIC: 254568.

Or, D. and Ghezzehei, T.A. 2000. "Dripping into Subterranean Cavities from 144773 Unsaturated Fractures under Evaporative Conditions." Water Resources Research, 36, (2), 381-393. Washington, D.C.: American Geophysical Union. TIC: 246982.

Oreskes, N.; Shrader-Frechette, K.; and Belitz, K. 1994. "Verification, Validation, 152512 and Confirmation of Numerical Models in the Earth Sciences." Science, 263, (5147), 641-646. Washington, D.C.: American Association for the Advancement of Science. TIC: 248958.

Philip, J.R.; Knight, J.H.; and Waechter, R.T. 1989. "Unsaturated Seepage and 105743 Subterranean Holes: Conspectus, and Exclusion Problem for Circular Cylindrical Cavities." Water Resources Research, 25, (1), 16-28. Washington, D.C.: American Geophysical Union. TIC: 239117.

Pruess, K. 1987. TOUGH User's Guide. NUREG/CR-4645. Washington, D.C.: 100684 U.S. Nuclear Regulatory Commission. TIC: 217275.

Pruess, K.; Faybishenko, B.; and Bodvarsson, G.S. 1999. "Alternative Concepts 117112 and Approaches for Modeling Flow and Transport in Thick Unsaturated Zones of Fractured Rocks." Journal of Contaminant Hydrology, 38, (1-3), 281-322. New York, New York: Elsevier. TIC: 244160.

Richards, L.A. 1931. "Capillary Conduction of Liquids Through Porous Mediums." 104252 Physics, 1, 318-333. [New York, New York: American Physical Society].

TIC: 225383. 
Rohsenow, W.M. and Choi, H.Y. 1961. Heat, Mass, and Momentum Transfer.

158324 Englewood Cliffs, New Jersey: Prentice-Hall. TIC: 249864.

Salve, R.; Wang, J.S.Y.; and Doughty, C. 2002. "Liquid-Release Tests in 161318 Unsaturated Fractured Welded Tuffs: I. Field Investigations." Journal of Hydrology, 256, ([1-2]), 60-79. [New York, New York]: Elsevier. TIC: 253774.

Tokunaga, T.K. and Wan, J. 1997. "Water Film Flow Along Fracture Surfaces of Porous Rock." Water Resources Research, 33, (6), 1287-1295. Washington, D.C.: American Geophysical Union. TIC: 242739.

Trautz, R. 2001. UZ Drift Scale Model (YMP-LBNL-RCT-DSM-1). Scientific Notebook SN-LBNL-SCI-157-V1. ACC: MOL.19990723.0302; MOL.20010201.0423; MOL.20010724.0145; MOL.20030402.0304.

Trautz, R.C. 2001. Moisture Monitoring in the ESF (Phase 2)/Drift Seepage Test. Scientific Notebook YMP-LBNL-RCT-2. ACC: MOL.20011030.0706.

Trautz, R.C. and Wang, J.S.Y. 2002. "Seepage into an Underground Opening Constructed in Unsaturated Fractured Rock Under Evaporative Conditions." Water Resources Research, 38, (10), 6-1 through 6-14. [Washington, D.C.]: American Geophysical Union. TIC: 253348.

van Genuchten, M.T. 1980. "A Closed-Form Equation for Predicting the Hydraulic Conductivity of Unsaturated Soils." Soil Science Society of America Journal, 44, (5), 892-898. Madison, Wisconsin: Soil Science Society of America. TIC: 217327.

Wang, J. 1999. Characterization of Yucca Mountain Percolation in the Unsaturated 153449 Zone - ESF Study. Scientific Notebook YMP-LBNL-JSW-6C. ACC: MOL.19991013.0462.

Wang, J.S. 2003. "Scientific Notebooks Referenced in Model Report U0080, 161456 Seepage Calibration Model and Seepage Testing Data MDL-NBS-HS-000004 REV 02." Memorandum from J.S. Wang (BSC) to File, March 13, 2003, with attachments. ACC: MOL.20030320.0082.

Wang, J.S.Y. and Elsworth, D. 1999. "Permeability Changes Induced by 104366 Excavation in Fractured Tuff." Rock Mechanics for Industry, Proceedings of the 37th U.S. Rock Mechanics Symposium, Vail, Colorado, USA, 6-9 June 1999. Amadei, B.; Kranz, R.L.; Scott, G.A.; and Smeallie, P.H., eds. 2, 751-757. Brookfield, Vermont: A.A. Balkema. TIC: 245246.

Whelan, J.F.; Paces, J.B.; and Peterman, Z.E. 2002. "Physical and Stable-Isotope 160442 Evidence for Formation of Secondary Calcite and Silica in the Unsaturated Zone, Yucca Mountain, Nevada." Applied Geochemistry, 17, ([6]), 735-750. [New York, New York]: Elsevier. TIC: 253462. 


\subsection{CODES, STANDARDS, REGULATIONS, AND PROCEDURES}

10 CFR 63. Energy: Disposal of High-Level Radioactive Wastes in a Geologic 156605 Repository at Yucca Mountain, Nevada. Readily available.

AP-2.22Q, Rev. 01, ICN 1. Classification Analayses and Maintenance of the QList. Washington, D.C.: U.S. Department of Energy, Office of Civilian Radioactive Waste Management. ACC: DOC.20040714.0002.

AP-2.27Q, Rev. 01, ICN 4. Planning for Science Activities. Washington, D.C.: U.S. Department of Energy, Office of Civilian Radioactive Waste Management. ACC: DOC.20040610.0006.

AP-SIII.10Q, Rev. 2, ICN 6. Models. Washington, D.C.: U.S. Department of Energy, Office of Civilian Radioactive Waste Management. ACC: DOC.200406805.0005.

\subsection{SOURCE DATA, LISTED BY DATA TRACKING NUMBER}

LB00090012213U.001. Air K Testing in Borehole SYBT-ERCB-LA\#2 at CS 17+26 153141 in Cross Drift. Submittal date: 11/03/2000.

LB00090012213U.002. Liquid Release Tests from Borehole SYBT-ECRB-LA\#2 at 153154 CS 17+26 in Cross Drift. Submittal date: 11/09/2000.

LB0010NICH3LIQ.001. Niche 3107 Seepage Test. Submittal date: 11/02/2000. 153144

LB0010NICH4LIQ.001. Niche 4788 Seepage Test. Submittal date: 11/02/2000. 153145

LB0011AIRKTEST.001. Air Permeability Testing in Niches 3566 and 3650.

153155

Submittal date: $11 / 08 / 2000$.

LB0110AKN5POST.001. Niche 5 (1620 in ECRB) Post-Excavation Air-K.

156904 Submittal date: 11/12/2001.

LB0110ECRBLIQR.002. Systematic Testing in ECRB-SYBT-LA\#1, 2/28/2001. 156879 Submittal date: 11/12/2001.

LB0110SYST0015.001. Developed Data for Systematic Testing. Submittal date: 160409 $12 / 06 / 2001$.

LB0203ECRBLIQR.001. Systematic Testing in ECRB-SYBT-LA\#3(May-July 158462 2001). Submittal date: 03/20/2002.

LB0205REVUZPRP.001. Fracture Properties for UZ Model Layers Developed from 159525 Field Data. Submittal date: 05/14/2002. 
LB0207NICH5LIQ.001. Niche 5 Seepage Tests (CD 1620). Submittal date:

160408 07/09/2002.

LB0207PRESCMN5.001. Pre-Test Prediction of Seepage into Niche 5: Modeling 160410 Input/Output Files. Submittal date: 07/26/2002.

LB0207PRESCMN5.002. Pre-Test Prediction of Seepage into Niche 5: Data

161192 Summary. Submittal date: 07/26/2002.

LB0209NICH5LIQ.001. Niche 5 Seepage Tests (CD 1620), June-August 2002. Submittal date: 09/11/2002.

LB0211NICH5LIQ.001. Niche 5 Seepage Tests (CD 1620), August-October 2002. 160792 Submittal date: 11/14/2002.

LB0301N5CEILNG.001. Niche 5 Field Measurements of the Niche Ceiling and Slot Geometry. Submittal date: 01/27/2003.

LB03023DSSCP9I.001. 3-D Site Scale UZ Flow Field Simulations for 9 Infiltration 163044 Scenarios. Submittal date: 02/28/2003.

LB980001233124.004. Liquid Release Test Data from Niche 3566 and Niche 3650 of the ESF in Milestone Report, "Drift Seepage Test and Niche Moisture Study: Phase 1 Report on Flux Threshold Determination, Air Permeability Distribution, and Water Potential Measurement. Submittal date: 11/23/1999.

LB990601233124.001. Seepage Data Feed to UZ Drift-Scale Flow Model for 105888 TSPA-SR. Submittal date: 06/18/1999.

LB990701233129.001. 3-D UZ Model Grids for Calculation of Flow Fields for PA 106785 for AMR U0000, "Development of Numerical Grids for UZ Flow and Transport Modeling". Submittal date: 09/24/1999.

LB990801233129.003. TSPA Grid Flow Simulations for AMR U0050, "UZ Flow Models and Submodels" (Flow Field \#3). Submittal date: 11/29/1999.

LB997141233129.001. Calibrated Basecase Infiltration 1-D Parameter Set for the UZ Flow and Transport Model, FY99. Submittal date: 07/21/1999.

MO0002GSC00064.000. Exploratory Studies Facilities (ESF) Niche \#3 (Niche 152625 3107) Borehole As-Built Information. Submittal date: 02/09/2000.

MO0002GSC00076.000. Exploratory Studies Facility (ESF) Niche \#2 (Niche 3650) 152623 Borehole As-Built Information. Submittal date: 02/15/2000.

MO0003GSC00096.000. Exploratory Studies Facility (ESF) Niche \#2 Profile 152167 Alignment. Submittal date: 03/01/2000. 
MO0003GSC00103.000. Exploratory Studies Facility (ESF) Niche 3 Profile

152176

Alignment. Submittal date: 03/03/2000.

MO0008GSC00273.000. Exploratory Studies Facility (ESF) Niche 4, Profile

152626

Alignment. Submittal date: 08/01/2000.

MO0008GSC00310.000. ESF Niche \#4 (Niche 4788) Borehole As-Built

152627

Information. Submittal date: 08/28/2000.

MO0009GSC00332.000. Exploratory Studies Facility (ESF) Niche 5, Plan and

155370

Profile As-Built. Submittal date: 09/27/2000.

MO0107GSC01061.000. As-Built Profile of Bat-Wing Excavation, Niche \#5 ECRB. 155369

Submittal date: 07/03/2001.

MO0107GSC01069.000. ESF Niche \#4 (Niche 4788) Borehole As-Built

156941

Information. Submittal date: 07/19/2001.

MO0312GSC03176.000. ECRB - Niche \#5 (Niche 1620) Borehole As-Built

169532

Information. Submittal date: 12/01/2003.

MO0407SEPFEPLA.000. LA FEP List. Submittal date: 07/20/2004.

170760

\subsection{OUTPUT DATA, LISTED BY DATA TRACKING NUMBER}

LB0010SCMREV01.001. Input/Output for Seepage Calibration Modeling AMR U0080. Submittal date: 11/29/2000.

LB0302SCMREV02.001. Seepage-Related Model Parameters K and 1/ $\alpha$ :

Supporting Files. Submittal date: 02/28/2003.

LB0302SCMREV02.002. Seepage-Related Model Parameters K and $1 / \alpha$ : Data Summary. Submittal date: 02/28/2003.

\subsection{SOFTWARE CODES}

CRWMS M\&O 1999. Software Routine: ECRB-XYZ. V.03. PC. 30093-V.03. 147402

Dynamic Graphics 2003. EarthVision. V4.0. SGI/IRIX 6.2. 10174-4.0-00. 162369

LBNL (Lawrence Berkeley National Laboratory) 10/17/2000. Software Routine: 152814 AddCoord. V1.0. SUN w/Unix OS. 10355-1.0-00.

LBNL (Lawrence Berkeley National Laboratory) 10/17/2000. Software Routine: 152815 CutNiche. V1.2. SUN w/Unix OS. 10356-1.2-00.

LBNL (Lawrence Berkeley National Laboratory) 1999. Software Code: EXT. V1.0. 134141 Sun. 10047-1.0-00. 
LBNL (Lawrence Berkeley National Laboratory) 1999. Software Code: GSLIB.

134139

V1.0MGAMV2V1.201. Sun. 10087-1.0MGAMV2V1.201-00.

LBNL (Lawrence Berkeley National Laboratory) 1999. Software Code: GSLIB.

134136

V1.0MSISIMV1.203. Sun, PC. 10001-1.0MSISIMV1.203-00.

LBNL (Lawrence Berkeley National Laboratory) 1999. Software Code: iTOUGH2.

139918

V4.0. SUN, DEC. 10003-4.0-00.

LBNL (Lawrence Berkeley National Laboratory) 2000. Software Code: GSLIB.

153099

V1.0GAMV3V1.201. SUN w/Unix OS. 10398-1.0GAMV3V1.201-00.

LBNL (Lawrence Berkeley National Laboratory) 2000. Software Code: GSLIB.

153100

V1.0SISIMV1.204. SUN w/Unix OS. 10397-1.0SISIMV1.204-00.

LBNL (Lawrence Berkeley National Laboratory) 2000. Software Routine:

152822

AddBorehole. V1.0. SUN w/Unix OS. 10373-1.0-00.

LBNL (Lawrence Berkeley National Laboratory) 2000. Software Routine: AddBound. 152823 V1.0. SUN w/Unix OS. 10357-1.0-00.

LBNL (Lawrence Berkeley National Laboratory) 2000. Software Routine: CutDrift. 152816 V1.0. SUN w/Unix OS. 10375-1.0-00.

LBNL (Lawrence Berkeley National Laboratory) 2000. Software Routine: CutNiche. 152828 V1.3. SUN w/Solaris OS. 10402-1.3-00.

LBNL (Lawrence Berkeley National Laboratory) 2000. Software Routine: MoveMesh. 152824 V1.0. SUN w/Unix OS. 10358-1.0-00.

LBNL (Lawrence Berkeley National Laboratory) 2000. Software Routine:

152826

Perm2Mesh. V1.0. SUN w/Unix OS. 10359-1.0-00.

LBNL (Lawrence Berkeley National Laboratory) 2002. Software Code: iTOUGH2. 160106

V5.0. SUN UltraSparc., DEC ALPHA, LINUX. 10003-5.0-00. 
APPENDIX A

LIST OF COMPUTER FILES SUBMITTED WITH THIS MODEL REPORT UNDER

DTN: LB0302SCMREV02.001 
Computer files needed to reproduce the model results discussed in this Model Report are listed below and were submitted to the TDMS under output DTN: LB0302SCMREV02.001. Reproducibility is given by referring to the pertinent scientific notebook pages as listed in Table 6-1 and throughout this Model Report. Each file name is complemented with a short description of its contents and/or purpose.

Table A-1 contains the files pertaining to the modeling of liquid-release tests conducted in Niche 5; Table A-2 contains those for the modeling of test in the ECRB Cross-Drift. The files used to analyze data from seepage experiments in Niches 2, 3, and 4 (located in the middle nonlithophysal zone) were previously submitted under output DTN: LB0010SCMREV01.001.

Table A-1. File Name and Description for Modeling of Liquid-Release Tests in Niche 5

\begin{tabular}{|c|c|}
\hline File/Folder Name & Description/File Location \\
\hline \multicolumn{2}{|l|}{ Meshgeneration/ } \\
\hline \multicolumn{2}{|l|}{ Meshgeneration/Permeabilityl } \\
\hline measured_log-k_12_N5.dat & Measured air permeability data, input file mesh generation \\
\hline N5-airK.dat & Measured air permeability data, input file to GAMV3 \\
\hline N5-airK.par & Parameter file, input to GAMV3 \\
\hline N5-airK.var & Computed variogram by GAMV3 \\
\hline N5-airK.xIs & Excel file to compile variogram \\
\hline
\end{tabular}

Meshgeneration/Roughness/

\begin{tabular}{|c|c|}
\hline ceiling_N5_survey.dat & $\begin{array}{l}\text { Compilation of the original survey and roughness measurements of } \\
\text { the main niche }\end{array}$ \\
\hline ceiling_N5_interpolated.dat & Interpolated data on a regular $x-y$ coordinate $(10 \mathrm{~cm} \times 10 \mathrm{~cm}$ grid $)$ \\
\hline ceiling_N5_1.dat & Interpolated main niche ceiling for $15.60<y<17.60$ \\
\hline ceiling_N5_2.dat & Interpolated main niche ceiling for $18.60<y<20.60$ \\
\hline ceiling_N5_3.dat & Interpolated main niche ceiling for $20.90<y<22.90$ \\
\hline leftbatwing_N5_survey.dat & $\begin{array}{l}\text { Compilation of the original survey and roughness measurements of } \\
\text { the left batwing niche }\end{array}$ \\
\hline leftbatwing_N5_interpolated.dat & Interpolated data on a regular $x-y$ coordinate $(10 \mathrm{~cm} \times 10 \mathrm{~cm}$ grid $)$ \\
\hline leftbatwing_N5_1.dat & Interpolated left batwing niche ceiling for $15.60<y<17.60$ \\
\hline leftbatwing_N5_2.dat & Interpolated left batwing niche ceiling for $18.60<y<20.60$ \\
\hline leftbatwing_N5_3.dat & Interpolated left batwing niche ceiling for $20.90<y<22.90$ \\
\hline rightbatwing_N5_survey.dat & $\begin{array}{l}\text { Compilation of the original survey and roughness measurements of } \\
\text { the right batwing niche }\end{array}$ \\
\hline rightbatwing_N5_interpolated.dat & Interpolated data on a regular $x-y$ coordinate $(10 \mathrm{~cm} \times 10 \mathrm{~cm}$ grid $)$ \\
\hline rightbatwing_N5_1.dat & Interpolated right batwing niche ceiling for $15.60<y<17.60$ \\
\hline rightbatwing_N5_2.dat & Interpolated right batwing niche ceiling for $18.60<y<20.60$ \\
\hline rightbatwing_N5_3.dat & Interpolated right batwing niche ceiling for $20.90<y<22.90$ \\
\hline Niche1620_ceiling.Ipk & Tecplot file with the top view of the niche 5 ceiling \\
\hline Niche1620_ceiling.wmf & Tecplot file with the top view of the niche 5 ceiling \\
\hline Niche5SurveySummary.xls & Excel file to compile the survey data \\
\hline
\end{tabular}


Table A-1. File Name and Description for Modeling of Liquid-Release Tests in Niche 5 (Continued)

\begin{tabular}{|c|c|}
\hline File/Folder Name & Description/File Location \\
\hline \multicolumn{2}{|l|}{ Meshgeneration/N5BH4_10-11ft/ } \\
\hline N5BH4_10-11ft & TOUGH2 input file with MESHMAKER block \\
\hline onestep & TOUGH2 input file to perform a single time step \\
\hline N5BH4_10-11ft_sisim.par & Parameter file for generation of random permeability field \\
\hline sh.N5BH4_10-11ft_mesh & $\begin{array}{l}\text { Sequence of instructions to execute multiple steps of mesh } \\
\text { generations }\end{array}$ \\
\hline sh.N5BH4_10-11ft_run & $\begin{array}{l}\text { Sequence of instructions to run the above Sequence of } \\
\text { instructions multiple times by changing the permeability } \\
\text { field seed number }\end{array}$ \\
\hline sh.onestep & Sequence of instructions to run one time step \\
\hline N5BH4_10-11ft.mes1 & Mesh with permeability realization \#1 \\
\hline N5BH4_10-11ft.mes2 & Mesh with permeability realization \#2 \\
\hline N5BH4_10-11ft.mes3 & Mesh with permeability realization \#3 \\
\hline N5BH4_10-11ft.mes4 & Mesh with permeability realization \#4 \\
\hline N5BH4_10-11ft.mes5 & Mesh with permeability realization \#5 \\
\hline N5BH4_10-11ft.mes6 & Mesh with permeability realization \#6 \\
\hline N5BH4_10-11ft.mes7 & Mesh with permeability realization \#7 \\
\hline N5BH4_10-11ft.mes8 & Mesh with permeability realization \#8 \\
\hline N5BH4_10-11ft.mes9 & Mesh with permeability realization \#9 \\
\hline N5BH4_10-11ft.mes10 & Mesh with permeability realization \#10 \\
\hline N5BH4_10-11ft.mes11 & Mesh with permeability realization \#11 \\
\hline N5BH4_10-11ft.mes12 & Mesh with permeability realization $\# 12$ \\
\hline N5BH4_10-11ft.mes13 & Mesh with permeability realization \#13 \\
\hline N5BH4_10-11ft.mes14 & Mesh with permeability realization \#14 \\
\hline N5BH4_10-11ft.mes15 & Mesh with permeability realization \#15 \\
\hline N5BH4_10-11ft.mes16 & Mesh with permeability realization \#16 \\
\hline N5BH4_10-11ft.mes17 & Mesh with permeability realization \#17 \\
\hline N5BH4_10-11ft.mes18 & Mesh with permeability realization \#18 \\
\hline N5BH4_10-11ft.mes19 & Mesh with permeability realization \#19 \\
\hline N5BH4_10-11ft.mes20 & Mesh with permeability realization \#20 \\
\hline N5BH4_10-11ft.mes21 & Mesh with permeability realization \#21 \\
\hline N5BH4_10-11ft.mes22 & Mesh with permeability realization \#22 \\
\hline N5BH4_10-11ft.mes23 & Mesh with permeability realization \#23 \\
\hline N5BH4_10-11ft.mes24 & Mesh with permeability realization \#24 \\
\hline N5BH4_10-11ft.mes25 & Mesh with permeability realization \#25 \\
\hline N5BH4_10-11ft.mes26 & Mesh with permeability realization \#26 \\
\hline N5BH4_10-11ft.mes27 & Mesh with permeability realization \#27 \\
\hline N5BH4_10-11ft.mes28 & Mesh with permeability realization \#28 \\
\hline N5BH4_10-11ft.mes29 & Mesh with permeability realization \#29 \\
\hline N5BH4_10-11ft.mes30 & Mesh with permeability realization \#30 \\
\hline
\end{tabular}


Table A-1. File Name and Description for Modeling of Liquid-Release Tests in Niche 5 (Continued)

\begin{tabular}{|l|l|l|}
\hline \multicolumn{2}{|c|}{ File/Folder Name } & \multicolumn{1}{c|}{ Description/File Location } \\
\hline \multirow{2}{*}{ ceiling_N5_1.dat } & File is in folder: Meshgeneration/Roughness/ \\
\cline { 2 - 3 } measured_log-k_12_N5.dat & File is in folder: Meshgeneration/Permeabilityl \\
\cline { 2 - 3 }
\end{tabular}

Meshgeneration/N5BH5_21-22ft/
\begin{tabular}{|l|l|}
\hline N5BH5_21-22ft & TOUGH2 input file \\
\hline sh.N5BH5_21-22ft_mes & $\begin{array}{c}\text { Sequence of instructions to execute multiple steps of mesh } \\
\text { generations }\end{array}$ \\
\hline N5BH5_21-22ft.mes & Mesh with permeability realization \# \\
\hline onestep & File is in folder: Meshgeneration/N5BH4_10-11ft/ \\
\hline sh.onestep & File is in folder: Meshgeneration/N5BH4_10-11ft/ \\
\hline ceiling_N5_2.dat & File is in folder: Meshgeneration/Roughness/ \\
\hline leftbatwing_N5_2.dat & File is in folder: Meshgeneration/Roughness/ \\
\hline rightbatwing_N5_2.dat & File is in folder: Meshgeneration/RoughnessI \\
\hline
\end{tabular}

\begin{tabular}{|c|c|}
\hline N5BH5_28-29ft & TOUGH2 input file \\
\hline N5BH5_28-29ft_sisim.par & Parameter file for generation of random permeability field \\
\hline sh.N5BH5_28-29ft_mesh & $\begin{array}{l}\text { Sequence of instructions to execute multiple steps of mesh } \\
\text { generations }\end{array}$ \\
\hline sh.N5BH5_28-29ft_run & $\begin{array}{l}\text { Sequence of instructions to run the above sequence of } \\
\text { instructions multiple times by changing the permeability } \\
\text { field seed number }\end{array}$ \\
\hline N5BH5_28-29ft.mes1 & Mesh with permeability realization \#1 \\
\hline N5BH5_28-29ft.mes2 & Mesh with permeability realization \#2 \\
\hline N5BH5_28-29ft.mes3 & Mesh with permeability realization \#3 \\
\hline N5BH5_28-29ft.mes4 & Mesh with permeability realization \#4 \\
\hline N5BH5_28-29ft.mes5 & Mesh with permeability realization \#5 \\
\hline N5BH5_28-29ft.mes6 & Mesh with permeability realization \#6 \\
\hline N5BH5_28-29ft.mes7 & Mesh with permeability realization \#7 \\
\hline N5BH5_28-29ft.mes8 & Mesh with permeability realization \#8 \\
\hline N5BH5_28-29ft.mes9 & Mesh with permeability realization \#9 \\
\hline N5BH5_28-29ft.mes10 & Mesh with permeability realization \#10 \\
\hline N5BH5_28-29ft.mes11 & Mesh with permeability realization \#11 \\
\hline N5BH5_28-29ft.mes12 & Mesh with permeability realization \#12 \\
\hline N5BH5_28-29ft.mes13 & Mesh with permeability realization $\# 13$ \\
\hline N5BH5_28-29ft.mes14 & Mesh with permeability realization \#14 \\
\hline N5BH5_28-29ft.mes15 & Mesh with permeability realization \#15 \\
\hline N5BH5_28-29ft.mes16 & Mesh with permeability realization \#16 \\
\hline N5BH5_28-29ft.mes17 & Mesh with permeability realization \#17 \\
\hline N5BH5_28-29ft.mes18 & Mesh with permeability realization \#18 \\
\hline N5BH5_28-29ft.mes19 & Mesh with permeability realization \#19 \\
\hline
\end{tabular}


Table A-1. File Name and Description for Modeling of Liquid-Release Tests in Niche 5 (Continued)

\begin{tabular}{|l|l|l|}
\hline \multicolumn{1}{|c|}{ File/Folder Name } & \multicolumn{1}{c|}{ Description/File Location } \\
\cline { 2 - 3 } & N5BH5_28-29ft.mes20 & Mesh with permeability realization \#20 \\
\hline N5BH5_28-29ft.mes21 & Mesh with permeability realization \#21 \\
\hline N5BH5_28-29ft.mes22 & Mesh with permeability realization \#22 \\
\hline N5BH5_28-29ft.mes23 & Mesh with permeability realization \#23 \\
\hline N5BH5_28-29ft.mes24 & Mesh with permeability realization \#24 \\
\hline N5BH5_28-29ft.mes25 & Mesh with permeability realization \#25 \\
\hline N5BH5_28-29ft.mes26 & Mesh with permeability realization \#26 \\
\hline N5BH5_28-29ft.mes28 & Mesh with permeability realization \#27 \\
\hline N5BH5_28-29ft.mes29 & Mesh with permeability realization \#28 \\
\hline N5BH5_28-29ft.mes30 & Mesh with permeability realization \#29 \\
\hline measured_log-k_12_N5.dat & Mesh with permeability realization \#30 \\
\hline ceiling_N5_3.dat & File is in folder: Meshgeneration/Permeabilityl \\
\hline leftbatwing_N5_3.dat & File is in folder: Meshgeneration/Roughness/ \\
\hline rightbatwing_N5_3.dat & File is in folder: Meshgeneration/Roughness/ \\
\hline Onestep & File is in folder: Meshgeneration/Roughness/ \\
\hline sh.onestep & File is in folder: Meshgeneration/N5BH4_10-11ft/ \\
\hline
\end{tabular}

LiquidReleaseTestDatal

\begin{tabular}{|c|c|}
\hline LB0207NICH5LIQ5-01-RH-T.XIs & $\begin{array}{l}\text { Compilation of Relative humidity and temperature data from } \\
\text { DTN: LB0207NICH5LIQ.001 [DIRS 160408] }\end{array}$ \\
\hline LB0207NICH5LIQ5-01.xIs & $\begin{array}{l}\text { Compilation of Liquid release test data from } \\
\text { DTN: LB0207NICH5LIQ.001 [DIRS 160408] }\end{array}$ \\
\hline LB0207NICH5LIQ5-02.xIs & $\begin{array}{l}\text { Compilation of Liquid release test data from } \\
\text { DTN: LB0207NICH5LIQ.001 [DIRS 160408] }\end{array}$ \\
\hline LB0209NICH5LIQ7-15.xIs & $\begin{array}{l}\text { Compilation of Liquid release test data from } \\
\text { DTN: LB0209NICH5LIQ.001 [DIRS 160796] }\end{array}$ \\
\hline LB0209NICH5LIQ7-16.xIs & $\begin{array}{l}\text { Compilation of Liquid release test data from } \\
\text { DTN: LB0209NICH5LIQ.001 [DIRS 160796] }\end{array}$ \\
\hline LB0211NICH5LIQ9-17\#1.xIs & $\begin{array}{l}\text { Compilation of Liquid release test data from } \\
\text { DTN: LB0211NICH5LIQ.001 [DIRS 160792] }\end{array}$ \\
\hline LB0211NICH5LIQ9-17\#2.xIS & $\begin{array}{l}\text { Compilation of Liquid release test data from } \\
\text { DTN: LB0211NICH5LIQ.001 [DIRS 160792] }\end{array}$ \\
\hline N5BH4_10-11ft_rate.dat & Seepage rate for Borehole \#4 (10-11ft) \\
\hline N5BH5 21-22ft rate.dat & Seepage rate for Borehole \#5 (21-22ft) \\
\hline N5BH5_28-29ft_05-06-02_rate.dat & $\begin{array}{l}\text { Seepage rate for Borehole \#5 (28-29ft), for test started on } \\
5 / 6 / 02\end{array}$ \\
\hline N5BH5_28-29ft_rate.dat & $\begin{array}{l}\text { Seepage rate for Borehole \#5 (28-29ft), for test started on } \\
7 / 15 / 02\end{array}$ \\
\hline
\end{tabular}

Calibrationl

\begin{tabular}{|l|l}
\hline CalibrationSummary.xls & Excel file with compilation of the calibration results \\
\hline
\end{tabular}

\section{Calibration/N5B4_10-11ft/}

\begin{tabular}{|l|l}
\hline sh.N5BH4 101-11ft_cal & $\begin{array}{c}\text { Sequence of commands to start iTOUGH2 on a numbered } \\
\text { node (Node } 1 \text { to Node 10) }\end{array}$ \\
\hline
\end{tabular}


Table A-1. File Name and Description for Modeling of Liquid-Release Tests in Niche 5 (Continued)

\begin{tabular}{|c|c|}
\hline File/Folder Name & Description/File Location \\
\hline sh.N5BH4_101-11ft_calm & Sequence of commands to start iTOUGH2 on the master node \\
\hline N5BH4_10-11ft_SS & TOUGH2 input file for initial condition without evaporation \\
\hline N5BH4_10-11ft_cal & TOUGH2 input file \\
\hline N5BH4_10-11ft_cali & iTOUGH2 input file \\
\hline N5BH4_10-11ft_cal1i.out & iTOUGH2 output file, permeability realization \#1 \\
\hline N5BH4_10-11ft_cal2i.out & iTOUGH2 output file, permeability realization \#2 \\
\hline N5BH4_10-11ft_cal3i.out & iTOUGH2 output file, permeability realization \#3 \\
\hline N5BH4_10-11ft_cal4i.out & iTOUGH2 output file, permeability realization \#4 \\
\hline N5BH4_10-11ft_cal5i.out & iTOUGH2 output file, permeability realization \#5 \\
\hline N5BH4_10-11ft_cal6i.out & iTOUGH2 output file, permeability realization \#6 \\
\hline N5BH4_10-11ft_cal7i.out & iTOUGH2 output file, permeability realization \#7 \\
\hline N5BH4_10-11ft_cal8i.out & iTOUGH2 output file, permeability realization \#8 \\
\hline N5BH4_10-11ft_cal9i.out & iTOUGH2 output file, permeability realization \#9 \\
\hline N5BH4_10-11ft_cal10i.out & iTOUGH2 output file, permeability realization \#10 \\
\hline N5BH4_10-11ft_cal11i.out & iTOUGH2 output file, permeability realization \#11 \\
\hline N5BH4_10-11ft_cal12i.out & iTOUGH2 output file, permeability realization \#12 \\
\hline N5BH4_10-11ft_cal13i.out & iTOUGH2 output file, permeability realization \#13 \\
\hline N5BH4_10-11ft_cal14i.out & iTOUGH2 output file, permeability realization \#14 \\
\hline N5BH4_10-11ft_cal15i.out & iTOUGH2 output file, permeability realization \#15 \\
\hline N5BH4_10-11ft_cal16i.out & iTOUGH2 output file, permeability realization \#16 \\
\hline N5BH4_10-11ft_cal17i.out & iTOUGH2 output file, permeability realization \#17 \\
\hline N5BH4_10-11ft_cal18i.out & iTOUGH2 output file, permeability realization \#18 \\
\hline N5BH4_10-11ft_cal19i.out & iTOUGH2 output file, permeability realization \#19 \\
\hline N5BH4_10-11ft_cal20i.out & iTOUGH2 output file, permeability realization \#20 \\
\hline N5BH4_10-11ft_cal21i.out & iTOUGH2 output file, permeability realization \#21 \\
\hline N5BH4_10-11ft_cal22i.out & iTOUGH2 output file, permeability realization \#22 \\
\hline N5BH4_10-11ft_cal23i.out & iTOUGH2 output file, permeability realization \#23 \\
\hline N5BH4_10-11ft_cal24i.out & iTOUGH2 output file, permeability realization \#24 \\
\hline N5BH4_10-11ft_cal25i.out & iTOUGH2 output file, permeability realization \#25 \\
\hline N5BH4_10-11ft_cal26i.out & iTOUGH2 output file, permeability realization \#26 \\
\hline N5BH4_10-11ft_cal27i.out & iTOUGH2 output file, permeability realization \#27 \\
\hline N5BH4_10-11ft_cal28i.out & iTOUGH2 output file, permeability realization \#28 \\
\hline N5BH4_10-11ft_cal29i.out & iTOUGH2 output file, permeability realization \#29 \\
\hline N5BH4_10-11ft_cal30i.out & iTOUGH2 output file, permeability realization \#30 \\
\hline N5BH4_10-11ft_rate.dat & File is in folder: LiquidReleaseTestData/ \\
\hline
\end{tabular}


Table A-1. File Name and Description for Modeling of Liquid-Release Tests in Niche 5 (Continued)

\begin{tabular}{|c|c|}
\hline File/Folder Name & Description/File Location \\
\hline \multicolumn{2}{|l|}{ Calibration/N5B5_28-29ft/ } \\
\hline sh.N5BH5_28-29ft_cal & $\begin{array}{l}\text { Sequence of commands start iTOUGH2 on a numbered node } \\
\text { (Node } 1 \text { to Node 10) }\end{array}$ \\
\hline sh.N5BH5_28-29ft_calM & Sequence of commands to start iTOUGH2 on the master node \\
\hline N5BH5_28-29ft_ininonevap & TOUGH2 input file for initial condition without evaporation \\
\hline N5BH5_28-29ft_inievap & TOUGH2 input file for initial condition with evaporation \\
\hline N5BH5_28-29ft_cal & TOUGH2 input file \\
\hline N5BH5_28-29ft_cali & iTOUGH2 input file \\
\hline N5BH5_28-29ft_cal1i.out & iTOUGH2 output file, permeability realization \#1 \\
\hline N5BH5_28-29ft_cal3i.out & iTOUGH2 output file, permeability realization \#2 \\
\hline N5BH5_28-29ft_cal4i.out & iTOUGH2 output file, permeability realization \#3 \\
\hline N5BH5_28-29ft_cal6i.out & iTOUGH2 output file, permeability realization \#4 \\
\hline N5BH5_28-29ft_cal7i.out & iTOUGH2 output file, permeability realization \#5 \\
\hline N5BH5_28-29ft_cal8i.out & iTOUGH2 output file, permeability realization \#6 \\
\hline N5BH5_28-29ft_cal9i.out & iTOUGH2 output file, permeability realization \#7 \\
\hline N5BH5_28-29ft_cal11i.out & iTOUGH2 output file, permeability realization \#8 \\
\hline N5BH5_28-29ft_cal12i.out & iTOUGH2 output file, permeability realization \#9 \\
\hline N5BH5_28-29ft_cal13i.out & iTOUGH2 output file, permeability realization \#10 \\
\hline N5BH5_28-29ft_cal14i.out & iTOUGH2 output file, permeability realization \#11 \\
\hline N5BH5_28-29ft_cal15i.out & iTOUGH2 output file, permeability realization \#12 \\
\hline N5BH5_28-29ft_cal16i.out & iTOUGH2 output file, permeability realization \#13 \\
\hline N5BH5_28-29ft_cal18i.out & iTOUGH2 output file, permeability realization \#14 \\
\hline N5BH5_28-29ft_cal19i.out & iTOUGH2 output file, permeability realization \#15 \\
\hline N5BH5_28-29ft_cal20i.out & iTOUGH2 output file, permeability realization \#16 \\
\hline N5BH5_28-29ft_cal21i.out & iTOUGH2 output file, permeability realization \#17 \\
\hline N5BH5_28-29ft_cal23i.out & iTOUGH2 output file, permeability realization \#18 \\
\hline N5BH5_28-29ft_cal24i.out & iTOUGH2 output file, permeability realization \#19 \\
\hline N5BH5_28-29ft_cal25i.out & iTOUGH2 output file, permeability realization \#20 \\
\hline N5BH5_28-29ft_cal26i.out & iTOUGH2 output file, permeability realization \#21 \\
\hline N5BH5_28-29ft_cal27i.out & iTOUGH2 output file, permeability realization \#22 \\
\hline N5BH5_28-29ft_cal28i.out & iTOUGH2 output file, permeability realization \#23 \\
\hline N5BH5_28-29ft_cal29i.out & iTOUGH2 output file, permeability realization \#24 \\
\hline N5BH5_28-29ft.mesX & $\begin{array}{l}\text { Files are in folder: Meshgeneration/N5BH4_10-11ft/ where } X \\
\text { is mesh number }\end{array}$ \\
\hline N5BH5_28-29ft rate.dat & File is in folder: LiquidReleaseTestDatal \\
\hline
\end{tabular}

\section{Validationl}

Validation/N5BH4_1011ft/

\begin{tabular}{|l|l|}
\hline N5BH4_10-11ft_val & TOUGH2 input file \\
\hline N5BH4_10-11ft_vali & iTOUGH2 input file \\
\hline
\end{tabular}


Table A-1. File Name and Description for Modeling of Liquid-Release Tests in Niche 5 (Continued)

\begin{tabular}{|c|c|}
\hline File/Folder Name & Description/File Location \\
\hline N5BH4_10-11ft_vali.out & iTOUGH2 output file \\
\hline N5BH4_10-11ft_vali.tec & iTOUGH2 output file for Tecplot \\
\hline N5BH4_10-11ft_vali_mc.tec & iTOUGH2 output file for Tecplot (Monte Carlo) \\
\hline N5BH4_10-11ft_val.dat & Tecplot input file \\
\hline N5BH4_10-11ft_val.Ipk & Tecplot file (packaged data) \\
\hline N5BH4_10-11ft_val.wmf & Image file \\
\hline measured_log-k_12_N5.dat & File is in folder: Meshgeneration/Permeabilityl \\
\hline N5BH4_10-11ft.mes1 & File is in folder: Meshgeneration/N5BH4_10-11ft/ \\
\hline N5BH4_10-11ft_rate.dat & File is in folder: LiquidReleaseTestDatal \\
\hline
\end{tabular}

Validation/N5BH5_21-22ft/
\begin{tabular}{|l|}
\hline N5BH5_21-22ft_val \\
\hline N5BH5_21-22ft_vali \\
\hline N5BH5_21-22ft_vali.out \\
\hline N5BH5_21-22ft_vali.tec \\
\hline N5BH5_21-22ft_vali_mc.tec \\
\hline N5BH5_21-22ft_val.dat \\
\hline N5BH5_21-22ft_val.Ipk \\
\hline N5BH5_21-22ft_val.wmf \\
\hline measured_log-k_12_N5.dat \\
\hline N5BH5_21-22ft.mes \\
\hline N5BH5_21-22ft_rate.dat \\
\hline
\end{tabular}

\begin{tabular}{|l|}
\hline TOUGH2 input file \\
\hline iTOUGH2 input file \\
\hline iTOUGH2 output file \\
\hline iTOUGH2 output file for Tecplot \\
\hline iTOUGH2 output file for Tecplot (Monte Carlo) \\
\hline Input file for Tecplot \\
\hline Tecplot file (packaged data) \\
\hline Image file \\
\hline File is in folder: Meshgeneration/Permeability/ \\
\hline File is in folder: Meshgeneration/N5BH5_21-22ft/ \\
\hline File is in folder: LiquidReleaseTestData/ \\
\hline
\end{tabular}

Validation/N5BH5_28-29ft_05-06-02I
\begin{tabular}{|l|}
\hline N5BH5_28-29ft_05-06-02_val \\
\hline N5BH5_28-29ft_05-06-02_vali \\
\hline N5BH5_28-29ft_05-06-02_vali.out \\
\hline N5BH5_28-29ft_05-06-02_vali.tec \\
\hline N5BH5_28-29ft_05-06-02_vali_mc.tec \\
\hline N5BH5_28-29ft_05-06-02_val.dat \\
\hline N5BH5_28-29ft_05-06-02_val.Ipk \\
\hline N5BH5_28-29ft_05-06-02_val.wmf \\
\hline measured_log-k_12_N5.dat \\
\hline N5BH5_28-29ft.mes1 \\
\hline N5BH5_28-29ft_05-06-02_rate.dat \\
\hline
\end{tabular}

\begin{tabular}{|l|}
\hline TOUGH2 input file \\
\hline iTOUGH2 input file \\
\hline iTOUGH2 output file \\
\hline iTOUGH2 output file for Tecplot \\
\hline iTOUGH2 output file for Tecplot (Monte Carlo) \\
\hline Input file for Tecplot \\
\hline Tecplot file (packaged data) \\
\hline Image file \\
\hline File is in folder: Meshgeneration/Permeability/ \\
\hline File is in folder: Meshgeneration/N5BH5_28-29ft/ \\
\hline File is in folder: LiquidReleaseTestData/ \\
\hline
\end{tabular}

Validation/N5BH5_28-29ft_07-15-02I
\begin{tabular}{|l|l|}
\hline N5BH5_28-29ft_07-15-02_val & TOUGH2 input file \\
\hline N5BH5_28-29ft_07-15-02_vali & iTOUGH2 input file \\
\hline
\end{tabular}


Table A-1. File Name and Description for Modeling of Liquid-Release Tests in Niche 5 (Continued)

\begin{tabular}{|l|l|l|}
\hline \multicolumn{2}{|c|}{ File/Folder Name } & \multicolumn{1}{c|}{ Description/File Location } \\
\hline \multirow{2}{*}{ N5BH5_28-29ft_07-15-02_vali.out } & iTOUGH2 output file \\
\cline { 2 - 3 } & N5BH5_28-29ft_07-15-02_vali.tec & iTOUGH2 output file for Tecplot \\
\cline { 2 - 3 } & N5BH5_28-29ft_07-15-02_vali_mc.tec & iTOUGH2 output file for Tecplot (Monte Carlo) \\
\cline { 2 - 3 } N5BH5_28-29ft_07-15-02_val.dat & Input file for Tecplot \\
\cline { 2 - 3 } N5BH5_28-29ft_07-15-02_val.Ipk & Tecplot file (packaged data) \\
\cline { 2 - 3 } N5BH5_28-29ft_07-15-02_val.wmf & Image file \\
\cline { 2 - 3 } measured_log-k_12_N5.dat & File is in folder: Meshgeneration/Permeabilityl \\
\cline { 2 - 3 } & F5ile is in folder: Meshgeneration/N5BH5_28-29ft/ \\
\cline { 2 - 3 } & File is in folder: LiquidReleaseTestDatal \\
\cline { 2 - 3 }
\end{tabular}

MassBalancel

\begin{tabular}{|l|l|}
\hline N5BH4_10-11ft_forwardevap & TOUGH2 input file \\
\hline N5BH4_10-11ft_forwardevapi & iTOUGH2 input file, with evaporation connections \\
\hline N5BH4_10-11ft_forwardevapi.out & iTOUGH2 output file, with evaporation connections \\
\hline N5BH4_10-11ft_forwardevapi.tec & Tecplot input file, with evaporation connections \\
\hline N5BH4_10-11ft_forwardseep & TOUGH input file \\
\hline N5BH4_10-11ft_forwardseepi & iTOUGH2 input file, with seepage and deep flow connections \\
\hline N5BH4_10-11ft_forwardseepi.out & iTOUGH2 output file, with seepage and deep flow connections \\
\hline N5BH4_10-11ft_forwardseepi.tec & $\begin{array}{c}\text { iTOUGH2 output file for Tecplot, with seepage and deep flow } \\
\text { connections }\end{array}$ \\
\hline N5BH5_28-29ft.mes1 & File is in folder: Meshgeneration/N5BH4_10-11ft/ \\
\hline
\end{tabular}

FlowDiversion/

\begin{tabular}{|l|l|}
\hline N5BH5_28-29ft_forwarddeep & TOUGH2 input file \\
\hline N5BH5_28-29ft_forwarddeepi & iTOUGH2 input file, with seepage components connections \\
\hline N5BH5_28-29ft_forwarddeepi.out & iTOUGH2 output file, with seepage components connections \\
\hline N5BH5_28-29ft_forwarddeepi.tec & $\begin{array}{l}\text { iTOUGH2 output file for Tecplot, with seepage components } \\
\text { connections }\end{array}$ \\
\hline N5BH5_28-29ft_forwardseep & TOUGH2 input file \\
\hline N5BH5_28-29ft_forwardseepi & iTOUGH2 input file, with seepage connections \\
\hline N5BH5_28-29ft_forwardseepi.out & iTOUGH2 output file, with seepage connections \\
\hline N5BH5_28-29ft_forwardseepi.tec & iTOUGH2 output file for Tecplot, with seepage connections \\
\hline N5BH5_28-29ft.mes1 & File is in folder: Meshgeneration/N5BH5_28-29ft/ \\
\hline
\end{tabular}

\section{Evaporation/}

Evaporation_Calibration.xIs

Estimation of boundary-layer thickness $(\delta)$ for evaporation by vapor diffusion 
Table A-2. File Name and Description for Modeling of Liquid-Release Tests in ECRB Cross-Drift

\begin{tabular}{|c|c|}
\hline File/Folder Name & Description/File Location \\
\hline \multicolumn{2}{|l|}{ STI } \\
\hline ST/Figures/ & (files used for visualization purposes only) \\
\hline 122.dat & For plot rate vs. time, LA\#1, Zone 2, Set 2 \\
\hline 122Sat.dat & For saturation and flux distribution plot, LA\#1, Zone 2, Set 2 \\
\hline 211.dat & For plot rate vs. time, LA\#2, Zone 1, Set 1 \\
\hline 221.dat & For plot rate vs. time, LA\#2, Zone 2, Set 1 \\
\hline 222.dat & For plot rate vs. time, LA\#2, Zone 2, Set 2 \\
\hline 222_0Sat.dat & For saturation distribution plot after 0 days, LA\#2 Zone 2 Set 2 \\
\hline 222_10Sat.dat & For saturation distribution plot after 10 days, LA\#2 Zone 2 Set 2 \\
\hline 222_20Sat.dat & For saturation distribution plot after 20 days, LA\#2 Zone 2 Set 2 \\
\hline 222_30Sat.dat & For saturation distribution plot after 30 days, LA\#2 Zone 2 Set 2 \\
\hline 231.dat & For plot rate vs. time, LA\#2, Zone 3, Set 1 \\
\hline 232.dat & For plot rate vs. time, LA\#2, Zone 3, Set 2 \\
\hline 311.dat & For plot rate vs. time, LA\#3, Zone 1, Set 1 \\
\hline 321.dat & For plot rate vs. time, LA\#3, Zone 2, Set 1 \\
\hline
\end{tabular}

ST/LA1/

ST/LA1/Zone2

\begin{tabular}{|l|l|}
\hline LA1_zone2.mes1 & Mesh with permeability realization \#1 \\
\hline LA1_zone2.mes2 & Mesh with permeability realization \#2 \\
\hline LA1_zone2.mes3 & Mesh with permeability realization \#3 \\
\hline LA1_zone2.mes4 & Mesh with permeability realization \#4 \\
\hline LA1_zone2.mes6 & Mesh with permeability realization \#6 \\
\hline LA1_zone2.mes10 & Mesh with permeability realization \#10 \\
\hline LA1_zone2.mes11 & Mesh with permeability realization \#11 \\
\hline LA1_zone2.mes12 & Mesh with permeability realization \#12 \\
\hline LA1_zone2.mes13 & Mesh with permeability realization \#13 \\
\hline LA1_zone2.mes14 & Mesh with permeability realization \#14 \\
\hline LA1_zone2.mes16 & Mesh with permeability realization \#16 \\
\hline LA1_zone2.mes17 & Mesh with permeability realization \#17 \\
\hline LA1_zone2.mes21 & Mesh with permeability realization \#21 \\
\hline LA1_zone2.mes23 & Mesh with permeability realization \#23 \\
\hline LA1_zone2.mes24 & Mesh with permeability realization \#24 \\
\hline LA1_zone2.mes25 & Mesh with permeability realization \#25 \\
\hline LA1_zone2.mes26 & Mesh with permeability realization \#26 \\
\hline
\end{tabular}


Table A-2. File Name and Description for Modeling of Liquid-Release Tests in ECRB Cross-Drift (Continued)

\begin{tabular}{|c|c|}
\hline File/Folder Name & Description/File Location \\
\hline \multicolumn{2}{|l|}{ ST/LA1/Zone2/Set2 } \\
\hline Cum.xls & $\begin{array}{l}\text { Excel file with processed seepage data from } \\
\text { DTN: LB0110ECRBLIQR.002 [DIRS 156879] }\end{array}$ \\
\hline LA1_zone2_inievap & TOUGH2 input file to create initial conditions with dry-out zone \\
\hline LA1_zone2_ininoevap & TOUGH2 input file to create initial conditions without ventilation \\
\hline LA1_zone2_set2.bc & Relative humidity boundary condition file \\
\hline LA1_zone2_set2.dat & Seepage-rate data file for calibration \\
\hline LA1_zone2_set2 & TOUGH2 input for simulating liquid-release test \\
\hline LA1_zone2_set2i & iTOUGH2 input for calibrating against seepage-rate data \\
\hline LA1_zone2_set2i.out1 & iTOUGH2 output file with permeability realization \#1 \\
\hline LA1_zone2_set2i.out2 & iTOUGH2 output file with permeability realization \#2 \\
\hline LA1_zone2_set2i.out3 & iTOUGH2 output file with permeability realization \#3 \\
\hline LA1_zone2_set2i.out4 & iTOUGH2 output file with permeability realization \#4 \\
\hline LA1_zone2_set2i.out6 & iTOUGH2 output file with permeability realization \#6 \\
\hline LA1_zone2_set2i.out10 & iTOUGH2 output file with permeability realization \#10 \\
\hline LA1_zone2_set2i.out11 & iTOUGH2 output file with permeability realization \#11 \\
\hline LA1_zone2_set2i.out12 & iTOUGH2 output file with permeability realization \#12 \\
\hline LA1_zone2_set2i.out13 & iTOUGH2 output file with permeability realization \#13 \\
\hline LA1_zone2_set2i.out14 & iTOUGH2 output file with permeability realization \#14 \\
\hline LA1_zone2_set2i.out16 & iTOUGH2 output file with permeability realization \#16 \\
\hline LA1_zone2_set2i.out17 & iTOUGH2 output file with permeability realization \#17 \\
\hline LA1_zone2_set2i.out21 & iTOUGH2 output file with permeability realization \#21 \\
\hline LA1_zone2_set2i.out23 & iTOUGH2 output file with permeability realization \#23 \\
\hline LA1_zone2_set2i.out24 & iTOUGH2 output file with permeability realization \#24 \\
\hline LA1_zone2_set2i.out25 & iTOUGH2 output file with permeability realization \#25 \\
\hline LA1_zone2_set2i.out26 & iTOUGH2 output file with permeability realization \#26 \\
\hline RH.xIs & $\begin{array}{l}\text { Excel file with processed relative-humidity data from } \\
\text { DTN: LB0110ECRBLIQR.002 [DIRS 156879] }\end{array}$ \\
\hline inievapi & $\begin{array}{l}\text { Dummy iTOUGH2 input file for generating initial conditions with } \\
\text { evaporation }\end{array}$ \\
\hline
\end{tabular}

ST/LA2I

ST/LA2/Zone1

ST/LA2/Zone1/Set1

\begin{tabular}{|l|l|}
\hline Cum.xls & $\begin{array}{c}\text { Excel file with processed seepage data from } \\
\text { DTN: LB00090012213U.002 [DIRS 153154] }\end{array}$ \\
\hline LA2_zone1_set1.dat & Seepage-rate data file for validation \\
\hline LA2_zone1_set1_val & TOUGH2 input file for simulating liquid-release test \\
\hline LA2_zone1_set1_vali & iTOUGH2 input file for performing Monte Carlo simulations \\
\hline LA2_zone1_set1_vali.out & iTOUGH2 output file \\
\hline LA2_zone1_val.mes & Mesh file used for validation runs \\
\hline
\end{tabular}


Table A-2. File Name and Description for Modeling of Liquid-Release Tests in ECRB Cross-Drift (Continued) File/Folder Name Description/File Location

ST/LA2/Zone2

\begin{tabular}{|c|c|}
\hline LA2_zone2.mes1 & Mesh with permeability realization \#1 \\
\hline LA2_zone2.mes2 & Mesh with permeability realization \#2 \\
\hline LA2_zone2.mes3 & Mesh with permeability realization \#3 \\
\hline LA2_zone2.mes4 & Mesh with permeability realization \#4 \\
\hline LA2_zone2.mes5 & Mesh with permeability realization \#5 \\
\hline LA2_zone2.mes6 & Mesh with permeability realization \#6 \\
\hline LA2_zone2.mes8 & Mesh with permeability realization \#8 \\
\hline LA2_zone2.mes9 & Mesh with permeability realization \#9 \\
\hline LA2_zone2.mes10 & Mesh with permeability realization \#10 \\
\hline LA2_zone2.mes11 & Mesh with permeability realization \#11 \\
\hline LA2_zone2.mes12 & Mesh with permeability realization \#12 \\
\hline LA2_zone2.mes13 & Mesh with permeability realization \#13 \\
\hline LA2_zone2.mes14 & Mesh with permeability realization \#14 \\
\hline LA2_zone2.mes16 & Mesh with permeability realization \#16 \\
\hline LA2_zone2.mes17 & Mesh with permeability realization \#17 \\
\hline LA2_zone2.mes18 & Mesh with permeability realization \#18 \\
\hline LA2_zone2.mes21 & Mesh with permeability realization \#21 \\
\hline LA2_zone2.mes22 & Mesh with permeability realization \#22 \\
\hline LA2_zone2.mes24 & Mesh with permeability realization \#24 \\
\hline LA2_zone2.mes25 & Mesh with permeability realization \#25 \\
\hline LA2_zone2.mes26 & Mesh with permeability realization \#26 \\
\hline LA2_zone2.mes98 & Mesh, boundary-layer thickness $0.5 \mathrm{~cm}$ \\
\hline LA2_zone2.mes99 & Mesh, boundary-layer thickness $2.0 \mathrm{~cm}$ \\
\hline LA2_zone2.mes200 & Mesh, extended mesh \\
\hline
\end{tabular}

ST/LA2/Zone2/Set1

\begin{tabular}{|l|l}
\hline LA2_zone2_set1.bc & \\
\hline LA2_zone2_set1.dat & \\
\hline LA2_zone2_set1_val & \\
\hline LA2_zone2_set1_vali & \\
\hline LA2_zone2_set1_vali.out & \\
\hline LA2_zone2_val.mes & \\
\hline
\end{tabular}

ST/LA2/Zone2/Set2

\begin{tabular}{|l|}
\hline LA2_zone2_inievap \\
\hline LA2_zone2_ininoevap \\
\hline LA2_zone2_set2.bc \\
\hline
\end{tabular}

(seepage data from DTN: LB00090012213U.002 [DIRS 153154]) Relative humidity boundary condition file Seepage-rate data file TOUGH2 input file for simulating liquid-release test iTOUGH2 input file for performing Monte Carlo simulations iTOUGH2 output file Mesh file used for validation runs 
Table A-2. File Name and Description for Modeling of Liquid-Release Tests in ECRB Cross-Drift (Continued)

\begin{tabular}{|c|c|}
\hline File/Folder Name & Description/File Location \\
\hline LA2_zone2_set2.dat & Seepage-rate data file for calibration \\
\hline LA2_zone2_set2 & TOUGH2 input for simulating liquid-release test \\
\hline LA2_zone2_set2_rates_RH.prn & $\begin{array}{c}\text { Processed seepage and relative humidity data from } \\
\text { DTN: LB0110SYST0015.001 [DIRS 160409] }\end{array}$ \\
\hline LA2_zone2_set2i & iTOUGH2 input for calibrating against seepage-rate data \\
\hline LA2_zone2_set2i.out1 & iTOUGH2 output file with permeability realization \#1 \\
\hline LA2_zone2_set2i.out2 & iTOUGH2 output file with permeability realization \#2 \\
\hline LA2_zone2_set2i.out3 & iTOUGH2 output file with permeability realization \#3 \\
\hline LA2_zone2_set2i.out4 & iTOUGH2 output file with permeability realization \#4 \\
\hline LA2_zone2_set2i.out5 & iTOUGH2 output file with permeability realization \#5 \\
\hline LA2_zone2_set2i.out6 & iTOUGH2 output file with permeability realization \#6 \\
\hline LA2_zone2_set2i.out8 & iTOUGH2 output file with permeability realization \#8 \\
\hline LA2_zone2_set2i.out9 & iTOUGH2 output file with permeability realization \#9 \\
\hline LA2_zone2_set2i.out10 & iTOUGH2 output file with permeability realization \#10 \\
\hline LA2_zone2_set2i.out11 & iTOUGH2 output file with permeability realization \#11 \\
\hline LA2_zone2_set2i.out12 & iTOUGH2 output file with permeability realization \#12 \\
\hline LA2_zone2_set2i.out13 & iTOUGH2 output file with permeability realization \#13 \\
\hline LA2_zone2_set2i.out14 & iTOUGH2 output file with permeability realization \#14 \\
\hline LA2_zone2_set2i.out16 & iTOUGH2 output file with permeability realization \#16 \\
\hline LA2_zone2_set2i.out17 & iTOUGH2 output file with permeability realization \#17 \\
\hline LA2_zone2_set2i.out18 & iTOUGH2 output file with permeability realization \#18 \\
\hline LA2_zone2_set2i.out21 & iTOUGH2 output file with permeability realization \#21 \\
\hline LA2_zone2_set2i.out22 & iTOUGH2 output file with permeability realization \#22 \\
\hline LA2_zone2_set2i.out24 & iTOUGH2 output file with permeability realization \#24 \\
\hline LA2_zone2_set2i.out25 & iTOUGH2 output file with permeability realization \#25 \\
\hline LA2_zone2_set2i.out26 & iTOUGH2 output file with permeability realization \#26 \\
\hline LA2_zone2_set2i.out98 & iTOUGH2 output file, boundary-layer thickness $0.5 \mathrm{~cm}$ \\
\hline LA2_zone2_set2i.out99 & iTOUGH2 output file, boundary-layer thickness $2.0 \mathrm{~cm}$ \\
\hline
\end{tabular}

ST/LA2/Zone2/Set2half

\begin{tabular}{|l|l|}
\hline LA2_zone2_inievap & TOUGH2 input file to create initial conditions with dry-out zone \\
\hline LA2_zone2_ininoevap & TOUGH2 input file to create initial conditions without ventilation \\
\hline LA2_zone2_set2.dat & Seepage-rate data file for calibration \\
\hline LA2_zone2_set2half.bc & Relative humidity boundary condition file \\
\hline LA2_zone2_set2half & TOUGH2 input for simulating liquid-release test \\
\hline LA2_zone2_set2halfi & iTOUGH2 input for calibrating against seepage-rate data \\
\hline LA2_zone2_set2halfi.out17 & iTOUGH2 output for calibrating against seepage-rate data \\
\hline
\end{tabular}

\section{ST/LA2/Zone2/Set2large}

(sensitivity to extent of model domain) 
Table A-2. File Name and Description for Modeling of Liquid-Release Tests in ECRB Cross-Drift (Continued)

\begin{tabular}{|c|c|}
\hline File/Folder Name & Description/File Location \\
\hline LA2_zone2_inievap & TOUGH2 input file to create initial conditions with dry-out zone \\
\hline LA2_zone2_ininoevap & TOUGH2 input file to create initial conditions without ventilation \\
\hline LA2_zone2_set2.dat & Seepage-rate data file for calibration \\
\hline LA2_zone2_set2large.bc & Relative humidity boundary condition file \\
\hline LA2_zone2_set2large_forward & TOUGH2 input for simulating liquid-release test \\
\hline LA2_zone2_set2large_forwardi & iTOUGH2 input for calibrating against seepage-rate data \\
\hline LA2_zone2_set2large_forwardi.out & iTOUGH2 output for calibrating against seepage-rate data \\
\hline
\end{tabular}

ST/LA2/Zone2/Set2lessevap

\begin{tabular}{|l|l|}
\hline LA2_zone2_inievap & TO \\
\hline LA2_zone2_ininoevap & TO \\
\hline LA2_zone2_set2.dat & Se \\
\hline LA2_zone2_set2lessevap.bc & Re \\
\hline LA2_zone2_set2lessevap & \\
\hline LA2_zone2_set2lessevapi & i \\
\hline LA2_zone2_set2lessevapi.out & i C \\
\hline
\end{tabular}

ST/LA2/Zone2/Set2noevap

\begin{tabular}{|l|l|}
\hline LA2_zone2_inievap & \\
\hline LA2_zone2_ininoevap & \\
\hline LA2_zone2_set2.dat & \\
\hline LA2_zone2_set2noevap.bc & \\
\hline LA2_zone2_set2noevap & \\
\hline LA2_zone2_set2noevapi & \\
\hline LA2_zone2_set2noevapi.out & \\
\hline
\end{tabular}

ST/LA2/Zone2/Set2sens

\begin{tabular}{|l|l|}
\hline LA2_zone2_inievap & TOUGH2 input file to create initial conditions with dry-out zone \\
\hline LA2_zone2_ininoevap & TOUGH2 input file to create initial conditions without ventilation \\
\hline LA2_zone2_set2.dat & Seepage-rate data file for calibration \\
\hline LA2_zone2_set2sens.bc & Relative humidity boundary condition file \\
\hline LA2_zone2_set2sens_forward & TOUGH2 input for simulating liquid-release test \\
\hline LA2_zone2_set2sens_forwardi & iTOUGH2 input for performing sensitivity analysis \\
\hline LA2_zone2_set2sens_forwardi.out & iTOUGH2 output for sensitivity analysis \\
\hline
\end{tabular}

(sensitivity to evaporative surface area)

TOUGH2 input file to create initial conditions with dry-out zone TOUGH2 input file to create initial conditions without ventilation Seepage-rate data file for calibration

Relative humidity boundary condition file

TOUGH2 input for simulating liquid-release test

iTOUGH2 input for calibrating against seepage-rate data

iTOUGH2 output for calibrating against seepage-rate data

(sensitivity to evaporation)

Dummy TOUGH2 input file to create initial conditions

TOUGH2 input file to create initial conditions without ventilation

Seepage-rate data file for calibration

Relative humidity boundary condition file

TOUGH2 input for simulating liquid-release test

iTOUGH2 input for calibrating against seepage-rate data

iTOUGH2 output for calibrating against seepage-rate data

\section{ST/LA2/Zone3}

\begin{tabular}{|l|l|}
\hline LA2_zone3.mes1 & Mesh with permeability realization \#1 \\
\hline LA2_zone3.mes2 & Mesh with permeability realization \#2 \\
\hline LA2_zone3.mes3 & Mesh with permeability realization \#3 \\
\hline
\end{tabular}


Table A-2. File Name and Description for Modeling of Liquid-Release Tests in ECRB Cross-Drift (Continued)

\begin{tabular}{|l|l|}
\hline \multicolumn{1}{|c|}{ File/Folder Name } & \multicolumn{1}{c|}{ Description/File Location } \\
\hline LA2_zone3.mes4 & Mesh with permeability realization \#4 \\
\hline LA2_zone3.mes5 & Mesh with permeability realization \#5 \\
\hline LA2_zone3.mes6 & Mesh with permeability realization \#6 \\
\hline LA2_zone3.mes9 & Mesh with permeability realization \#9 \\
\hline LA2_zone3.mes10 & Mesh with permeability realization \#10 \\
\hline LA2_zone3.mes11 & Mesh with permeability realization \#11 \\
\hline LA2_zone3.mes12 & Mesh with permeability realization \#12 \\
\hline LA2_zone3.mes13 & Mesh with permeability realization \#13 \\
\hline LA2_zone3.mes14 & Mesh with permeability realization \#14 \\
\hline LA2_zone3.mes15 & Mesh with permeability realization \#15 \\
\hline LA2_zone3.mes16 & Mesh with permeability realization \#16 \\
\hline LA2_zone3.mes18 & Mesh with permeability realization \#18 \\
\hline LA2_zone3.mes19 & Mesh with permeability realization \#19 \\
\hline LA2_zone3.mes20 & Mesh with permeability realization \#20 \\
\hline LA2_zone3.mes21 & Mesh with permeability realization \#21 \\
\hline LA2_zone3.mes22 & Mesh with permeability realization \#22 \\
\hline
\end{tabular}

ST/LA2/Zone3/Set1

\begin{tabular}{|l|l}
\hline LA2_zone3_set1.dat & \\
\hline LA2_zone3_set1_val & TO \\
\hline LA2_zone3_set1_vali & iTC \\
\hline LA2_zone3_set1_vali.out & iTC \\
\hline LA2_zone3_val.mes & \\
\hline
\end{tabular}

ST/LA2/Zone3/Set 2

\begin{tabular}{|l|l|}
\hline LA2_zone3_inievap & TO \\
\hline LA2_zone3_ininoevap & TO \\
\hline LA2_zone3_set2.bc & Re \\
\hline LA2_zone3_set2.dat & S \\
\hline LA2_zone3_set2 & TO \\
\hline LA2_zone3_set2i & i \\
\hline LA2_zone3_set2i.out1 & i \\
\hline LA2_zone3_set2i.out2 & i \\
\hline LA2_zone3_set2i.out3 & $\mathrm{i}$ \\
\hline LA2_zone3_set2i.out4 & $\mathrm{i}$ \\
\hline LA2_zone3_set2i.out5 & $\mathrm{i}$ \\
\hline LA2_zone3_set2i.out6 & $\mathrm{i}$ \\
\hline LA2_zone3_set2i.out9 & $\mathrm{i}$ \\
\hline LA2_zone3_set2i.out10 & $\mathrm{i}$ \\
\hline
\end{tabular}

(seepage data from DTN: LB00090012213U.002 [DIRS 153154]) Seepage-rate data file TOUGH2 input file for simulating liquid-release test iTOUGH2 input file for performing Monte Carlo simulations iTOUGH2 output file Mesh file used for validation runs

(seepage data from DTN: LB0110SYST0015.001 [DIRS 160409]) TOUGH2 input file to create initial conditions with dry-out zone TOUGH2 input file to create initial conditions without ventilation Relative humidity boundary condition file Seepage-rate data file for calibration TOUGH2 input for simulating liquid-release test iTOUGH2 input for calibrating against seepage-rate data iTOUGH2 output file with permeability realization \#1 iTOUGH2 output file with permeability realization \#2 iTOUGH2 output file with permeability realization \#3 iTOUGH2 output file with permeability realization \#4 iTOUGH2 output file with permeability realization \#5 iTOUGH2 output file with permeability realization \#6 iTOUGH2 output file with permeability realization \#9 iTOUGH2 output file with permeability realization \#10 
Table A-2. File Name and Description for Modeling of Liquid-Release Tests in ECRB Cross-Drift (Continued)

\begin{tabular}{|c|c|}
\hline File/Folder Name & Description/File Location \\
\hline LA2_zone3_set2i.out11 & iTOUGH2 output file with permeability realization \#11 \\
\hline LA2_zone3_set2i.out12 & iTOUGH2 output file with permeability realization \#12 \\
\hline LA2_zone3_set2i.out13 & iTOUGH2 output file with permeability realization \#13 \\
\hline LA2_zone3_set2i.out14 & iTOUGH2 output file with permeability realization \#14 \\
\hline LA2_zone3_set2i.out15 & iTOUGH2 output file with permeability realization \#15 \\
\hline LA2_zone3_set2i.out16 & iTOUGH2 output file with permeability realization \#16 \\
\hline LA2_zone3_set2i.out18 & iTOUGH2 output file with permeability realization \#18 \\
\hline LA2_zone3_set2i.out19 & iTOUGH2 output file with permeability realization \#19 \\
\hline LA2_zone3_set2i.out20 & iTOUGH2 output file with permeability realization \#20 \\
\hline LA2_zone3_set2i.out21 & iTOUGH2 output file with permeability realization \#21 \\
\hline LA2_zone3_set2i.out22 & iTOUGH2 output file with permeability realization \#22 \\
\hline
\end{tabular}

ST/LA3I

ST/LA3/Zone1

\begin{tabular}{|c|c|}
\hline LA3_zone1.mes1 & Mesh with permeability realization \#1 \\
\hline LA3_zone1.mes2 & Mesh with permeability realization \#2 \\
\hline LA3_zone1.mes3 & Mesh with permeability realization \#3 \\
\hline LA3_zone1.mes4 & Mesh with permeability realization \#4 \\
\hline LA3_zone1.mes5 & Mesh with permeability realization \#5 \\
\hline LA3_zone1.mes6 & Mesh with permeability realization \#6 \\
\hline LA3_zone1.mes7 & Mesh with permeability realization \#7 \\
\hline LA3_zone1.mes8 & Mesh with permeability realization \#8 \\
\hline LA3_zone1.mes9 & Mesh with permeability realization \#9 \\
\hline LA3_zone1.mes10 & Mesh with permeability realization \#10 \\
\hline LA3_zone1.mes11 & Mesh with permeability realization \#11 \\
\hline LA3_zone1.mes12 & Mesh with permeability realization \#12 \\
\hline LA3_zone1.mes13 & Mesh with permeability realization \#13 \\
\hline LA3_zone1.mes14 & Mesh with permeability realization \#14 \\
\hline LA3_zone1.mes15 & Mesh with permeability realization \#15 \\
\hline LA3_zone1.mes16 & Mesh with permeability realization \#16 \\
\hline LA3_zone1.mes17 & Mesh with permeability realization \#17 \\
\hline LA3_zone1.mes18 & Mesh with permeability realization \#18 \\
\hline LA3_zone1.mes19 & Mesh with permeability realization \#19 \\
\hline LA3_zone1.mes20 & Mesh with permeability realization \#20 \\
\hline LA3_zone1.mes21 & Mesh with permeability realization \#21 \\
\hline LA3_zone1.mes22 & Mesh with permeability realization \#22 \\
\hline LA3_zone1.mes23 & Mesh with permeability realization \#23 \\
\hline LA3_zone1.mes24 & Mesh with permeability realization \#24 \\
\hline LA3_zone1.mes25 & Mesh with permeability realization \#25 \\
\hline
\end{tabular}

(files used for simulation of liquid-release tests in borehole SYBT-ECRB-LA\#3) 
Table A-2. File Name and Description for Modeling of Liquid-Release Tests in ECRB Cross-Drift (Continued) File/Folder Name Description/File Location

ST/LA3/Zone1/Set1

\begin{tabular}{|c|c|}
\hline Cum.xls & $\begin{array}{l}\text { Excel file with processed seepage data from } \\
\text { DTN: LB0203ECRBLIQR.001 [DIRS 158462] }\end{array}$ \\
\hline LA3_zone1_inievap & TOUGH2 input file to create initial conditions with dry-out zone \\
\hline LA3_zone1_ininoevap & TOUGH2 input file to create initial conditions without ventilation \\
\hline LA3_zone1_set1.bc & Relative humidity boundary condition file \\
\hline LA3_zone1_set1.dat & Seepage-rate data file for calibration \\
\hline LA3_zone1_set1 & TOUGH2 input for simulating liquid-release test \\
\hline LA3_zone1_set1i & iTOUGH2 input for calibrating against seepage-rate data \\
\hline LA3_zone1_set1i.out1 & iTOUGH2 output file with permeability realization \#1 \\
\hline LA3_zone1_set1i.out2 & iTOUGH2 output file with permeability realization \#2 \\
\hline LA3_zone1_set1i.out3 & iTOUGH2 output file with permeability realization \#3 \\
\hline LA3_zone1_set1i.out4 & iTOUGH2 output file with permeability realization \#4 \\
\hline LA3_zone1_set1i.out5 & iTOUGH2 output file with permeability realization \#5 \\
\hline LA3_zone1_set1i.out6 & iTOUGH2 output file with permeability realization \#6 \\
\hline LA3_zone1_set1i.out7 & iTOUGH2 output file with permeability realization \#7 \\
\hline LA3_zone1_set1i.out8 & iTOUGH2 output file with permeability realization \#8 \\
\hline LA3_zone1_set1i.out9 & iTOUGH2 output file with permeability realization \#9 \\
\hline LA3_zone1_set1i.out10 & iTOUGH2 output file with permeability realization \#10 \\
\hline LA3_zone1_set1i.out11 & iTOUGH2 output file with permeability realization \#11 \\
\hline LA3_zone1_set1i.out12 & iTOUGH2 output file with permeability realization \#12 \\
\hline LA3_zone1_set1i.out13 & iTOUGH2 output file with permeability realization \#13 \\
\hline LA3_zone1_set1i.out14 & iTOUGH2 output file with permeability realization \#14 \\
\hline LA3_zone1_set1i.out15 & iTOUGH2 output file with permeability realization \#15 \\
\hline LA3_zone1_set1i.out16 & iTOUGH2 output file with permeability realization \#16 \\
\hline LA3_zone1_set1i.out17 & iTOUGH2 output file with permeability realization \#17 \\
\hline LA3_zone1_set1i.out18 & iTOUGH2 output file with permeability realization \#19 \\
\hline LA3_zone1_set1i.out20 & iTOUGH2 output file with permeability realization \#20 \\
\hline LA3_zone1_set1i.out22 & iTOUGH2 output file with permeability realization \#22 \\
\hline LA3_zone1_set1i.out23 & iTOUGH2 output file with permeability realization \#23 \\
\hline LA3_zone1_set1i.out24 & iTOUGH2 output file with permeability realization \#24 \\
\hline LA3_zone1_set1i.out25 & iTOUGH2 output file with permeability realization \#25 \\
\hline
\end{tabular}

\section{ST/LA3/Zone2}

ST/LA3/Zone2/Set1

\begin{tabular}{|l|l|}
\hline Cum.xls & $\begin{array}{l}\text { Excel file with processed seepage data from } \\
\text { DTN: LB0203ECRBLIQR.001 [DIRS 158462] }\end{array}$ \\
\hline LA3_zone2_set1.dat & Seepage-rate data file \\
\hline LA3_zone2_set1_val & TOUGH2 input file for simulating liquid-release test \\
\hline
\end{tabular}


Table A-2. File Name and Description for Modeling of Liquid-Release Tests in ECRB Cross-Drift (Continued)

\begin{tabular}{|l|l|l|}
\hline \multicolumn{2}{|c|}{ File/Folder Name } & \multicolumn{1}{c|}{ Description/File Location } \\
\hline \multirow{2yy}{*}{} & LA3_zone2_set1_vali & iTOUGH2 input file for performing Monte Carlo simulations \\
\cline { 2 - 3 } & LA3_zone2_set1_vali.out & iTOUGH2 output file \\
\cline { 2 - 3 } & LA3_zone2_val.mes & Mesh file used for validation runs \\
\cline { 2 - 3 }
\end{tabular}

ST/Meshgeneration/

\begin{tabular}{|c|c|}
\hline mesh3dblock & TOUGH2 input file with MESHMAKER block \\
\hline mesh3dlargeblock & TOUGH2 input file with MESHMAKER block, extended model \\
\hline onestep & TOUGH2 input file to perform single time step \\
\hline perm.par & $\begin{array}{l}\text { SISIM input file for generating heterogeneous log-permeability } \\
\text { modifier field }\end{array}$ \\
\hline primary.mes & Primary mesh file \\
\hline primarylarge.mes & Primary mesh file, extended model domain \\
\hline sh.LA1_zone2_mesh & $\begin{array}{l}\text { Sequence of commands used to generate meshes for tests in zone } 2 \\
\text { of borehole SYBT-ECRB-LA\#1 }\end{array}$ \\
\hline sh.LA2_zone1_mesh & $\begin{array}{l}\text { Sequence of commands used to generate meshes for tests in zone } 1 \\
\text { of borehole SYBT-ECRB-LA\#2 }\end{array}$ \\
\hline sh.LA2_zone2_largemesh & $\begin{array}{l}\text { Sequence of commands used to generate extended mesh for tests in } \\
\text { zone } 2 \text { of borehole SYBT-ECRB-LA\#2 } \\
\end{array}$ \\
\hline sh.LA2_zone2_mesh & $\begin{array}{l}\text { Sequence of commands used to generate meshes for tests in zone } 2 \\
\text { of borehole SYBT-ECRB-LA\#2 }\end{array}$ \\
\hline sh.LA2_zone3_mesh & $\begin{array}{l}\text { Sequence of commands used to generate meshes for tests in zone } 3 \\
\text { of borehole SYBT-ECRB-LA\#2 }\end{array}$ \\
\hline sh.LA3_zone1_mesh & $\begin{array}{l}\text { Sequence of commands used to generate meshes for tests in zone } 1 \\
\text { of borehole SYBT-ECRB-LA\#3 }\end{array}$ \\
\hline sh.LA3_zone2_mesh & $\begin{array}{l}\text { Sequence of commands used to generate meshes for tests in zone } 2 \\
\text { of borehole SYBT-ECRB-LA\#3 }\end{array}$ \\
\hline sh.onestep & $\begin{array}{l}\text { Sequence of commands used to run iTOUGH2 simulation with a } \\
\text { single time step }\end{array}$ \\
\hline
\end{tabular}

\begin{tabular}{|l|l|}
\hline results.xls & Excel file with compilation of inverse modeling results \\
\hline sh.run & $\begin{array}{l}\text { Sequence of commands used to perform multiple inversions with } \\
\text { multiple realizations of underlying permeability field }\end{array}$ \\
\hline sh.run_forward & Sequence of commands used to perform a single forward run \\
\hline sh.run_val & Sequence of commands used to perform validation runs \\
\hline
\end{tabular}




\section{INTENTIONALLY LEFT BLANK}


APPENDIX B

\section{VARIOGRAM FITTING}


Section 6.6.2.1 discusses the fitting of a spherical variogram model to the empirical variogram data obtained from the geostatistical analysis of air-permeability data. The purpose of the fitting was to determine the nugget effect, sill value, and correlation length of the log-permeability field. Weighted least-squares fitting was performed using standard functions of the exempt software EXCEL (97 SR-2). The following narrative explains the fitting process for clarification, using worksheet N3107_airk_SD of file Vario.xls as an example.

1. The result of the variogram calculation using GAMV3 V1.201 (LBNL 2000 [DIRS 153099]) (see file N3107_airk.var, submitted with this Model Report under output DTN: LB0302SCMREV02.001) was loaded into the worksheet. Each data line in file N3107_airk.var is labeled. Lines 3 through 31 contain the empirical variogram information; Lines 1, 2, and 32 through 52 contain unrelated information and are removed. The relevant information is now contained in Rows 7 through 35 of the worksheet N3107_airk_SD of spreadsheet Vario.xls (in the remainder of this appendix, all references to a column are restricted to Rows 7 through 35).

2. Performing a weighted least-square fit consists of minimizing the following objective function $S$ :

$$
S=\sum_{i=1}^{m} \frac{\left(\gamma_{i}-\gamma_{i}^{*}\right)^{2}}{w_{i}^{2}}
$$

where $\gamma_{i}$ is the value calculated with the spherical variogram model at lag distance $h_{i}, \gamma^{*}{ }_{i}$ is the corresponding empirical variogram value, and $w_{i}$ is a coefficient for weighting the data. The spherical variogram with a nugget effect is given by (after Deutsch and Journel 1992 [DIRS 100567], p. 23, Eq. B-2):

$$
\begin{array}{rlrl}
\gamma(h ; n, a, c) & =n+c\left[1.5 \frac{h}{a}-0.5\left(\frac{h}{a}\right)^{3}\right] & & \text { if } \quad h<a \\
& =n+c & \text { if } \quad h \geq a
\end{array}
$$

Here, $h$ is the lag distance (stored in Column C), $n$ is the nugget effect (stored in Cell J2), $a$ is the correlation length (stored in Cell J3), and $c$ is the sill value (stored in Cell J4). The coefficient $w$ in Eq. B-1 is taken to be the inverse of the number of data pairs supporting the empirical variogram value (stored in Column $\mathrm{E}$; the inverse is stored in a newly inserted Column F).

3. Column J contains Eq. B-2, Column K holds the squared weighted differences (see Eq. B-1), and Cell K6 holds the objective function $S$.

4. The objective function of Cell K6 is minimized by updating the three parameters stored in Cells J2, J3, and J4 using the EXCEL Solver Add-in (to be loaded by clicking on "Tools | Add-ins... | Solver Add-in”). Click on “Tools | Solver...," set "Set Target Cell” to \$K\$6, "Equal to" to "Min”, "By Changing Cells" to \$J\$2:\$J\$4, and “Subject to the Constraints" to $\$ \mathrm{~J} \$ 2>=0, \$ \mathrm{~J} \$ 3>=0$, and $\$ \mathrm{~J} \$ 4>=0$. Looking at the empirical variogram, provide reasonable 
initial guesses for the three parameters (e.g., $n=0.1, a=1.0, c=0.5$ ) and click on "Solve" to get the best-fit parameters, which are displayed in Cells J2 through J4.

The appropriateness of the fitting procedure was checked as follows:

1. The spreadsheet was developed by Rick Ahlers. Stefan Finsterle has verified that Eqs. B-1 and B-2 were correctly coded into the appropriate cells.

2. The calculated variogram value (shown in Column $\mathrm{H}$ ) was spot-checked.

Figure 6-12 shows that the variogram model fits the data in a least-square sense.

The EXCEL spreadsheet Vario.xls has been submitted as part of an earlier revision (CRWMS M\&O 2001 [DIRS 153045]) under output DTN: LB0010SCMREV01.001; therefore, the input, equations used (click on the appropriate cells), and output is available, traceable, and reproducible by an appropriately qualified individual. The spreadsheet is reproduced in Table B-1. 
Table B-1. EXCEL Spreadsheet Vario.xls for Fitting Spherical Variogram to Empirical LogPermeability Variogram

\begin{tabular}{|c|c|c|c|c|c|c|c|c|c|}
\hline A & $\mathrm{B}$ & $\mathrm{C}$ & $\mathrm{D}$ & $\mathrm{E}$ & $\mathrm{F}$ & $\mathrm{G}$ & $\mathrm{H}$ & $\mathrm{J}$ & $\mathrm{K}$ \\
\hline 2 & & & & & & & nugget & 0.005957 & \\
\hline 3 & & & & & & & correlation length & 0.608829 & \\
\hline 4 & & & & & & & sill & 0.487922 & \\
\hline 5 & & & & & & & & & $\mathrm{~K} 6=$ objective func \\
\hline 6 & & $\operatorname{Lag}[\mathrm{m}]$ & Gamma & \# of pairs & 1/(\# of pairs) & $\log \left(k \_\right.$head $)$ & Log(k_tail) & Spherical & 3173.542618 \\
\hline 7 & 3 & 0.305 & 0.34193 & 138 & 0.00725 & -12.21159 & -12.21159 & 0.34193 & $6.78058 \mathrm{E}-12$ \\
\hline 8 & 4 & 0.609 & 0.51454 & 132 & 0.00758 & -12.23576 & -12.23576 & 0.493878 & 7.430211773 \\
\hline 9 & 5 & 0.928 & 0.48461 & 282 & 0.00355 & -12.24096 & -12.24096 & 0.493878 & 6.815955381 \\
\hline 10 & 6 & 1.226 & 0.43619 & 454 & 0.0022 & -12.19152 & -12.19152 & 0.493878 & 687.5866471 \\
\hline 11 & 7 & 1.512 & 0.48658 & 332 & 0.00301 & -12.20027 & -12.20027 & 0.493878 & 5.878806928 \\
\hline 12 & 8 & 1.817 & 0.4684 & 320 & 0.00313 & -12.201 & -12.201 & 0.493878 & 66.25919213 \\
\hline 13 & 9 & 2.145 & 0.48656 & 564 & 0.00177 & -12.23769 & -12.23769 & 0.493878 & 17.09435459 \\
\hline 14 & 10 & 2.45 & 0.50127 & 386 & 0.00259 & -12.23959 & -12.23959 & 0.493878 & 8.145356588 \\
\hline 15 & 11 & 2.733 & 0.55705 & 318 & 0.00314 & -12.2467 & -12.2467 & 0.493878 & 404.751331 \\
\hline 16 & 12 & 3.033 & 0.47056 & 318 & 0.00314 & -12.22242 & -12.22242 & 0.493878 & 55.14775388 \\
\hline 17 & 13 & 3.342 & 0.46302 & 298 & 0.00336 & -12.23587 & -12.23587 & 0.493878 & 84.34520866 \\
\hline 18 & 14 & 3.653 & 0.49027 & 266 & 0.00376 & -12.20598 & -12.20598 & 0.493878 & 0.920845218 \\
\hline 19 & 15 & 3.963 & 0.5031 & 244 & 0.0041 & -12.22635 & -12.22635 & 0.493878 & 5.059074452 \\
\hline 20 & 16 & 4.265 & 0.54863 & 214 & 0.00467 & -12.24701 & -12.24701 & 0.493878 & 137.4561849 \\
\hline 21 & 17 & 4.576 & 0.53108 & 216 & 0.00463 & -12.22051 & -12.22051 & 0.493878 & 64.56062946 \\
\hline 22 & 18 & 4.89 & 0.62485 & 178 & 0.00562 & -12.18056 & -12.18056 & 0.493878 & 543.1046002 \\
\hline 23 & 19 & 5.198 & 0.59026 & 168 & 0.00595 & -12.14107 & -12.14107 & 0.493878 & 262.3957768 \\
\hline 24 & 20 & 5.507 & 0.55459 & 136 & 0.00735 & -12.15426 & -12.15426 & 0.493878 & 68.22957436 \\
\hline 25 & 21 & 5.806 & 0.6776 & 124 & 0.00806 & -12.16726 & -12.16726 & 0.493878 & 519.5790967 \\
\hline 26 & 22 & 6.114 & 0.56408 & 116 & 0.00862 & -12.20509 & -12.20509 & 0.493878 & 66.32586675 \\
\hline 27 & 23 & 6.433 & 0.39963 & 94 & 0.01064 & -12.21426 & -12.21426 & 0.493878 & 78.46250161 \\
\hline 28 & 24 & 6.745 & 0.49685 & 74 & 0.01351 & -12.30514 & -12.30514 & 0.493878 & 0.048389527 \\
\hline 29 & 25 & 7.041 & 0.42472 & 58 & 0.01724 & -12.29034 & -12.29034 & 0.493878 & 16.09206783 \\
\hline 30 & 26 & 7.34 & 0.55424 & 44 & 0.02273 & -12.30341 & -12.30341 & 0.493878 & 7.052232487 \\
\hline 31 & 27 & 7.638 & 0.66126 & 32 & 0.03125 & -12.33875 & -12.33875 & 0.493878 & 28.68909386 \\
\hline 32 & 28 & 7.938 & 0.48026 & 20 & 0.05 & -12.1745 & -12.1745 & 0.493878 & 0.074181294 \\
\hline 33 & 29 & 8.233 & 0.86247 & 14 & 0.07143 & -12.03286 & -12.03286 & 0.493878 & 26.62748957 \\
\hline 34 & 30 & 8.522 & 0.75716 & 8 & 0.125 & -12.06625 & -12.06625 & 0.493878 & 4.43631024 \\
\hline \multirow[t]{2}{*}{35} & 31 & 8.753 & 0.00045 & 2 & 0.5 & -11.625 & -11.625 & 0.493878 & 0.973885245 \\
\hline & & & & & & & & \multicolumn{2}{|c|}{ K7-K35 = weighted residuals } \\
\hline
\end{tabular}




\section{INTENTIONALLY LEFT BLANK}




\section{APPENDIX C MESH GENERATION FOR SIMULATION OF SEEPAGE TESTS IN ECRB}


Multiple numerical meshes of a $12 \mathrm{ft}(3.6576 \mathrm{~m})$ long section of the ECRB Cross-Drift were developed, each with a different stochastic realization of the underlying heterogeneous permeability field. The following steps are performed:

1. A mesh was generated with $\mathrm{X}-\mathrm{Y}-\mathrm{Z}$ dimensions of $4.0 \mathrm{~m} \times 3.6576 \mathrm{~m} \times 11.0 \mathrm{~m}$, respectively, discretized into regular gridblocks with side lengths of $0.1 \mathrm{~m} \times 0.3 \mathrm{~m} \times 0.1 \mathrm{~m}$. The $\mathrm{Y}$-axis was aligned with the drift axis. Figure C-1 shows the input file mesh3dblock and the command used to generate the mesh.

2. The Z-coordinate of the mesh is shifted by $8 \mathrm{~m}$ using software MoveMesh V1.0 (LBNL 2000 [DIRS 152824]) to translate the origin of the mesh to the center of the drift. The resulting grid is referred to as the primary mesh (file primary.mes).

3. For each realization, a new seed number is inserted into the SISIM V1.204 input file perm.par (see Figure C-2). SISIM V1.204 (LBNL 2000 [DIRS 153100]) is then executed to generate a random, spatially correlated field of log-permeability modifiers (file perm.dat).

4. The heterogeneous field of permeability modifiers is mapped onto the mesh using software Perm2Mesh V1.0 (LBNL 2000 [DIRS 152826]).

5. A cylindrical drift of radius $2.5 \mathrm{~m}$ is cut from the mesh using software CutDrift V1.0 (LBNL 2000 [DIRS 152816]). The drift is centered at $\mathrm{X}=0$ and $\mathrm{Z}=0$ with its axis parallel to the $\mathrm{Y}$ axis.

6. Software AddBound V1.0 (LBNL 2000 [DIRS 152823]) is used to attach boundary elements at the top and bottom of the model domain. The bottom-boundary gridblock is assigned to a special material domain (DRAIN) to allow specifying a free-drainage boundary condition.

7. Software AddBorehole V1.0 (LBNL 2000 [DIRS 152822]) is used to insert gridblocks representing a $6 \mathrm{ft}(1.8288 \mathrm{~m})$ long injection interval with a diameter of 3 inches $(0.076 \mathrm{~m})$. The injection interval lies within the $\mathrm{Y}-\mathrm{Z}$ plane at a $15^{\circ}$ angle from the horizontal, centered at $\mathrm{X}=0.0 \mathrm{~m}, \mathrm{Y}=1.8288 \mathrm{~m}$, and a $\mathrm{Z}$ coordinate that depends on the packed-off zone being tested (see also Table C-1). The elevations $Z$ [m] of the beginning and end of the borehole interval are calculated from their respective distances from the borehole collar $d$ [ft] as follows:

$$
Z=d \cdot 0.3048 \cdot \sin \left(15^{\circ}\right)+2.5
$$

8. Drift elements (DRI98 and DRI99) were assigned a large volume so that Dirichlet boundary conditions could be specified. Flux into the drift elements represents seepage.

9. Two new evaporation elements (EVA98 and EVA99) were added and connected to the same formation elements as the drift elements. The nodal distance from the formation elements to the evaporation elements was set to the diffusive boundary-layer thickness. Flux into these elements represents evaporation.

10. A single time step was performed using a generic TOUGH2 input file onestep (as input to iTOUGH2 V5.0 (LBNL 2002 [DIRS 160106]); see Figure C-3) to test the mesh and to 
obtain cross-referencing information. The execution of the simulation is performed using file sh.onestep (Figure C-4)

11. The final mesh is stored on file $L A x \_z o n e Y$.mesZ, where $x$ refers to the borehole number, $Y$ designates the test interval, and $Z$ labels the realization of the underlying random permeability field.

File sh.LAx_zoneY_mes (see Figure C-5) was used to execute Mesh Generation Steps 3-11. The file documents all the Unix commands used as well as input variables to the individual software codes. An excerpt from a final sample mesh file LAx_zoneY.mesZ is shown in Figure C-6.

Table C-1. Input Z-Coordinates to Software AddBorehole V1.0 (Borehole Interval Elevations)

\begin{tabular}{|c|c|c|c|c|c|c|}
\hline \multirow[b]{2}{*}{ Borehole } & \multirow[b]{2}{*}{ Source } & \multirow[b]{2}{*}{ Zone } & \multicolumn{2}{|c|}{ Beginning of Interval } & \multicolumn{2}{|c|}{ End of interval } \\
\hline & & & $\begin{array}{c}\text { Distance from } \\
\text { Collar } \\
d[\mathrm{ft}]\end{array}$ & $\begin{array}{c}\text { Elevation } \\
Z[\mathrm{~m}]\end{array}$ & $\begin{array}{c}\text { Distance from } \\
\text { Collar } \\
d[\mathrm{ft}]\end{array}$ & $\begin{array}{c}\text { Elevation } \\
Z[\mathrm{~m}]\end{array}$ \\
\hline $\begin{array}{l}\text { SYBT-ECRB- } \\
\text { LA\#1 }\end{array}$ & $\begin{array}{c}\text { LB0110ECRBLIQR.002 } \\
\text { [DIRS 156879] }\end{array}$ & 2 & 10 & 3.29 & 16 & 3.76 \\
\hline \multirow{3}{*}{$\begin{array}{l}\text { SYBT-ECRB- } \\
\text { LA\#2 }\end{array}$} & \multirow{3}{*}{$\begin{array}{l}\text { LB00090012213U.002 } \\
\text { [DIRS 153154] }\end{array}$} & 1 & 17 & 3.84 & 23 & 4.31 \\
\hline & & 2 & 33 & 5.10 & 39 & 5.58 \\
\hline & & 3 & 49 & 6.37 & 55 & 6.84 \\
\hline \multirow{2}{*}{$\begin{array}{l}\text { SYBT-ECRB- } \\
\text { LA\#3 }\end{array}$} & \multirow{2}{*}{$\begin{array}{l}\text { LB0203ECRBLIQR.001 } \\
\text { [DIRS 158462] }\end{array}$} & 1 & 18 & 3.92 & 24 & 4.39 \\
\hline & & 2 & 34 & 5.18 & 40 & 5.66 \\
\hline
\end{tabular}

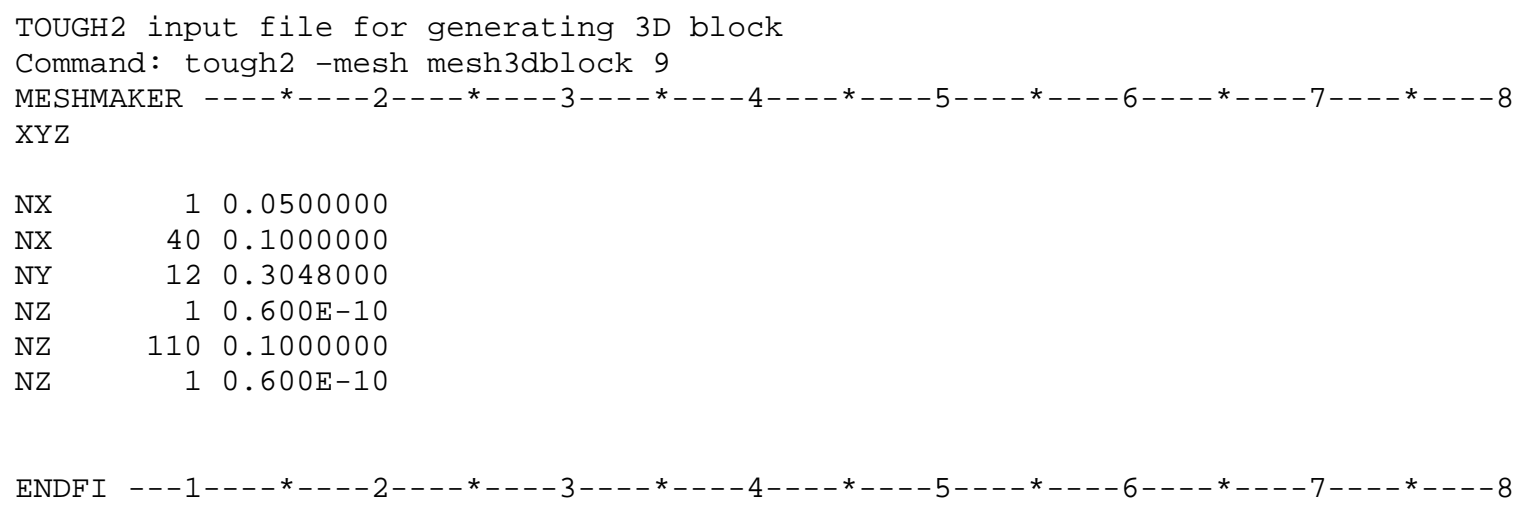

Figure C-1. Input File mesh3dblock to Generate Primary Mesh 


\section{SISIM V1.204 INPUT FILE perm.par}

Generates weakly correlated random field of log-permeability modifiers for the seepage model of the systematic testing area in the ECRB Cross-Drift.

START OF PARAMETERS:

dummy . dat

$\begin{array}{llll}1 & 2 & 3 & 4\end{array}$

$-1.0 \mathrm{e} 21 \quad 1.0 \mathrm{e} 21$

$-2.0 \quad 2.0$

$1 \quad 2.5$

$1 \quad 1.0$

$4 \quad 2.5$

dummy . dat

30

direct.ik

perm. dat

1

perm. dbg

$\odot$

59067

1

$41 \quad 0.00 \quad 0.10$

$12 \quad 0.1524 \quad 0.3048$

$\begin{array}{lll}110 & -3.00 & 0.10\end{array}$

1

0

2.0

$\begin{array}{ccccc}0.0 & 0.0 & 0.0 & 1.0 & 1.0\end{array}$

$0 \quad 20$

12

$0 \quad 2.5$

$\odot$

$\begin{array}{llll}-1.75 & 0.025 & 1 & 0.0\end{array}$

$1 \quad 0.21 .00$

$0.0 \quad 0.0 \quad 0.0 \quad 1.01 .0$

$\begin{array}{llll}-1.25 & 0.10 \quad 1 & 0.0\end{array}$

$1 \quad 0.21 .00$

$0.0 \quad 0.0 \quad 0.0 \quad 1.01 .0$

$\begin{array}{llll}-0.75 & 0.225 & 1 & 0.0\end{array}$

$1 \quad 0.21 .00$

$\begin{array}{ccccc}0.0 & 0.0 & 0.0 & 1.0 & 1.0\end{array}$

$\begin{array}{llll}-0.25 & 0.40 \quad 1 & 0.0\end{array}$

10.21 .00

$\begin{array}{ccccc}1.0 & 0.0 & 0.0 & 1.0 & 1.0\end{array}$

$0.250 .60 \quad 1 \quad 0.0$

$1 \quad 0.21 .00$

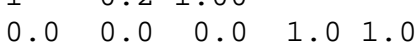

$0.750 .775 \quad 1 \quad 0.0$

$1 \quad 0.21 .00$

$\begin{array}{ccccc}10 & 0.0 & 0.0 & 1.0 & 1.0\end{array}$

$\begin{array}{llll}1.25 & 0.90 \quad 1 & 0.0\end{array}$

10.21 .00

$0.0 \quad 0.0 \quad 0.0 \quad 1.0 \quad 1.0$

$\begin{array}{llll}1.75 & 0.975 & 1 & 0.0\end{array}$

$1 \quad 0.21 .00$

$0 . \odot \quad 0.0 \quad 0.0 \quad 1.01 .0$
Idata file

\column: $\mathrm{x}, \mathrm{y}, \mathrm{z}, \mathrm{vr}$

ldata trimming limits

Iminimum and maximum data value

llower tail option and parameter

Imiddle option and parameter

lupper tail option and parameter

\tabulated values for classes

\column for variable, weight

ldirect input of indicators

loutput file for simulation

$\backslash$ debugging level: $0,1,2,3$

loutput File for Debugging

$\backslash \odot=$ standard order relation cor $r$

\seed number

$\backslash$ number of simulations

$\backslash n x, x m n, x s i z$

$\backslash n y, y m n, y s i z$

$\backslash \mathrm{nz}, \mathrm{zmn}, \mathrm{zsiz}$

$\backslash 0=$ two part search, 1=data-nodes

( max per octant ( 0 -> not used)

$\backslash$ maximum search radius

\ sang1, sang2, sang3, sanis1, 2

I min, max data for simulation

\number simulated nodes to use

$\backslash \Theta=$ full IK, 1=med approx(cutoff)

$\backslash 0=\mathrm{SK}, 1=0 \mathrm{~K}$

\number cutoffs

\cutoff, global cdf, nst, nugget

$\backslash$ it, aa, cc

\ang1, ang2, ang3, anis1, 2

\cutoff, global cdf, nst, nugget

I it, aa, cc

। ang1, ang2, ang3, anis1, 2

\cutoff, global cdf, nst, nugget

1 it, aa, cc

। ang1, ang2, ang3, anis1, 2

lcutoff, global cdf, nst, nugget

1 it, aa, cc

। ang1, ang2, ang3, anis1, 2

\cutoff, global cdf, nst, nugget

1 it, aa, cc

( ang1, ang2, ang3, anis1, 2

\cutoff, global cdf, nst, nugget

1 it, aa, cc

। ang1, ang2, ang3, anis1, 2

\cutoff, global cdf, nst, nugget

I it, aa, cc

\ang1, ang2, ang3, anis1, 2

\cutoff, global cdf, nst, nugget

I it, aa, cc ang1, ang2, ang3, anis1, 2

Figure C-2. Input File perm.par to Generate Random Field of Log-Permeability Modifiers 


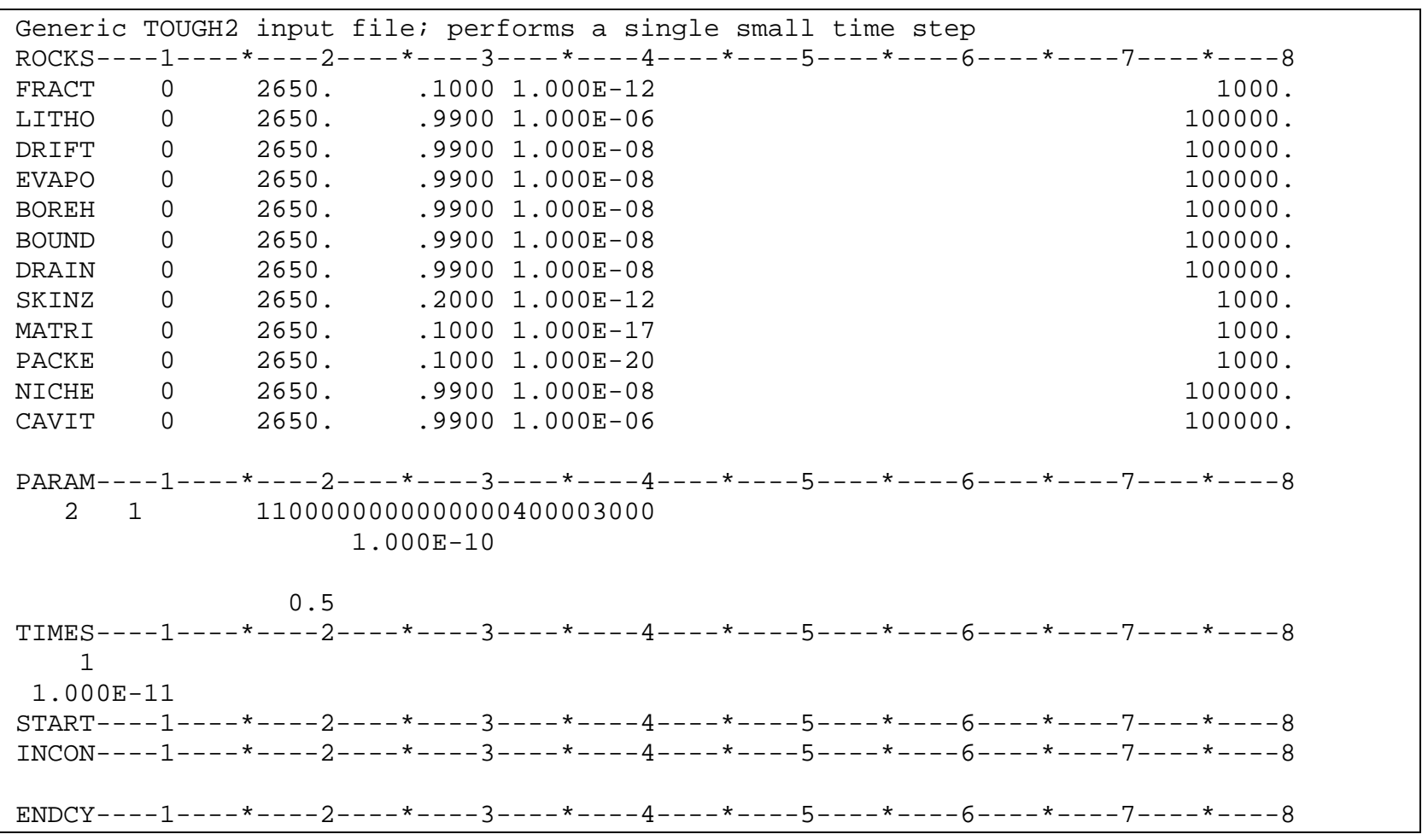

Figure C-3. Input File onestep Used to Perform a Single Time Step

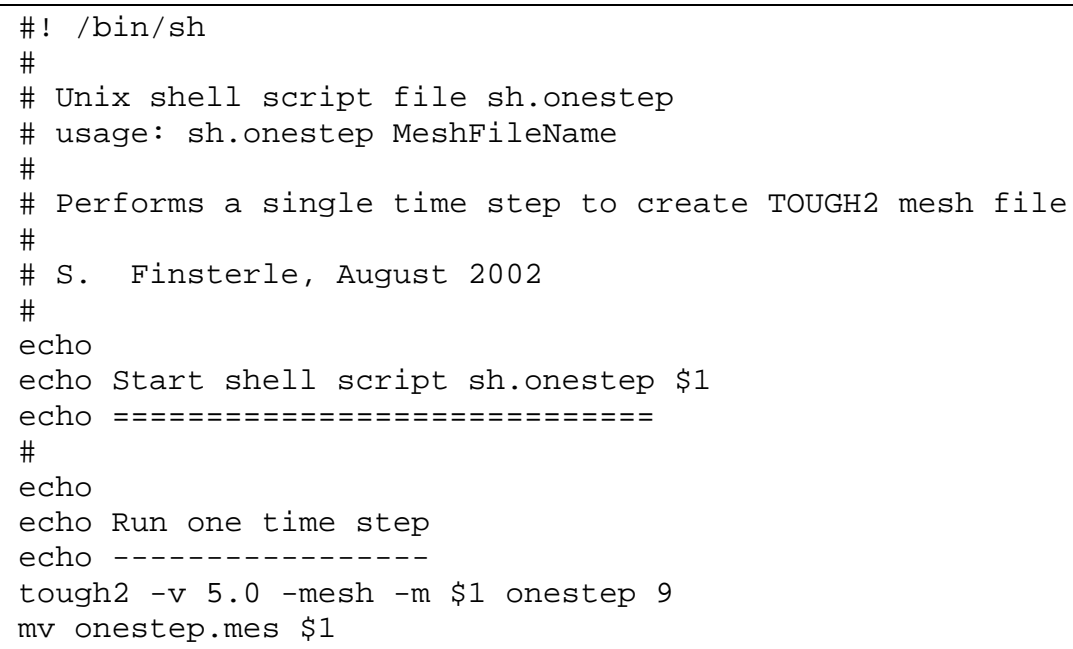

Figure C-4. File sh.onestep Used to Execute a Forward Run with a Single Time Step 


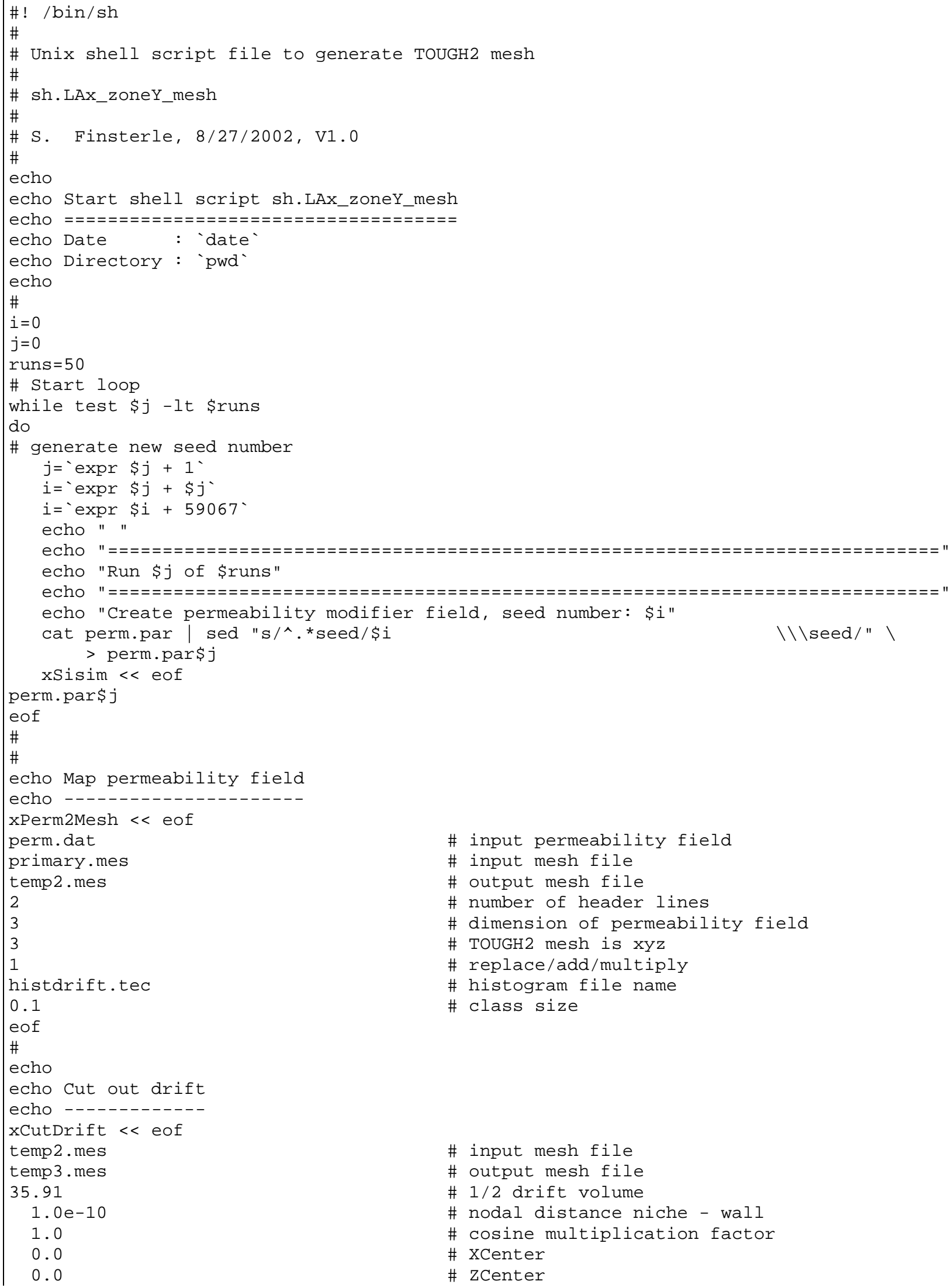




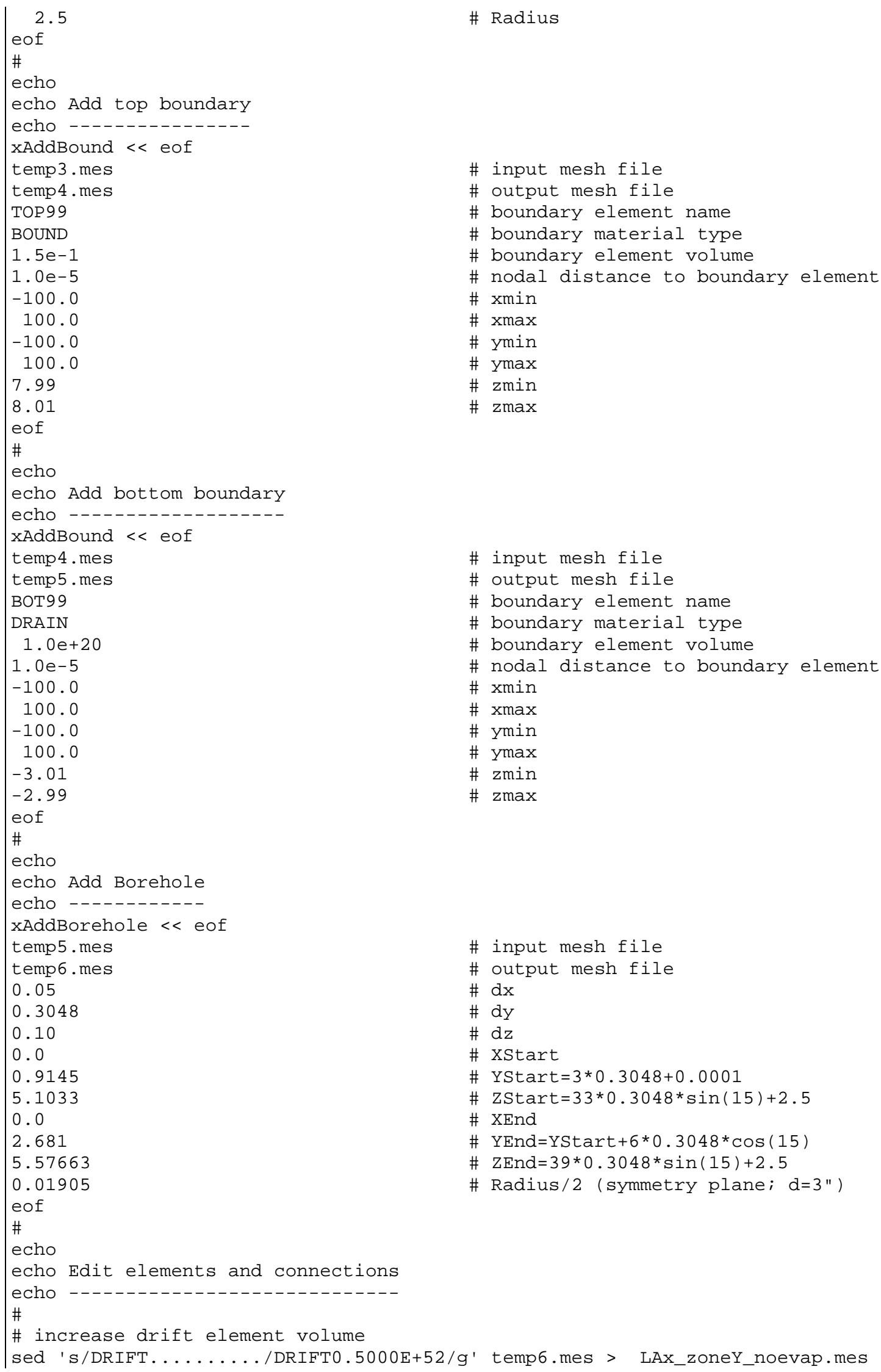

\# Radius 


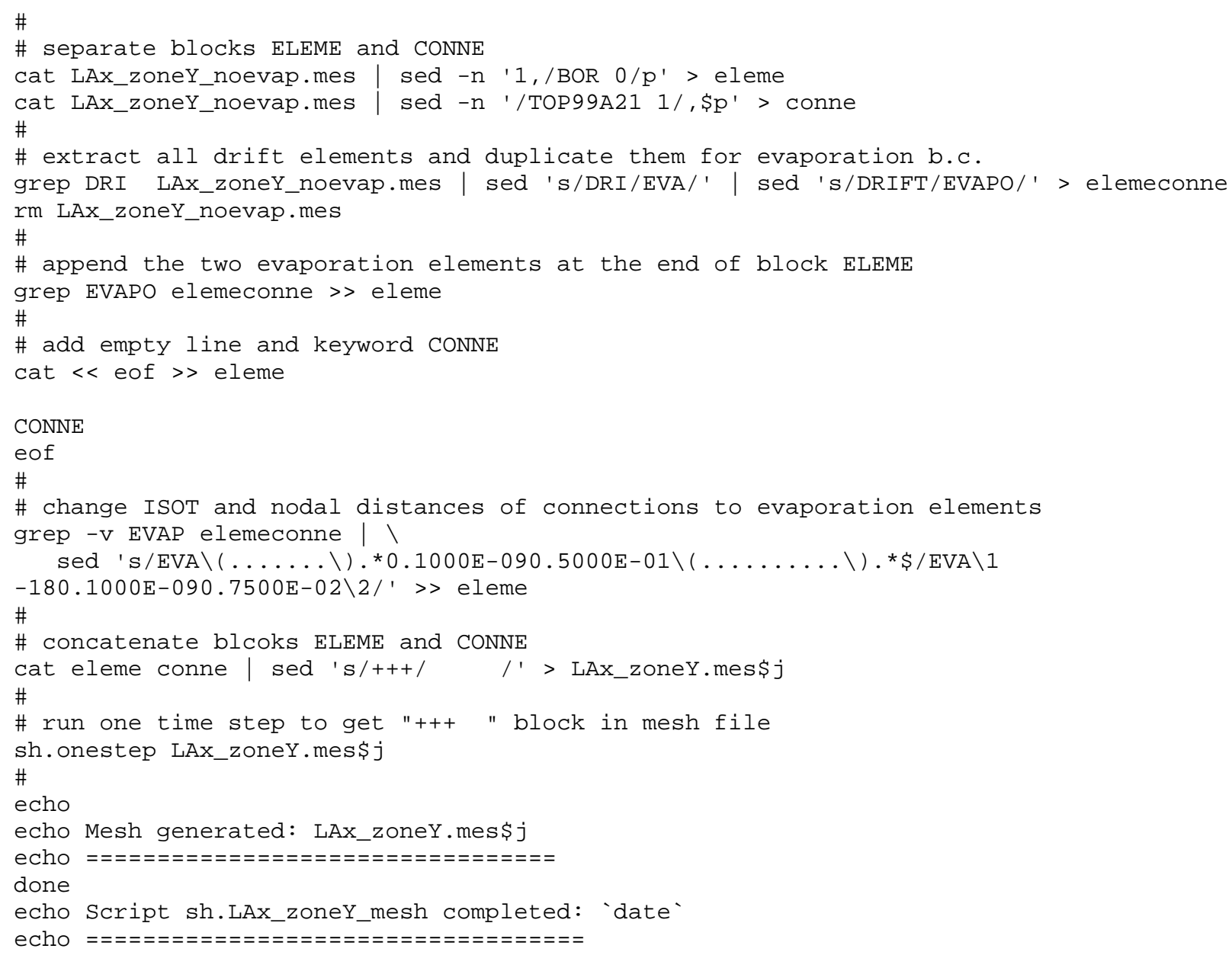

Figure C-5. File sh.LAx_zoneY_mes Used To Execute Mesh Generation Steps 3-11 


\begin{tabular}{|c|c|c|}
\hline ELEME5 & $\mathrm{NY}=12 \quad \mathrm{NZ}=112$ & $\mathrm{dx} / \mathrm{dy} / \mathrm{dz}$ ०.0000E+000.0000E+000.8000E+01 \\
\hline A21 1 & $1 \odot .1524 \mathrm{E}-02$ & $-.4604 \mathrm{E}+020.2500 \mathrm{E}-010.1524 \mathrm{E}+00 \odot .7950 \mathrm{E}+01$ \\
\hline A31 1 & $10.1524 \mathrm{E}-02$ & $-.1644 \mathrm{E}-010.2500 \mathrm{E}-010.1524 \mathrm{E}+00 \odot .7850 \mathrm{E}+01$ \\
\hline A41 1 & $10.1524 E-02$ & $-.1477 \mathrm{E}+\odot 1 \odot .2500 \mathrm{E}-\odot 1 \odot .1524 \mathrm{E}+\odot \odot \odot .7750 \mathrm{E}+\odot 1$ \\
\hline A51 1 & $10.1524 \mathrm{E}-02$ & $-.1477 \mathrm{E}+010.2500 \mathrm{E}-010.1524 \mathrm{E}+00 \odot .7650 \mathrm{E}+01$ \\
\hline $\begin{array}{l}\cdots \\
\mathrm{D} 3 \mathrm{C} 41\end{array}$ & $\begin{array}{l}3 \ldots \ldots \\
10.3048 \mathrm{E}-02\end{array}$ & $\begin{array}{l}\ldots \\
-.1320 \mathrm{E}+010.4000 \mathrm{E}+010.3505 \mathrm{E}+01-.2650 \mathrm{E}+\odot 1\end{array}$ \\
\hline D4C41 & $10.3048 \mathrm{E}-02$ & $-.1236 \mathrm{E}+010.4000 \mathrm{E}+010.3505 \mathrm{E}+01-.2750 \mathrm{E}+01$ \\
\hline D5C41 & $10.3048 E-02$ & $-.1236 \mathrm{E}+010.4000 \mathrm{E}+010.3505 \mathrm{E}+01-.2850 \mathrm{E}+01$ \\
\hline D6C41 & $10.3048 E-02$ & $-.6929 E+000.4000 E+010.3505 E+01-.2950 E+01$ \\
\hline DRI98 & DRIFT0.5000E+52 & 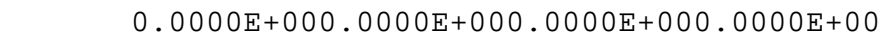 \\
\hline DRI99 & DRIFTO. 5000E +52 & 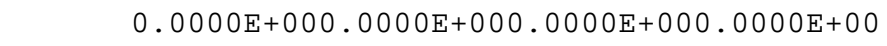 \\
\hline TOP99 & BOUND $.150 \odot E+\odot \odot$ & $\odot .0 \odot \odot \odot E+\odot \odot-.10 \odot \odot E+\odot 4-.10 \odot \odot E+\odot 4-.100 \odot E+\odot 4$ \\
\hline Вот99 & DRAINO . $1000 \mathrm{E}+21$ & $0.000 \odot \mathrm{E}+00-.1000 \mathrm{E}+04-.1000 \mathrm{E}+\odot 4-.1000 \mathrm{E}+\odot 4$ \\
\hline B 1 & BOREH० . 3598E- -3 & $\odot .08633-.1000 \mathrm{E}+010.0000 \mathrm{E}+00 \odot .1067 \mathrm{E}+010.5144 \mathrm{E}+01$ \\
\hline 2 & BOREH०. 6585E- - 4 & $\odot .18851-.1000 \mathrm{E}+010.0000 \mathrm{E}+00 \odot .1247 \mathrm{E}+010.5193 \mathrm{E}+01$ \\
\hline 3 & BOREHO . 2939E - ๑3 & $\odot .27478-.100 \odot \mathrm{E}+010.00 \odot \odot \mathrm{E}+\odot \odot \odot .140 \odot \mathrm{E}+010.5233 \mathrm{E}+\odot 1$ \\
\hline B & 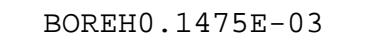 & $\odot .38019-.100 \odot \mathrm{E}+010.00 \odot \odot \mathrm{E}+\odot \odot \odot .1586 \mathrm{E}+010.5283 \mathrm{E}+\odot 1$ \\
\hline B & BOREHO . 2122E- - 3 & $\odot .46646-.1000 \mathrm{E}+010.0000 \mathrm{E}+00 \odot .1738 \mathrm{E}+010.5324 \mathrm{E}+01$ \\
\hline B & BOREHO . 2280E - ०3 & $\odot .57215-.1000 \mathrm{E}+010.0000 \mathrm{E}+00 \odot .1925 \mathrm{E}+010.5374 \mathrm{E}+01$ \\
\hline 7 & 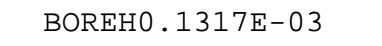 & $\odot .65842-.100 \odot \mathrm{E}+010.00 \odot \odot \mathrm{E}+\odot \odot \odot .2078 \mathrm{E}+01 \odot .5415 \mathrm{E}+01$ \\
\hline 8 & BOREH० . 3085E- -3 & $\odot .76411-.1000 \mathrm{E}+010.0000 \mathrm{E}+00 \odot .2264 \mathrm{E}+010.5465 \mathrm{E}+01$ \\
\hline & BOREHO. 5121E- - 4 & $\odot .85039-.1000 \mathrm{E}+010.0000 \mathrm{E}+000.2417 \mathrm{E}+010.5506 \mathrm{E}+01$ \\
\hline B 10 & BOREH० . 2861E- - & $\odot .93139-.1000 \mathrm{E}+010.000 \odot \mathrm{E}+00 \odot .2560 \mathrm{E}+010.5544 \mathrm{E}+01$ \\
\hline BOR $\odot$ & BOREH० . 2085E- - 2 & $-.100 \odot \mathrm{E}+010.00 \odot \odot \mathrm{E}+\odot \odot \odot .1798 \mathrm{E}+010.5340 \mathrm{E}+\odot 1$ \\
\hline EVA98 & EVAP00.5000E +52 & 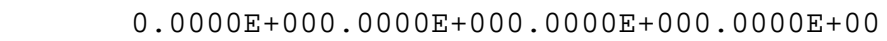 \\
\hline EVA99 & EVAP0๑. $5000 \mathrm{E}+52$ & $\odot . \odot \odot \odot \odot E+\odot \odot \odot . \odot \odot \odot \odot E+\odot \odot \odot . \odot \odot \odot \odot E+\odot \odot \odot . \diamond \odot \odot \odot E+\odot \odot$ \\
\hline \multicolumn{3}{|l|}{ CONNE } \\
\hline EVA99BL1 1 & -180.1 & $\odot \odot \odot E-\odot 9 \odot .7500 \mathrm{E}-02 \odot .1524 \mathrm{E}-\odot 1$ \\
\hline EVA99D21 1 & -180.1 & 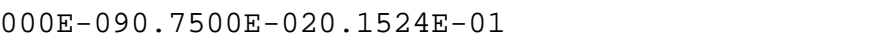 \\
\hline EVA99BL2 1 & -180.1 & $\odot \odot E-\odot 9 \odot .750 \odot E-02 \odot .1524 E-\odot 1$ \\
\hline EVA98CHC26 & $\begin{array}{l}\ldots \ldots \\
-180.1\end{array}$ & 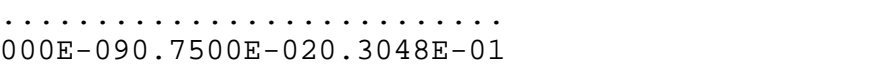 \\
\hline EVA98CIC26 & $-180 \cdot 1$ & $\odot \odot E-\odot 9 \odot .750 \odot E-020.3048 E-01$ \\
\hline EVA99CJC25 & -180.1 & $\odot \odot \odot E-\odot 9 \odot .750 \odot E-\odot 2 \odot .3048 E-01$ \\
\hline T0P99A21 1 & 30.1 & ๑००E - $\odot 4 \odot .500 \odot E-010.1524 \mathrm{E}-010.1000 \mathrm{E}+01$ \\
\hline A21 1 A21 2 & 10.2 & $500 \mathrm{E}-010.50 \odot \odot \mathrm{E}-010.3048 \mathrm{E}-010.0 \odot \odot \odot \mathrm{E}+\odot \odot$ \\
\hline A21 1 A22 1 & 20.1 & $524 \mathrm{E}+\odot \odot \odot .1524 \mathrm{E}+\odot \odot \odot .50 \odot \odot \mathrm{E}-\odot 2 \odot . \odot \odot \odot \odot \mathrm{E}+\odot \odot$ \\
\hline A21 1 A31 1 & 30.5 & $\odot \odot \odot E-\odot 1 \odot .5 \odot \odot \odot E-\odot 1 \odot . ~ 1524 E-\odot 1 \odot .10 \odot \odot E+\odot 1$ \\
\hline BK1 $\ddot{1 B L} \ddot{1}$ & $\begin{array}{ll}\cdots \\
30.5\end{array}$ & 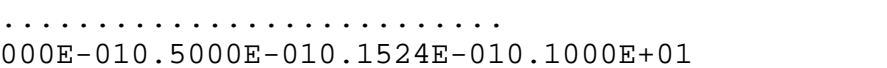 \\
\hline BL1 1BL1 2 & 10.2 & $500 E-010.5000 E-010.3048 E-010.0000 E+\odot \odot$ \\
\hline BL1 1BL2 1 & 20.1 & $524 \mathrm{E}+\odot \odot \odot .1524 \mathrm{E}+\odot \odot \odot .50 \odot \odot \mathrm{E}-\odot 2 \odot . \odot \odot \odot \odot \mathrm{E}+\odot \odot$ \\
\hline DRI99BL1 1 & 30.1 & ๑००E- $\odot 9 \odot .50 \odot \odot E-010.1524 E-01-.100 \odot E+\odot 1$ \\
\hline DRI99D21 1 & 30.1 & 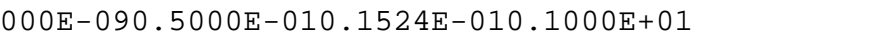 \\
\hline D21 1D21 2 & 10.2 & $500 \mathrm{E}-010.500 \odot \mathrm{E}-010.3048 \mathrm{E}-010.00 \odot \odot \mathrm{E}+\odot \odot$ \\
\hline D21 1D22 1 & 20.1 & $524 \mathrm{E}+00 \odot .1524 \mathrm{E}+00 \odot .5000 \mathrm{E}-\odot 20.000 \odot \mathrm{E}+\odot \odot$ \\
\hline D21 1D31 1 & 30.5 & $\odot \odot \odot E-01 \odot .50 \odot \odot E-010.1524 \mathrm{E}-010.10 \odot \odot \mathrm{E}+\odot 1$ \\
\hline $\begin{array}{l}\ldots \ldots \\
\mathrm{D} 61 \\
1 \mathrm{D} 61\end{array}$ & $\begin{array}{l}\ldots \\
10.2\end{array}$ & $\begin{array}{l}\ldots \ldots \ldots \ldots \ldots \ldots \\
500 \mathrm{E}-\odot 1 \odot .500 \odot \mathrm{E}-\odot 10.3048 \mathrm{E}-\odot 10.00 \odot \odot \mathrm{E}+\odot \odot\end{array}$ \\
\hline D61 1 D62 1 & 20.1 & $524 \mathrm{E}+\odot \odot \odot .1524 \mathrm{E}+\odot \odot \odot .50 \odot \odot \mathrm{E}-\odot 20.00 \odot \odot \mathrm{E}+\odot \odot$ \\
\hline D61 1B0T99 & 30.5 & ๑००E- $010.100 \odot E-\odot 4 \odot .1524 E-010.100 \odot E+\odot 1$ \\
\hline T0P99A22 1 & 30.1 & ๑००E- $\odot 4 \odot .500 \odot E-010.1524 \mathrm{E}-010.100 \odot \mathrm{E}+\odot 1$ \\
\hline A22 1A22 2 & 10.2 & 500E - $010.5000 E-010.3048 E-010.000 \odot E+\odot \odot$ \\
\hline A22 1 A23 1 & 20.1 & $524 \mathrm{E}+\odot \odot \odot .1524 \mathrm{E}+\odot \odot \odot .50 \odot \odot \mathrm{E}-\odot 2 \odot . \odot \odot \odot \odot \mathrm{E}+\odot \odot$ \\
\hline A22 1A32 1 & 30.5 & $\odot \odot \odot E-01 \odot .50 \odot \odot E-010.1524 \mathrm{E}-\odot 1 \odot .10 \odot \odot E+\odot 1$ \\
\hline D4C41D5C41 & $\begin{array}{l}\cdots \\
30.5\end{array}$ & 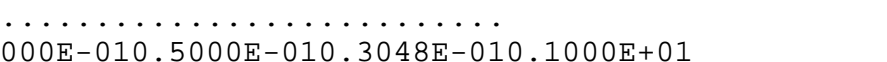 \\
\hline D5C41D6C41 & 30.5 & ๑००E - $110.500 \odot E-010.3048 \mathrm{E}-010.100 \odot \mathrm{E}+\odot 1$ \\
\hline D6C41B0T99 & 30.5 & ๑००E - $010.100 \odot E-\odot 40.3048 E-010.100 \odot E+\odot 1$ \\
\hline B $\quad 1 A U 41$ & 10.1 & $\odot \odot \odot E-\odot 9 \odot .500 \odot E-\odot 10.3777 \mathrm{E}-010.9659 \mathrm{E}+\odot \odot$ \\
\hline 2AU5 1 & 10.1 & $\odot \odot \odot E-\odot 9 \odot .5 \odot \odot \odot E-\odot 1 \odot .6913 E-\odot 2 \odot .9659 E+\odot \odot$ \\
\hline
\end{tabular}




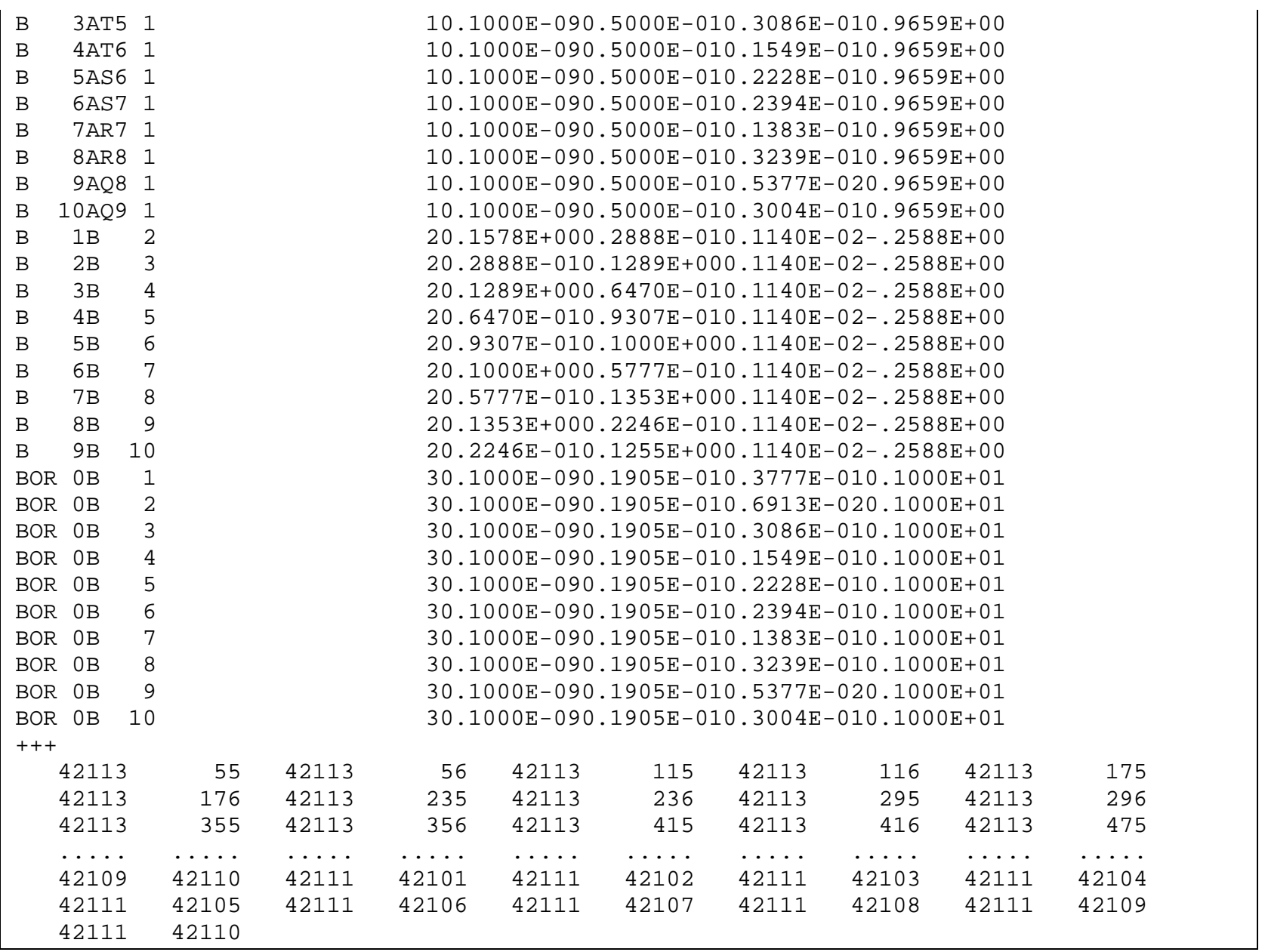

Figure C-6. Excerpt from Sample Mesh File LAx_zoneY.mesZ 


\section{INTENTIONALLY LEFT BLANK}




\section{APPENDIX D}

MESH GENERATION FOR SIMULATION OF SEEPAGE TESTS

IN NICHES 2, 3, AND 4 
Four 3-D meshes for the simulation of liquid-release tests in niches located in the middle nonlithophysal zone were generated: two $1.5 \mathrm{~m}$ long sections of Niche 2 centered (a) $4.42 \mathrm{~m}$ and (b) $5.64 \mathrm{~m}$ from the collar of borehole UM, (c) a $1.5 \mathrm{~m}$ long section of Niche 3 centered at Niche 3 station $00+10.25 \mathrm{~m}$, and (d) a $2.0 \mathrm{~m}$ long section of Niche 4 centered at Niche 4 station $00+11.45 \mathrm{~m}$. The meshes were created in several steps as follows (where steps differ, information for each mesh is preceded by the letter referring to a specific panel of Figure 6-16):

1. Primary meshes were generated with $X-Y-Z$ dimensions of (a \& b) $6.0 \mathrm{~m} \times 1.5 \mathrm{~m} \times 5.0 \mathrm{~m}$, (c) $6.5 \mathrm{~m} \times 1.5 \mathrm{~m} \times 5.0 \mathrm{~m}$, and (d) $6.0 \mathrm{~m} \times 2.0 \mathrm{~m} \times 5.0 \mathrm{~m}$, respectively, that are discretized into regular gridblocks with side lengths of $0.1 \mathrm{~m} \times 0.1 \mathrm{~m} \times 0.1 \mathrm{~m}$. The Y-axis is parallel to the niche axis.

2. The X-, Y-, and Z-coordinates of each primary mesh are translated using software MoveMesh V1.0 (LBNL 2000 [DIRS 152824]) so that $X=0$ is at the center of the Niche, $\mathrm{Y}=0$ coincides with Niche station $00+0.0 \mathrm{~m}$ for Meshes (c) and (d), and Z $=0$ is (a \& b) at the bottom of the mesh and (c \& d) coincides with the local survey $\mathrm{Z}$ datum.

3. The heterogeneous permeability fields were mapped onto their respective meshes using routine Perm2Mesh V1.0 (LBNL 2000 [DIRS 152826]).

4. (a \& b) A niche with vertical walls at $X=-2 \mathrm{~m}$ and $\mathrm{X}=2 \mathrm{~m}$ and a ceiling of radius $3.04 \mathrm{~m}$ with the crown at (a) $\mathrm{Z}=3.13 \mathrm{~m}$ and (b) $\mathrm{Z}=3.33 \mathrm{~m}$ was cut from the mesh using software CutNiche V1.3 (LBNL 2000 [DIRS 152828]). (c \& d) Niches with vertical walls at (c) $\mathrm{X}=-2.15 \mathrm{~m}$ and $\mathrm{X}=2.35 \mathrm{~m}$ and (d) $\mathrm{X}=-2.00 \mathrm{~m}$ and $\mathrm{X}=1.90 \mathrm{~m}$ and ceilings defined by survey data are cut from their respective meshes using software CutNiche V1.2 (LBNL 2000 [DIRS 152815]). A very small nodal distance was defined between the interfaces representing the drift surface and the gridblocks denoting the drift, which sets boundary conditions directly at the drift wall. The length of the last vertical connection from the gridblocks representing the formation and the interface denoting the drift surface is thus $\Delta \mathrm{Z} / 2=0.05 \mathrm{~m}$.

5. Software AddBound V1.0 (LBNL 2000 [DIRS 152823]) was used to attach boundary elements at the top and bottom of the model domain. The bottom boundary gridblock was assigned to a special material domain to allow specifying a free-drainage boundary condition.

6. Gridblocks along the alignment of the injection boreholes were modified to represent $1 \mathrm{ft}$ $(0.3048 \mathrm{~m})$ long injection intervals with a diameter of 3 inches $(0.076 \mathrm{~m})$.

The final meshes (see Figure 6-16) contain approximately (a) 28,000 gridblocks and 79,000 connections between them, (b) 26,000 gridblocks and 76,000 connections between them, (c) 34,000 gridblocks and 99,000 connections between them, (d) 36,000 gridblocks and 108,000 connections between them. Mesh generation is further documented in various SNs (Finsterle 1999 [DIRS 153448], pp. 100-102; Ahlers 2002 [DIRS 161045], pp. 27-29, 42-44, 54; Hedegaard 2002 [DIRS 161046], pp. 27-29; Wang 1999 [DIRS 153449], pp. 108-123; and Trautz 2001 [DIRS 156903], pp. 35-45). 


\section{INTENTIONALLY LEFT BLANK}




\section{APPENDIX E MESH GENERATION FOR SEEPAGE TEST SIMULATIONS IN NICHE 5}


Preparation of the computational meshes for simulating liquid-release tests performed in Niche 5 involved three major steps: (1) preparation of niche ceiling coordinates, (2) preparation of geostatistical parameters of the permeability field, and (3) preparation of numerical grids.

\section{E1. PREPARATION OF NICHE CEILING COORDINATES}

The niche surface roughness was reproduced by interpolation from niche survey data (data sources are listed in Table E-1).

Table E-1. Survey Data Sources for the Ceiling of Niche 5

\begin{tabular}{|c|c|l|l|}
\hline DTN & DIRS & \multicolumn{1}{c|}{ Description } & \multicolumn{1}{|c|}{ Coordinate System } \\
\hline M00009GSC00332.000 & $\begin{array}{c}\text { [DIRS } \\
\text { 155370] }\end{array}$ & ECRB Niche 5 profile survey data & \multirow{2}{*}{ Nevada State Plane } \\
\hline M00107GSC01061.000 & $\begin{array}{c}\text { [DIRS } \\
155369]\end{array}$ & ECRB Niche 5 slot survey data & \\
\hline LB0301N5CEILNG.001 & $\begin{array}{c}\text { [DIRS } \\
161733]\end{array}$ & $\begin{array}{l}\text { ECRB Niche 5 survey data for collars, } \\
\text { projected bottoms, and intervals }\end{array}$ & Distance from reference frame \\
\hline LB0301N5CEILNG.001 & $\begin{array}{c}\text { [DIRS } \\
161733]\end{array}$ & ECRB Niche 5 detailed profile survey data & \\
\hline
\end{tabular}

DIRS=Document Input Reference System; DTN=Data Tracking Number

The steps followed in preparing the interpolated Niche 5 ceiling profiles are described below. The datum point for the meshes was selected to be the intersection of the ECRB centerline and Niche 5 centerline (DTN: MO0009GSC00332.000 [DIRS 155370]). The location of the datum in the Nevada coordinate system is given in Table E-2.

Table E-2. Datum of Niche 5 in the Nevada Coordinate System

\begin{tabular}{|c|c|c|c|}
\hline $\begin{array}{c}\text { Northing } \\
N_{D}[\mathrm{~m}]\end{array}$ & $\begin{array}{c}\text { Easting } \\
E S_{D}[\mathrm{~m}]\end{array}$ & $\begin{array}{c}\text { Elevation } \\
E L_{D}[\mathrm{~m}]\end{array}$ & $\begin{array}{c}\text { Azimuth } \\
\text { [degrees] }\end{array}$ \\
\hline 233276.41 & 170662.51 & 1105.91 & 181 \\
\hline
\end{tabular}

Source: DTN: MO0009GSC00332.000 [DIRS 155370].

The coordinates of the ECRB Niche 5 profile survey data (DTN: MO0009GSC00332.000 [DIRS 155370]), slot survey data (DTN: MO0107GSC01061.000 [DIRS 155369]), and survey data for collars, projected bottoms, and intervals (DTN: MO0312GSC03176.000 [DIRS 169532]) were transformed to a regular $X-Y-Z$ coordinate system using the following elementary analytical geometry formulae:

$$
\begin{gathered}
X=\left(E S-E S_{D}\right) \cdot \cos (\theta)+\left(N-N_{D}\right) \cdot \sin (\theta) \\
Y=\left(N-N_{D}\right) \cdot \cos (\theta)+\left(E S-E S_{D}\right) \cdot \sin (\theta) \\
Z=\left(E L-E L_{D}\right)
\end{gathered}
$$

where $E S[\mathrm{~m}]$ is easting, $N[\mathrm{~m}]$ is northing, $E L[\mathrm{~m}]$ is elevation, and the subscript $D$ denotes the values of the datum (see Table E-2). The angle $\theta$ [degrees] is related to the azimuth angle $A[\mathrm{~m}]$ by, 


$$
\theta=360^{\circ}-A
$$

The original ECRB Niche 5 profile survey data (DTN: MO0009GSC00332.000 [DIRS 155370]), slot survey data (DTN: MO0107GSC01061.000 [DIRS 155369]) and their corresponding values in $X-Y-Z$ are given in Table E-3.

Table E-3. Niche 5 Profile Survey Data and Slot Survey Data and Their Corresponding Values in the $X-Y-Z$ Coordinate System

\begin{tabular}{|c|c|c|c|c|c|c|}
\hline \multicolumn{7}{|c|}{ Niche 5 Profile } \\
\hline Station & Easting [m] & Northing [m] & Elevation [m] & $X[\mathrm{~m}]$ & $\mathrm{Y}[\mathrm{m}]$ & $\mathrm{Z}[\mathrm{m}]$ \\
\hline $0+00.97$ & 170667.36 & 233277.30 & 1108.24 & -4.83 & -0.81 & 2.33 \\
\hline $0+00.83$ & 170665.36 & 233275.54 & 1108.23 & -2.86 & 0.92 & 2.32 \\
\hline $0+01.48$ & 170662.48 & 233274.93 & 1106.39 & 0.00 & 1.48 & 0.48 \\
\hline $0+01.49$ & 170662.48 & 233274.92 & 1110.70 & 0.00 & 1.49 & 4.79 \\
\hline $0+02.11$ & 170662.47 & 233274.31 & 1110.63 & 0.00 & 2.10 & 4.72 \\
\hline $0+02.12$ & 170662.47 & 233274.30 & 1106.42 & 0.00 & 2.11 & 0.51 \\
\hline $0+02.37$ & 170662.47 & 233274.04 & 1111.72 & 0.00 & 2.37 & 5.81 \\
\hline $0+02.38$ & 170662.47 & 233274.04 & 1106.42 & 0.00 & 2.37 & 0.51 \\
\hline $0+05.12$ & 170662.42 & 233271.29 & 1112.09 & 0.00 & 5.12 & 6.18 \\
\hline $0+05.12$ & 170662.42 & 233271.29 & 1106.51 & 0.00 & 5.12 & 0.60 \\
\hline $0+06.18$ & 170659.37 & 233270.29 & 1108.42 & 3.03 & 6.06 & 2.51 \\
\hline $0+06.88$ & 170658.44 & 233269.60 & 1107.96 & 3.95 & 6.74 & 2.05 \\
\hline $0+07.45$ & 170665.05 & 233268.92 & 1108.40 & -2.67 & 7.53 & 2.49 \\
\hline $0+07.86$ & 170659.65 & 233268.60 & 1108.46 & 2.72 & 7.76 & 2.55 \\
\hline $0+09.57$ & 170662.34 & 233266.84 & 1112.87 & 0.00 & 9.57 & 6.96 \\
\hline $0+09.57$ & 170662.34 & 233266.84 & 1106.59 & 0.00 & 9.57 & 0.68 \\
\hline $0+09.88$ & 170659.75 & 233266.58 & 1108.52 & 2.59 & 9.78 & 2.61 \\
\hline $0+11.57$ & 170665.07 & 233264.80 & 1108.38 & -2.76 & 11.65 & 2.47 \\
\hline $0+12.50$ & 170659.63 & 233263.96 & 1108.48 & 2.66 & 12.40 & 2.57 \\
\hline $0+13.04$ & 170662.28 & 233263.37 & 1112.82 & 0.00 & 13.03 & 6.91 \\
\hline $0+13.24$ & 170662.28 & 233263.18 & 1106.60 & 0.00 & 13.22 & 0.69 \\
\hline $0+13.26$ & 170662.28 & 233263.16 & 1111.52 & 0.00 & 13.24 & 5.61 \\
\hline $0+13.69$ & 170659.76 & 233262.77 & 1108.62 & 2.51 & 13.59 & 2.71 \\
\hline $0+14.00$ & 170662.27 & 233262.42 & 1110.09 & 0.00 & 13.98 & 4.18 \\
\hline $0+14.02$ & 170662.27 & 233262.39 & 1106.57 & 0.00 & 14.01 & 0.66 \\
\hline $0+14.17$ & 170664.52 & 233262.21 & 1108.48 & -2.26 & 14.23 & 2.57 \\
\hline $0+14.18$ & 170660.22 & 233262.28 & 1108.57 & 2.04 & 14.09 & 2.66 \\
\hline $0+14.96$ & 170662.25 & 233261.45 & 1110.08 & 0.00 & 14.95 & 4.17 \\
\hline $0+14.98$ & 170662.25 & 233261.44 & 1106.64 & 0.00 & 14.96 & 0.73 \\
\hline $0+14.98$ & 170660.22 & 233261.47 & 1108.21 & 2.03 & 14.90 & 2.30 \\
\hline $0+15.10$ & 170664.42 & 233261.27 & 1108.41 & -2.17 & 15.17 & 2.50 \\
\hline $0+17.47$ & 170662.21 & 233258.94 & 1106.58 & 0.00 & 17.46 & 0.67 \\
\hline $0+17.47$ & 170662.21 & 233258.94 & 1110.10 & 0.00 & 17.46 & 4.19 \\
\hline $0+18.63$ & 170660.11 & 233257.82 & 1108.55 & 2.08 & 18.55 & 2.64 \\
\hline $0+18.75$ & 170664.04 & 233257.64 & 1108.55 & -1.86 & 18.79 & 2.64 \\
\hline $0+20.39$ & 170662.16 & 233256.02 & 1106.65 & -0.01 & 20.38 & 0.74 \\
\hline $0+20.41$ & 170662.16 & 233256.01 & 1110.17 & -0.01 & 20.39 & 4.26 \\
\hline
\end{tabular}


Table E3. Niche 5 Profile Survey Data and Slot Survey Data and Their Corresponding Values in the $X-Y-Z$ Coordinate System (Continued)

\begin{tabular}{|c|c|c|c|c|c|c|}
\hline \multicolumn{7}{|c|}{ Niche 5 Profile } \\
\hline Station & Easting [m] & Northing [m] & Elevation [m] & $X[\mathrm{~m}]$ & $\mathrm{Y}[\mathrm{m}]$ & $\mathrm{Z}[\mathrm{m}]$ \\
\hline $0+21.52$ & 170660.00 & 233254.94 & 1108.68 & 2.13 & 21.42 & 2.77 \\
\hline $0+21.94$ & 170664.00 & 233254.44 & 1108.57 & -1.87 & 21.99 & 2.66 \\
\hline $0+24.77$ & 170660.11 & 233251.68 & 1108.50 & 1.97 & 24.68 & 2.59 \\
\hline $0+24.89$ & 170664.26 & 233251.49 & 1108.56 & -2.18 & 24.95 & 2.65 \\
\hline $0+25.94$ & 170662.06 & 233250.47 & 1106.70 & 0.00 & 25.93 & 0.79 \\
\hline $0+25.95$ & 170662.06 & 233250.47 & 1110.29 & 0.00 & 25.93 & 4.38 \\
\hline $0+26.79$ & 170664.49 & 233249.58 & 1108.61 & -2.45 & 26.86 & 2.70 \\
\hline $0+27.33$ & 170664.12 & 233249.05 & 1108.55 & -2.09 & 27.38 & 2.64 \\
\hline $0+28.45$ & 170662.02 & 233247.97 & 1110.16 & -0.01 & 28.43 & 4.25 \\
\hline $0+28.46$ & 170662.02 & 233247.96 & 1106.71 & -0.01 & 28.44 & 0.80 \\
\hline $0+28.46$ & 170659.96 & 233247.99 & 1108.78 & 2.05 & 28.37 & 2.87 \\
\hline $0+28.57$ & 170664.02 & 233247.81 & 1108.66 & -2.01 & 28.62 & 2.75 \\
\hline $0+28.97$ & 170662.01 & 233247.45 & 1110.10 & -0.01 & 28.95 & 4.19 \\
\hline $0+28.97$ & 170662.01 & 233247.45 & 1106.88 & -0.01 & 28.95 & 0.97 \\
\hline $0+29.21$ & 170662.00 & 233247.21 & 1108.73 & 0.00 & 29.19 & 2.82 \\
\hline \multicolumn{7}{|c|}{ Niche 5 Slots } \\
\hline Point No. & Easting [m] & Northing [m] & Elevation [m] & $X[\mathrm{~m}]$ & $\mathrm{Y}[\mathrm{m}]$ & $\mathbf{Z}[\mathrm{m}]$ \\
\hline 100 & 170664.23 & 233256.66 & 1108.93 & -2.06 & 19.78 & 3.02 \\
\hline 101 & 170664.58 & 233256.63 & 1108.94 & -2.41 & 19.81 & 3.03 \\
\hline 102 & 170665.03 & 233256.61 & 1109.09 & -2.87 & 19.84 & 3.18 \\
\hline 103 & 170665.35 & 233256.60 & 1108.96 & -3.19 & 19.86 & 3.05 \\
\hline 104 & 170665.55 & 233256.65 & 1108.91 & -3.38 & 19.81 & 3.00 \\
\hline 105 & 170665.75 & 233256.68 & 1108.86 & -3.58 & 19.78 & 2.95 \\
\hline 106 & 170665.72 & 233256.66 & 1108.51 & -3.55 & 19.80 & 2.60 \\
\hline 107 & 170665.62 & 233256.66 & 1108.27 & -3.45 & 19.80 & 2.36 \\
\hline 108 & 170665.23 & 233256.58 & 1108.06 & -3.07 & 19.87 & 2.15 \\
\hline 109 & 170664.89 & 233256.60 & 1107.96 & -2.73 & 19.85 & 2.05 \\
\hline 110 & 170664.48 & 233256.57 & 1107.84 & -2.32 & 19.87 & 1.93 \\
\hline 111 & 170664.24 & 233256.50 & 1107.55 & -2.08 & 19.94 & 1.64 \\
\hline 112 & 170664.10 & 233256.79 & 1109.08 & -1.93 & 19.64 & 3.17 \\
\hline 113 & 170664.06 & 233255.67 & 1109.15 & -1.91 & 20.76 & 3.24 \\
\hline 114 & 170664.20 & 233255.72 & 1108.97 & -2.05 & 20.72 & 3.06 \\
\hline 115 & 170664.69 & 233255.79 & 1108.97 & -2.54 & 20.65 & 3.06 \\
\hline 116 & 170664.89 & 233255.91 & 1109.02 & -2.74 & 20.54 & 3.11 \\
\hline 117 & 170665.16 & 233255.79 & 1109.28 & -3.01 & 20.66 & 3.37 \\
\hline 118 & 170665.55 & 233255.76 & 1109.32 & -3.40 & 20.70 & 3.41 \\
\hline 119 & 170665.85 & 233255.79 & 1109.18 & -3.70 & 20.68 & 3.27 \\
\hline 120 & 170666.00 & 233255.84 & 1108.87 & -3.85 & 20.63 & 2.96 \\
\hline 121 & 170665.97 & 233255.78 & 1108.54 & -3.82 & 20.69 & 2.63 \\
\hline 122 & 170665.60 & 233255.71 & 1108.19 & -3.45 & 20.75 & 2.28 \\
\hline 123 & 170665.35 & 233255.76 & 1107.95 & -3.20 & 20.70 & 2.04 \\
\hline 124 & 170665.16 & 233255.71 & 1107.90 & -3.01 & 20.74 & 1.99 \\
\hline 125 & 170664.57 & 233255.62 & 1107.72 & -2.42 & 20.82 & 1.81 \\
\hline
\end{tabular}


Table E3. Niche 5 Profile Survey Data and Slot Survey Data and Their Corresponding Values in the $X-Y-Z$ Coordinate System (Continued)

\begin{tabular}{|c|c|c|c|c|c|c|}
\hline \multicolumn{7}{|c|}{ Niche 5 Profile } \\
\hline Station & Easting [m] & Northing [m] & Elevation [m] & $X[\mathrm{~m}]$ & $\mathrm{Y}[\mathrm{m}]$ & $\mathrm{Z}[\mathrm{m}]$ \\
\hline 126 & 170664.40 & 233255.49 & 1107.38 & -2.25 & 20.95 & 1.47 \\
\hline 127 & 170664.08 & 233254.52 & 1109.29 & -1.95 & 21.91 & 3.38 \\
\hline 128 & 170664.34 & 233254.59 & 1109.11 & -2.21 & 21.85 & 3.20 \\
\hline 129 & 170664.78 & 233254.58 & 1109.35 & -2.65 & 21.87 & 3.44 \\
\hline 130 & 170665.34 & 233254.54 & 1109.33 & -3.21 & 21.92 & 3.42 \\
\hline 131 & 170665.61 & 233254.52 & 1109.27 & -3.48 & 21.94 & 3.36 \\
\hline 132 & 170665.84 & 233254.42 & 1109.01 & -3.71 & 22.04 & 3.10 \\
\hline 133 & 170665.73 & 233254.43 & 1108.61 & -3.60 & 22.03 & 2.70 \\
\hline 134 & 170665.63 & 233254.29 & 1108.40 & -3.51 & 22.17 & 2.49 \\
\hline 135 & 170665.50 & 233254.31 & 1108.10 & -3.38 & 22.15 & 2.19 \\
\hline 136 & 170665.15 & 233254.39 & 1108.01 & -3.02 & 22.06 & 2.10 \\
\hline 137 & 170664.59 & 233254.48 & 1107.94 & -2.46 & 21.96 & 2.03 \\
\hline 138 & 170664.18 & 233254.48 & 1107.45 & -2.05 & 21.96 & 1.54 \\
\hline 139 & 170664.16 & 233253.96 & 1109.11 & -2.04 & 22.48 & 3.20 \\
\hline 140 & 170664.34 & 233253.91 & 1109.06 & -2.22 & 22.53 & 3.15 \\
\hline 141 & 170664.68 & 233253.90 & 1109.17 & -2.56 & 22.54 & 3.26 \\
\hline 142 & 170665.07 & 233253.99 & 1109.26 & -2.95 & 22.46 & 3.35 \\
\hline 143 & 170665.30 & 233254.03 & 1109.24 & -3.18 & 22.43 & 3.33 \\
\hline 144 & 170665.75 & 233253.98 & 1109.41 & -3.63 & 22.48 & 3.50 \\
\hline 145 & 170666.06 & 233253.77 & 1109.25 & -3.94 & 22.70 & 3.34 \\
\hline 146 & 170666.12 & 233253.75 & 1109.01 & -4.00 & 22.72 & 3.10 \\
\hline 147 & 170665.73 & 233253.78 & 1108.73 & -3.61 & 22.68 & 2.82 \\
\hline 148 & 170665.74 & 233253.82 & 1108.37 & -3.62 & 22.64 & 2.46 \\
\hline 149 & 170665.40 & 233253.91 & 1108.15 & -3.28 & 22.55 & 2.24 \\
\hline 150 & 170665.07 & 233253.88 & 1108.12 & -2.95 & 22.57 & 2.21 \\
\hline 151 & 170664.71 & 233253.81 & 1108.04 & -2.59 & 22.63 & 2.13 \\
\hline 152 & 170664.44 & 233253.66 & 1107.96 & -2.33 & 22.78 & 2.05 \\
\hline 153 & 170664.35 & 233253.75 & 1107.83 & -2.24 & 22.69 & 1.92 \\
\hline 154 & 170664.22 & 233254.08 & 1108.87 & -2.10 & 22.36 & 2.96 \\
\hline 155 & 170664.28 & 233257.61 & 1108.66 & -2.10 & 18.83 & 2.75 \\
\hline 156 & 170664.35 & 233257.44 & 1108.66 & -2.17 & 19.00 & 2.75 \\
\hline 157 & 170664.44 & 233257.30 & 1107.87 & -2.26 & 19.14 & 1.96 \\
\hline 158 & 170664.34 & 233257.33 & 1108.65 & -2.16 & 19.11 & 2.74 \\
\hline 159 & 170664.47 & 233257.22 & 1107.86 & -2.29 & 19.22 & 1.95 \\
\hline 160 & 170664.22 & 233256.09 & 1108.76 & -2.06 & 20.35 & 2.85 \\
\hline 161 & 170664.25 & 233256.04 & 1106.73 & -2.10 & 20.40 & 0.82 \\
\hline 162 & 170664.18 & 233254.74 & 1107.45 & -2.05 & 21.70 & 1.54 \\
\hline 163 & 170664.20 & 233254.76 & 1108.87 & -2.07 & 21.68 & 2.96 \\
\hline 164 & 170664.24 & 233254.20 & 1108.93 & -2.12 & 22.24 & 3.02 \\
\hline 165 & 170664.25 & 233254.13 & 1107.53 & -2.13 & 22.31 & 1.62 \\
\hline 166 & 170664.40 & 233252.89 & 1108.74 & -2.30 & 23.55 & 2.83 \\
\hline 167 & 170664.36 & 233253.57 & 1108.67 & -2.25 & 22.87 & 2.76 \\
\hline 168 & 170664.65 & 233253.77 & 1108.73 & -2.53 & 22.67 & 2.82 \\
\hline 169 & 170665.15 & 233253.86 & 1108.67 & -3.03 & 22.59 & 2.76 \\
\hline
\end{tabular}


Table E3. Niche 5 Profile Survey Data and Slot Survey Data and Their Corresponding Values in the $X-Y-Z$ Coordinate System (Continued)

\begin{tabular}{|c|c|c|c|c|c|c|}
\hline \multicolumn{7}{|c|}{ Niche 5 Profile } \\
\hline Station & Easting [m] & Northing [m] & Elevation [m] & $X[\mathrm{~m}]$ & $\mathrm{Y}[\mathrm{m}]$ & $\mathrm{Z}[\mathrm{m}]$ \\
\hline 170 & 170665.64 & 233253.87 & 1108.71 & -3.52 & 22.59 & 2.80 \\
\hline 171 & 170664.20 & 233257.98 & 1108.63 & -2.01 & 18.46 & 2.72 \\
\hline 172 & 170664.36 & 233257.73 & 1108.75 & -2.18 & 18.71 & 2.84 \\
\hline 173 & 170664.73 & 233257.23 & 1108.81 & -2.55 & 19.22 & 2.90 \\
\hline 174 & 170665.26 & 233257.03 & 1109.12 & -3.09 & 19.43 & 3.21 \\
\hline 175 & 170665.46 & 233256.97 & 1109.14 & -3.29 & 19.49 & 3.23 \\
\hline 176 & 170665.31 & 233257.07 & 1108.04 & -3.14 & 19.39 & 2.13 \\
\hline 177 & 170664.88 & 233257.14 & 1108.02 & -2.71 & 19.31 & 2.11 \\
\hline 178 & 170664.31 & 233257.45 & 1107.90 & -2.13 & 18.99 & 1.99 \\
\hline 179 & 170664.24 & 233257.79 & 1107.88 & -2.05 & 18.65 & 1.97 \\
\hline 180 & 170664.25 & 233257.80 & 1108.32 & -2.06 & 18.64 & 2.41 \\
\hline 181 & 170664.34 & 233257.46 & 1108.32 & -2.16 & 18.98 & 2.41 \\
\hline 182 & 170664.73 & 233257.32 & 1108.38 & -2.55 & 19.13 & 2.47 \\
\hline 183 & 170664.86 & 233257.16 & 1108.42 & -2.69 & 19.29 & 2.51 \\
\hline 184 & 170665.36 & 233257.08 & 1108.50 & -3.19 & 19.38 & 2.59 \\
\hline 185 & 170660.10 & 233255.84 & 1109.44 & 2.05 & 20.52 & 3.53 \\
\hline 186 & 170659.81 & 233255.88 & 1109.15 & 2.34 & 20.48 & 3.24 \\
\hline 187 & 170659.58 & 233255.87 & 1108.88 & 2.57 & 20.49 & 2.97 \\
\hline 188 & 170659.29 & 233255.88 & 1108.73 & 2.86 & 20.47 & 2.82 \\
\hline 189 & 170659.34 & 233255.88 & 1108.55 & 2.81 & 20.47 & 2.64 \\
\hline 190 & 170659.66 & 233255.83 & 1108.42 & 2.49 & 20.53 & 2.51 \\
\hline 191 & 170659.91 & 233255.74 & 1108.19 & 2.24 & 20.62 & 2.28 \\
\hline 192 & 170660.01 & 233255.80 & 1107.87 & 2.14 & 20.56 & 1.96 \\
\hline 193 & 170659.92 & 233256.93 & 1108.65 & 2.25 & 19.43 & 2.74 \\
\hline 194 & 170659.82 & 233256.57 & 1108.62 & 2.34 & 19.79 & 2.71 \\
\hline 195 & 170659.52 & 233256.31 & 1108.61 & 2.64 & 20.04 & 2.70 \\
\hline 196 & 170659.39 & 233256.02 & 1108.68 & 2.76 & 20.33 & 2.77 \\
\hline 197 & 170659.26 & 233255.84 & 1108.62 & 2.89 & 20.51 & 2.71 \\
\hline 198 & 170659.42 & 233255.68 & 1108.61 & 2.73 & 20.67 & 2.70 \\
\hline 199 & 170659.70 & 233255.42 & 1108.58 & 2.44 & 20.94 & 2.67 \\
\hline 200 & 170659.68 & 233255.04 & 1108.62 & 2.46 & 21.32 & 2.71 \\
\hline 201 & 170659.82 & 233254.56 & 1108.66 & 2.31 & 21.80 & 2.75 \\
\hline
\end{tabular}

Source: DTN: MO0009GSC00332.000 [DIRS 155370], MO0107GSC01061.000 [DIRS 155369]).

Detailed measurement of the niche ceiling roughness was carried out with reference to a horizontal frame located $2.98 \mathrm{~m}$ above the datum as shown in Table E-4 (DTN: LB0301N5CEILNG.001 [DIRS 161733]). 
Table E-4. Niche 5 Ceiling Roughness Data

\begin{tabular}{|c|c|c|}
\hline$X[\mathrm{~m}]$ & $\mathrm{Y}[\mathrm{m}]$ & $\mathrm{Z}[\mathrm{m}]$ \\
\hline-1.40 & 27.86 & 4.02 \\
\hline-1.09 & 27.86 & 4.29 \\
\hline-0.78 & 27.86 & 4.38 \\
\hline-0.48 & 27.86 & 4.54 \\
\hline-0.17 & 27.86 & 4.30 \\
\hline 0.14 & 27.86 & 4.27 \\
\hline 0.45 & 27.86 & 4.25 \\
\hline 0.76 & 27.86 & 4.26 \\
\hline 1.06 & 27.86 & 4.30 \\
\hline 1.37 & 27.86 & 4.17 \\
\hline 1.68 & 27.86 & 3.96 \\
\hline-1.40 & 26.56 & 4.21 \\
\hline-1.09 & 26.56 & 4.30 \\
\hline-0.78 & 26.56 & 4.36 \\
\hline-0.48 & 26.56 & 4.40 \\
\hline-0.17 & 26.56 & 4.54 \\
\hline 0.14 & 26.56 & 4.46 \\
\hline 0.45 & 26.56 & 4.39 \\
\hline 0.76 & 26.56 & 4.37 \\
\hline 1.06 & 26.56 & 4.35 \\
\hline 1.37 & 26.56 & 4.20 \\
\hline 1.68 & 26.56 & 3.98 \\
\hline-1.40 & 25.26 & 4.06 \\
\hline-1.09 & 25.26 & 4.26 \\
\hline-0.78 & 25.26 & 4.27 \\
\hline-0.48 & 25.26 & 4.57 \\
\hline-0.17 & 25.26 & 4.36 \\
\hline 0.14 & 25.26 & 4.35 \\
\hline 0.45 & 25.26 & 4.38 \\
\hline 0.76 & 25.26 & 4.38 \\
\hline 1.06 & 25.26 & 4.28 \\
\hline 1.37 & 25.26 & 4.15 \\
\hline 1.68 & 25.26 & 4.09 \\
\hline-1.40 & 23.96 & 4.18 \\
\hline-1.09 & 23.96 & 4.29 \\
\hline-0.78 & 23.96 & 4.33 \\
\hline-0.48 & 23.96 & 4.36 \\
\hline-0.17 & 23.96 & 4.49 \\
\hline 0.14 & 23.96 & 4.42 \\
\hline 0.45 & 23.96 & 4.42 \\
\hline 0.76 & 23.96 & 4.47 \\
\hline 1.06 & 23.96 & 4.38 \\
\hline 1.37 & 23.96 & 4.28 \\
\hline 1.68 & 23.96 & 4.05 \\
\hline-1.40 & 22.66 & 3.98 \\
\hline-1.09 & 22.66 & 4.18 \\
\hline
\end{tabular}


Table E4. Niche 5 Ceiling Roughness Data (Continued)

\begin{tabular}{|c|c|c|}
\hline$X[\mathrm{~m}]$ & $\mathrm{Y}[\mathrm{m}]$ & $\mathrm{Z}[\mathrm{m}]$ \\
\hline-0.78 & 22.66 & 4.32 \\
\hline-0.48 & 22.66 & 4.42 \\
\hline-0.17 & 22.66 & 4.58 \\
\hline 0.14 & 22.66 & 4.42 \\
\hline 0.45 & 22.66 & 4.71 \\
\hline 0.76 & 22.66 & 4.38 \\
\hline 1.06 & 22.66 & 4.36 \\
\hline 1.37 & 22.66 & 4.26 \\
\hline 1.68 & 22.66 & 4.36 \\
\hline-1.40 & 21.36 & 3.97 \\
\hline-1.09 & 21.36 & 4.13 \\
\hline-0.78 & 21.36 & 4.18 \\
\hline-0.48 & 21.36 & 4.25 \\
\hline-0.17 & 21.36 & 4.35 \\
\hline 0.14 & 21.36 & 4.33 \\
\hline 0.45 & 21.36 & 4.63 \\
\hline 0.76 & 21.36 & 4.28 \\
\hline 1.06 & 21.36 & 4.19 \\
\hline 1.37 & 21.36 & 4.18 \\
\hline 1.68 & 21.36 & 3.99 \\
\hline-1.40 & 20.06 & 3.90 \\
\hline-1.09 & 20.06 & 4.11 \\
\hline-0.78 & 20.06 & 4.17 \\
\hline-0.48 & 20.06 & 4.25 \\
\hline-0.17 & 20.06 & 4.27 \\
\hline 0.14 & 20.06 & 4.21 \\
\hline 0.45 & 20.06 & 4.22 \\
\hline 0.76 & 20.06 & 4.32 \\
\hline 1.06 & 20.06 & 4.31 \\
\hline 1.37 & 20.06 & 4.16 \\
\hline 1.68 & 20.06 & 4.00 \\
\hline-1.40 & 18.76 & 3.96 \\
\hline-1.09 & 18.76 & 3.89 \\
\hline-0.78 & 18.76 & 4.03 \\
\hline-0.48 & 18.76 & 4.10 \\
\hline-0.17 & 18.76 & 4.09 \\
\hline 0.14 & 18.76 & 4.07 \\
\hline 0.45 & 18.76 & 4.08 \\
\hline 0.76 & 18.76 & 4.08 \\
\hline 1.06 & 18.76 & 4.13 \\
\hline 1.37 & 18.76 & 4.20 \\
\hline 1.68 & 18.76 & 3.79 \\
\hline-1.40 & 17.46 & 4.00 \\
\hline-1.09 & 17.46 & 3.91 \\
\hline-0.78 & 17.46 & 3.93 \\
\hline-0.48 & 17.46 & 3.99 \\
\hline
\end{tabular}


Table E4. Niche 5 Ceiling Roughness Data (Continued)

\begin{tabular}{|c|c|c|}
\hline$X[\mathrm{~m}]$ & $\mathrm{Y}[\mathrm{m}]$ & $\mathrm{Z}[\mathrm{m}]$ \\
\hline-0.17 & 17.46 & 4.17 \\
\hline 0.14 & 17.46 & 4.19 \\
\hline 0.45 & 17.46 & 4.06 \\
\hline 0.76 & 17.46 & 4.10 \\
\hline 1.06 & 17.46 & 4.05 \\
\hline 1.37 & 17.46 & 3.92 \\
\hline 1.68 & 17.46 & 3.62 \\
\hline-1.40 & 16.16 & 3.83 \\
\hline-1.09 & 16.16 & 3.86 \\
\hline-0.78 & 16.16 & 4.06 \\
\hline-0.48 & 16.16 & 4.14 \\
\hline-0.17 & 16.16 & 4.12 \\
\hline 0.14 & 16.16 & 4.09 \\
\hline 0.45 & 16.16 & 4.18 \\
\hline 0.76 & 16.16 & 4.09 \\
\hline 1.06 & 16.16 & 4.07 \\
\hline 1.37 & 16.16 & 3.92 \\
\hline 1.68 & 16.16 & 3.77 \\
\hline-1.40 & 14.87 & 3.65 \\
\hline-1.09 & 14.87 & 3.79 \\
\hline-0.78 & 14.87 & 3.92 \\
\hline-0.48 & 14.87 & 4.15 \\
\hline-0.17 & 14.87 & 4.20 \\
\hline 0.14 & 14.87 & 4.05 \\
\hline 0.45 & 14.87 & 4.18 \\
\hline 0.76 & 14.87 & 4.24 \\
\hline 1.06 & 14.87 & 4.34 \\
\hline 1.37 & 14.87 & 3.90 \\
\hline 1.68 & 14.87 & 3.98 \\
\hline-1.40 & 15.19 & 3.66 \\
\hline-1.40 & 15.51 & 3.62 \\
\hline-1.40 & 15.84 & 3.63 \\
\hline-1.40 & 16.49 & 3.77 \\
\hline-1.40 & 16.81 & 3.91 \\
\hline-1.40 & 17.14 & 3.78 \\
\hline-1.40 & 17.79 & 4.08 \\
\hline-1.40 & 18.11 & 3.70 \\
\hline-1.40 & 18.44 & 3.73 \\
\hline-1.40 & 19.09 & 3.88 \\
\hline-1.40 & 19.41 & 3.93 \\
\hline-1.40 & 19.74 & 3.97 \\
\hline-1.40 & 20.39 & 4.16 \\
\hline-1.40 & 20.71 & 4.09 \\
\hline-1.40 & 21.04 & 4.10 \\
\hline-1.40 & 21.69 & 4.00 \\
\hline-1.40 & 22.01 & 3.96 \\
\hline
\end{tabular}


Table E4. Niche 5 Ceiling Roughness Data (Continued)

\begin{tabular}{|c|c|c|}
\hline$X[\mathrm{~m}]$ & $\mathrm{Y}[\mathrm{m}]$ & $\mathrm{Z}[\mathrm{m}]$ \\
\hline-1.40 & 22.34 & 3.96 \\
\hline-1.40 & 22.99 & 4.09 \\
\hline-1.40 & 23.31 & 4.19 \\
\hline-1.40 & 23.64 & 4.17 \\
\hline-1.40 & 24.29 & 4.12 \\
\hline-1.40 & 24.61 & 4.18 \\
\hline-1.40 & 24.94 & 4.28 \\
\hline-1.40 & 25.59 & 4.20 \\
\hline-1.40 & 25.91 & 4.27 \\
\hline-1.40 & 26.24 & 4.34 \\
\hline-1.40 & 26.89 & 4.40 \\
\hline-1.40 & 27.21 & 4.11 \\
\hline-1.40 & 27.54 & 4.07 \\
\hline 1.68 & 15.19 & 3.87 \\
\hline 1.68 & 15.51 & 3.74 \\
\hline 1.68 & 15.84 & 3.79 \\
\hline 1.68 & 16.49 & 3.84 \\
\hline 1.68 & 16.81 & 3.82 \\
\hline 1.68 & 17.14 & 3.81 \\
\hline-2.19 & 14.87 & 2.98 \\
\hline-2.49 & 16.16 & 2.98 \\
\hline-2.21 & 17.46 & 2.98 \\
\hline-2.15 & 18.76 & 2.98 \\
\hline-1.87 & 20.06 & 2.98 \\
\hline-1.98 & 21.36 & 2.98 \\
\hline-1.85 & 22.66 & 2.98 \\
\hline-1.77 & 23.96 & 2.98 \\
\hline-1.85 & 25.26 & 2.98 \\
\hline-1.91 & 26.56 & 2.98 \\
\hline-2.11 & 27.86 & 2.98 \\
\hline 2.13 & 14.87 & 2.98 \\
\hline 2.14 & 16.16 & 2.98 \\
\hline 2.19 & 17.46 & 2.98 \\
\hline 2.22 & 18.76 & 2.98 \\
\hline 2.33 & 20.06 & 2.98 \\
\hline 2.34 & 21.36 & 2.98 \\
\hline 2.21 & 22.66 & 2.98 \\
\hline 2.38 & 23.96 & 2.98 \\
\hline 2.18 & 25.26 & 2.98 \\
\hline 2.22 & 26.56 & 2.98 \\
\hline 2.09 & 27.86 & 2.98 \\
\hline-1.40 & 27.86 & 2.98 \\
\hline 0.14 & 27.86 & 2.98 \\
\hline 1.68 & 27.86 & 2.98 \\
\hline
\end{tabular}


The survey data shown in Table E-3 and Table E-4 were interpolated onto a regular $X-Y$ plane of $0.1 \mathrm{~m} \times 0.1 \mathrm{~m}$ resolution using a linear interpolation tool of the software Tecplot V9.0. Excerpts of the resulting Niche 5 ceiling and slot profiles are shown in Figure E-1, and Figure E-2 shows the plan view of the ceiling roughness.

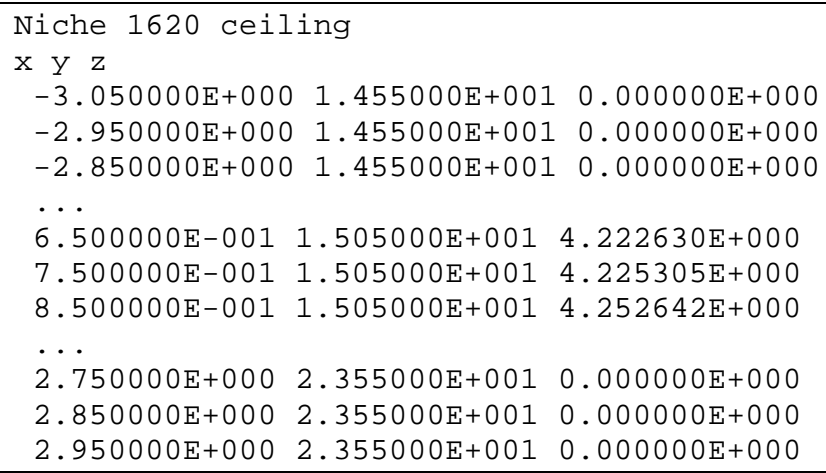

Figure E-1. Excerpts from Interpolated Ceiling Profile of Niche 5

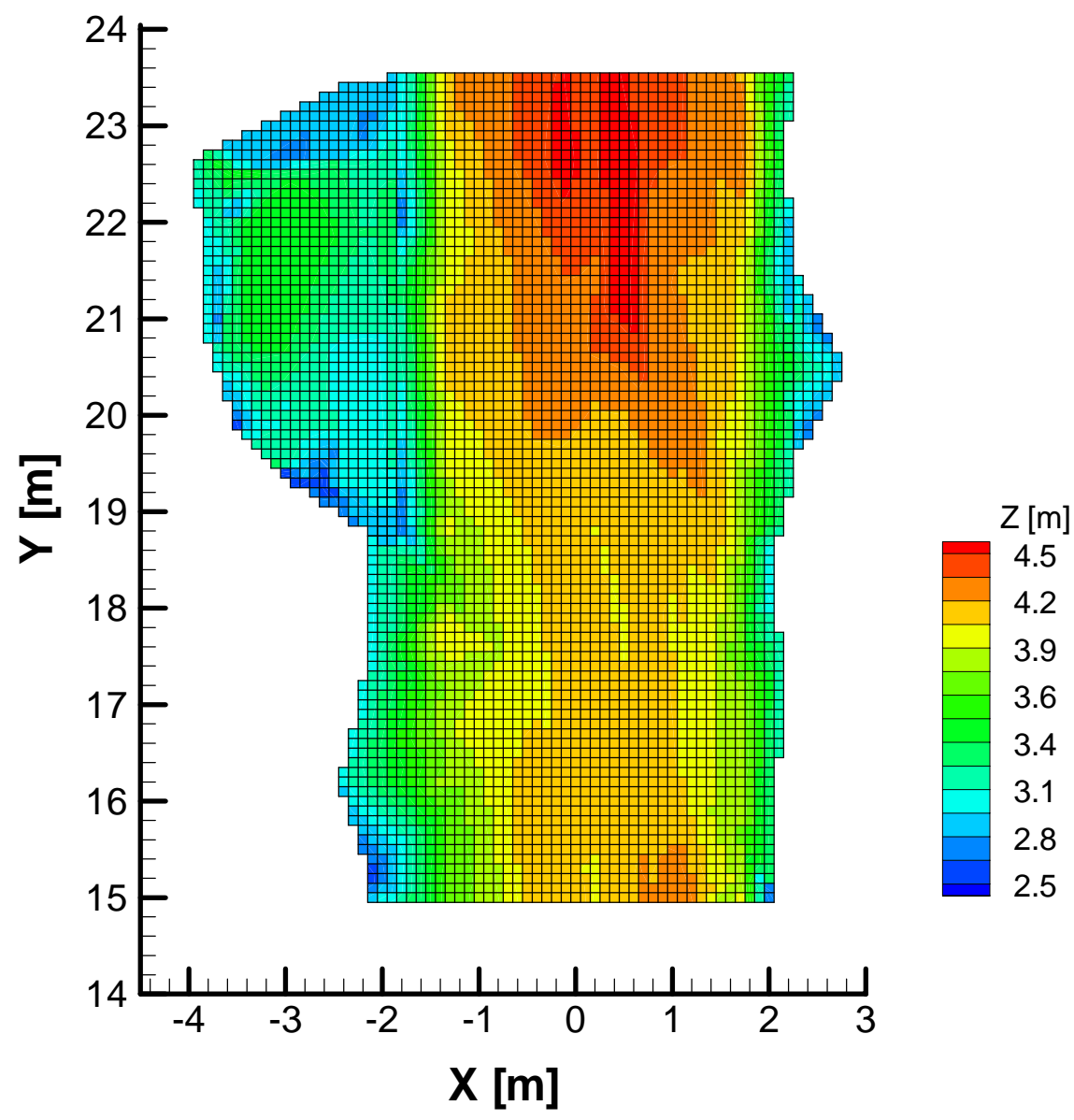

Output DTN: LB0302SCMREV02.002.

Figure E-2. Plan View of Niche 5 Ceiling and Slot Surface Roughness. 


\section{E2. LOCATION OF BOREHOLES AND PREPARATION OF GEOSTATISTICAL PARAMETERS OF AIR-PERMEABILITY}

The locations of the borehole collars and projected endpoints (DTN: MO0312GSC03176.000 [DIRS 169532]) were transformed from the Nevada coordinate system to the regular $X-Y-Z$ coordinate system using Eqs. E-1 to E-4. The original borehole surveys and their transformed equivalents are listed in Table E-5.

Table E-5. Original and Transformed Coordinates of Borehole Collars and Projected Bottoms

\begin{tabular}{|c|c|c|c|c|c|c|c|}
\hline Borehole Collar/Bottom & Easting $(\mathrm{m})$ & $\begin{array}{c}\text { Northing } \\
(\mathrm{m})\end{array}$ & $\begin{array}{c}\text { Elevation } \\
(\mathrm{m})\end{array}$ & Depth (m) & $X(m)$ & $Y(m)$ & $Z(m)$ \\
\hline ECRB-NICHE1620\#1 & & & & & & & \\
\hline Collar \#1. & 170662.22 & 233262.19 & 1108.99 & \multirow{2}{*}{15.39} & 0.04 & 14.21 & 3.08 \\
\hline Projected Bottom & 170661.91 & 233246.82 & 1109.14 & & 0.08 & 29.58 & 3.23 \\
\hline \multicolumn{8}{|l|}{ ECRB-NICHE1620 \#2 } \\
\hline Collar \#2. & 170663.25 & 233262.93 & 1110.99 & \multirow{2}{*}{16.02} & -0.98 & 13.49 & 5.08 \\
\hline Projected Bottom & 170662.83 & 233246.93 & 1111.61 & & -0.83 & 29.48 & 5.70 \\
\hline \multicolumn{8}{|l|}{ ECRB-NICHE1620 \#3 } \\
\hline Collar \#3 & 170662.25 & 233262.72 & 1111.00 & \multirow{2}{*}{15.50} & 0.02 & 13.68 & 5.09 \\
\hline Projected Bottom & 170661.98 & 233247.23 & 1111.29 & & 0.02 & 29.17 & 5.38 \\
\hline \multicolumn{8}{|l|}{ ECRB-NICHE1620 \#4 } \\
\hline Collar \#4 & 170661.26 & 233262.76 & 1111.04 & \multirow{2}{*}{15.02} & 1.01 & 13.63 & 5.13 \\
\hline Projected Bottom & 170661.16 & 233247.76 & 1111.57 & & 0.85 & 28.62 & 5.66 \\
\hline \multicolumn{8}{|l|}{ ECRB-NICHE1620 \#5 } \\
\hline Collar \#5 & 170663.27 & 233262.84 & 1111.42 & \multirow{2}{*}{15.88} & -1.00 & 13.58 & 5.51 \\
\hline Projected Bottom & 170662.87 & 233247.08 & 1113.25 & & -0.87 & 29.33 & 7.34 \\
\hline \multicolumn{8}{|l|}{ ECRB-NICHE1620 \#6 } \\
\hline Collar \#6 & 170662.26 & 233262.78 & 1111.44 & \multirow{2}{*}{16.00} & 0.01 & 13.62 & 5.53 \\
\hline Projected Bottom & 170662.21 & 233246.93 & 1113.58 & & -0.21 & 29.47 & 7.67 \\
\hline \multicolumn{8}{|l|}{ ECRB-NICHE1620 \#7 } \\
\hline Collar\#7 & 170661.28 & 233262.71 & 1111.47 & \multirow{2}{*}{14.81} & 0.99 & 13.68 & 5.56 \\
\hline Projected Bottom & 170661.17 & 233248.01 & 1113.27 & & 0.84 & 28.37 & 7.36 \\
\hline
\end{tabular}

Permeability was measured by air-injection tests conducted in boreholes \#2, \#3, and \#5 (see Section 6.5.2). The tests were performed by isolating a $1 \mathrm{ft}$ section of the boreholes using an inflatable packer system (DTN: LB0110AKN5POST.001 [DIRS 156904]), and then injecting compressed air at a constant rate into the isolated injection interval. The pressure buildup in the injection interval and in nearby observation intervals was monitored with time until steady-state conditions were reached, which typically occurred within a few minutes. Air-permeability values were derived from the steady-state pressure data. For the purpose of air-injection tests, the boreholes were named differently (borehole ECRB-NICHE1620 \#5 was renamed as \#0, ECRB-NICHE1620 \#2 was renamed as \#3, and ECRB-NICHE1620 \#3 was renamed as \#4). The locations of the air-injection test intervals were reported as distances in feet from the borehole 
collars. These distances were first converted to meters and then transformed to their corresponding $X-Y-Z$ coordinates by the following elementary analytical geometry formulae:

$$
\begin{aligned}
& X=x^{\prime}+\frac{d\left(x^{\prime \prime}-x^{\prime}\right)}{\sqrt{\left(x^{\prime}-x^{\prime \prime}\right)^{2}+\left(y^{\prime}-y^{\prime \prime}\right)^{2}+\left(z^{\prime}-z^{\prime \prime}\right)^{2}}} \\
& Y=y^{\prime}+\frac{d\left(y^{\prime \prime}-y^{\prime}\right)}{\sqrt{\left(x^{\prime}-x^{\prime \prime}\right)^{2}+\left(y^{\prime}-y^{\prime \prime}\right)^{2}+\left(z^{\prime}-z^{\prime \prime}\right)^{2}}} \\
& Z=z^{\prime}+\frac{d\left(z^{\prime \prime}-z^{\prime}\right)}{\sqrt{\left(x^{\prime}-x^{\prime \prime}\right)^{2}+\left(y^{\prime}-y^{\prime \prime}\right)^{2}+\left(z^{\prime}-z^{\prime \prime}\right)^{2}}}
\end{aligned}
$$

where $d$ is the midpoint of the test interval (see Table E-6). The collar and projected endpoints of the borehole are denoted by $\left(x^{\prime}, y^{\prime}, z^{\prime}\right)$ and $\left(x^{\prime \prime}, y^{\prime \prime}, z^{\prime \prime}\right)$, respectively (see Table E-5 for

\begin{tabular}{|c|c|c|c|c|c|c|c|c|c|}
\hline \multicolumn{4}{|c|}{$\begin{array}{c}\text { DTN: LB0110AKN5POST.001 } \\
\text { [DIRS 156904] }\end{array}$} & \multicolumn{6}{|c|}{ Calculated } \\
\hline $\mathrm{BH}$ & $\begin{array}{l}\text { Start } \\
{[\mathrm{ft}]}\end{array}$ & $\begin{array}{l}\text { End } \\
{[\mathrm{ft}]}\end{array}$ & $k\left[m^{2}\right]$ & $\begin{array}{l}\text { Midpoint } \\
{[\mathrm{ft}]}\end{array}$ & $\begin{array}{l}\text { Midpoint } \\
\text { d [m] }\end{array}$ & $X[\mathrm{~m}]$ & $\mathrm{Y}[\mathrm{m}]$ & $\mathrm{Z}[\mathrm{m}]$ & $\log \left(k\left[m^{2}\right]\right)$ \\
\hline 0 & 3 & 4 & $2.70 \mathrm{E}-12$ & 3.5 & 1.07 & -0.99 & 14.26 & 5.63 & -11.5686 \\
\hline 0 & 4 & 5 & $5.62 \mathrm{E}-12$ & 4.5 & 1.37 & -0.99 & 14.56 & 5.66 & -11.2503 \\
\hline 0 & 5 & 6 & 5.48E-09 & 5.5 & 1.68 & -0.98 & 14.86 & 5.70 & -8.2612 \\
\hline 0 & 6 & 7 & 4.27E-09 & 6.5 & 1.98 & -0.98 & 15.16 & 5.73 & -8.3696 \\
\hline 0 & 7 & 8 & $4.08 \mathrm{E}-12$ & 7.5 & 2.29 & -0.98 & 15.47 & 5.77 & -11.3893 \\
\hline 0 & 8 & 9 & $1.21 \mathrm{E}-11$ & 8.5 & 2.59 & -0.98 & 15.77 & 5.80 & -10.9172 \\
\hline 0 & 9 & 10 & 7.77E-12 & 9.5 & 2.90 & -0.97 & 16.07 & 5.84 & -11.1096 \\
\hline 0 & 10 & 11 & 3.30E-12 & 10.5 & 3.20 & -0.97 & 16.38 & 5.87 & -11.4815 \\
\hline 0 & 11 & 12 & $2.79 \mathrm{E}-11$ & 11.5 & 3.51 & -0.97 & 16.68 & 5.90 & -10.5544 \\
\hline 0 & 12 & 13 & 3.83E-11 & 12.5 & 3.81 & -0.97 & 16.98 & 5.94 & -10.4168 \\
\hline 0 & 13 & 14 & 1.65E-10 & 13.5 & 4.11 & -0.97 & 17.28 & 5.97 & -9.7825 \\
\hline 0 & 14 & 15 & $1.82 \mathrm{E}-10$ & 14.5 & 4.42 & -0.96 & 17.59 & 6.01 & -9.7399 \\
\hline 0 & 15 & 16 & 2.35E-11 & 15.5 & 4.72 & -0.96 & 17.89 & 6.04 & -10.6289 \\
\hline 3 & 4 & 5 & $1.61 \mathrm{E}-11$ & 4.5 & 1.37 & -0.96 & 14.57 & 5.13 & -10.7932 \\
\hline 3 & 5 & 6 & 3.18E-12 & 5.5 & 1.68 & -0.96 & 14.87 & 5.14 & -11.4976 \\
\hline 3 & 6 & 7 & $1.56 \mathrm{E}-11$ & 6.5 & 1.98 & -0.96 & 15.18 & 5.16 & -10.8069 \\
\hline 3 & 7 & 8 & $1.47 \mathrm{E}-12$ & 7.5 & 2.29 & -0.96 & 15.48 & 5.17 & -11.8327 \\
\hline 3 & 8 & 9 & $4.08 \mathrm{E}-10$ & 8.5 & 2.59 & -0.95 & 15.79 & 5.18 & -9.3893 \\
\hline 3 & 9 & 10 & $6.23 \mathrm{E}-10$ & 9.5 & 2.90 & -0.95 & 16.09 & 5.19 & -9.2055 \\
\hline 3 & 10 & 11 & $6.24 \mathrm{E}-10$ & 10.5 & 3.20 & -0.95 & 16.40 & 5.20 & -9.2048 \\
\hline 3 & 11 & 12 & $5.52 \mathrm{E}-10$ & 11.5 & 3.51 & -0.94 & 16.70 & 5.21 & -9.2581 \\
\hline 3 & 12 & 13 & 1.19E-12 & 12.5 & 3.81 & -0.94 & 17.01 & 5.22 & -11.9245 \\
\hline 3 & 13 & 14 & $3.20 \mathrm{E}-11$ & 13.5 & 4.11 & -0.94 & 17.31 & 5.24 & -10.4949 \\
\hline 3 & 14 & 15 & 3.23E-11 & 14.5 & 4.42 & -0.94 & 17.61 & 5.25 & -10.4908 \\
\hline
\end{tabular}
coordinates of endpoints). The transformation of coordinates is shown in Table E-6.

Table E-6. Locations of Air-Injection Test Intervals and Measured Air-Permeabilities 
Table E-7. Locations of Air-Injection Test Intervals and Measured Air-Permeabilities

\begin{tabular}{|c|c|c|c|c|c|c|c|c|c|}
\hline \multicolumn{4}{|c|}{$\begin{array}{c}\text { DTN: LB0110AKN5POST.001 } \\
\text { [DIRS 156904] }\end{array}$} & \multicolumn{6}{|c|}{ Calculated } \\
\hline BH & $\begin{array}{c}\text { Start } \\
{[\mathrm{ft}]}\end{array}$ & $\begin{array}{l}\text { End } \\
{[\mathrm{ft}]}\end{array}$ & $k\left[m^{2}\right]$ & $\begin{array}{l}\text { Midpoint } \\
{[\mathrm{ft}]}\end{array}$ & $\begin{array}{c}\text { Midpoint } \\
\text { d [m] }\end{array}$ & $X[\mathrm{~m}]$ & $\mathrm{Y}[\mathrm{m}]$ & $\mathrm{Z}[\mathrm{m}]$ & $\log \left(k\left[m^{2}\right]\right)$ \\
\hline 3 & 15 & 16 & 2.23E-12 & 15.5 & 4.72 & -0.93 & 17.92 & 5.26 & -11.6517 \\
\hline 3 & 16 & 17 & 4.03E-09 & 16.5 & 5.03 & -0.93 & 18.22 & 5.27 & -8.3947 \\
\hline 3 & 17 & 18 & 1.92E-09 & 17.5 & 5.33 & -0.93 & 18.53 & 5.28 & -8.7167 \\
\hline 4 & 3 & 4 & 5.85E-09 & 3.5 & 1.07 & 0.02 & 14.39 & 5.11 & -8.2328 \\
\hline 4 & 4 & 5 & 9.51E-09 & 4.5 & 1.37 & 0.02 & 14.70 & 5.12 & -8.0218 \\
\hline 4 & 5 & 6 & 9.32E-12 & 5.5 & 1.68 & 0.02 & 15.00 & 5.12 & -11.0306 \\
\hline 4 & 6 & 7 & 8.85E-12 & 6.5 & 1.98 & 0.02 & 15.31 & 5.13 & -11.0531 \\
\hline 4 & 7 & 8 & $9.68 \mathrm{E}-12$ & 7.5 & 2.29 & 0.02 & 15.61 & 5.13 & -11.0141 \\
\hline 4 & 8 & 9 & $4.16 \mathrm{E}-13$ & 8.5 & 2.59 & 0.02 & 15.92 & 5.14 & -12.3809 \\
\hline 4 & 9 & 10 & 1.87E-12 & 9.5 & 2.90 & 0.02 & 16.22 & 5.14 & -11.7282 \\
\hline 4 & 10 & 11 & 1.16E-13 & 10.5 & 3.20 & 0.02 & 16.53 & 5.15 & -12.9355 \\
\hline 4 & 11 & 12 & 4.87E-14 & 11.5 & 3.51 & 0.02 & 16.83 & 5.15 & -13.3125 \\
\hline 4 & 12 & 13 & $5.25 \mathrm{E}-13$ & 12.5 & 3.81 & 0.02 & 17.14 & 5.16 & -12.2798 \\
\hline 4 & 13 & 14 & $2.20 \mathrm{E}-11$ & 13.5 & 4.11 & 0.02 & 17.44 & 5.17 & -10.6576 \\
\hline 4 & 14 & 15 & 3.66E-11 & 14.5 & 4.42 & 0.02 & 17.75 & 5.17 & -10.4365 \\
\hline 4 & 15 & 16 & 4.82E-14 & 15.5 & 4.72 & 0.02 & 18.05 & 5.18 & -13.3170 \\
\hline 4 & 16 & 17 & 5.91E-13 & 16.5 & 5.03 & 0.02 & 18.36 & 5.18 & -12.2284 \\
\hline 4 & 17 & 18 & $1.34 \mathrm{E}-11$ & 17.5 & 5.33 & 0.02 & 18.66 & 5.19 & -10.8729 \\
\hline 4 & 18 & 19 & 3.71E-11 & 18.5 & 5.64 & 0.02 & 18.97 & 5.19 & -10.4306 \\
\hline 4 & 19 & 20 & $8.39 \mathrm{E}-13$ & 19.5 & 5.94 & 0.02 & 19.27 & 5.20 & -12.0762 \\
\hline 4 & 20 & 21 & $2.48 \mathrm{E}-12$ & 20.5 & 6.25 & 0.02 & 19.58 & 5.20 & -11.6055 \\
\hline 4 & 21 & 22 & $1.82 \mathrm{E}-12$ & 21.5 & 6.55 & 0.02 & 19.88 & 5.21 & -11.7399 \\
\hline 4 & 22 & 23 & 1.86E-13 & 22.5 & 6.86 & 0.02 & 20.18 & 5.22 & -12.7305 \\
\hline 4 & 23 & 24 & 2.33E-13 & 23.5 & 7.16 & 0.02 & 20.49 & 5.22 & -12.6326 \\
\hline 4 & 24 & 25 & $2.65 \mathrm{E}-12$ & 24.5 & 7.47 & 0.02 & 20.79 & 5.23 & -11.5768 \\
\hline 4 & 25 & 26 & $2.14 \mathrm{E}-12$ & 25.5 & 7.77 & 0.02 & 21.10 & 5.23 & -11.6696 \\
\hline 4 & 26 & 27 & $2.11 \mathrm{E}-13$ & 26.5 & 8.08 & 0.02 & 21.40 & 5.24 & -12.6757 \\
\hline 4 & 27 & 28 & $2.95 \mathrm{E}-13$ & 27.5 & 8.38 & 0.02 & 21.71 & 5.24 & -12.5302 \\
\hline 4 & 28 & 29 & $6.71 \mathrm{E}-11$ & 28.5 & 8.69 & 0.02 & 22.01 & 5.25 & -10.1733 \\
\hline 4 & 29 & 30 & $6.87 \mathrm{E}-11$ & 29.5 & 8.99 & 0.02 & 22.32 & 5.25 & -10.1630 \\
\hline 4 & 30 & 31 & 1.64E-11 & 30.5 & 9.30 & 0.02 & 22.62 & 5.26 & -10.7852 \\
\hline 4 & 31 & 32 & 7.19E-12 & 31.5 & 9.60 & 0.02 & 22.93 & 5.27 & -11.1433 \\
\hline 4 & 32 & 33 & $2.43 \mathrm{E}-12$ & 32.5 & 9.91 & 0.02 & 23.23 & 5.27 & -11.6144 \\
\hline 4 & 33 & 34 & 4.88E-13 & 33.5 & 10.21 & 0.02 & 23.54 & 5.28 & -12.3116 \\
\hline 4 & 34 & 35 & 1.06E-12 & 34.5 & 10.52 & 0.02 & 23.84 & 5.28 & -11.9747 \\
\hline 4 & 35 & 36 & 1.57E-12 & 35.5 & 10.82 & 0.02 & 24.15 & 5.29 & -11.8041 \\
\hline 4 & 36 & 37 & $1.48 \mathrm{E}-10$ & 36.5 & 11.13 & 0.02 & 24.45 & 5.29 & -9.8297 \\
\hline
\end{tabular}

$\mathrm{BH}=$ borehole; DTN=Data Tracking Number 


\section{E3. PREPARATION OF MESHES}

Multiple numerical meshes of a $2 \mathrm{~m}$ long section of the Niche 5 were developed, each with a different stochastic realization of the underlying heterogeneous permeability field. There were three test zones, labeled Niche5a, Niche5b, and Niche5c. The locations and primary dimensions of these meshes are listed below in Table E-8.

Table E-8. Primary Dimensions of Niche 5 Meshes

\begin{tabular}{|c|c|c|c|}
\hline \multirow{2}{*}{$\begin{array}{c}\text { Location of Test Zone Along Y- } \\
\text { axis from ECRB Centerline }\end{array}$} & \multicolumn{3}{|c|}{ Dimensions [m] } \\
\cline { 2 - 4 } & $\mathbf{X}$ & $\mathbf{Y}$ & $\mathbf{Z}$ \\
\hline $0.0+15.60$ & 6.0 & 4.0 & 2.0 \\
\hline $0.0+19.60$ & 8.0 & 4.0 & 2.0 \\
\hline $0.0+21.90$ & 8.0 & 5.0 & 2.0 \\
\hline
\end{tabular}

The following mesh generation steps were performed. File names in the following steps refer to mesh of borehole \#5 (28-29 ft).

1. A mesh was generated with $\mathrm{X}-\mathrm{Y}-\mathrm{Z}$ dimensions as listed in Table E-8, discretized into regular gridblocks with side lengths of $0.1 \mathrm{~m} \times 0.1 \mathrm{~m} \times 0.1 \mathrm{~m}$. The Y-axis was aligned with the Niche centerline. Figure E-3 shows the input file N5BH5_28-29ft and the command used to generate the mesh.

2. The mesh was shifted using software MoveMesh V1.0 (LBNL 2000 [DIRS 152824]) to translate the origin of the mesh to the datum of Niche 5.

3. The GSLIB module SISIM V1.204 (LBNL 2000 [DIRS 153100]) was executed to generate a random, spatially correlated field of log-permeability modifiers. For each realization, a new seed number was inserted into the SISIM V1.204 input file N5BH5_28-29ft_sisim.par (see Figure E-4). The generated permeability field was conditioned on measured air-permeability data provided in the file measured_log-k_12_N5.dat (see Figure E-5). An excerpt of the generated permeability field is shown in Figure E-6.

4. The heterogeneous field of permeability modifiers was mapped onto the mesh using software Perm2Mesh V1.0 (LBNL 2000 [DIRS 152826]).

5. A niche was cut from the mesh with software CutDrift V1.0 (LBNL 2000 [DIRS 152816]), using interpolated ceiling surface data given in Figure E-1.

6. Left and right slots were cut from the mesh with software CutDrift V1.0 (LBNL 2000 [DIRS 152816]), using interpolated ceiling surface data given in Figures E-7 and E-8, respectively.

7. Software AddBound V1.0 (LBNL 2000 [DIRS 152823]) was used to attach boundary elements at the top and bottom of the model domain. The bottom boundary gridblock was assigned to a special material domain (DRAIN) to allow specifying a free-drainage boundary condition. 
8. Gridblocks along the alignment of the injection boreholes were modified to represent $1 \mathrm{ft}$ $(0.3 \mathrm{~m})$ long injection intervals and $3 \mathrm{ft}(0.9 \mathrm{~m})$ long packers on both sides of the injection interval.

9. Drift elements (DRI78, DRI79, DRI88, DRI89, DRI98, and DRI99) were assigned a large volume so Dirichlet boundary conditions can be specified. Flux into the drift elements represents seepage.

10. Six new evaporation elements (EVP78, EVP79, EVP88, EVP89, EVP98 and EVP99) were added and connected to the same formation elements as the drift elements. The nodal distance from the formation elements to the evaporation elements is set to the diffusive boundary-layer thickness. Flux into these elements represents evaporation.

11. A single time step was performed using a generic TOUGH2 input onestep file (as input to iTOUGH2 V5.0 (LBNL 2002 [DIRS 160106]); see Figure C-3) to test the mesh and to obtain cross-referencing information. The execution of the simulation was performed using file sh.onestep (Figure C-4)

Steps 1-11 listed above were executed using file sh.N5BH5_28-29ft_mesh shown in Figure E-9. The script file sh.N5BH5_28-29ft_run (see Figure E-10) assigns new seed numbers for the generation of permeability field and generates multiple meshes by calling the script file sh.N5BH5_28-29ft_mesh.

The final mesh is stored on file N5BH5_28-29ft.mes $Z$ where $Z$ labels the realization of the underlying random permeability field.

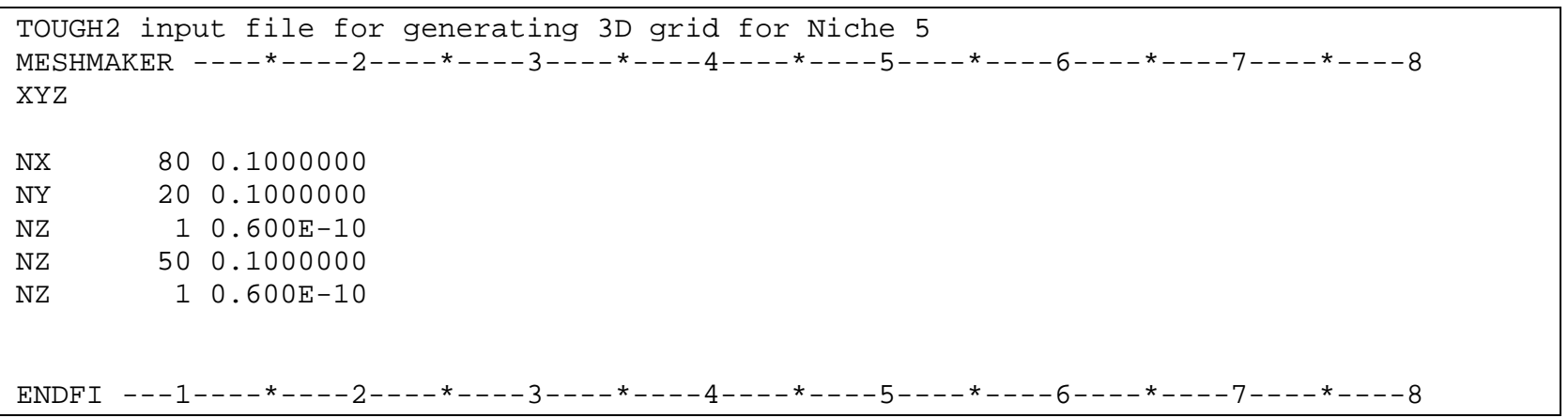

Figure E-3. Input File N5BH5_28-29ft Used to Generate Primary Mesh 


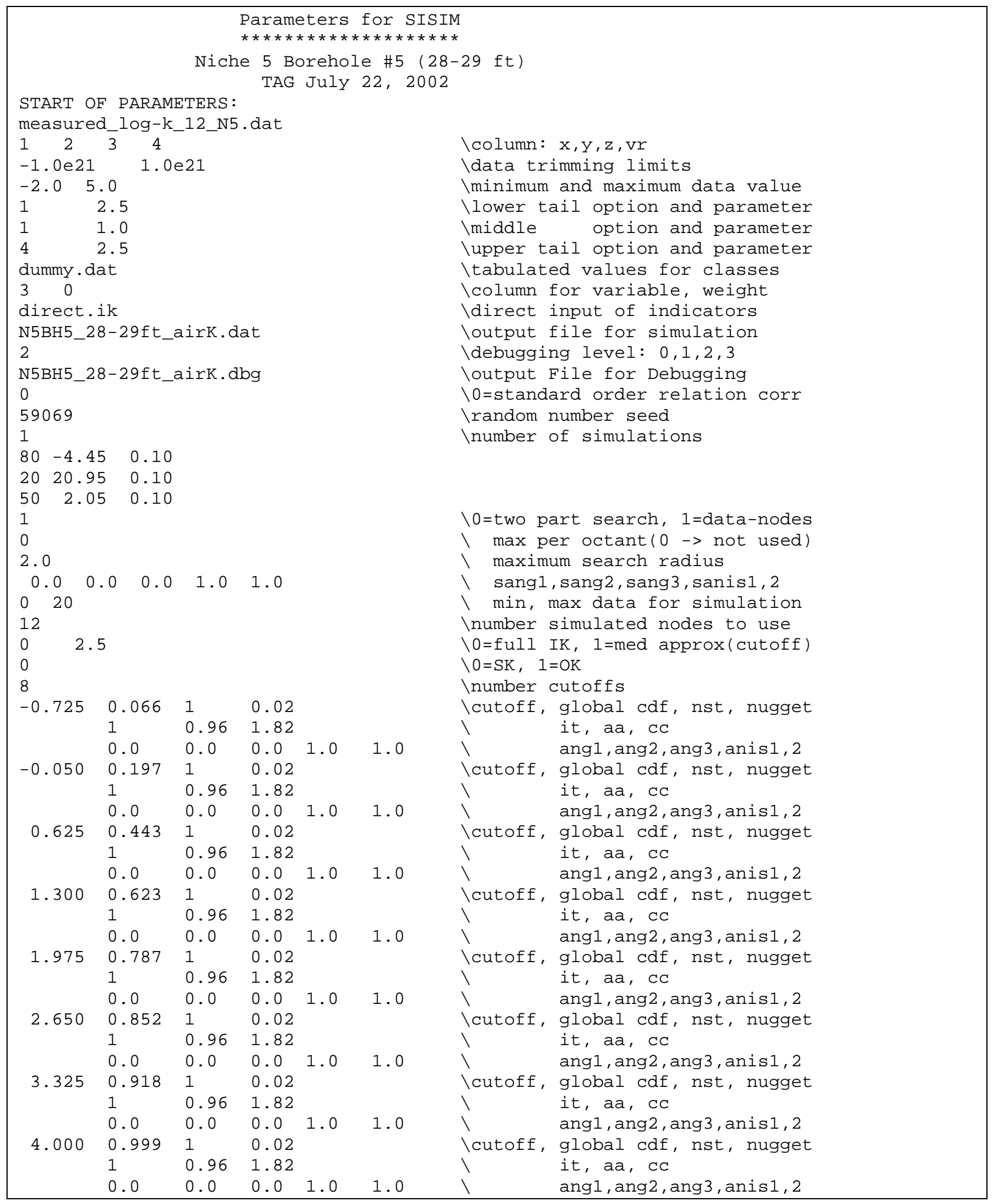

Figure E-4. Input File Parameter File N5BH5_28-29ft_sisim.par for Random Permeability Field Generating Software SISIM 


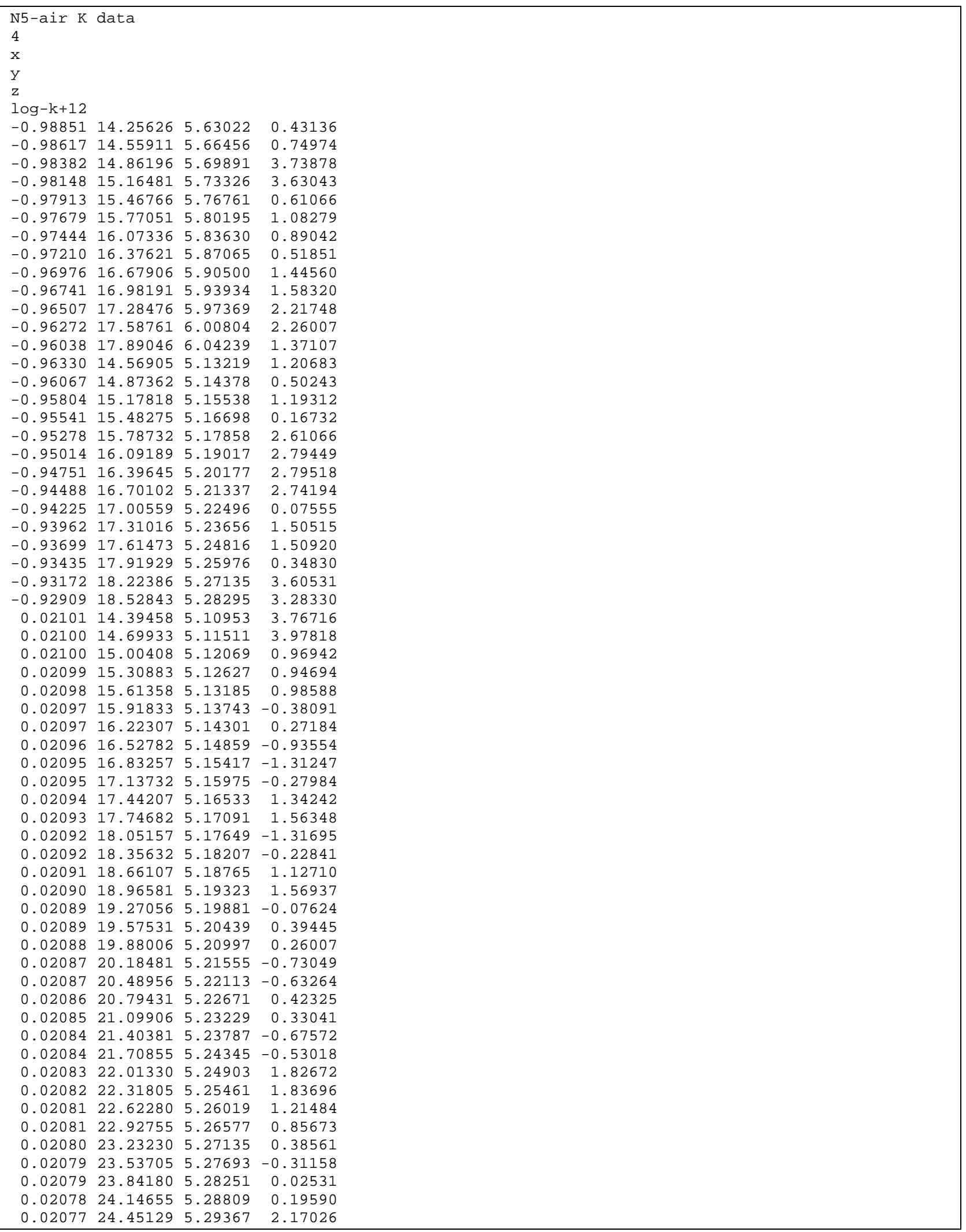

Figure E-5. Measured Air-Permeability Data Provided in File measured_log-k_12_N5.dat for Conditioning the Generated Permeability Field 


\begin{tabular}{|c|c|c|c|}
\hline variables $=x y$ & z var & & \\
\hline zone $i=80 \mathrm{j}=$ & $20 \mathrm{k}=50$ & & \\
\hline$-0.4450000 E+01$ & $\odot .2095000 \mathrm{E}+02$ & $\odot .2050000 \mathrm{E}+01$ & $\odot .6853335 \mathrm{E}+\odot \odot$ \\
\hline$-0.4350000 E+01$ & $\odot .2095000 \mathrm{E}+02$ & $\odot .2050000 \mathrm{E}+01$ & $0.1218344 \mathrm{E}+01$ \\
\hline$-\odot .42500 \odot \odot E+\odot 1$ & $\odot .2095000 \mathrm{E}+02$ & $\odot .2050000 \mathrm{E}+01$ & $\odot .7149986 \mathrm{E}+\odot \odot$ \\
\hline 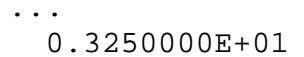 & $\odot .2285000 \mathrm{E}+\odot 2$ & $\odot .6950 \odot \odot \odot E+\odot 1$ & $\odot .2682163 \mathrm{E}+01$ \\
\hline$\odot .3350000 \mathrm{E}+01$ & $\odot .2285000 \mathrm{E}+02$ & $\odot .6950000 \mathrm{E}+01$ & $\odot .3089783 E+01$ \\
\hline$\odot .3450000 \mathrm{E}+01$ & $\odot .2285000 \mathrm{E}+02$ & $\odot .6950000 \mathrm{E}+01$ & ๑. 2990684E+01 \\
\hline
\end{tabular}

Figure E-6. Excerpt from the Generated Permeability Field

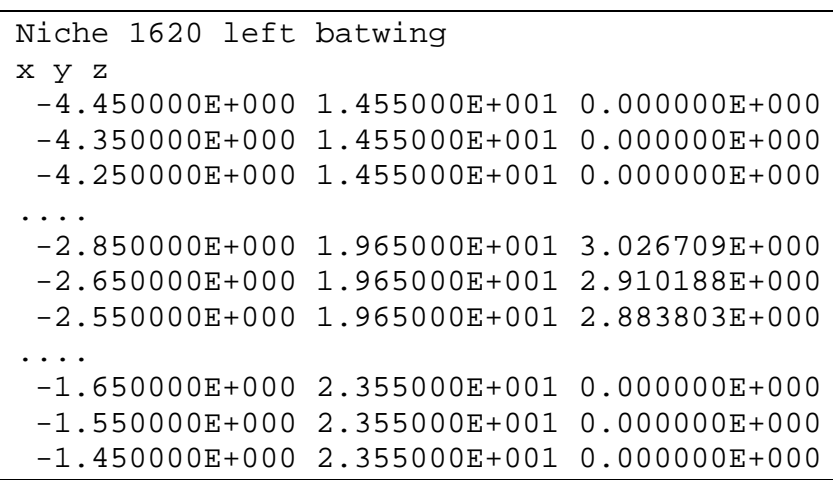

Figure E-7.Excerpts from Interpolated Left Slot Profile of Niche 5

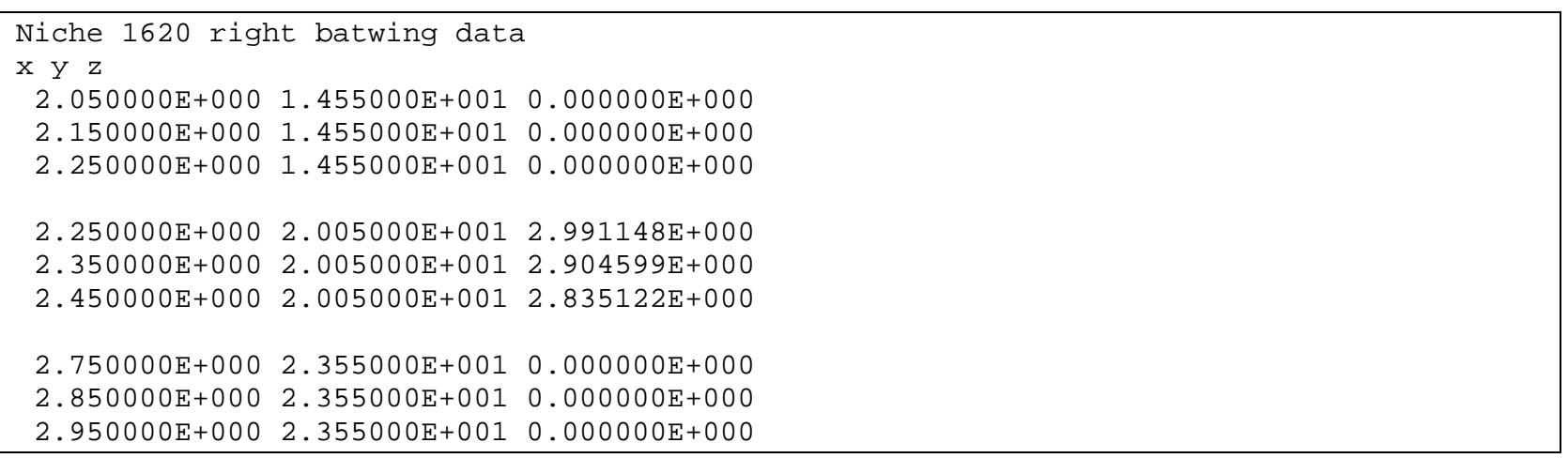

Figure E-8. Excerpts from Interpolated Right Slot Profile of Niche 5 


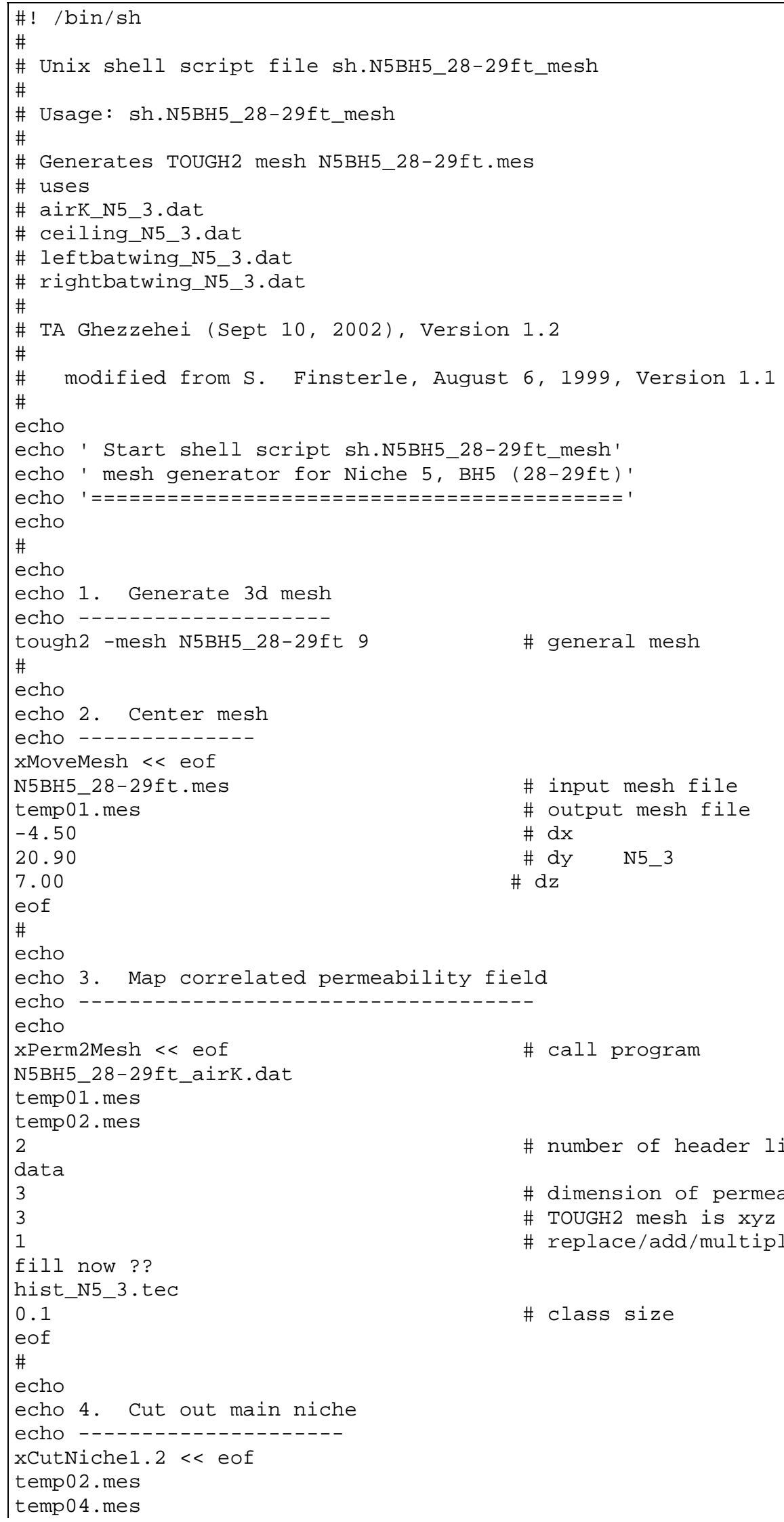




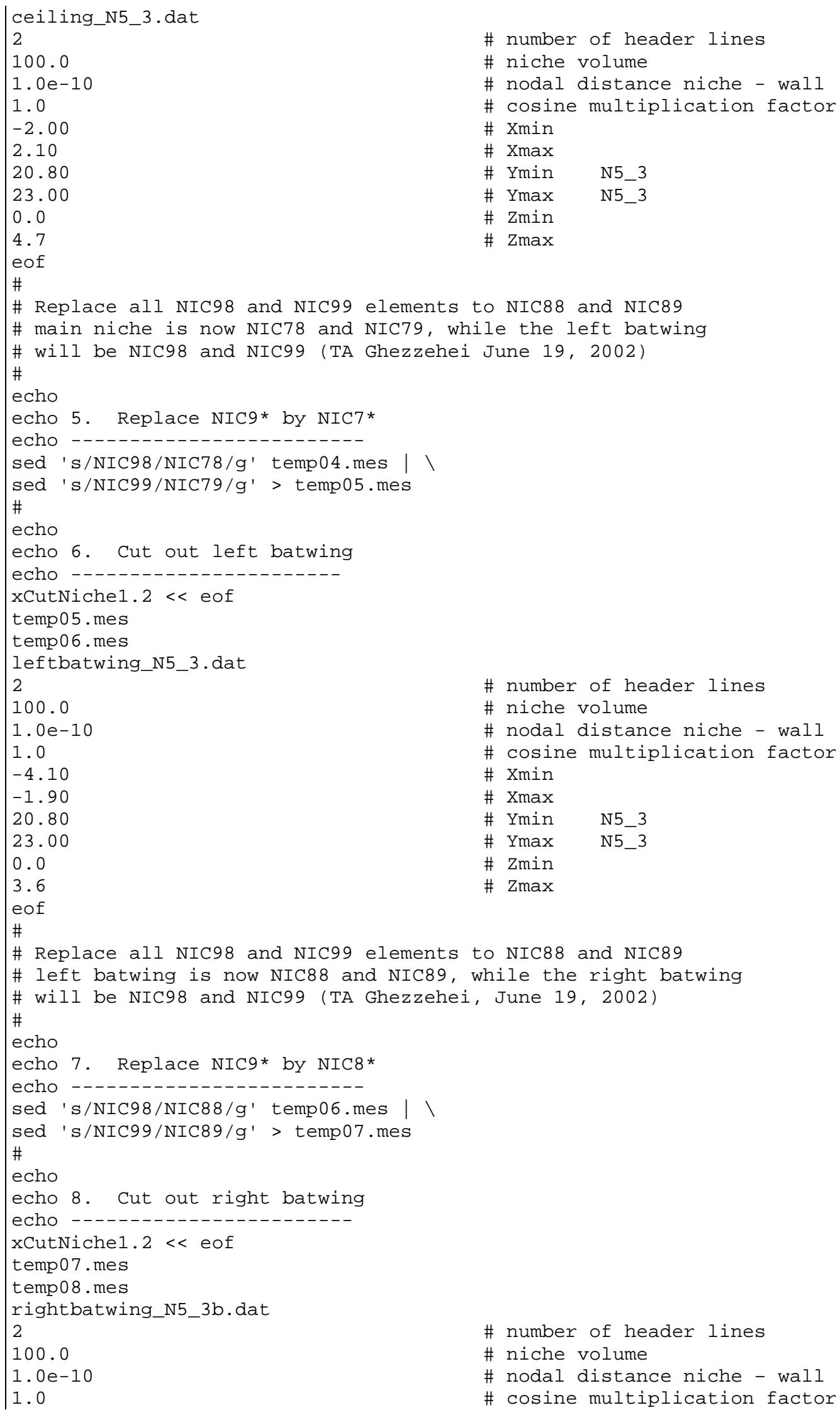




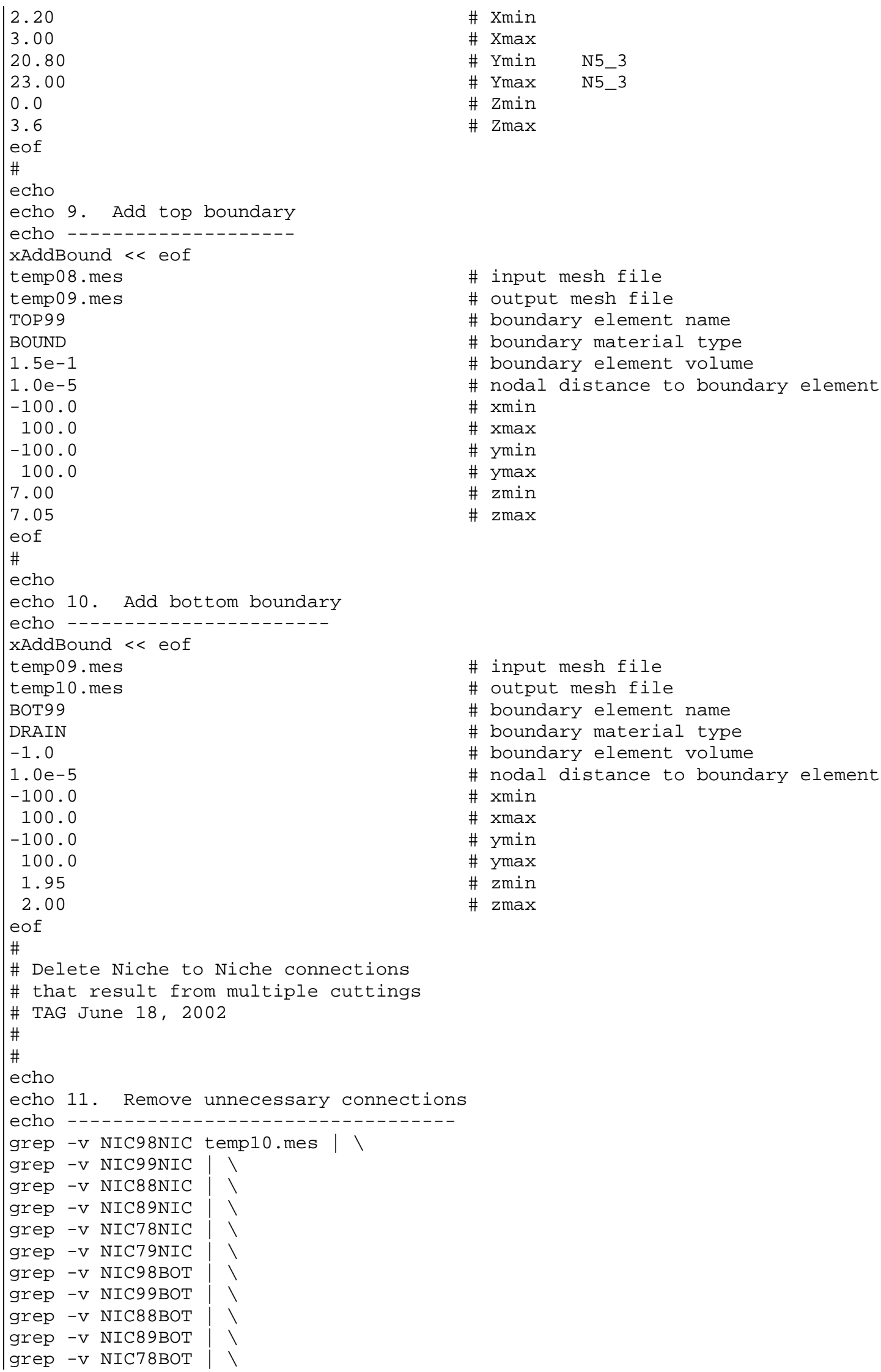

N5 3

N5_3

\# zmax 


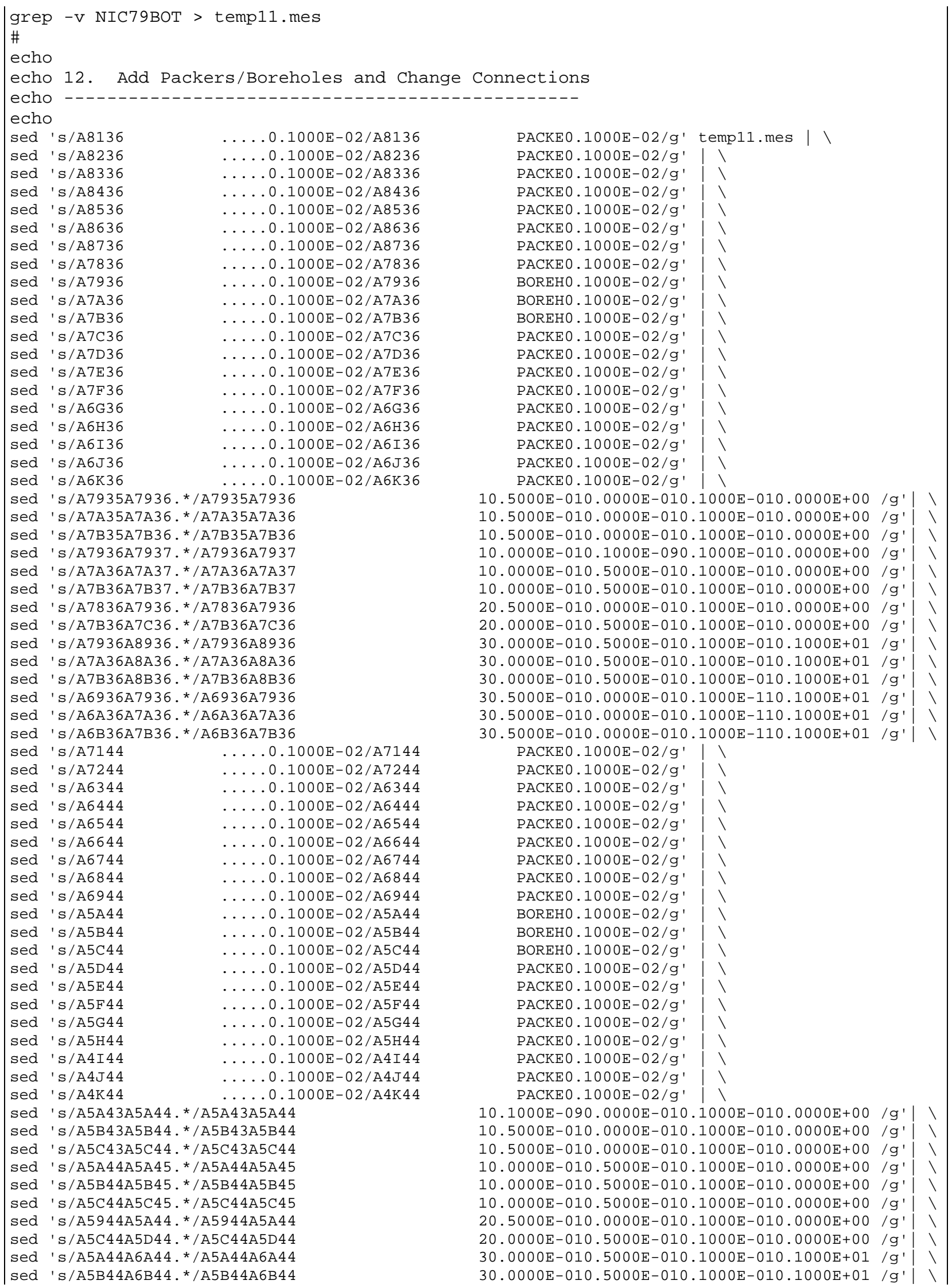




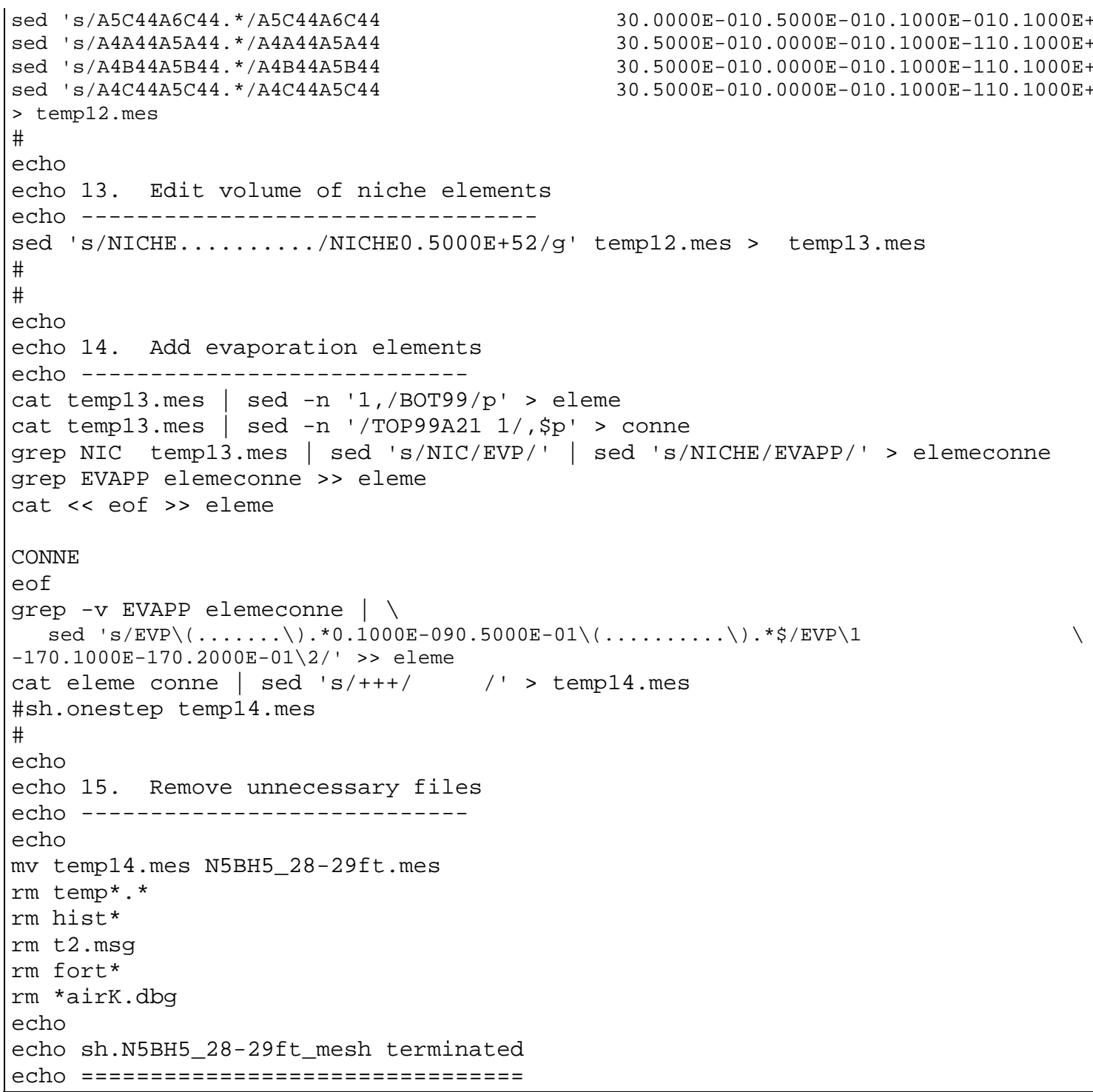

Figure E-9. File sh.N5BH5_28-29ft_mesh Used to Execute Mesh Generation Steps 1-11 


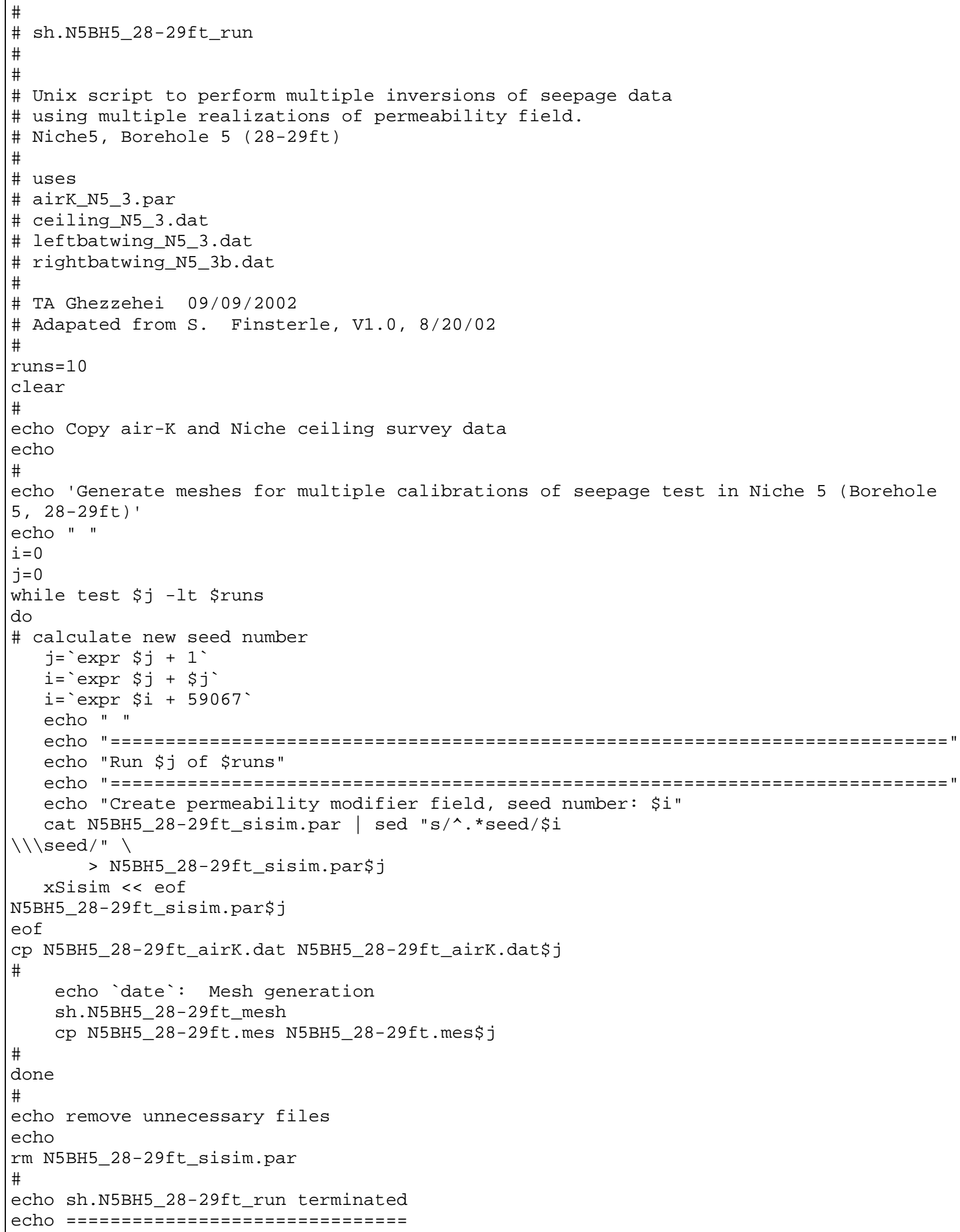

Figure E-10. Script File sh.N5BH5_28-29ft_run Used to Generate Multiple Meshes with Different Permeability Field Realizations 


\section{APPENDIX F}

PREPARATION OF SEEPAGE RATE AND RELATIVE-HUMIDITY DATA FOR THE SIMULATION OF LIQUID-RELEASE TESTS IN THE ECRB CROSS-DRIFT 
Measured data from the liquid-release tests performed in the ECRB Cross-Drift were submitted to the TDMS under various DTNs. The SCM is calibrated against seepage-rate data, taking into account evaporation effects, which are driven by relative humidity changes. Time series of seepage rates and relative-humidity data were extracted from the respective DTNs using the steps described in this appendix. The procedure is outlined in detail for the liquid-release tests conducted in zone 2 of borehole SYBT-ECRB-LA\#1 (DTN: LB0110ECRBLIQR.002 [DIRS 156879]); similar procedures were applied for other liquid-release tests (see Wang 2003 [DIRS 161456], SN-LBNL-SCI-228-V1, pp. 9, 18-21, 26). (Note that the files and formats of the data in DTN: LB0110ECRBLIQR.002 [DIRS 156879] was changed on November 22, 2002; the discussion below describes the steps as they were performed during model development using the original files and formats.)

1. DTN: LB0110ECRBLIQR.002 [DIRS 156879] was obtained from the TDMS.

2. Data were stored in four archive files (s01221_001.zip, s01221_002.zip, s01221_003.zip, and s01221_004.zip). Four text files (zz_sep_193257.txt, zz_sep_193258.txt, zz_sep_193259.txt, and zz_sep_193261.txt) were extracted from the archive files using WinZip 8.0. The four text files contain four data reports labeled s01221_001, s01221_002, s01221_003, and s01221_004, respectively.

For the preparation of a calibration file with seepage-rate data, the following steps were performed:

1. Concatenate zz_sep_193261.txt and zz_sep_193259.txt; new file name: Cum.txt.

2. Open Cum.txt using the text editor vim 6.0.12.

3. Delete header lines.

4. Replace all slashes (except those in dates) with spaces to separate the data columns.

5. Save file Cum.txt and exit vim.

6. Open file Cum.txt in Excel 2000 (9.0.3821 SR-1) such that Column 1 holds the date and time, Column 2 holds the cumulative injection, Column 3 holds cumulative return flow, and Column 4 holds cumulative seepage.

7. Translate date to seconds after February 28, 2001, 13:59 using the following EXCEL equation:

Col. $5=(\operatorname{RC}[-4]-“ 2 / 28 / 200113: 59 ") * 86400$

8. Calculate release rate $[\mathrm{ml} / \mathrm{min}]$ from cumulative injection $[\mathrm{ml}]$ and cumulative return $[\mathrm{ml}]$ :

Col. $6=((\operatorname{RC}[-4]-R[-1] C[-4])-(\operatorname{RC}[-3]-R[-1] C[-3])) /(\operatorname{RC}[-1]-R[-1] C[-1]) * 60$

9. Calculate seepage rate $[\mathrm{ml} / \mathrm{min}]$ from cumulative seepage $[\mathrm{ml}]$ :

Col. $7=(\operatorname{RC}[-3]-R[-1] C[-3]) /(\operatorname{RC}[-2]-R[-1] C[-2]) * 6 \odot$ 
10. Save as Microsoft Excel Workbook Cum.xls (for traceability only) and as space delimited text file Cum.prn.

11. Open Cum.prn using text editor vim.

12. Delete all columns except time [sec] and seepage rate $[\mathrm{ml} / \mathrm{min}]$.

13. Add header:

Time [sec] since Seepage rate

02/28/01 13:59:00 [ml/min]

14. Save as LA1_zone2_set2.dat (see excerpt in Figure F-1). This file will be read as a calibration data file by iTOUGH2 V5.0 (LBNL 2002 [DIRS 160106]).

\begin{tabular}{|cc|}
\hline Time [sec] since & Seepage rate \\
$02 / 28 / 01$ 13:59: $0 \odot$ & {$[\mathrm{ml} / \mathrm{min}]$} \\
0.0 & $0.0 \odot$ \\
1200.0 & 11.26 \\
2400.0 & 0.00 \\
3600.0 & -0.07 \\
$480 \odot .0$ & -0.07 \\
6000.0 & 0.00 \\
$\ldots \ldots \ldots$ & $\cdots \cdots$ \\
5241780.0 & 5.44 \\
5242980.0 & 0.00 \\
5244180.0 & -0.86 \\
5245380.0 & -0.73 \\
5246580.0 & -0.62 \\
\hline
\end{tabular}

Figure F-1.Excerpt from Calibration Data File LA1_zone2_set2.dat

For the preparation of a boundary condition file with relative-humidity data, the following steps are performed:

1. Concatenate zz_sep_193258.txt and zz_sep_193257.txt; new file name: RH.txt.

2. Open RH.txt using the text editor vim.

3. Delete header lines.

4. Delete all columns except date, time, and inside RH.

5. Append “E- 02” to RH column to convert from [\%] to dimensionless fraction.

6. Save RH.txt and exit vim.

7. Open RH.txt in Excel.

8. $\quad$ Add new Column 2. 
9. Translate date and time to seconds after February 28, 2001 13:46:

Col. $2=(\operatorname{RC}[-1]-“ 2 / 28 / 200113: 46 ") * 86400$

10. Save as space delimited text file RH.txt.

11. Open RH.txt using text editor vim.

12. Delete columns with date and time.

13. Add first dummy data point ( $-1 \mathrm{E} 20,0.190)$ to provide historic relative humidity.

14. Add last dummy data point $(1 \mathrm{E} 20,0.252)$ to cover potential prediction time frame.

15. Duplicate all 4141 lines twice.

16. Add “4141 2” to top of file.

17. Remove second column from Line 2 to Line 4142.

18. Remove first column from Line 4143 to end of file.

19. Add new line “EVA98”, Line 4143.

20. Add new line “EVA99”, Line 8285.

21. Save as LA1_zone2_set2.bc. This file is supplied as time dependent boundary condition file to iTOUGH2 V5.0 (LBNL 2002 [DIRS 160106]). An excerpt is shown in Figure F-2.

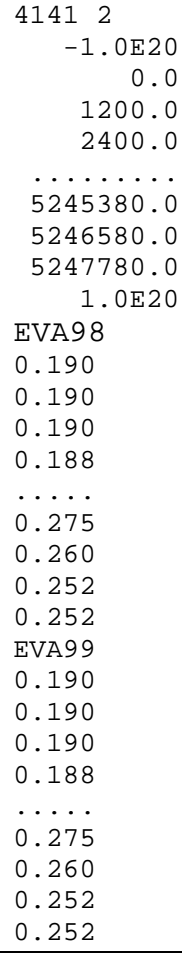

Figure F-2.Excerpt from Boundary Condition Data File LA1_zone2_set2.bc 
INTENTIONALLY LEFT BLANK 


\section{APPENDIX G EXECUTION OF MULTIPLE INVERSIONS OF DATA FROM ECRB}


Multiple inversions of seepage-rate data from the systematic testing area in the ECRB Cross-Drift were performed, based on multiple realizations of the underlying permeability field. The following steps were performed (see also file sh.run, Figure G-1):

1. Go to the appropriate subdirectory .../LAx/ZoneY/SetZ, where $x$ indicates the borehole number, $Y$ represents the injection zone, and $Z$ designates the data set number (if multiple test sequences were performed in the same interval).

2. Select the appropriate mesh corresponding to the permeability field realization $j$.

3. Perform a steady-state simulation with background percolation, neglecting evaporation effects (vapor diffusion coefficient is set to zero). A representative TOUGH2 input file (as input to iTOUGH2 V5.0 (LBNL 2002 [DIRS 160106])) LAx_zoneY_ininoevap is reproduced in Figure G-2.

4. Take saturation distribution from previous simulation as initial conditions for a simulation with evaporation effects added (vapor diffusion coefficient at standard conditions is set to $\left.2.13 \times 10-5 \mathrm{~m}^{2} / \mathrm{s}\right)$. A dry-out zone develops around the drift.

5. Take saturation distribution from previous simulation as initial conditions for the inversion. A representative TOUGH2 input file $L A x \_z o n e Y \_s e t Z$ (as input to iTOUGH2 V5.0 (LBNL 2002 [DIRS 160106])) is shown in Figure G-3; an excerpt from a representative iTOUGH2 V5.0 (LBNL 2002 [DIRS 160106]) input file LAx_zoneY_setZi is shown in Figure G-4.

6. Figure G-5 contains an excerpt from a representative iTOUGH2 V5.0 (LBNL 2002 [DIRS 160106]) output file LAx_zoneY_setZi.out, showing the best estimate parameter value obtained from a single inversion.

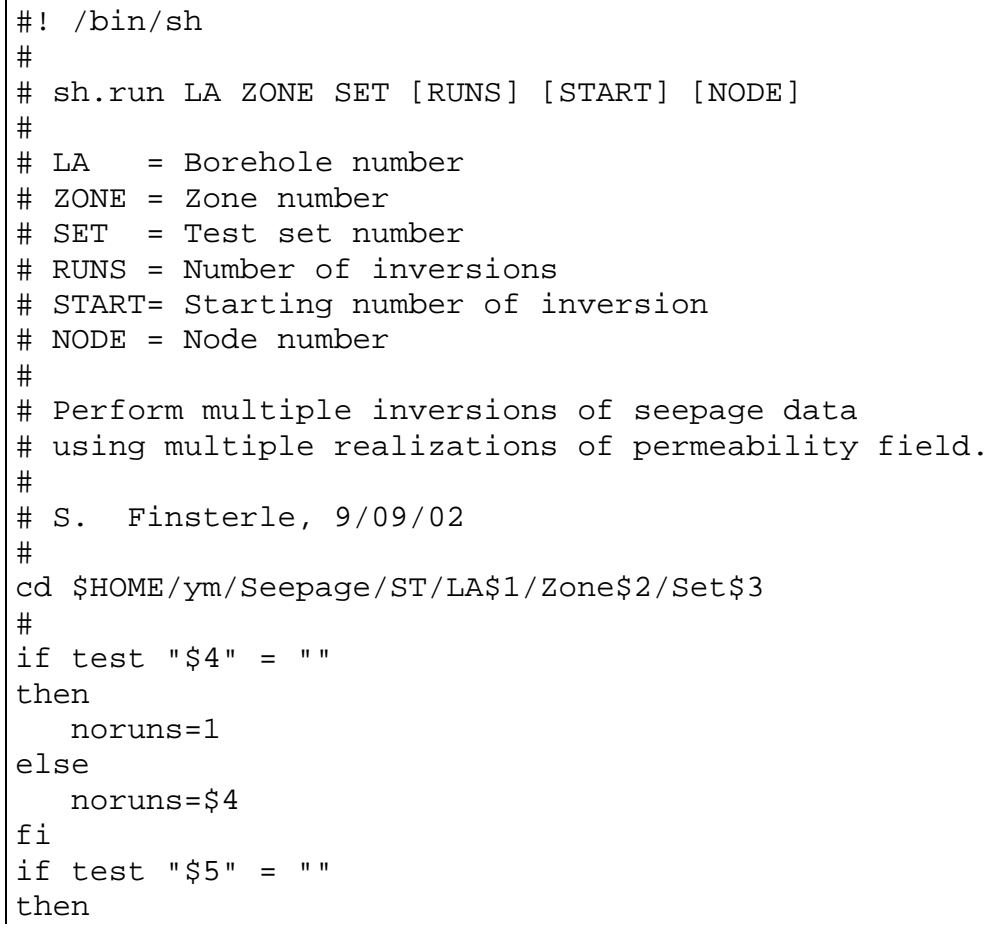




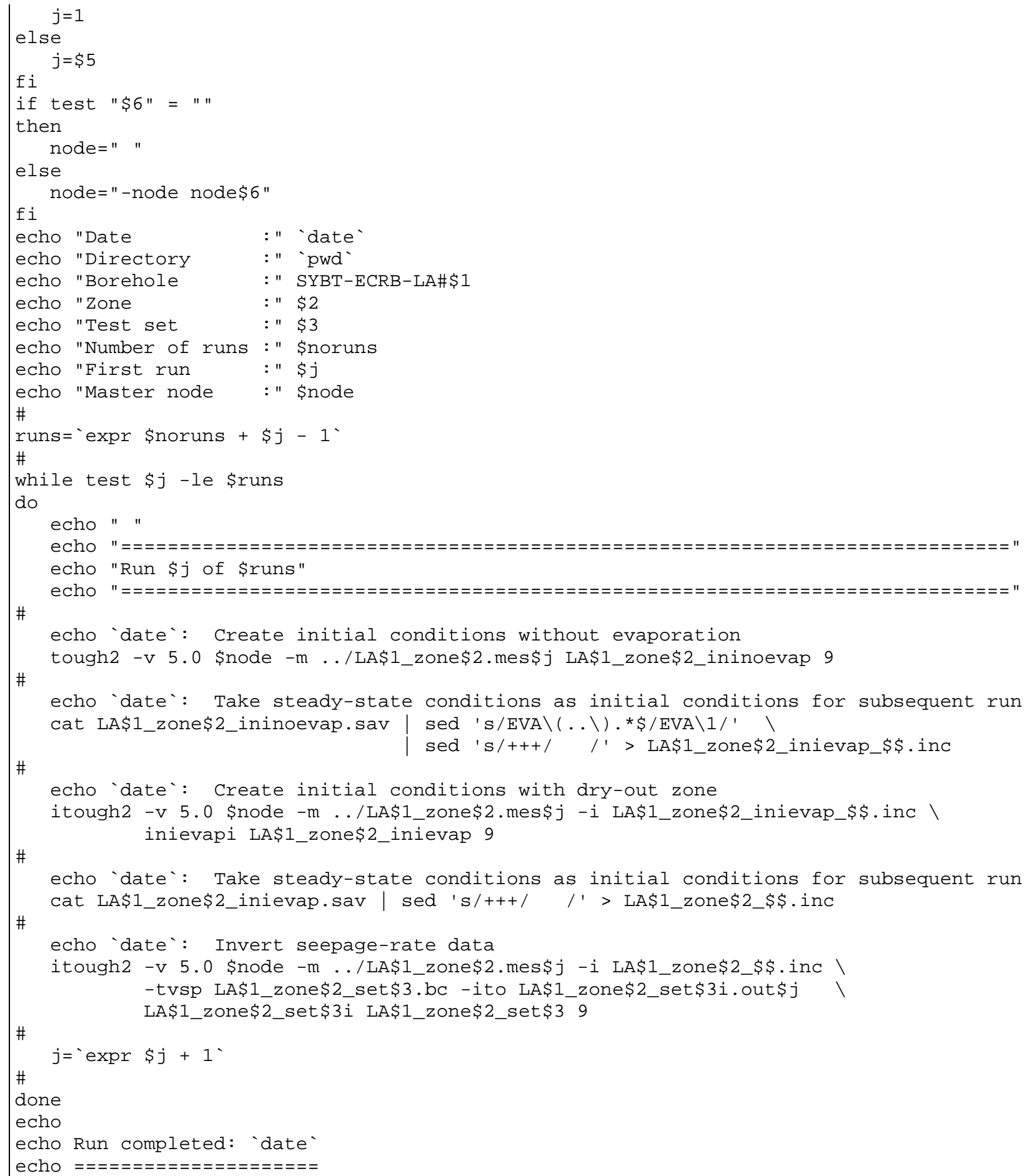

Figure G-1. File sh.run Used to Execute Multiple Inversions 


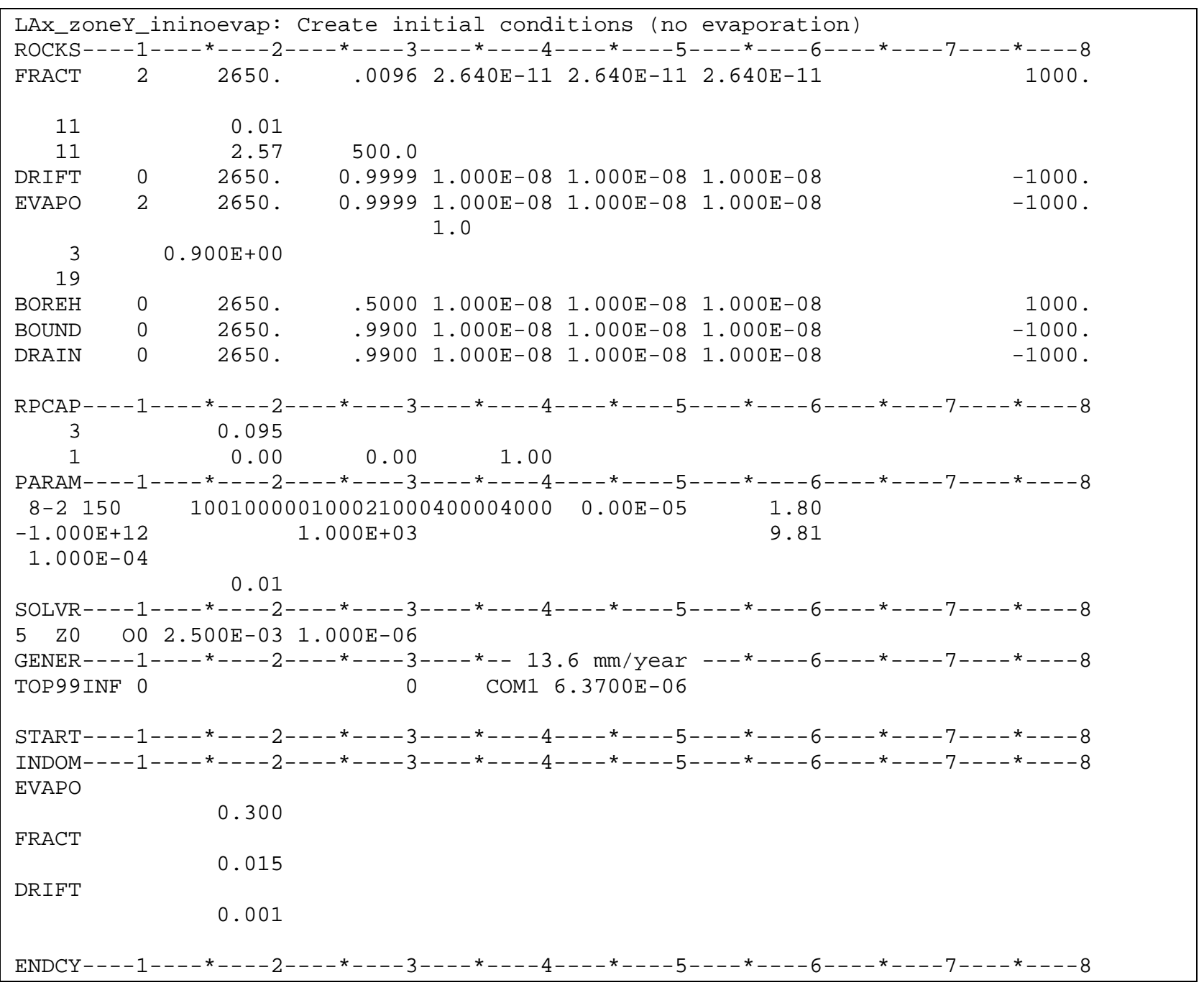

Figure G-2. Representative TOUGH2 Input File $L A x \_z o n e Y \_$ininoevap (as Input to iTOUGH2 V5.0 (LBNL 2002 [DIRS 160106])) to Execute Initial Steady-State Simulation without Evaporation Effects 


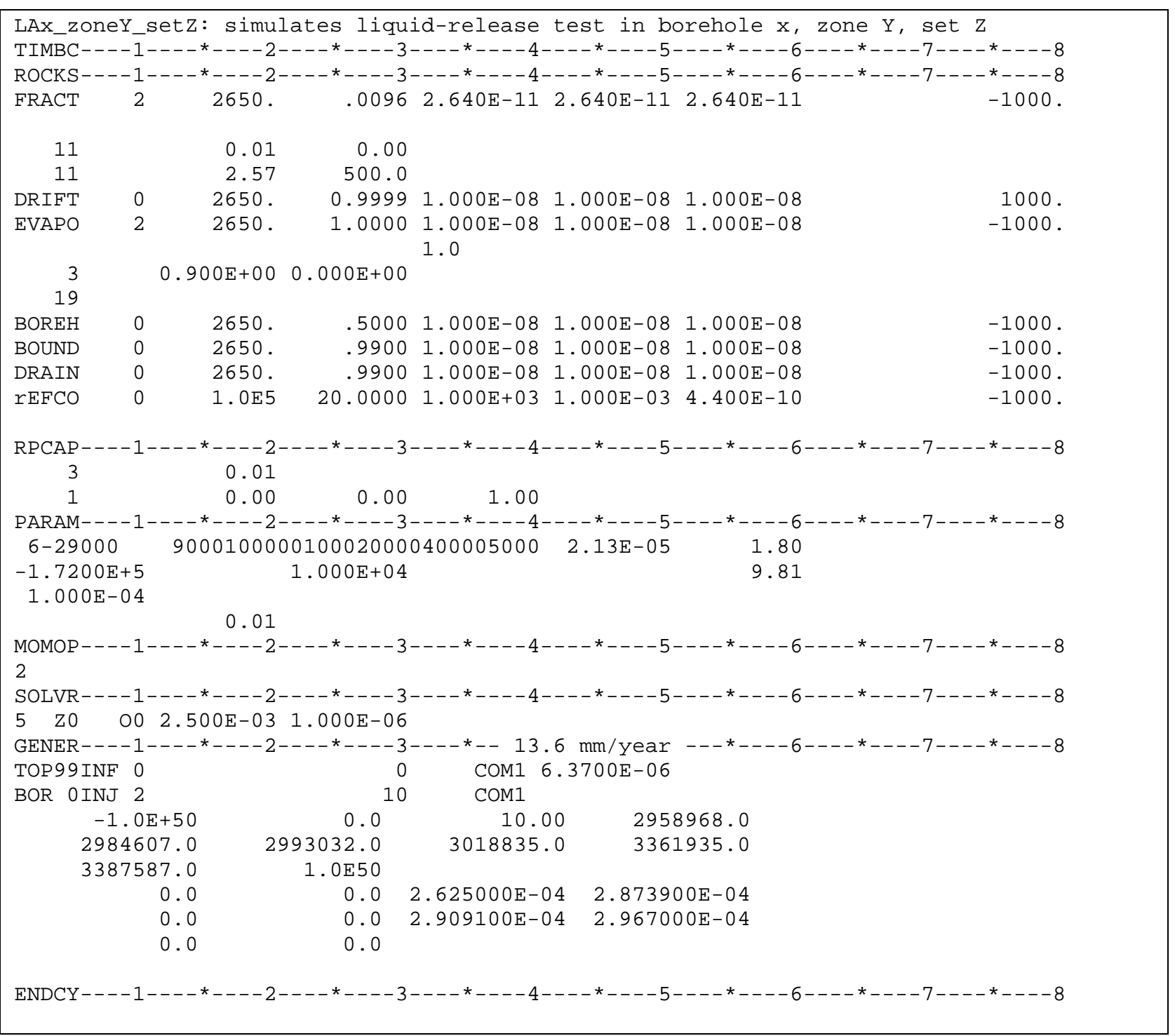

Figure G-3. Representative TOUGH2 Input File $L A x \_z o n e Y \_s e t Z$ (as Input to iTOUGH2 V5.0 (LBNL 2002 [DIRS 160106])) Used to Simulate Liquid Release Test and Solving the Forward Problem 


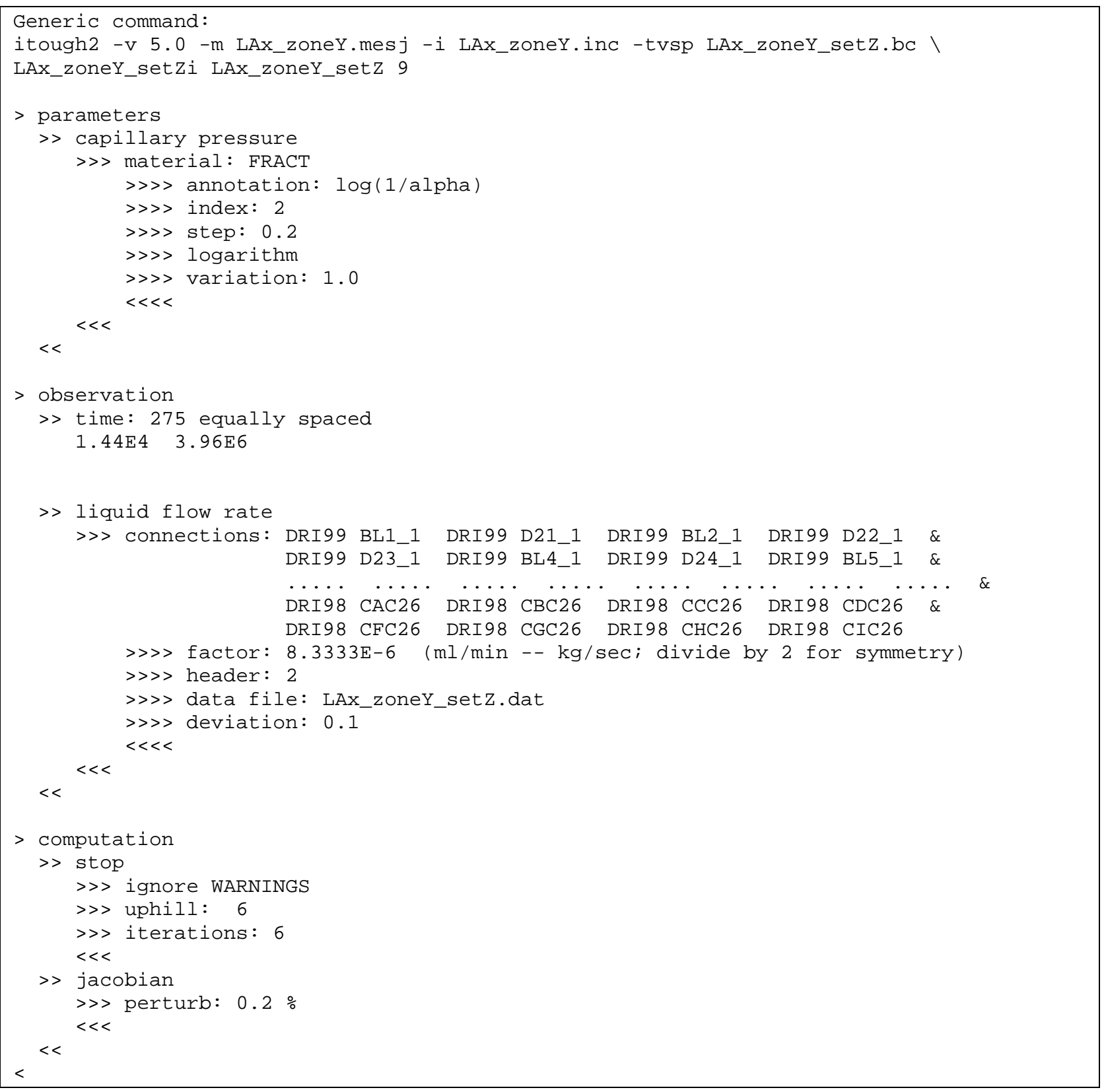

Figure G-4. Excerpt from Representative iTOUGH2 (LBNL 2002 [DIRS 160106]) Input File $L A x \_z o n e Y \_s e t 2 i$ Used to Solve the Inverse Problem

\begin{tabular}{|c|c|c|c|c|c|c|}
\hline $\begin{array}{l}\text { ESTIMATED PARAMETER } \\
\log (1 / \text { alpha })\end{array}$ & $\begin{array}{l}\text { V/L/F } \\
\text { LOG10 }\end{array}$ & $\begin{array}{l}\text { ROCKS } \\
\text { FRACT }\end{array}$ & $\begin{array}{c}\text { PAR } \\
2\end{array}$ & $\begin{array}{c}\text { INITIAL GUESS } \\
0.26990 \mathrm{E}+01\end{array}$ & $\begin{array}{c}\text { BEST ESTIMATE } \\
0.26758 \mathrm{E}+01\end{array}$ & $\begin{array}{l}\text { STANDARD DEVIATION } \\
0.164 \mathrm{E}-02\end{array}$ \\
\hline
\end{tabular}

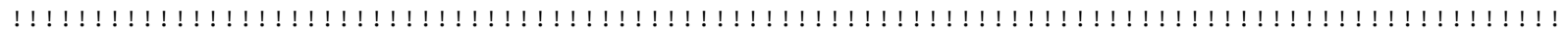

Figure G-5. Reformatted Excerpt from Representative iTOUGH2 (LBNL 2002 [DIRS 160106]) Output File LAx_zoneY_set2i.out Showing Estimated Parameter 


\section{INTENTIONALLY LEFT BLANK}

